\author{
UNIVERSIDADE DE SÃO PAULO \\ INSTITUTO DE ENERGIA E AMBIENTE \\ PROGRAMA DE PÓS-GRADUÇÃO EM ENERGIA
}

DANILO FERREIRA DE SOUZA

UMA AVALIAÇÃO DO DESEMPENHO DE MOTORES ELÉTRICOS DE INDUÇÃO TRIFÁSICOS COMERCIALIZADOS NO BRASIL ENTRE 1945 - 2016 E O IMPACTO DA LEGISLAÇÃO BRASILEIRA 


\section{UMA AVALIAÇÃO DO DESEMPENHO DE MOTORES ELÉTRICOS DE INDUÇÃO TRIFÁSICOS COMERCIALIZADOS NO BRASIL ENTRE 1945 - 2016 E O IMPACTO DA LEGISLAÇÃO BRASILEIRA}

\section{VERSÃO CORRIGIDA}

Dissertação apresentada ao Programa de PósGraduação em Energia do Instituto de Energia e Ambiente da Universidade de São Paulo (IEE/USP) para obtenção do título de Mestre em Ciências.

Orientador: Prof. Dr. Arnaldo G. Kanashiro

\section{SÃO PAULO}


AUTORIZO A REPRODUÇÃO TOTAL OU PARCIAL DESTE TRABALHO, POR QUALQUER MEIO CONVENCIONAL OU ELETRÔNICO, PARA FINS DE ESTUDO E PESQUISA, DESDE QUE CITADA A FONTE.

\section{FICHA CATALOGRÁFICA}

Souza, Danilo Ferreira de.

Uma avaliação do desempenho de motores elétricos de indução trifásicos comercializados no Brasil entre 1945-2016 e o impacto da legislação brasileira. / Danilo Ferreira de Souza; orientador: Arnaldo G. Kanashiro. - São Paulo, 2018. $156 \mathrm{f.:} \mathrm{il;} 30 \mathrm{~cm}$.

Dissertação (Mestrado em Ciências) - Programa de Pós-

Graduação em Energia - Instituto de Energia e Ambiente da

Universidade de São Paulo.

1. Motores de indução. 2. Eficiência energética. 3. Trifásicos. I. Título.

Elaborado por Maria Penha da Silva Oliveira CRB-8/6961 
Nome: SOUZA, Danilo Ferreira de.

Título: Uma avaliação do desempenho de motores elétricos de indução trifásicos comercializados no Brasil entre 1945-2016 e o impacto da legislação brasileira.

Dissertação apresentada ao Programa de PósGraduação em Energia do Instituto de Energia e Ambiente da Universidade de São Paulo (IEE/USP) para obtenção do título de Mestre em Ciências.

Aprovado em: $\underline{09 / 05 / 2018}$

\section{Banca Examinadora}

Prof. Dr. Arnaldo Gakiya Kanashiro

Instituição: IEE - USP

Julgamento: Aprovado

Prof. Dr. Hédio Tatizawa

Instituição: IEE - USP

Julgamento: Aprovado

Prof. Dr. Enio Carlos Segatto

Instituição: IFECT - Externo

Julgamento: Aprovado

Prof. Dr. Mario César do Espírito Santo Ramos

Instituição: Externo

Julgamento: Aprovado 
Dedico este trabalho à minha avó Rita e ao meu avô Cícero. Trabalhadores que, a despeito de todas as adversidades, fizeram-se exemplos de retidão de caráter. 


\section{AGRADECIMENTOS}

Reconheço, primeiramente, a importância de ter sido admitido como docente na condição de graduado na Universidade Federal de Mato Grosso, onde tive a oportunidade do afastamento para desenvolver este trabalho.

Agradeço ao meu orientador, professor Arnaldo G. Kanashiro, que contribuiu significativamente com o trabalho, sempre com imensa disposição e atenção. Certamente, sua orientação me ensina também como orientar.

Ao professor Francisco Salotti, com quem diariamente tive a oportunidade de aprender, elucidando dúvidas sobre máquinas elétricas que carregava há alguns anos.

Ao Professor Hédio Tatizawa, meu supervisor no Programa de Aperfeiçoamento de Ensino - PAE, com quem tive a oportunidade de lecionar na Escola Politécnica de Engenharia da USP.

Aos colegas do Laboratório de Máquinas Elétricas, que contribuíram com discussões diárias sobre o tema: Almir Sabino, Antônio Quirino, Abraão Garcia, Fernando Gava, Alcio Shimizu (Buda) e Luís Caires.

Aos professores Ildo Sauer, Nilton Amado e Carlos Meza, pelas prazerosas horas de debate sobre economia política.

Aos professores Alexandre Piantini e Hélio Sueta, com quem muito aprendi sobre descargas atmosféricas.

Aos colegas do Laboratório de Fotometria, onde também tive oportunidade de aprender: Marcelo, Rinaldo, Márcio, Elvo, José Gil e Liliana.

Aos colegas da vila, que fizeram os dias de São Paulo serem mais animados: Mauro, Guilherme, Nema, Daniel e Marcelo.

Aos colegas da turma: Pedro, Fontenele, Fazzi, Camila, Gallo, Angélica, Cylon, Kauê, Vinicius, Denis, Mariana, Thiago e Richardson.

A todos e todas do Departamento de Engenharia Elétrica da UFMT, em especial aqueles que estiveram mais presentes neste período de mestrado: Evandro, Perillo, Rodolfo e Fabrício.

Aos amigos de Cuiabá, que sempre de alguma forma estiveram presentes.

Aos amigos Luiz Fontenele e Carlos Beuter pelas grandes contribuições nas abordagens estatísticas. 
Aos amigos da USP e de São Paulo que estiveram presentes nesta caminhada.

Aos colegas que contribuíram fazendo a leitura e crítica do trabalho: Vinicius, Murilo e Beuter.

Ao CNPq pela bolsa de estudos disponibilizada.

À classe trabalhadora do estado de São Paulo, que por meio dos impostos e de decisão política, construíram uma universidade pública, gratuita e de excelência.

Este trabalho só foi possível pela dedicação e acúmulo histórico de todos os trabalhadores que atuaram no Laboratório de Máquinas Elétricas. Assim, utilizando as assinaturas nos relatórios de ensaios, é apresentada a memória do laboratório naqueles que construíram o referido espaço.

\begin{tabular}{|c|}
\hline Francisco Antônio Marino Salotti \\
\hline Fernando Gava \\
\hline Almir Sabino \\
\hline Luis Eduardo Caires \\
\hline Abrão Garcia de Oliveira Junior \\
\hline Alcio Katsuyoshi Shimizu \\
\hline Antônio Quirino da Silva Neto \\
\hline Jorge Shimabukuro \\
\hline Carlos Alberto Ferraz \\
\hline José Carlos Martins \\
\hline Luciano Pugliese \\
\hline Shigueharo Deyama \\
\hline Eduardo Zanella \\
\hline Eduardo Adatti \\
\hline Carlos César Barioni \\
\hline Ubaldo Hitoshi Nakata \\
\hline Aldemar Silva de Melo \\
\hline Gildete Bispo Liberino \\
\hline Glicério de Almeida de Sena \\
\hline Roberto Kiyoshi Yokoyama \\
\hline Dilean Marques Lopes \\
\hline Marcos Aurélio do Nascimento \\
\hline Marcelo Monteiro Brasil \\
\hline Pedro Pereira de Paula \\
\hline
\end{tabular}


"O ruim no Brasil e efetivo fator do atraso, é o modo de ordenação da sociedade, estruturada contra os interesses da população, desde sempre sangrada para servir a desígnios alheios e opostos aos seus... $O$ que houve e há é uma minoria dominante, espantosamente eficaz na formulação $e$ manutenção de seu próprio projeto de prosperidade, sempre pronta a esmagar qualquer ameaça de reforma da ordem social vigente."

Darcy Ribeiro 


\section{RESUMO}

SOUZA. Danilo Ferreira. Uma Avaliação do Desempenho de Motores Elétricos de Indução Trifásicos Comercializados no Brasil entre 1945 - 2016 e o Impacto da Legislação Brasileira. 2018. 156 f. Dissertação (Mestrado) - Programa de Pós-Graduação em Energia, Universidade de São Paulo. São Paulo. 2018.

O motor de indução trifásico foi o elemento principal de aumento de produtividade na segunda revolução industrial no final do século XIX na Europa e nos Estados Unidos. Atualmente, em termos mundiais, é a principal carga nos sistemas elétricos, chegando a atingir mais de $65 \%$ do consumo no Brasil. Durante o século XX, os motores elétricos sofreram intensos processos de inovações tecnológicas que possibilitaram significativos ganhos de rendimento. Assim, inicialmente, esta dissertação analisa o rendimento de 419 motores elétricos com potência mecânica de $5 \mathrm{CV}, 50 \mathrm{CV}$ e $200 \mathrm{CV}$, de fabricação nacional ou importados, ensaiados entre 1945 e 2016, possuindo velocidades correspondentes de 2 a 8 polos e alimentados em baixa tensão, na frequência de $60 \mathrm{~Hz}$, onde foi possível verificar ganhos acumulados de rendimento, em alguns casos, acima de $10 \%$ no referido período. A legislação brasileira para o desempenho de motores elétricos teve papel importante no ganho de rendimento dos últimos anos. Neste sentido, em sequência, o trabalho avaliou o impacto do Decreto Presidencial $\mathrm{n}^{\circ} 4.508$ de 11 de dezembro de 2002, sendo o primeiro documento nacional a estabelecer o rendimento mínimo dos motores elétricos trifásicos de indução com rotor em gaiola de esquilo. Posteriormente, a Portaria $n^{\circ}$ 553/2005 avançou nas exigências para os níveis de rendimento e, recentemente, a Portaria $n^{\circ}$ 1/2017 eleva o patamar mínimo de rendimento. Em relação a essas três legislações, foi analisado o comportamento do rendimento de 435 motores ensaiados entre 2015 e 2016, com potências entre $1 \mathrm{CV}$ e $250 \mathrm{CV}$ para as 4 velocidades normatizadas. Todos os dados foram coletados, por meio de ensaios, no Laboratório de Máquinas Elétricas do Instituto de Energia e Ambiente da Universidade de São Paulo, o qual disponibilizou os resultados para esta pesquisa, de maneira que esta dissertação apresenta dados medidos. Os resultados desta dissertação fornecem subsídios para a comparação dos padrões de rendimento dos motores elétricos comercializados no Brasil, bem como na análise das mudanças que uma decisão política pode provocar.

Palavras-chave: Motor trifásico de indução. Rotor em gaiola. Eficiência energética. 


\begin{abstract}
SOUZA. Danilo Ferreira. Uma Avaliação do Desempenho de Motores Elétricos de Indução Trifásicos Comercializados no Brasil entre 1945 - 2016 e o Impacto da Legislação Brasileira. 2018. 156 f. Dissertação (Mestrado) - Programa de Pós-Graduação em Energia, Universidade de São Paulo. São Paulo. 2018.

The three-phase induction motor was the main element of increased productivity in the second industrial revolution in the late nineteenth century in Europe and the United States. Currently, in world terms, it is the main load in the electrical systems, reaching up to $65 \%$ of the consumption in Brazil. During the 20th century, electric motors underwent intense processes of technological innovations that allowed significant gains in efficiency. Thus, initially, this dissertation analyzes the performance of 419 electric motors with mechanical power of $5 \mathrm{HP}, 50 \mathrm{HP}$ and $200 \mathrm{HP}$, of national manufacture or imported, tested between 1945 and 2016, having corresponding speeds of 2 to 8 poles and fed in low voltage, in the frequency of $60 \mathrm{~Hz}$, where it was possible to verify accumulated gains in efficiency, in some cases, above $10 \%$ in said period. The Brazilian legislation for the performance of electric motors played an important role in the income gain of the last years. In this sense, in sequence, the work evaluated the impact of the Presidential Decree No. 4,508 of December 11, 2002, being the first national document to establish the minimum performance of three-phase induction electric motors with a rotor in the squirrel cage. Subsequently, Ordinance No. 553/2005 advanced the requirements for performance levels, and recently Ordinance No. 1/2017 has raised the minimum level of performance. In relation to these three legislations, the measured performance behavior of 435 motors tested between 2015 and 2016, with powers between $1 \mathrm{HP}$ and $250 \mathrm{HP}$ for the 4 regulated speeds was analyzed. All data were collected by means of tests in the Laboratory of Electrical Machines of the Institute of Energy and Environment of the University of São Paulo, which provided the results for this research, so that this dissertation presents measured data. The results of this dissertation provide subsidies for the comparison of the performance standards of commercial electric motors in Brazil, as well as the analysis of the changes that a political decision can cause.
\end{abstract}

Keywords: Three-phase induction motor. Cage rotor. Energy efficiency. 


\section{LISTA DE FIGURAS}

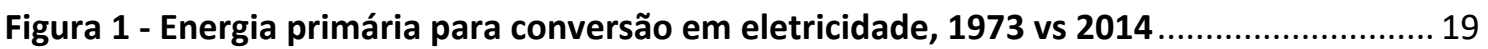

Figura 2 - Mapa das frequências de tensão utilizadas nos países ...................................... 31

Figura 3 - Representatividade estimadados setores da economia no consumo de energia elétrica

Figura 4 - Participação estimada do consumo de eletricidade por utilização final no mundo -

Participação estimada do consumo de eletricidade por utilização final no mundo ............... 37

Figura 5 - Participação dos eletrodomésticos consumo médio ........................................ 37

Figura 6 - Tipos de utilização final de energia elétrica no consumo residencial ...................... 38

Figura 7 - Tipos de utilização final de energia elétrica no consumo comercial e em prédios públicos 39

Figura 8 - Tipos de utilização final de energia elétrica no consumo industrial ...................... 39

Figura 9 - Demanda estimada de aplicações utilizando motores elétricos no mundo ........... 40

Figura 10 - Tipos básicos de motores elétricos .......................................................... 42

Figura 11 - Custo anualizado do ciclo de vida de um motor de indução trifásico .................. 44

Figura 12 - Motor de indução trifásico em corte ........................................................ 45

Figura 13 - Distribuição de polos no estator dos motores de indução ................................ 48

Figura 14 - Perdas em MITRGE de 100 CV e 4 polos operando em carga nominal .................. 50

Figura 15 - Comportamento das perdas em MITRGE de 100 CV e 4 polos operando em carga

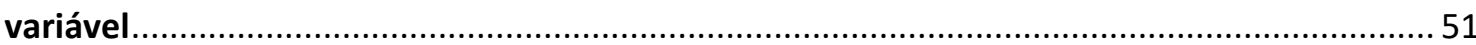

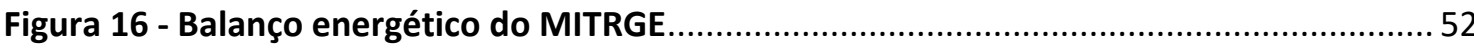

Figura 17 - Organização das associações normativas pelo mundo ................................... 53

Figura 18 - Michail von Dolivo-Dobrovolsky entrando no Hall da Fama com seu motor elétrico

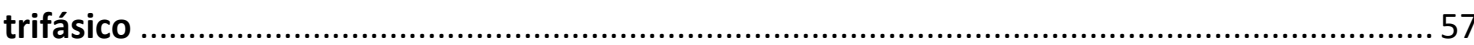

Figura 19 - Evolução do motor trifásico na relação Peso/Potência entre 1981-1984 ............. 58

Figura 20 - Evolução da massa de MITRGE de 1 CV entre 1900 e 1990 .................................. 59

Figura 21 - Espaço ocupado por condutores elétricos nas ranhuras isolados com diferentes materiais

Figura 22 - Evolução das dimensões dos MITRGE de 15 CV e 4 polos entre 1897 e 1974....... 61

Figura 23 - Evolução de rendimento de motores elétricos de 4 polos entre 1935 e $1996 \ldots . . . .63$

Figura 24 - Evolução de rendimento de motores elétricos de 4 polos entre 1944 e 2012...... 64

Figura 25 - Evolução de rendimento de motores elétricos de 4 polos entre 1935 e 2012 .......65

Figura 26 - Valores mínimos de eficiência de 50 Hz definidos na IEC 60034-30-1 .................67

Figura 27 - Implementação de legislação de rendimento mínimo para motores elétricos ..... 68

Figura 28 - Legislação de rendimento de MITRGE no Brasil............................................ 71

Figura 29 - Evolução da normativa nacional para MITRGE de 2 polos ............................... 72

Figura 30 - Evolução da normativa nacional para MITRGE de 4 polos ............................... 72

Figura 31 - Evolução da normativa nacional para MITRGE de 6 polos ............................... 73

Figura 32 - Evolução da normativa nacional para MITRGE de 8 polos ............................... 73

Figura 33 - Redimentos medidos de MITRGE de 4 polos comparado com a lesgislação

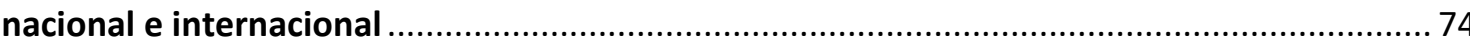

Figura 34 - Desvio de rendimento dos MITRGE ensaiados comparados ao Decreto 4.508/2002 
Figura 35 - Fluxograma metodológico

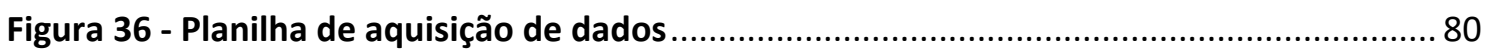

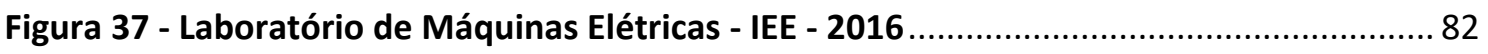

Figura 38 - Percentual de de motores ensaiados por tecnologia............................................. 85

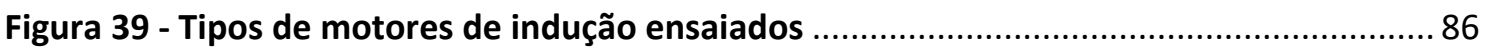

Figura 40 - Distribuição percentual dos motores de indução ensaiados por faixa de potência

Figura 41 - Distribuição dos motores de indução trifásicos por número de polos..................... 88

Figura 42 - Comportamento do rendimento médio dos motores de 2 polos entre 1945 e 2016

Figura 43 - Comportamento do rendimento médio dos motores de 4 polos entre 1945 e 2016

Figura 44 - Comportamento do rendimento médio dos motores de 6 polos entre 1945 e 2016

Figura 45 - Comportamento do rendimento médio dos motores de 8 polos entre 1945 e 2016

Figura 46 - Distribuição de temperatura pelo estator............................................................ 95

Figura 47 - Evolução do motor trifásico na relação Massa/Potência entre 1891-2016 ........... 96

Figura 48 - Desvio absoluto de fator de potência para motores de 2 Polos .......................... 100

Figura 49 - Desvio absoluto de fator de potência para motores de 4 Polos .......................... 102

Figura 50 - Desvio absoluto de fator de potência para motores de 6 Polos ........................... 103

Figura 51 - Desvio absoluto de fator de potência para motores de 8 Polos ........................... 104

Figura 52 - Desvio absoluto de rendimento para motores de 2 Polos .................................. 106

Figura 53 - Desvio absoluto de rendimento para motores de 4 Polos .................................. 107

Figura 54 - Desvio absoluto de rendimento para motores de 6 Polos .................................... 108

Figura 55 - Desvio absoluto de rendimento para motores de 8 Polos .................................. 109

Figura 56 - Comparação da normativa brasileira com resultados dos ensaios $\mathbf{- 2}$ polos ...... 112

Figura 57 - Comparação da normativa brasileira com resultados dos ensaios -4 polos ...... 113

Figura 58 - Comparação da normativa brasileira com resultados dos ensaios - 4 polos (até 40

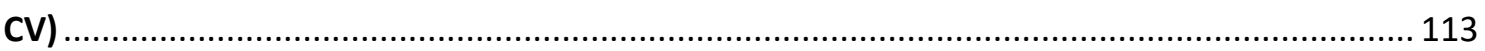

Figura 59 - Comparação da normativa brasileira com resultados dos ensaios - 6 polos ...... 114

Figura 60 - Comparação da normativa brasileira com resultados dos ensaios $\mathbf{-} 8$ polos ...... 115

Figura 61 - Desvio absoluto do rendimento de MITRGE de 2 Polos em relação ao Decreto no

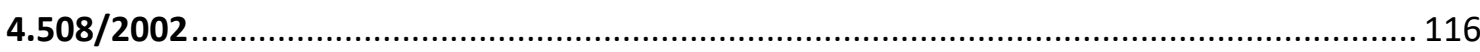

Figura 62 - Desvio absoluto do rendimento de MITRGE de 4 Polos em relação ao Decreto no

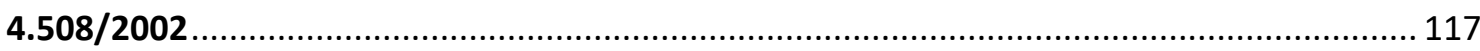

Figura 63 - Desvio absoluto do rendimento de MITRGE de 6 Polos em relação ao Decreto no

$4.508 / 2002$

Figura 64 - Desvio absoluto do rendimento de MITRGE de 8 Polos em relação ao Decreto no

4.508/2002

Figura 65 - Desvio absoluto do rendimento de MITRGE de 2 Polos em relação Portaria no $553 / 2005$

Figura 66 - Desvio absoluto do rendimento de MITRGE de 4 Polos em relação Portaria no $553 / 2005$ 
Figura 67 - Desvio absoluto do rendimento de MITRGE de 6 Polos em relação Portaria no $553 / 2005$

Figura 68 - Desvio absoluto do rendimento de MITRGE de 8 Polos em relação Portaria no $553 / 2005$

Figura 69 - Desvio absoluto do rendimento de MITRGE de 2 Polos em relação Portaria no

$1 / 2017$

Figura 70 - Desvio absoluto do rendimento de MITRGE de 4 Polos em relação Portaria no $1 / 2017$

Figura 71 - Desvio absoluto do rendimento de MITRGE de 6 Polos em relação Portaria no $1 / 2017$

Figura 72 - Desvio absoluto do rendimento de MITRGE de 8 Polos em relação Portaria no $1 / 2017$

Figura 73 - Relação potência (CV) vs preço (US\$) de motores elétricos de indução

Figura 74 - Relação potência (CV) vs massa (kg) de motores elétricos de indução até 40CV 131

Figura 75 - Relação potência (CV) vs massa (kg) de motores elétricos de indução 132

Figura 76 - Relação potência (CV) vs fator de potência (FP) de motores elétricos de indução até $40 \mathrm{CV}$

Figura 77 - Relação potência (CV) vs fator de potência (FP) de motores elétricos de indução 


\section{LISTA DE TABELAS}

Tabela 1 - Interconexão elétrica na América do Sul utilizando conversor de frequência......... 32 Tabela 2 - Decreto 4.508/2002 e os rendimentos percentuais mínimos para os motores elétricos. 35

Tabela 3 - Principais componentes dos motores de indução trifásicos enumerados na Figura

12

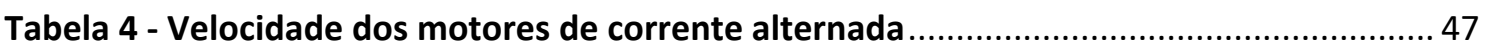

Tabela 5 - Incrementos de potência mecânica em mesma carcaça de 1898 à 1974 ................. 62

Tabela 6 - Portaria no 1/2017 e os rendimentos percentuais mínimos para os MITRGE

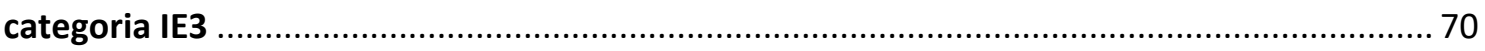

Tabela 7 - Comparação dos níveis de rendimento dos MITRGE (2000-2012) em relação ao

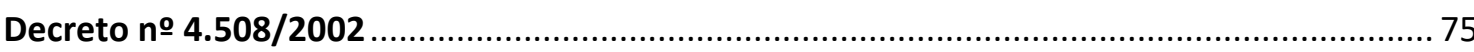

Tabela 8 - Avaliação estatística de rendimento dos MITRGE (2000-2012) em relação ao

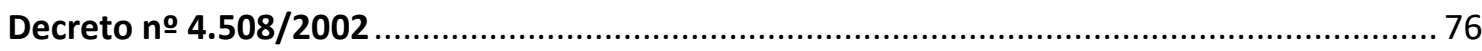

Tabela 9 - Comportamento do rendimento médio dos motores de 2 polos entre 1945 e 2016

Tabela 10 - Comportamento do rendimento médio dos motores de 4 polos entre 1945 e 2016

Tabela 11 - Comportamento do rendimento médio dos motores de 6 polos entre 1945 e 2016

Tabela 12 - Comportamento do rendimento médio dos motores de 8 polos entre 1945 e 2016

.

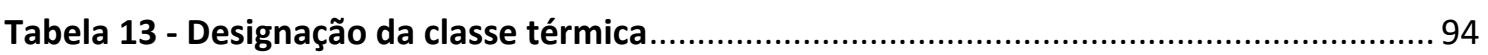

Tabela 14 - Avaliação estatística de fator de potência para motores de 2 Polos ................... 100

Tabela 15 - Avaliação estatística de fator de potência para motores de 4 Polos ................... 102

Tabela 16 - Avaliação estatística de fator de potência para motores de 6 Polos ................... 103

Tabela 17 - Avaliação estatística de fator de potência para motores de 8 Polos ................... 104

Tabela 18 - Comparação geral do fator de potência entre os valores medidos e valores

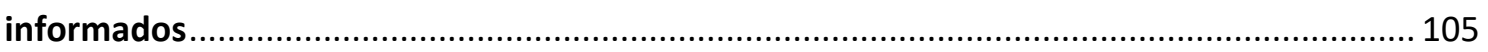

Tabela 19 - Avaliação estatística de rendimento para motores de 2 Polos ............................ 107

Tabela 20 - Avaliação estatística de rendimento para motores de 4 Polos ............................ 108

Tabela 21 - Avaliação estatística de rendimento para motores de 6 Polos ............................ 109

Tabela 22 - Avaliação estatística de rendimento para motores de 8 Polos ........................... 110

Tabela 23 - Comparação geral do rendimento entre os valores medidos e valores informados

Tabela 24 - Avaliação estatística do rendimento de MITRGE de 2 Polos em relação ao Decreto no 4.508/2002

Tabela 25 - Avaliação estatística do rendimento de MITRGE de 4 Polos em relação ao Decreto no 4.508/2002

Tabela 26 - Avaliação estatística do rendimento de MITRGE de 6 Polos em relação ao Decreto no 4.508/2002..

Tabela 27 - Avaliação estatística do rendimento de MITRGE de 8 Polos em relação ao Decreto no 4.508/2002 
Tabela 28 - Comparação dos níveis de rendimento dos MITRGE (2015-2016) em relação ao Decreto 4.508/2002.

Tabela 29 - Avaliação estatística do rendimento de MITRGE de 2 Polos em relação a Portaria no 553/2005

Tabela 30 - Avaliação estatística do rendimento de MITRGE de 4 Polos em relação a Portaria no 553/2005

Tabela 31 - Avaliação estatística do rendimento de MITRGE de 6 Polos em relação a Portaria no 553/2005

Tabela 32 - Avaliação estatística do rendimento de MITRGE de 8 Polos em relação a Portaria no 553/2005

Tabela 33 - Comparação dos níveis de rendimento dos MITRGE (2015-2016) em relação a Portaria no 553/2005

Tabela 34 - Avaliação estatística do rendimento de MITRGE de 2 Polos em relação a Portaria n으 1/2017

Tabela 35 - Avaliação estatística do rendimento de MITRGE de 4 Polos em relação a Portaria no 1/2017

Tabela 36 - Avaliação estatística do rendimento de MITRGE de 6 Polos em relação a Portaria no 1/2017

Tabela 37 - Avaliação estatística do rendimento de MITRGE de 8 Polos em relação a Portaria no 1/2017

Tabela 38 - Comparação dos níveis de rendimento dos MITRGE (2015-2016) em relação a Portaria no 1/2017 


\section{LISTA DE ABREVIATURAS E SÍMBOLOS}

A

ABNT

ABB

AEG

ANEEL

BEN

BIG

${ }^{\circ} \mathrm{C}$

$\mathrm{CA}$

CC

CEPEL

CGRE

CRL

$\mathrm{CV}$

EC

ELETROBRÁS

EPE

EU

EUA

FMI

FP

GWh

HP

I

$\mathrm{Hz}$

IEA

IEC

IEE

IEEE

IAAC

IAR

ILAC

INMETRO

IP

ISO

$\mathrm{K}$

$\mathrm{kg}$

$\mathrm{kW}$

LABELO

$\mathrm{m}$

MG

MME

MW
Ampères

Associação Brasileira de Normas Técnicas

Asea Brown Boveri

Allgemeine Electricitäts-Gesellschaft

Agência Nacional de Energia Elétrica

Balanço Energético Nacional

Banco de Informação da Geração

Graus Célsius

Corrente Alternada

Corrente Contínua

Centro de Pesquisa de Energia Elétrica

Coordenação Geral de Acreditação

Certificado de Registro de Laboratório

Cavalo-vapor

European Commission

Centrais Elétricas Brasileiras

Empresa de Pesquisa Energética

European Union

Estados Unidos da América

Fundo Monetário Internacional

Fator de Potência

Gigawatt-hora

Horse-power

Corrente

Hertz

International Energy Agency

International Electrotechnical Commission

Instituto de Energia e Ambiente

Institute of Electrical and Electronics Engineers

Interamerican Accreditation Cooperation

Índice de Afastamento de Resultado

International Laboratory Accreditation Cooperation

Instituto Nacional de Metrologia, Qualidade e Tecnologia

Índice de Proteção

International Organization for Standardization

Kelvin

quilogramas

quilowatts

Laboratórios Especializados em Eletroeletrônica

metros

Minas Gerais

Ministério de Minas e Energia

Megawatt 
MIT

MITRGE

NEMA

Manufacturers

NBR

OECD

ONU

ONS

$\mathrm{Pav}$

PBE

$\mathrm{Pf}$

Pje

PCM

Pjr

PIB

PR

PROCEL

$\mathrm{pu}$

PUC

R

RPM

RS

SI

SP

RBC

RBLE

USP

US\$

V

VS

$\operatorname{Cos} \Phi$

$\eta$
Motor de Indução Trifásico

Motor de Indução Trifásico com Rotor em Gaiola de Esquilo Association of Electrical Equipment and Medical Imaging

Norma Brasileira

Organization for Economic Co-operation and Development

Organização das Nações Unidas

Operador Nacional do Sistema

Perdas por Atrito nos mancais e ventilação

Programa Brasileiro de Etiquetagem

Perdas no ferro

Perdas Joule no estator

Pés cúbicos por minuto

Perdas Joule no rotor

Produto Interno Bruto

Paraná

Programa Nacional de Conservação de Energia Elétrica por unidade

Pontifícia Universidade Católica

Resistência

Rotações por Minuto

Rio Grande do Sul

Sistema Internacional

São Paulo

Rede Brasileira de Calibração

Rede Brasileira de Laboratórios de Ensaio

Universidade de São Paulo

Dólares Americanos

Volts

Versus

Fator de potência

Rendimento 


\section{SUMÁRIO}

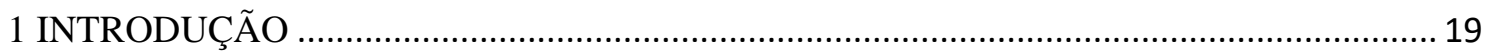

1.1 O CENÁRIO ENERGÉTICO MUNDIAL E NACIONAL ............................................. 19

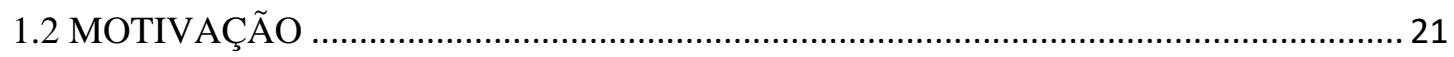

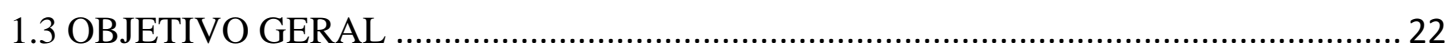

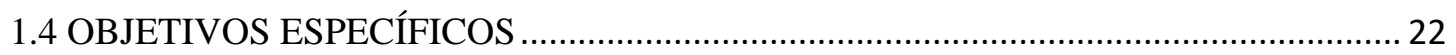

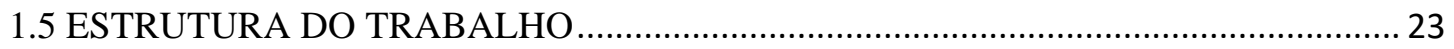

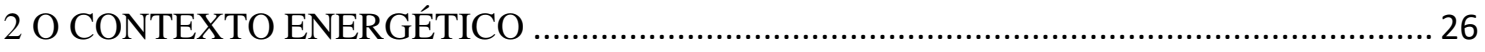

2.1 DO DOMÍNIO DA ELETRICIDADE AOS PRIMÓRDIOS DA INDÚSTRIA ................ 26

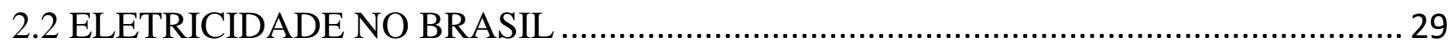

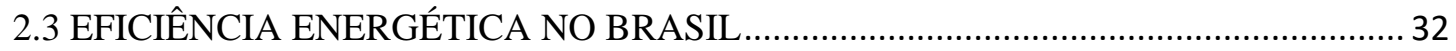

2.4 O USO FINAL DE ENERGIA ELÉTRICA NO BRASIL ................................................. 36

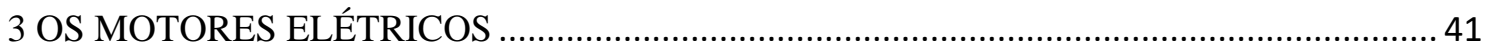

3.1 MOTOR DE INDUÇÃO TRIFÁSICO COM ROTOR EM GAIOLA …........................... 44

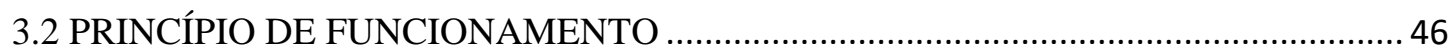

3.3 GRANDEZAS DOS MOTORES ELÉTRICOS DE INDUÇÃO .................................... 49

3.4 PERDAS NOS MOTORES ELÉTRICOS DE INDUÇÃO .............................................. 49

3.5 ENSAIOS NOS MOTORES ELÉTRICOS DE INDUÇÃO............................................. 52

3.6 A EVOLUÇÃO DOS MOTORES ELÉTRICOS DE INDUÇÃO..................................... 56

3.6.1 Mudança de massas e inovações tecnológicas .............................................................. 56

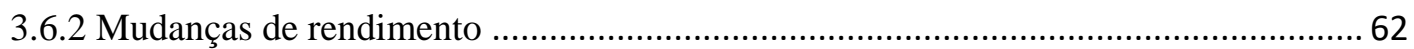

3.7 A NORMATIVA INTERNACIONAL PARA O RENDIMENTO DOS MITRGE..........66

3.8 A NORMATIVA BRASILEIRA PARA O RENDIMENTO DOS MITRGE ....................68

3.8.1 O impacto da legislação sobre os MITRGE comercializados no Brasil...................... 74

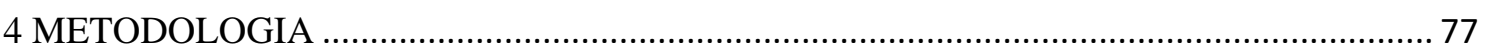

4.1 IDENTIFICAÇÃO DAS FICHAS DE ENSAIO DOS MOTORES ELÉTRICOS ........... 78

4.2 AQUISIÇÃO DE DADOS DE ACORDO COM AS PREMISSAS ................................... 78

4.3 APLICAÇÃO DE TESTE ESTATÍSTICO DE NORMALIDADE .................................. 81

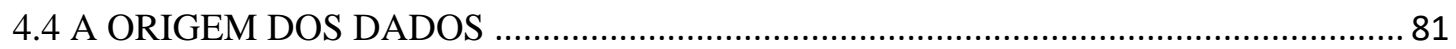

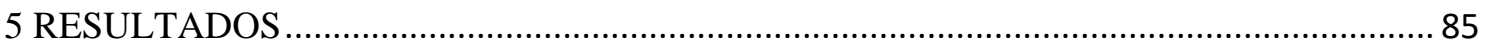

5.1 DISTRIBUIÇÃO DOS MOTORES ELÉTRICOS ENSAIADOS..................................... 85

5.2 MUDANÇA DE RENDIMENTO DOS MITRGE 1945-2016 …....................................... 88 
5.3.1 Dados de placa VS valores medidos - uma análise do fator de potência.................... 98

5.3.2 Dados de placa VS valores medidos - uma análise do rendimento .......................... 106

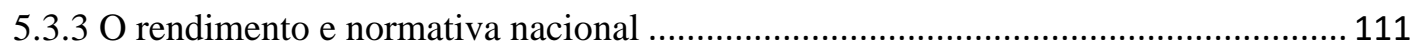

5.3.3.1 Avaliação do impacto do Decreto $\mathrm{n}^{\circ}$ 4.508/2002 …........................................ 115

5.3.3.2 Avaliação do impacto da Portaria $n^{\circ}$ 553/2005 …............................................ 120

5.3.3.3 Avaliação do impacto da Portaria $\mathrm{n}^{\circ}$ 1/2017 ……........................................... 125

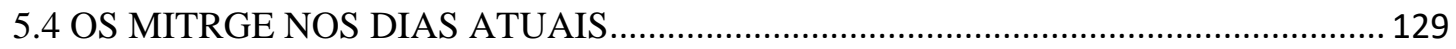

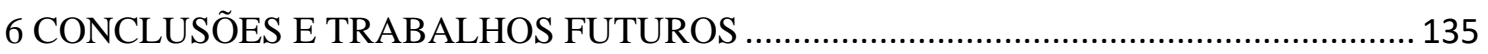

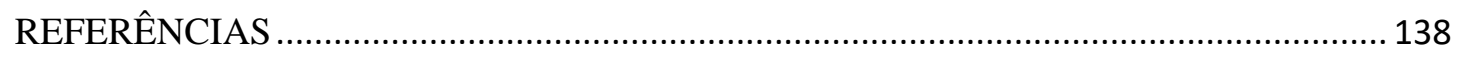

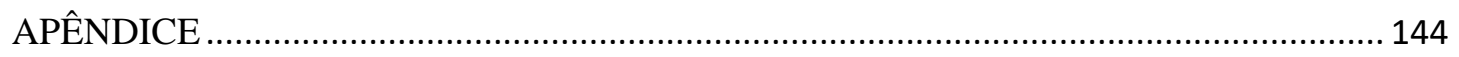

Análise da placa de informação de um MITRGE de 100 CV - 4 Polos ............................. 144

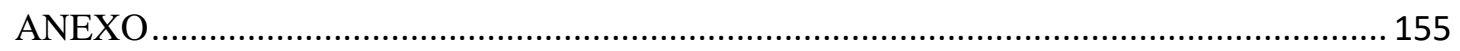

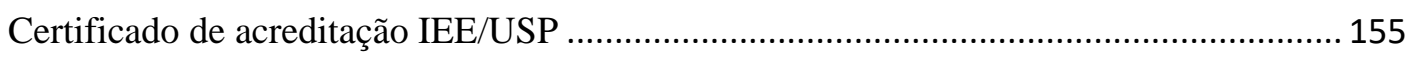




\section{INTRODUÇÃO}

\subsection{O CENÁRIO ENERGÉTICO MUNDIAL E NACIONAL}

Desde as últimas décadas do século $\mathrm{XX}$, o crescimento populacional tem acelerado de forma acentuada. Segundo as prospecções da Organização das Nações Unidas - ONU, a população mundial atingiu, em 2015, 7,349 bilhões de pessoas com previsão de alcançar 11,2 bilhões em 2100 (UNITED NATIONS, 2015). Em 1973, ano do primeiro grande choque do petróleo (MAYO, T.; NOHRIA, N., 2008) a população mundial era de aproximadamente 3,6 bilhões (Ibidem, 2015), o que significa que a população mundial dobrou em 45 anos. Conforme a Figura 1, o consumo energético também aumentou, porém, bem acima do aumento da população. Entre 1973 e 2014 o consumo de energia elétrica no mundo oriundo das mais diversas fontes primárias aumentou 388\% segundo a International Energy Agency (2016), passando de 6.171 TWh em 1973, para 23.816 TWh em 2014.

Figura 1 - Energia primária para conversão em eletricidade, 1973 vs 2014
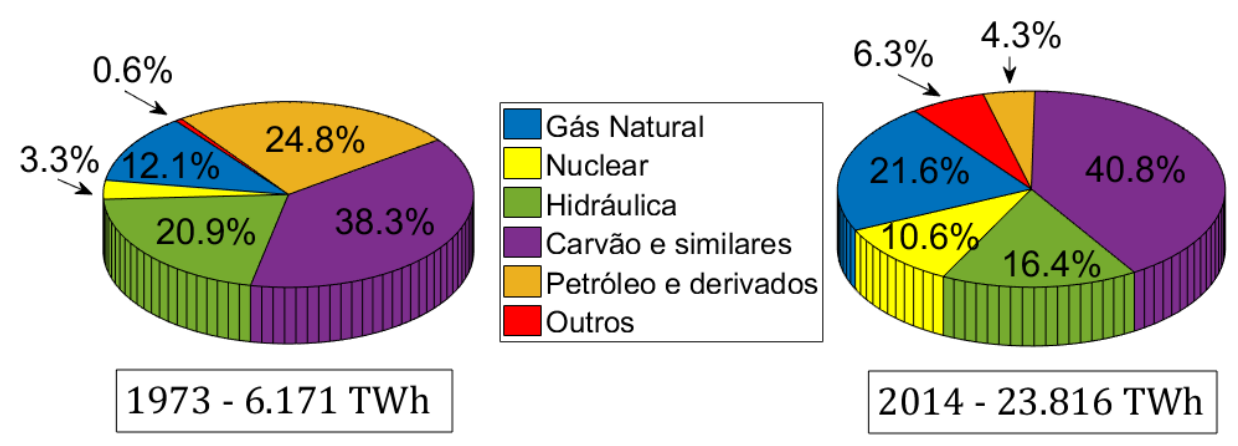

Fonte: (INTERNATIONAL ENERGY AGENCY, 2016; adaptação do autor).

A distribuição de demanda energética entre as fontes primárias apresentadas na Figura 1, também demonstra que, em termos percentuais, a utilização de fontes energéticas renováveis, como a hidráulica, diminuiu em relação à utilização das fontes fósseis e nucleares no mundo. A queima do carvão continua a ser a principal fonte primária de energia elétrica no mundo. 
Com o advento da revolução industrial, nos últimos dois séculos o consumo energético da humanidade foi intensivo, patrocinando grandes ganhos de produtividade em todo o mundo, sobretudo nos países com forte participação industrial no produto interno bruto.

Desde as duas décadas do século passado, a demanda crescente por energia tem colocado em pauta a mudança de conduta, tanto nas políticas públicas, quanto no grau de consciência e de exigência da população organizada. No campo das políticas públicas, foi iniciada uma intensa discussão para que o desenvolvimento possa ser mais sustentável e o setor de fontes energéticas ficou no centro da discussão.

O setor de energia elétrica, englobando todas as suas fontes primárias, possui destaque nesse processo, principalmente devido aos efeitos negativos causados ao meio ambiente e às populações próximas aos empreendimentos de grande porte. Tendo em vista o contexto citado, tornou-se atrativo pesquisar e implementar formas de realizar o mesmo trabalho com um consumo menor de energia. Segundo a National Energy Policy (2001), a "Eficiência Energética" nada mais é do que a capacidade de utilizar uma quantidade menor de energia para produzir a mesma quantidade de iluminação, aquecimento, movimento e demais serviços baseados na energia.

A eficiência energética vem se tornando cada vez mais um ponto de pauta comum nas discussões sobre a produção e a demanda de energia. Tanto no âmbito nacional como global, assume um papel central nas atuais políticas para o meio ambiente, focada no enfrentamento às causas das mudanças climáticas. Com a redução da demanda de energia via melhoria da eficiência energética, acredita-se apontar para um horizonte de manutenção do crescimento econômico, porém com a diminuição da necessidade de novos grandes empreendimentos de geração.

Para atuar na redução da demanda e consumo de energia elétrica, se faz necessário identificar e quantificar a utilização final da energia elétrica nos seguimentos da atual organização social, bem como as principais cargas elétricas. Dentre as principais utilizações finais do setor de energia elétrica se encontram: força motriz, aquecimento, iluminação e equipamentos eletrônicos (INTERNATIONAL ENERGY AGENCY, 2016).

Nos três principais segmentos da economia brasileira: residencial, comercial/serviço público e industrial, o consumo nos motores elétricos está presente. No setor industrial, as cargas motrizes correspondem a $68 \%$. No setor comercial e de serviços públicos $47,5 \%$ do consumo final de eletricidade está no condicionamento ambiental, ou seja, no acionamento de 
compressores para condicionadores de ar por motores elétricos. No setor residencial, os motores elétricos são encontrados principalmente nos compressores herméticos de refrigeradores, freezers e condicionadores de ar, representando juntas $47 \%$ do consumo médio de eletricidade das residências brasileiras (PROCEL, 2009).

Sendo os motores elétricos as cargas predominantes no sistema elétrico no mundo e no Brasil, a regulação para o desempenho mínimo destes equipamentos é uma medida de estado muito importante para os processos de eficientização do uso da energia elétrica.

\subsection{MOTIVAÇÃO}

O consumo total de eletricidade no Brasil em 1999 foi de 342,3 TWh. Em 2016, 567,5 TWh foram consumidos em todo o território brasileiro, registrando, portanto, um crescimento médio anual de aproximadamente 3,55\% (ONS, 2017). Segundo a (EPE, 2016), em 2015 foram consumidos $257,4 \mathrm{TWh}$ somente no setor industrial ${ }^{1}$, onde aproximadamente 175,1 TWh foram em motores elétricos. Desta forma, a importância dos motores elétricos para os sistemas produtivos são determinantes para a eficiência dos processos.

Tendo em vista o contexto citado, o rendimento dos motores elétricos é elemento fundamental para se obter processos eficientes. Assim, surgem as perguntas motivadoras deste trabalho:

a) Como se comportaram o rendimento dos motores elétricos comercializados no Brasil nas últimas décadas?

b) Como se comporta a legislação brasileira de desempenho mínimo de motores elétricos em relação à legislação dos principais mercados mundiais?

c) Como se comportou o rendimento dos motores elétricos comercializados no Brasil em relação à legislação de desempenho?

d) O rendimento dos motores elétricos declarados em placa está em harmonia com os valores medidos em ensaios padronizados?

\footnotetext{
${ }^{1}$ No setor industrial estão envolvidos também os setores de transportes, agropecuário e consumo interno no setor energético.
} 
O Decreto Presidencial 4.508/2002 especificou o rendimento mínimo dos motores elétricos comercializados no país a partir de 28 de fevereiro de 2003. Até então, não havia uma legislação direcionada aos padrões de rendimento dos motores elétricos comercializados no Brasil. Neste sentido, a investigação do comportamento do rendimento dos motores elétricos utilizados no país desde o processo de industrialização nas primeiras décadas do século XX até os dias atuais, irá possibilitar a avaliação dos principais ganhos de eficiência. Para tal análise, se faz necessário a avaliação de rendimento dos motores elétricos obtidos por meio de ensaios padronizados realizados neste período.

O Instituto de Energia e Ambiente da Universidade de São Paulo, desde 1926, quando teve o nome de Gabinete de Eletrotécnica alterado para Laboratório de Máquinas e Eletrotécnica, realiza ensaios em diversos equipamentos eletromecânicos, dentre eles, os motores elétricos. Por isto possui em seu acervo técnico, relatórios de ensaios de mais de 20 mil motores elétricos, nacionais e importados que, com as devidas considerações, fornecem um cenário do mercado brasileiro de 1945 até os dias atuais.

\subsection{OBJETIVO GERAL}

Este trabalho tem o objetivo de avaliar o rendimento dos motores elétricos de indução trifásicos ensaiados no Laboratório de Máquinas Elétricas do Instituto de Energia e Ambiente da Universidade de São Paulo desde 1945 até 2016, tendo-se por base a legislação de rendimento aplicados aos motores de indução.

\subsection{OBJETIVOS ESPECÍFICOS}

a) Comparar a legislação brasileira de motores elétricos com a legislação internacional;

b) Analisar as variações no rendimento dos motores elétricos de indução trifásicos com rotor em gaiola de esquilo comercializados no Brasil entre 1945 e 2016;

c) Avaliar o impacto da legislação de desempenho de motores elétricos para os motores comercializados no Brasil; 
d) Avaliar o comportamento do rendimento e do fator de potência dos motores elétricos ensaiados, tendo-se como referência os valores medidos e aqueles informados pelos fabricantes.

\subsection{ESTRUTURA DO TRABALHO}

A dissertação está dividida em 9 capítulos, incluindo esta Introdução como primeiro capítulo, onde é apresentado brevemente o cenário energético mundial, a motivação da realização deste trabalho, o objetivo geral e os objetivos específicos. Os demais capítulos são sintetizados a seguir:

\section{a) Capítulo 2 - $O$ contexto energético}

Neste capítulo é considerada uma revisão histórica da utilização de motores elétricos nos sistemas produtivos, iniciando pelas principais descobertas no campo da eletricidade, passando pelo desenvolvimento dos primeiros equipamentos elétricos, até a fundamental importância dos motores elétricos para a segunda revolução industrial no Século XIX. É abordada também a linha histórica dos processos de eficientização no uso da energia elétrica com foco especial para o uso final nos motores elétricos.

\section{b) Capítulo 3 - Os motores elétricos}

Neste capítulo são abordados conceitos básicos dos motores elétricos de indução, desde as particularidades dos motores elétricos de indução trifásicos, discutindo as perdas de energia, até as grandezas elétricas e mecânicas envolvidas na operação. Neste capítulo também são apresentados os ensaios elétricos padronizados para determinação de rendimento. São apresentados trabalhos relevantes sobre o rendimento de motores elétricos de indução. Também é analisada a atual legislação de desempenho de motores elétricos de indução trifásicos no contexto nacional e mundial. 


\section{c) Capítulo 4 - Metodologia}

Neste capítulo é mostrada a metodologia utilizada no trabalho, desde a aquisição e processamento de dados, até a obtenção dos resultados.

\section{d) Capítulo 5 - Resultados}

- No capítulo 5 é apresentada de forma sistematizada, a abrangência do banco de dados dos motores elétricos de indução trifásicos, utilizando os resultados de 2.762 motores elétricos, de diferentes tecnologias, ensaiados entre 1945-2016.

- É realizada uma comparação entre os dados disponibilizados nos informativos técnicos dos fabricantes e comparado com os resultados dos ensaios padronizados, quanto ao fator de potência e o rendimento, apresentando uma avaliação estatística do resultado. Nesta análise foram utilizados 435 motores elétricos de 4 diferentes velocidades, com potências entre $1 \mathrm{CV}$ e $250 \mathrm{CV}$, alimentados em baixa tensão na frequência de $60 \mathrm{~Hz}$, ensaiados nos anos de 2015 e 2016.

- Também é analisado o impacto das 3 legislações brasileiras de desempenho de motores elétricos, explorando as diferenças entre os valores encontrados nos ensaios e os valores padronizados para cada potência e velocidade.

- Foi avaliado o rendimento dos motores elétricos comercializados no Brasil entre 1945-2016, sendo apresentados os principais elementos que proporcionaram as mudanças no rendimento.

- A relação massa/potência dos motores elétricos é explorada neste capítulo, sob o aspecto das inovações tecnológicas que ocorreram no referido período.

\section{e) Capítulo 6 - Conclusões}

Este capítulo tem por objetivo apresentar uma síntese das contribuições deste trabalho, por meio dos principais dados apresentados e discutidos em todo o texto. 


\section{f) Capítulo 7 - Referências bibliográficas}

Neste capítulo é apresentada a relação das publicações utilizadas como referência para a construção deste trabalho. Excluindo os relatórios técnicos oficiais consultados no acervo do Instituto de Energia e Ambiente da Universidade de São Paulo.

\section{g) Capítulo 8 - Apêndice}

No Apêndice são apresentadas as definições das grandezas presentes em uma placa de identificação típica de um motor elétrico de indução trifásico.

\section{h) Capítulo 9 - Anexo}

No anexo é apresentada cópia do certificado de acreditação do IEE/USP. 


\section{O CONTEXTO ENERGÉTICO}

\subsection{DO DOMÍNIO DA ELETRICIDADE AOS PRIMÓRDIOS DA INDÚSTRIA}

Para abordar a discussão sobre os motores elétricos, muitos pesquisadores introduzem o tema elaborando um resgate histórico, desde a origem da observação dos fenômenos da eletricidade em Tales de Mileto na Grécia há aproximadamente 600 a.C. e do magnetismo em Lucretios 100 a.C. (SLATER, J. ; FRANK, N., 2011). Entretanto, a sociedade grega, não se apropriou desta forma de representação da natureza para os processos produtivos, de modo que a noção de eletricidade na sociedade grega não se desenvolveu (GONÇALVES JUNIOR, D., 2007). Assim, por mais de um milênio, pouco se avançou neste campo da ciência, sendo possível registrar mudança fundamental ocorrendo, quando o físico dinamarquês Hans Christian Oersted (1820) percebeu a interação entre a eletricidade e o magnetismo ao circular corrente elétrica por condutores localizados próximos de uma bússola (Ibidem, 2011). Após este significativo avanço, o físico francês André-Marie Ampère, contribuiu relacionando matematicamente os dois fenômenos físicos.

Em 1831, o físico britânico Michael Faraday, observou a possibilidade de desenvolver corrente elétrica em um meio material condutor, isolado eletricamente, a partir de variações de fluxo magnético, o que ficou conhecido como o fenômeno da indução eletromagnética (HAMMOND, P., 1986). Assim, as bases materiais para a concepção e o desenvolvimento dos geradores elétricos, dos motores elétricos, e dos transformadores elétricos, sendo estes, os principais equipamentos eletromecânicos responsáveis pela geração, transporte e uso final de energia elétrica, estavam colocadas.

É possível observar que o momento histórico em que os conceitos físicos e a modelagem matemática da eletricidade foram desenvolvidos, é justamente no período da primeira revolução industrial (1760-1840), onde o principal insumo energético utilizado foi à biomassa (lenha) e o carvão mineral (biomassa envelhecida), baseada na máquina a vapor (WRIGLEY, E. A., 2010). Assim, a eletricidade juntamente com o petróleo possibilitaram a segunda etapa da revolução industrial (1850-1940), momento da expansão do modo de produção capitalista pelo mundo, onde os fenômenos físicos foram apropriados pelos

processos produtivos, como elemento fundamental para a produção de mercadorias e a apropriação dos excedentes, sobretudo na forma de acumulação. 
A apropriação da eletricidade pela pujante indústria que se desenvolvia, foi objeto de estudo por muitos intelectuais, que elaboraram a interpretação da produção capitalista, durante e posteriormente às revoluções industriais. Para o filósofo italiano Antônio Gramsci (1926), a eletricidade é:

(...) historicamente ativa, mas não como mera força natural (como descarga elétrica que provoca incêndios, por exemplo), e sim como um elemento de produção dominado pelo homem e incorporado ao conjunto das forças materiais de produção, objeto de propriedade privada. Como força natural abstrata, a eletricidade existia mesmo antes de sua redução a força produtiva, mas não operava na história, sendo um tema para hipóteses na ciência natural (e, antes, era o 'nada' histórico, já que ninguém se ocupava dela e, ao contrário, todos a ignoravam). (GRAMSCI, A., 2004).

Deste modo, em meados dos anos 1880, a indústria elétrica estava se estabelecendo nas grandes cidades da Europa e dos EUA, predominantemente convertendo energia mecânica em elétrica, através de geradores, transportando por meio de linhas de transmissão e retornando a forma mecânica em pequenos motores elétricos, utilizados para a produção de movimento. A eletricidade também passa a ser utilizada para iluminar os grandes centros de produção do mundo (MOTTELAY , 2007). Com o cenário de previsível expansão, a indústria de equipamentos eletromecânicos sofre fortes mudanças, com o desenvolvimento para as tecnologias em corrente alternada, possibilitando a geração de grandes blocos de energia, bem como a transmissão em longas distâncias e grande flexibilidade na distribuição (MCPHERSON, S. S., 2012). Dessa maneira, a recém-criada indústria de eletricidade em corrente contínua, fica obsoleta com a recente "inovação tecnológica", momento em que os investimentos nos sistemas elétricos não haviam sido amortizados. Para Gonçalves Junior (2007):

Este evento é demonstrativo da natureza social e não física das tecnologias. A empresa capitalista não descarta uma tecnologia pela sua idade. É a condição de maior ou menor extração de mais-valia que determina o valor de uso de uma dada tecnologia, por isso, a sua substituição é motivada pelas condições sociais. Este resultado serviu como alerta a toda indústria elétrica, mostrando que um processo de livre competição era prejudicial a todos os interesses capitalistas do ramo. 
O desenvolvimento da indústria do setor elétrico pelos EUA e Europa foi determinado pela formação dos grandes grupos de empresas. Nos Estados Unidos se fortalecem principalmente a General Electric e a Westinghouse, atendendo o mercado norte americano de equipamentos eletromecânicos. Na Europa, o mercado é dominado principalmente pela Siemens, AEG e Brown Boveri (MARTIN, J.-M., 1992).

De posse do conhecimento da indução, e com as crescentes demandas da indústria, todas as condições estavam criadas para o desenvolvimento dos equipamentos em corrente alternada. Assim, os registros históricos indicam que as primeiras patentes do gerador de corrente alternada, do transformador elétrico e do motor de indução com rotor em gaiola, foram registradas pelo pesquisador sérvio Nikola Tesla (1856-1943) (CARLSON, B. , 2015). O motor de indução apresentou significativas vantagens sobre o motor de corrente contínua, como por exemplo: construção mais simples, mais silencioso, menores índices de manutenção e possibilidade de ser produzido para elevadas potências. Desta forma, a indústria da produção de eletricidade, intensifica o seu desenvolvimento, sobretudo na Europa e nos Estados Unidos.

As empresas que atuavam na cadeia de equipamentos eletromecânicos da Europa projetavam equipamentos para operarem na frequência de $50 \mathrm{~Hz}$, em contrapartida, as que operavam nos Estados Unidos produziam equipamentos projetados para operação em $60 \mathrm{~Hz}$. Isso ocorreu com o objetivo econômico de evitar a concorrência em territórios distintos, de maneira que, para produzir equipamentos em frequência diferentes dos convencionalmente produzidos, a fábrica teria de realizar alterações na sua linha de produção, o que elevaria o preço final dos equipamentos (GONÇALVES JUNIOR, D., 2007). Desta forma, esses grupos empresariais previam a expansão de seus negócios com instalações dos sistemas elétricos por outros territórios do mundo.

O engenheiro do Instituto de Eletrotécnica e Energia da USP, Duílio Leite, explicou que os europeus sempre pensaram no sistema métrico, múltiplos e submúltiplos de 10, como por exemplo: metro, decímetro, centímetro. Logo, pensaram em um período de $50 \mathrm{~Hz}$. Já as empresas dos Estados Unidos, raciocinaram no sentido que sendo a frequência dependente do tempo e o sistema do tempo sexagesimal é universal, pois uma hora possui 60 minutos, o minuto tem 60 segundos, portanto inevitavelmente, o segundo deve ter $60 \mathrm{~Hz}$ (CUNHA L., 2010). 


\subsection{ELETRICIDADE NO BRASIL}

No Brasil, as primeiras experiências com a eletricidade não demoraram muito tempo para serem realizadas. Em 1876, Dom Pedro II, em uma viagem aos Estados Unidos, fica deslumbrado com a eletricidade, utilizada tanto para a iluminação, como para a produção de força, através de motores elétricos e para comunicação nos telefones. Assim, Dom Pedro II consegue importar para o Brasil 2 dínamos (geradores de corrente contínua) da Fábrica de Thomas Alva Edison e algumas dezenas de Lâmpadas Yablochkov (lâmpada a arco voltaico operando em corrente contínua), substituindo 46 bicos de gás que realizavam a iluminação noturna da estação da Estrada de Ferro Central do Brasil (RJ), sendo portanto uma grande inovação tecnológica. Em 1881, foram instaladas 16 lâmpadas alimentadas com um grupo gerador termoelétrico com dínamo para a iluminação do espaço que hoje corresponde à Praça da República na Cidade do Rio de Janeiro.

Em junho de 1883, o imperador inaugura o serviço de iluminação na cidade de Campos dos Goytacazes (RJ), utilizando 39 lâmpadas incandescentes de Edison, alimentadas por um conjunto de dínamos acionados via máquinas a vapor. Com visível sucesso da nova representação energética, a inovação se espalha pelas cidades de maior desenvolvimento econômico no Brasil, chegando a Porto Alegre em 1887 pela Companhia Fiat Lux e São Paulo em 1889 com o objetivo de abastecimento de água (Memorial da Eletricidade, 2016).

O primeiro kWh consumido no Brasil de origem hidráulica foi em 1883, em uma usina construída na cidade de Diamantina (MG) no Rio Ribeirão do Inferno, afluente do Rio Jequitinhonha. A pequena usina foi idealizada pelo artífice inglês John Rose, sendo constituída de uma barragem que possibilitava um desnível hidráulico de 5 metros, possuindo uma casa de máquinas com dois geradores de corrente contínua tipo Gramme de 8 cavalos vapor $^{2}$ cada, acionados por uma roda d'água. A usina foi construída para alimentar bombas utilizadas no desmanche de terreno para a procura do diamante, ou seja, para uma atividade econômica. Assim, foi construída uma linha de transmissão de $2 \mathrm{~km}$, sendo considerada neste momento a maior linha do mundo, pois a linha de transmissão da hidroelétrica de Niagara Falls possuia 1,5 km (TIBÃES, M. C. D., 2001).

Nos Estudos Unidos, a corrente alternada já saia vencedora da famosa "guerra das correntes" devido à possibilidade de geração em grandes blocos de potência, bem como a

${ }^{2}$ Cavalo-vapor é uma unidade de medida de potência. Muito utilizada para expressar a potência mecânica no eixo de motores elétricos. Equivale a 737,4987 Watts para o Sistema Internacional (SI) (THORNTON, S.; MARION, J., 2010). 
utilização dos transformadores para transmissão em longas distâncias e uso dos motores de indução, que já se mostravam significativamente mais baratos que os motores de corrente contínua, de maneira que a cadeia dos equipamentos era viabilizada (MCPHERSON, S. S., 2012).

Este cenário motivou o industrial mineiro Bernardo Mascarenhas a construir uma hidroelétrica com o objetivo de substituir as máquinas a vapor, que utilizavam carvão importado, para movimentar a pequena indústria têxtil da família e o excedente da produção de eletricidade era vendido para a prefeitura da cidade, sendo utilizada para a iluminação da região central. A inauguração da primeira hidroelétrica no território brasileiro com máquinas de corrente alternada foi em Juiz de Fora (MG), em setembro de 1889, apenas dois meses antes da Proclamação da República. A hidroelétrica possuía duas unidades geradoras de 250 $\mathrm{kW}$, instalada na casa de máquinas, realizando o aproveitamento de parte do potencial hidráulico do Rio Paraibuna. As máquinas foram importadas da Companhia Westinghouse, sendo monofásicas, com tensão terminal de 100 Volts e operando em frequência de $60 \mathrm{~Hz}$ (ELETROBRÁS, 1977). Desta maneira, a geração em corrente alternada se inicia na América do Sul com importação de máquinas elétricas dos Estados Unidos, operando na frequência norte americana de $60 \mathrm{~Hz}$. Com o passar dos anos, o processo de eletrificação do Brasil se intensificou, tanto para o atendimento da produção (indústrias) como para o atendimento das cidades (iluminação, bombeamento hidráulico e ventilação). Como o país tem dimensões continentais, sendo fundamentalmente geração de energia elétrica de base hidráulica, portanto, distante dos centros de consumo, o país estava com uma malha elétrica não interligada. Assim, as frequências adotadas foram influenciadas pelos dois principais modelos, em $50 \mathrm{~Hz}$ e em $60 \mathrm{~Hz}$. Existiam até algumas cidades com frequência aleatória, como por exemplo, Curitiba (PR) em $42 \mathrm{~Hz}$, Jundiaí (SP) com $40 \mathrm{~Hz}$ e Petrópolis, que operou temporariamente em $125 \mathrm{~Hz}$ (CUNHA L., 2010). A necessidade da padronização da frequência em território nacional era evidente, pois não era possível interligar sistemas com diferentes frequências. Neste sentido, o Grupo Light teve de construir no município de Aparecida (SP), próximo ao estado do Rio de Janeiro, uma estação conversora, com potência de $50 \mathrm{MW}$, para a interligação dos sistemas em $50 \mathrm{~Hz}$ com o sistema paulista de $60 \mathrm{~Hz}$.

A frequência de $60 \mathrm{~Hz}$ tinha se fortalecido nas cidades mais industrializadas do país, como São Paulo, dentre outras da região centro-sul, de maneira que a frequência faria diferença, sobretudo para as cargas motrizes. Com relação às cargas residenciais, como iluminação e aquecimento, o efeito da mudança de frequência era mínimo. Já nos motores elétricos, a frequência é determinante para a velocidade de operação. Assim, naquele 
momento, já havia a tendência da predominância da frequência de $60 \mathrm{~Hz}$ pelo maior poder econômico das regiões citadas.

Várias tentativas de unificar a frequência foram estabelecidas, tanto em nível estadual como em nível federal. Entretanto, a medida somente foi efetivada a partir de 1964, com a Lei $\mathrm{n}^{\circ} 4.454$ de 6 de Novembro de 1964, em que o Presidente ${ }^{3}$ Castelo Branco, estabelece a frequência de $60 \mathrm{~Hz}$ para qualquer novo empreendimento e determina a mudança progressiva para zonas em que a frequência fosse diferente (LEI No 4.454, 1964).

Nas décadas de 60, 70 e 80 os países expandiram as suas malhas de linhas de transmissão de energia elétrica onde, mundialmente, duas frequências foram padronizadas (50 Hz e $60 \mathrm{~Hz}$ ). Observando a Figura 2, é possível compreender a geopolítica da influência das empresas nos primeiros momentos da expansão da indústria de eletricidade pelo mundo.

Figura 2 - Mapa das frequências de tensão utilizadas nos países

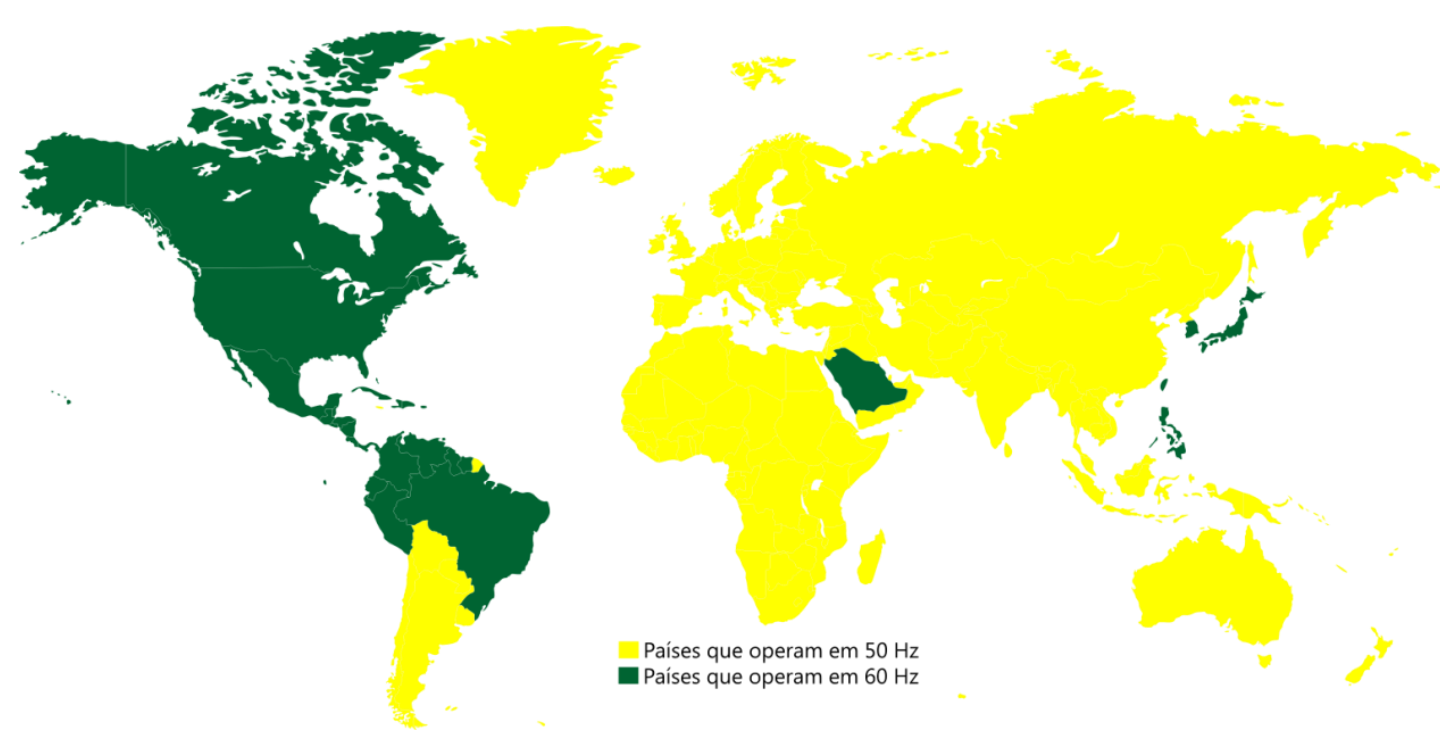

Fonte: Construído com base nos dados do U.S. Department of Commerce (2002).

O mapa da Figura 2, mostra claramente a influência das empresas dos Estados Unidos sobre o continente americano. Um caso excepcional é a Arábia Saudita, sendo o único país do Oriente Médio operando com frequência de $60 \mathrm{~Hz}$. No oriente, operam em $60 \mathrm{~Hz}$ apenas o Japão, Taiwan, Filipinas e Coréia do Sul. Assim, os países que possuem sistemas elétricos operando em $60 \mathrm{~Hz}$ representam hoje 11,9\% da população mundial e 13,1\% do PIB mundial (FMI, 2015).

\footnotetext{
${ }^{3} 1964$ foi o ano em se inicia do Brasil o período de ditadura militar. Este período se estendeu por 21 anos (FONTES, V., 2010).
} 
No Brasil, a frequência de $60 \mathrm{~Hz}$ é unificada em todo o território nos dias atuais. Este fato elevou os custos na interligação do sistema elétrico brasileiro com os países vizinhos que receberam maior influência do lobby empresarial das indústrias da Europa nos seus processos de instalação da indústria elétrica. Segue a Tabela 1, com o quadro atual de conversores de frequência para interligação das redes que operam em $50 \mathrm{~Hz}$ com as redes operantes em 60 Hz.

Tabela 1 - Interconexão elétrica na América do Sul utilizando conversor de frequência

\begin{tabular}{l|c|c}
\hline Cidade/País & Tensão (kV) & Potência (MW) \\
\hline Itaipu & 500 & 7.000 \\
\hline Foz do Iguaçu (Br)/Acaray (Pa) & 138 & 50 \\
\hline Rincón (Ar)/Garabi (Br) & 500 & 2.200 \\
\hline P. de los Libres (Ar)/Uruguaiana (Br) & 230 & 50 \\
\hline Livramento (Br)/Rivera (Ur) & 230 & 70 \\
\hline Pt. Médice (Br)/Carlos (Ur) & 500 & 500 \\
\hline
\end{tabular}

Fonte: (CIER, 2016).

As conexões elétricas para o atendimento do intercâmbio energético são o resultado de um processo de busca pela otimização na utilização dos recursos, com perspectiva de atender a tardia industrialização brasileira, como resposta a duas grandes crises mundiais do petróleo em 1973 e 1979, intensificando a utilização da eletricidade e realizando onde possível a substituição do petróleo e seus derivados. Essa busca pela eficiência se dá também nos equipamentos para o uso final de energia elétrica. Onde, em um primeiro momento, a eletricidade foi vista pela indústria como elemento de inovação tecnológica fundamental para obtenção de maior eficiência no resultado do trabalho, neste novo momento de crise para os sistemas produtivos, a busca por recuperar as taxas de acúmulo se dá no meio tecnológico, na busca pela redução das perdas nos processos produtivos.

\subsection{EFICIÊNCIA ENERGÉTICA NO BRASIL}

A preocupação mundial com o consumo de energia aumentou nos anos $70 \mathrm{com}$ a primeira grande crise do petróleo. Esse fato provocou a elevação dos preços em mais de $400 \%$ (MAYO, T.; NOHRIA, N., 2008). O aumento intensificou a busca por alternativas energéticas para continuar a produção e países como EUA, França, Grã-Bretanha e Finlândia, aumentaram as encomendas de novos projetos de reatores nucleares (RATTNER, H., 2008). No Brasil dos anos 70, uma das alternativas encontradas foi incentivar a produção de etanol, a 
partir da cana de açúcar, com o programa Pró-Álcool, uma vez que a produção de etanol já era de domínio nacional e o petróleo ainda possuía grande parcela importada. Em relação à produção de energia elétrica, gerada a partir de combustíveis (sobretudo diesel e gás natural), buscou-se a substituição pela geração hidráulica, momento de construção das grandes hidroelétricas no país, como Itaipu, Tucuruí e Ilha Solteira, uma vez que o território brasileiro possui elevado potencial hídrico e, até aquele momento, tal potencial era praticamente inexplorado.

A construção de usinas hidroelétricas é amplamente adotada desde os anos de 1970 até os dias atuais. Em 1970 já havia 12.000 MW de potência instalada em hidroelétricas e em 2014 86.000 MW, de acordo com o Banco de Informação da Geração - BIG (AGÊNCIA NACIONAL DE ENERGIA ELÉTRICA, 2016).

A construção de grandes usinas hidroelétricas para aumentar disponibilidade ofertada de energia elétrica visando o crescimento econômico, requer longo tempo para a implantação e acarreta também muitos impactos ambientais e sociais. Contudo, atuar no uso eficiente e racional da energia é bem menos oneroso, podendo resultar em redução de custos para o consumidor final, bem como postergar investimentos em geração, transmissão e distribuição de energia elétrica (ROMÉRO, M. A.; REIS, L. B., 2012). Entretanto, Willian Jevons em 1865, ao analisar o consumo de carvão na Inglaterra durante a primeira grande transformação nos processos produtivos (revolução industrial), afirma que apenas o senso comum pode acreditar que o progresso tecnológico pode contribuir, aumentando a eficiência objetivando a redução do consumo energético. Para elaborar esta afirmação, Jevons observou a demanda por carvão aumentando, onde simultaneamente as máquinas a vapor se tornavam mais eficientes. Nas palavras de Jevons (1866), “é uma confusão total de idéias supor que o uso econômico de combustível é equivalente a uma redução do consumo. Exatamente o contrário é a verdade".

Para Gonçalves Junior (2007), a discussão de eficiência energética está enraizada socialmente em como a produção é dividida entre aqueles que participam da sua realização.

\footnotetext{
No entanto, cabe observar que, em uma sociedade de classes, falar em eficiência e/ou utilização racional de um sistema de produção sem compreender estas categorias no interior das relações sociais estabelecidas é pura ideologia ou alienação. A Eficiência é pressuposto para avaliação dos resultados na produção, e seu sentido, numa sociedade em que os resultados da produção são privados, exige localizar os beneficiários - privados - desta produção. (GONÇALVES JUNIOR, D., 2007).
} 
O pensamento dominante sobre como se deveria comportar a busca pelo crescimento econômico em um mundo ambiental escasso é dado como resposta pela economia verde, que tenta conciliar o contínuo crescimento econômico, com a preservação do meio ambiente. Sendo, portanto, nesta perspectiva que é desenvolvido o conceito de uso racional de recursos energéticos.

\footnotetext{
É importante mudar o paradigma da economia extrativa para o da economia produtiva, com a racionalização da utilização dos recursos naturais, unindo eficiência econômica com eficiência ambiental, num contexto integrativo. $\mathrm{Na}$ realidade, precisamos "economizar" o meio ambiente. (SANTOS, M. T. L. F., 2006).
}

Para tanto, implantou-se o Programa Nacional de Conservação de Energia Elétrica PROCEL no ano de 1985. Posteriormente, em 1995, foi transformado no Programa de Combate ao Desperdício de Energia Elétrica. Com a implantação e o fomento dessas políticas, desejava-se reduzir a crescente necessidade de construção de hidroelétricas com longas linhas de transmissão, uma vez que essas fontes, na maioria das vezes, estão situadas distante dos centros consumidores.

Nos anos 90, devido à política de privatizações no setor elétrico brasileiro, foram retirados os subsídios da tarifa de eletricidade, que naquele momento, passava de um "bem" para uma "mercadoria", segundo Araújo (2009), sofrendo assim fortes reajustes na tarifa, forçando os usuários a redução de consumo, o que impulsionou o setor industrial no desenvolvimento de equipamentos mais eficientes e novas tecnologias para redução do consumo de energia nos segmentos: residencial e industrial.

No Brasil, a preocupação com o uso final dos recursos da natureza na matriz energética, foi retomada fortemente em 2001 quando o país enfrenta o racionamento, conhecido como "apagão". Para Ildo Sauer, o período em que o país teve de racionar aproximadamente $1 / 4$ de seu consumo energético é resultado de escolhas econômicas realizadas nos anos 90, e não um problema de escassez hídrica, como era o discurso dominante da época.

Após quase uma década de reformas, as promessas de ampliação de oferta, qualidade, confiabilidade e preços compatíveis com a realidade não se realizaram. Ao contrário disso, a exacerbação de um ambiente de incerteza e falta de regras 
claras, diante de um precipitado processo de desverticalização e privatização já, então, em curso, levou, entre os anos de 2001/2002, a um racionamento de $25 \%$ do consumo de eletricidade, sob condições hidrológicas normais ( 3 anos com afluências acima da média e 2 abaixo da média), que afetou o crescimento econômico e as condições de vida de toda a sociedade. (SAUER, I. L., 2002).

O cenário do racionamento de energia elétrica foi grande impulsionador do decreto $\mathrm{n}^{\circ}$ 4.508 de 11 de dezembro de 2002, que dispõe sobre a regulamentação específica que define os níveis mínimos de eficiência energética de motores elétricos trifásicos de indução, rotor gaiola de esquilo, de fabricação nacional ou importada, para comercialização ou uso no Brasil, conforme mostra a Tabela 2. O índice de eficiência escolhido foi o rendimento em condições nominais.

O Decreto $\mathrm{n}^{\circ} 4.508 / 2002$ foi o primeiro documento nacional determinando o rendimento mínimo esperado dos motores elétricos comercializados no Brasil. Neste sentido, surgiu uma série de dúvidas que motivaram a investigação proposta neste trabalho.

Tabela 2 - Decreto 4.508/2002 e os rendimentos percentuais mínimos para os motores elétricos

\begin{tabular}{|c|c|c|c|c|c|c|c|c|}
\hline \multirow[b]{2}{*}{$\mathbf{C V}$} & \multicolumn{4}{|c|}{$\begin{array}{l}\text { PADRÃO } \\
\text { Polos }\end{array}$} & \multicolumn{4}{|c|}{$\begin{array}{l}\text { ALTO RENDIMENTO } \\
\text { Polos }\end{array}$} \\
\hline & 2 & 4 & 6 & 8 & 2 & 4 & 6 & 8 \\
\hline 1,0 & 77,0 & 78,0 & 73,0 & 66,0 & 80,0 & 80,5 & 80,0 & 70,0 \\
\hline 1,5 & 78,5 & 79,0 & 75,0 & 73,5 & 82,5 & 81,5 & 77,0 & 77,0 \\
\hline 2,0 & 81,0 & 81,5 & 77,0 & 77,0 & 83,5 & 84,0 & 83,0 & 82,5 \\
\hline $\mathbf{3 , 0}$ & 81,5 & 83,0 & 78,5 & 78,0 & 85,0 & 85,0 & 83,0 & 84,0 \\
\hline 4,0 & 82,5 & 83,0 & 81,0 & 79,0 & 85,0 & 86,0 & 85,0 & 84,5 \\
\hline $\mathbf{5 , 0}$ & 84,5 & 85,0 & 83,5 & 80,0 & 87,5 & 87,5 & 87,5 & 85,5 \\
\hline 6,0 & 85,0 & 85,5 & 84,0 & 82,0 & 88,0 & 88,5 & 87,5 & 85,5 \\
\hline 7,5 & 86,0 & 87,0 & 85,0 & 84,0 & 88,5 & 89,5 & 88,0 & 85,5 \\
\hline 10 & 87,5 & 87,5 & 86,0 & 85,0 & 89,5 & 89,5 & 88,5 & 88,5 \\
\hline 12,5 & 87,5 & 87,5 & 87,5 & 86,0 & 89,5 & 90,0 & 88,5 & 88,5 \\
\hline 15 & 87,5 & 88,5 & 89,0 & 87,5 & 90,2 & 91,0 & 90,2 & 88,5 \\
\hline 20 & 88,5 & 89,5 & 89,5 & 88,5 & 90,2 & 91,0 & 90,2 & 89,5 \\
\hline 25 & 89,5 & 90,5 & 90,2 & 88,5 & 91,0 & 92,4 & 91,7 & 89,5 \\
\hline 30 & 89,5 & 91,0 & 91,0 & 90,2 & 91,0 & 92,4 & 91,7 & 91,0 \\
\hline 40 & 90,2 & 91,7 & 91,7 & 90,2 & 91,7 & 93,0 & 93,0 & 91,0 \\
\hline $\mathbf{5 0}$ & 91,5 & 92,4 & 91,7 & 91,0 & 92,4 & 93,0 & 93,0 & 91,7 \\
\hline 60 & 91,7 & 93,0 & 91,7 & 91,0 & 93,0 & 93,6 & 93,6 & 91,7 \\
\hline 75 & 92,4 & 93,0 & 92,1 & 91,5 & 93,0 & 94,1 & 93,6 & 93,0 \\
\hline 100 & 93,0 & 93,2 & 93,0 & 92,0 & 93,6 & 94,5 & 94,1 & 93,0 \\
\hline 125 & 93,0 & 93,2 & 93,0 & 92,5 & 94,5 & 94,5 & 94,1 & 93,6 \\
\hline 150 & 93,0 & 93,5 & 94,1 & 92,5 & 94,5 & 95,0 & 95,0 & 93,6 \\
\hline 175 & 93,5 & 94,1 & 94,1 & & 94,7 & 95,0 & 95,0 & \\
\hline 200 & 94,1 & 94,5 & 94,1 & & 95,0 & 95,0 & 95,0 & \\
\hline 250 & 94,1 & 94,5 & & & 95,4 & 95,0 & & \\
\hline
\end{tabular}

Fonte: (BRASIL, 2002). 


\subsection{O USO FINAL DE ENERGIA ELÉTRICA NO BRASIL}

A utilização final da energia no Brasil se dá em uma gama bastante ampla de possibilidades, devido à grande diversidade de necessidade. Geralmente os processos demandam aquecimento, refrigeração, movimento, pressão, força, iluminação, dentre outros.

Uma vez que o objeto deste trabalho está relacionado ao rendimento dos motores elétricos, é importante estratificar o consumo energético disponível na forma de eletricidade entre os segmentos econômicos. Desta forma, segundo a EPE (2016), e mostrado na Figura 3, a eletricidade no Brasil é consumida predominantemente no setor industrial, o que demonstra a maturidade econômica deste setor.

\section{Figura $3^{4}$ - Representatividade estimadados setores da economia no consumo de energia elétrica}

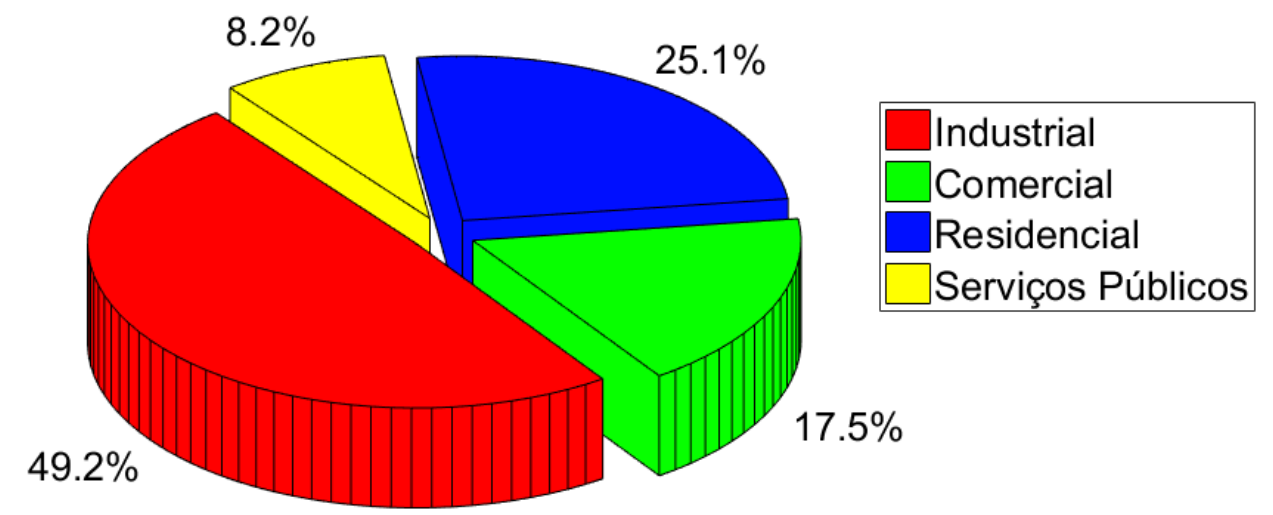

Fonte: Adaptado de EPE (2016).

Dentro de todos os seguimentos econômicos, existem cargas elétricas predominantes devido às necessidades humanas clássicas, bem como às necessidades dos sistemas produtivos atuais. Nesta perspectiva, observamos que os motores são predominantes como cargas, correspondendo diretamente por $46 \%$ das cargas elétricas no mundo, conforme mostra a Erro! onte de referência não encontrada.. É importante ainda observar, que dentro dos equipamentos eletrônicos também estão presentes pequenos motores elétricos para a refrigeração e outras funções. Dentro da parcela de $19 \%$ da produção de calor também se encontram as bombas de calor que são cargas motrizes, o que comprova a importância dos motores elétricos para os sistemas produtivos e para a organização da vida humana.

\footnotetext{
${ }^{4}$ No setor industrial estão envolvidos também os setores de transportes, agropecuário e consumo interno no setor energético. Neste gráfico não estão sendo consideradas as perdas acumuladas da geração até a disponibilização final de energia elétrica.
} 
Figura 4 - Participação estimada do consumo de eletricidade por utilização final no mundo -

Participação estimada do consumo de eletricidade por utilização final no mundo
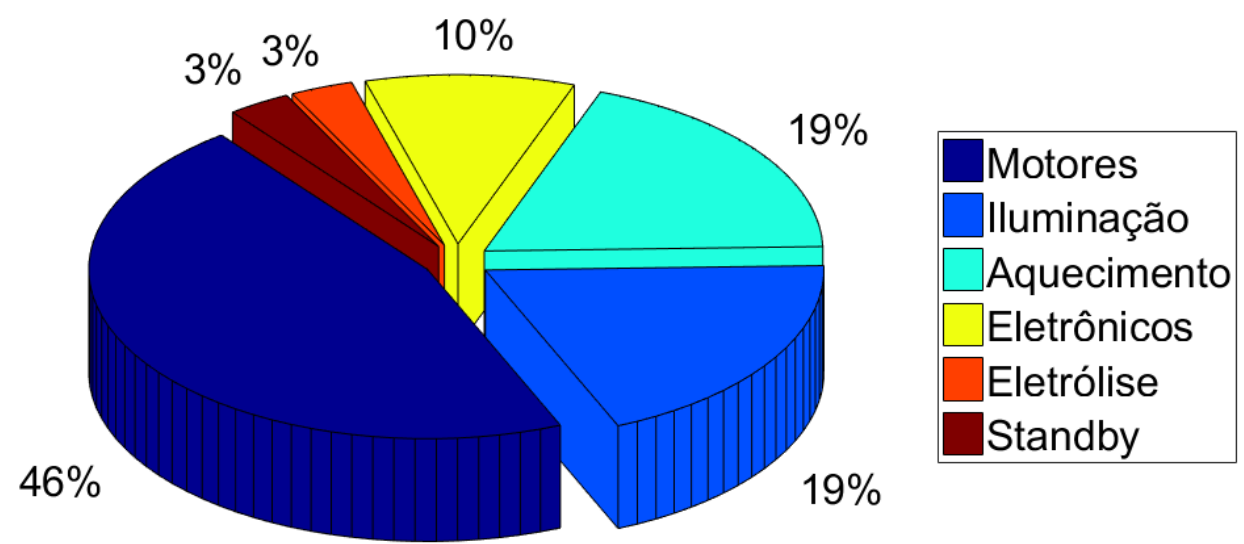

Fonte: (WAIDE, P.; BRUNNER, C., 2011,; adaptação do autor).

A parcela da demanda residencial estimada representa $25,1 \%$ do consumo total do sistema elétrico brasileiro conforme Figura 3. Existem diferentes tipos de utilização finais mais comuns nas residências brasileiras e a Figura 5, apresenta a demanda percentual eletrodoméstica estratificada por equipamento de uso final.

Figura 5 - Participação dos eletrodomésticos consumo médio

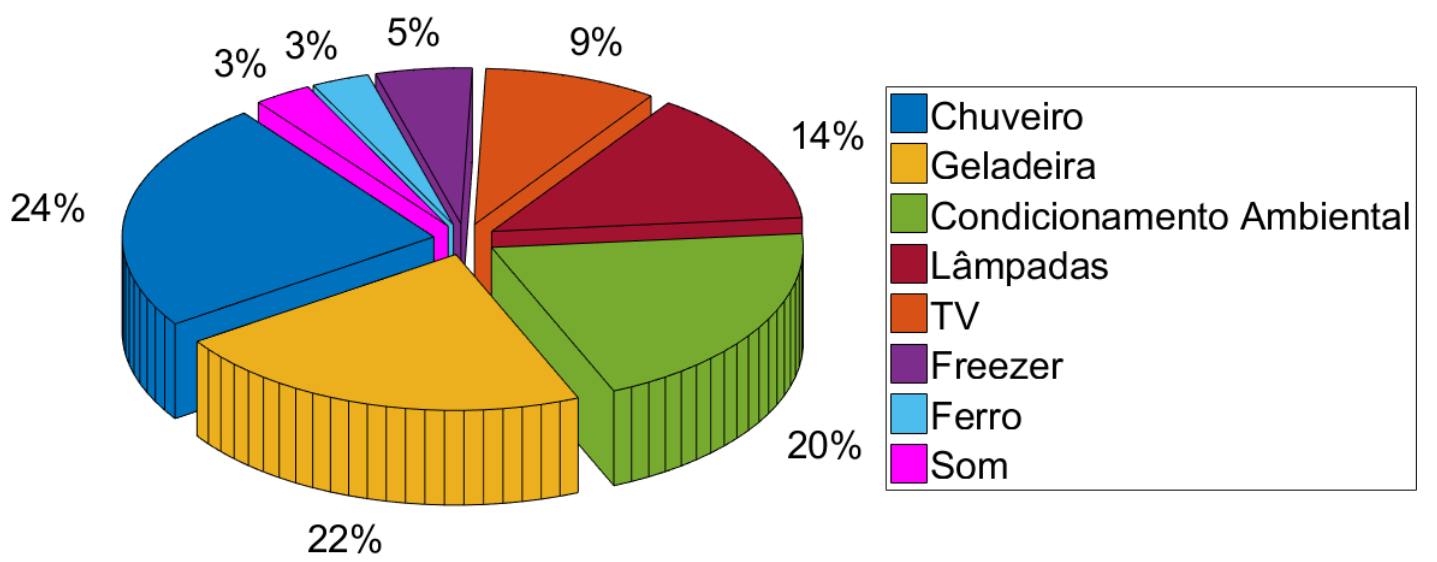

Fonte: (PROCEL, 2009; adaptação do autor).

É possível reagrupar o consumo médio presumido residencial brasileiro por categorias de uso final, sendo considerados a utilização de TV's e aparelhos de som, assim como computadores e outros na categoria de equipamentos eletrônicos. Chuveiros, ferros de passar roupas, micro-ondas, fornos elétricos são equipamentos de produção de calor. O consumo nas 
lâmpadas é classificado como iluminação. $O$ consumo em geladeiras, freezers, condicionamento ambiental (no Brasil - condicionador de ar para retirar calor), ventiladores, máquinas de lavar roupas, por exemplo, são cargas que operam com motores elétricos.

De posse desses conceitos com os dados do PROCEL (2009), foi construída a Figura 6, demonstrando que a predominância no consumo residencial também se dá pelos motores elétricos, internos aos equipamentos eletrodomésticos.

Figura 6 - Tipos de utilização final de energia elétrica no consumo residencial

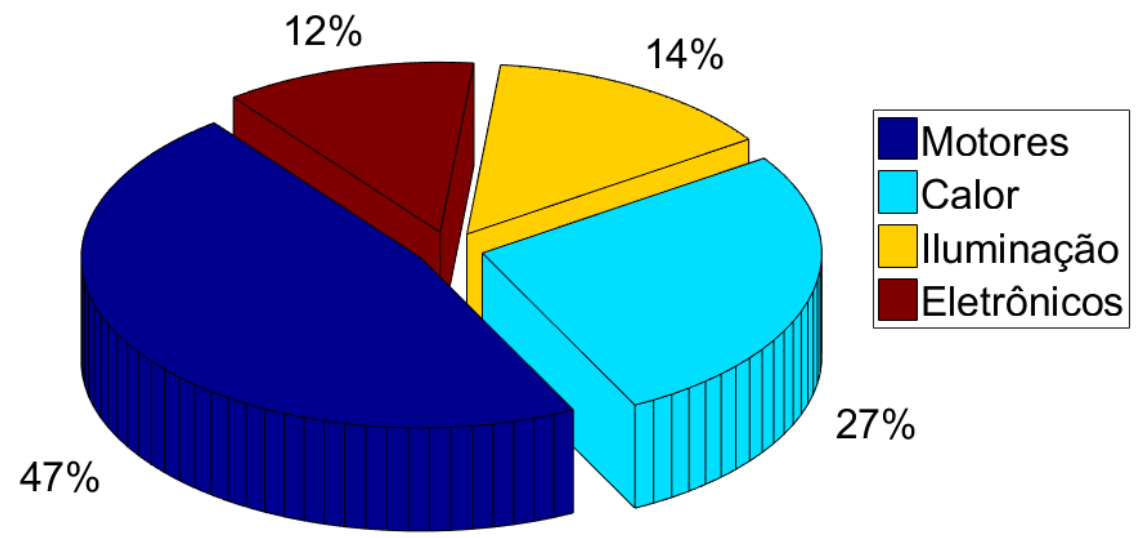

Fonte: (PROCEL, 2009; adaptação do autor).

A utilização final de energia elétrica em edifícios comerciais e em prédios públicos no Brasil se dá em uma distribuição bastante similar, na média dos casos. Desta maneira, foi construído o gráfico da Figura 7, onde, é possível observar a predominância dos motores elétricos nos aparelhos condicionadores de ar. Este comportamento ocorre pelo clima temperado e temperatura acima dos $25^{\circ}$ Celsius na maior parte do ano. 
Figura 7 - Tipos de utilização final de energia elétrica no consumo comercial e em prédios públicos

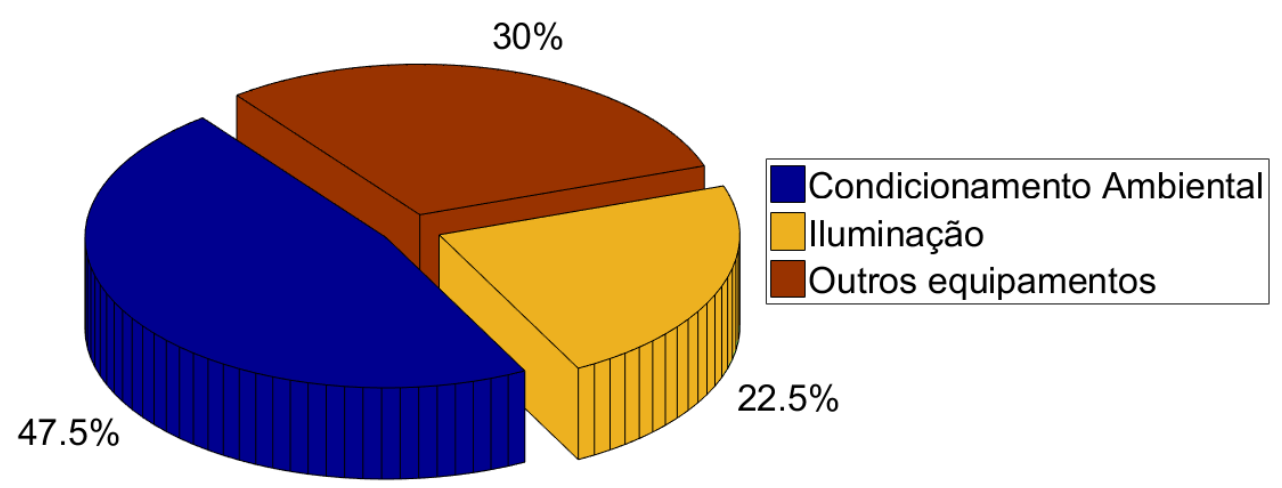

Fonte: (PROCEL, 2009; adaptação do autor).

No setor industrial brasileiro, a média de consumo percentual de energia elétrica em relação às demais fontes é de 17,2\% (EPE, 2016). Dentro do consumo de energia elétrica nas indústrias, a Figura 8, apresenta a estratificação nas quatro principais possibilidades de uso final de eletricidade no seguimento.

Figura 8 - Tipos de utilização final de energia elétrica no consumo industrial

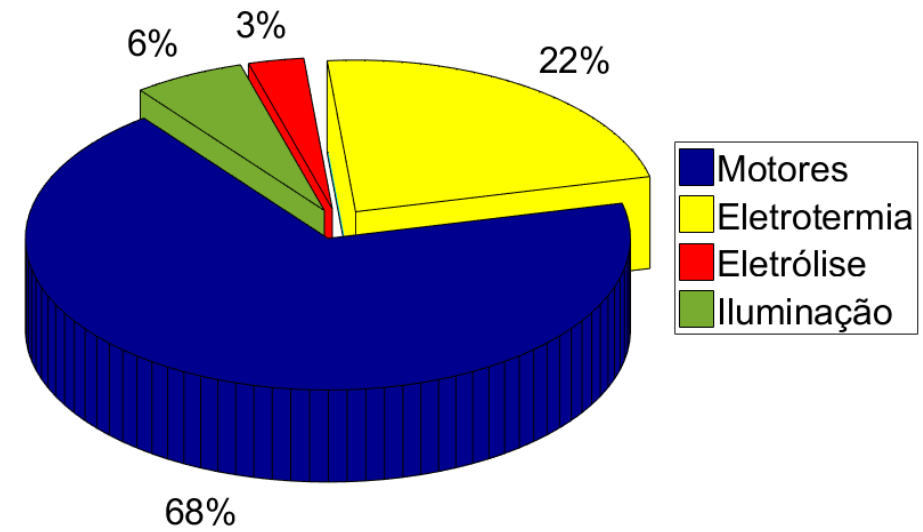

Fonte: (PROCEL, 2009; adaptação do autor).

É possível observar na Figura 8, a predominância absoluta dos motores elétricos no consumo percentual industrial brasileiro, representando $68 \%$ da eletricidade consumida nas indústrias.

Dentro do setor industrial, os motores elétricos são utilizados para acionar as mais diferentes cargas mecânicas. A Figura 9 ilustra as principais possibilidades de acionamentos mecânicos encontrados nas plantas industriais pelo mundo. 
Figura 9 - Demanda estimada de aplicações utilizando motores elétricos no mundo

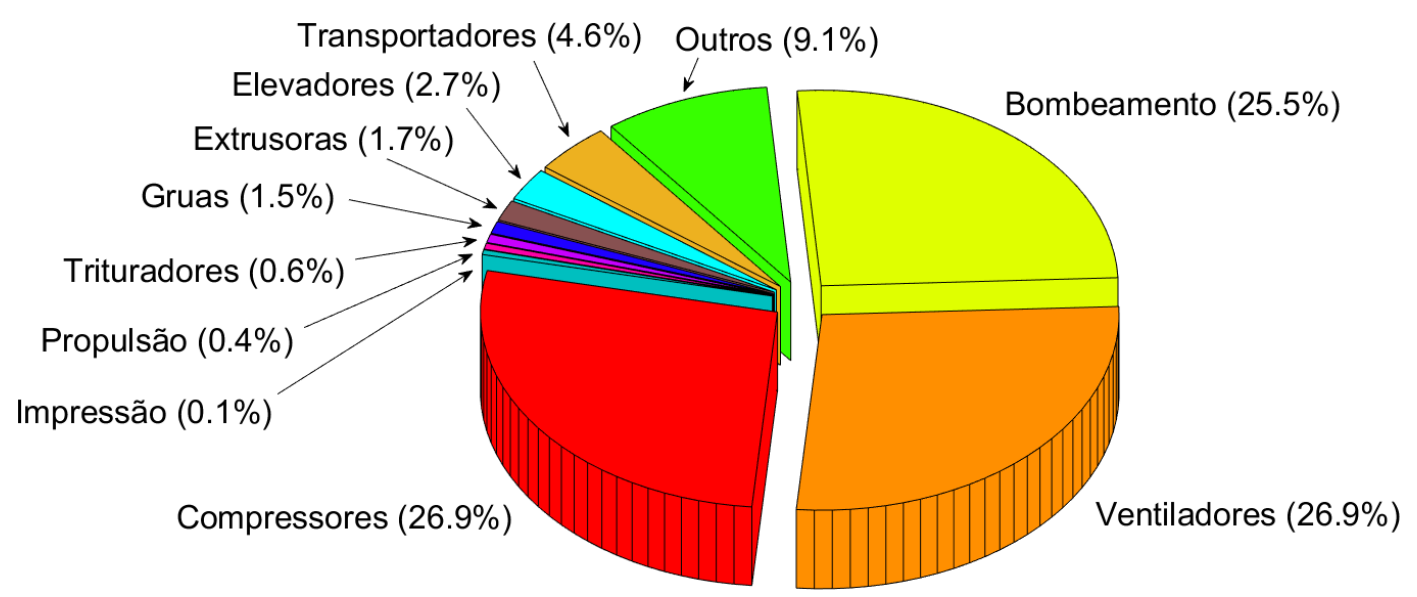

Fonte: (JUNG, H.-K., 2015). 


\section{OS MOTORES ELÉTRICOS}

Devido à fundamental importância dos motores elétricos e vasta possibilidade de aplicações nos mais diversos locais, ao longo de mais de 120 anos foram desenvolvidas diversas possibilidades de produção de movimento mecânico, força e pressão a partir da eletricidade, para as mais distintas exigências, como a necessidade de torque, controle de velocidade, robustez e baixo custo de fabricação.

As possibilidades se limitaram fundamentalmente, em motores de corrente contínua e motores que operam em corrente alternada. Esta disputa é plenamente compreensível, pois naquele momento, no final do século XIX, havia severas divergências sobre as formas de produção e distribuição de eletricidade, o que também desenrolou até mesmo no uso final, ou seja, nos motores elétricos, que junto com as lâmpadas elétricas eram as principais cargas elétricas.

As tecnologias (CA e CC) apresentam particularidades, sendo vantajosas para determinadas aplicações em detrimento de outras. A possibilidade de transporte de energia elétrica em grandes blocos por meio da elevação do nível de tensão via transformadores elétricos, tornou a corrente alternada hegemônica, fazendo com que os motores em corrente contínua saíssem de cena em muitas aplicações. As concepções básicas dos motores elétricos da atualidade se encontram na Figura 10, onde é possível observar a separação em três grandes grupos: os motores de corrente contínua, os motores síncronos e os motores assíncronos ou de indução. 
Figura 10 - Tipos básicos de motores elétricos

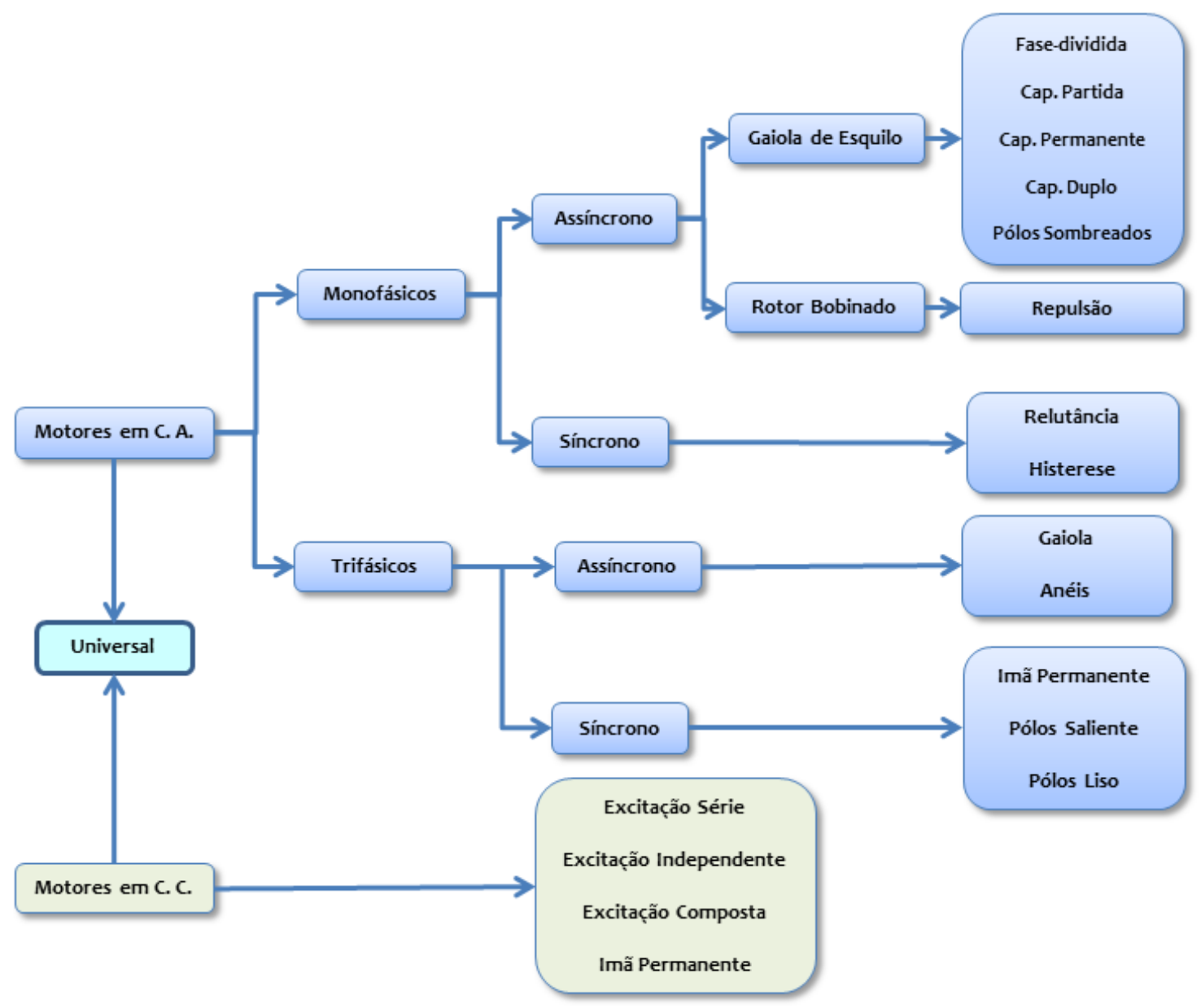

Fonte: (CHAPMAN, S., 2005; adaptação do autor).

Os motores de corrente contínua continuam no mercado para aplicações bastante específicas, onde as suas características básicas fundamentais são importantes para a operação. Os motores de corrente contínua podem operar em ampla faixa de velocidade com ajuste fino, por exemplo: tornos, bobinadeiras, máquinas de papel, máquinas têxteis, etc. Entretanto o alto custo, a necessidade maior de manutenção, quando comparado aos motores de corrente alternada e a necessidade de um conversor CA-CC para a operação, fazem com que a utilização seja restrita.

Os motores síncronos, assim como os de corrente contínua, possuem campo de aplicação bastante restrito, principalmente em função do elevado custo de aquisição. Também necessitam de conversores CA-CC para alimentar o enrolamento de campo. Para as máquinas síncronas, características positivas também se destacam, como o controle do fator de potência, o alto rendimento por possuir alimentação separada dos enrolamentos de campo e armadura, 
não havendo indução entre os enrolamentos localizados no estator e os localizados no rotor, velocidade constante e alta capacidade de torque em condições nominais. A utilização é comum no setor elétrico como compensação de energia reativa, onde nesta aplicação não é alocada carga mecânica em seu eixo. $\mathrm{Na}$ indústria a tecnologia síncrona utilizada principalmente em britadoras, laminadoras e extrusoras, dentre outras.

Os motores de indução possuem a mais ampla gama de aplicações, devido a uma série de fatores. Dentre eles, são destacados:

a) Baixo custo de aquisição e manutenção comparado às tecnologias concorrentes;

b) As características construtivas simples fazem com que a sua manufatura e substituição seja de fácil execução, não exigindo alta qualificação;

c) Com os avanços da eletrônica de potência, os conversores de frequência utilizados para controlar a frequência aplicada nos terminais dos motores elétricos, possibilitaram o controle de velocidade dos $\mathrm{MITRGE}^{5}$;

d) Pequenas dimensões, podendo ser utilizado em locais compactos;

e) Não produz faiscamento, possibilitando mais facilmente a sua aplicação em áreas classificadas;

f) Elevado torque de partida comparado as outras tecnologias concorrentes;

g) Elevada vida útil;

h) Silencioso quando comparado com as tecnologias concorrentes;

i) Não possui contato elétrico entre o rotor e o estator, o contato é realizado apenas pelos mancais, possuindo desta forma, alta segurança de operação;

j) É energizado em corrente alternada sem a necessidade de conversores $\mathrm{CA}-\mathrm{CC}$;

Por estes argumentos, este trabalho se dedicou a estudar os motores elétricos trifásicos de indução.

\footnotetext{
${ }^{5}$ Motor de Indução Trifásico com Rotor em Gaiola de Esquilo
} 


\subsection{MOTOR DE INDUÇÃO TRIFÁSICO COM ROTOR EM GAIOLA}

De acordo com Garcia (2003), os motores de indução com rotor em gaiola são responsáveis por mais de $90 \%$ do consumo total de eletricidade em motores elétricos. A simplicidade de sua construção faz com que consequentemente o custo de produção seja baixo, quando comparado a outras tecnologias. O motor de indução trifásico com rotor em gaiola de esquilo (MITRGE) também é conhecido por exigir baixíssimos índices de manutenção, consistindo basicamente em lubrificação dos mancais. A Figura 11 evidencia, percentualmente, os custos de aquisição e manutenção dos MITRGE, que somados correspondem a 5,6\% do custo total anualizado.

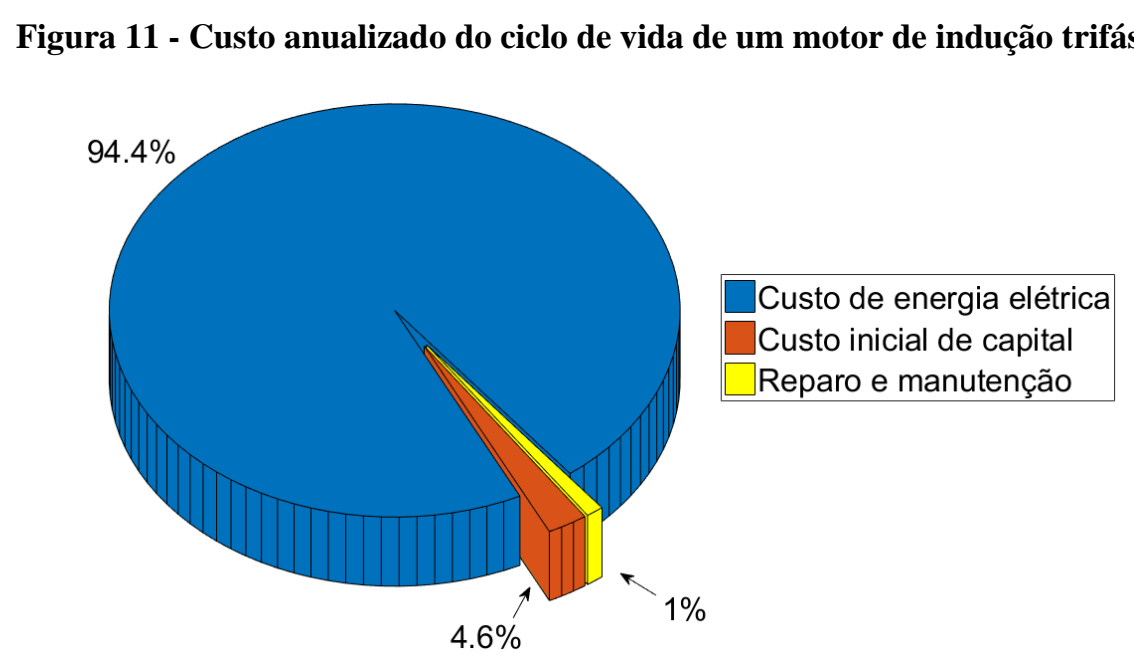

Fonte: Construído a partir dos dados de Almeida et al. (2008).

As máquinas assíncronas trifásicas (motor de indução) possuem uma parte fixa (estator) e uma parte girante (rotor). A Figura 12 ilustra um motor trifásico de indução com rotor em gaiola, em corte, com as principais partes construtivas.

\footnotetext{
${ }^{6}$ Custo do ciclo de vida do motor IE3 de 15CV com 2000 horas de operação por ano, em condições nominais, por toda a vida útil do motor elétrico (15 anos).
} 
Figura 12 - Motor de indução trifásico em corte

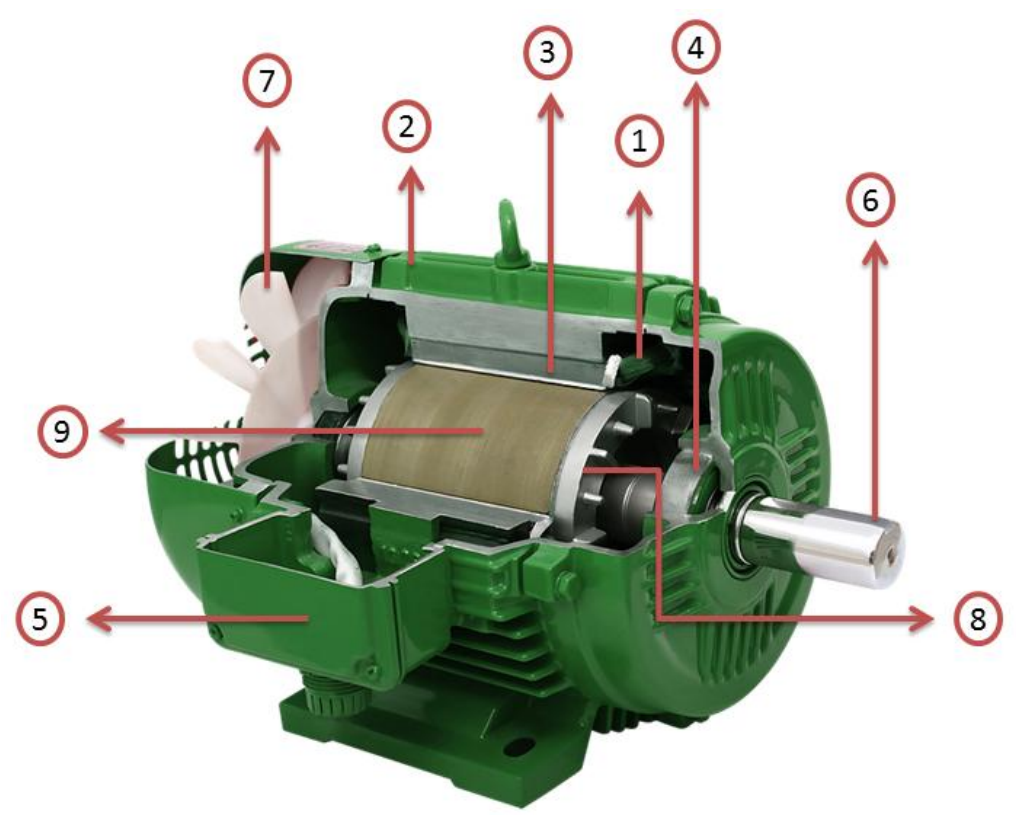

Fonte: (NOVA MOTORES ELÉTRICOS, 2017, adaptação do autor).

Tabela 3 - Principais componentes dos motores de indução trifásicos enumerados na Figura 12

\begin{tabular}{|c|c|}
\hline Parte construtiva & Características \\
\hline Estator & Componente fixa do motor elétrico, composta pelas partes: \\
\hline $\begin{array}{l}\text { 1- Enrolamento } \\
\text { trifásico }\end{array}$ & $\begin{array}{l}\text { Condutores elétrico de cobre, isolados por meio de esmalte, enrolados formando } \\
\text { bobinas, ligadas à rede elétrica trifásica. As bobinas com a circulação da corrente } \\
\text { produzem fluxo magnético responsável pela interação entre rotor e estator. Existem } \\
\text { três conjuntos de bobinas, uma para cada fase que estão defasadas geometricamente em } \\
120^{\circ} \text {. }\end{array}$ \\
\hline 2 - Carcaça & $\begin{array}{l}\text { Responsável pela sustentação física do equipamento, a carcaça é construída em ferro } \\
\text { fundido. Pela carcaça o fluxo magnético se fecha, de maneira que a função também é } \\
\text { magnética no motor elétrico. A geometria da carcaça também é responsável pela } \\
\text { dissipação de calor do equipamento. }\end{array}$ \\
\hline $\begin{array}{l}3 \text { - Núcleo do } \\
\quad \text { estator }\end{array}$ & $\begin{array}{l}\text { Constituído de material ferromagnético laminado, geralmente }\left(F e_{26}-S i_{14}\right) \text {, isoladas e } \\
\text { prensadas, destinadas a diminuir a relutância do meio para a circulação do fluxo } \\
\text { magnético. O núcleo contém ranhuras, onde estão alocados os condutores elétricos dos } \\
\text { enrolamentos trifásicos, isolados eletricamente do estator por meio de fita. }\end{array}$ \\
\hline 4 - Rolamentos & $\begin{array}{l}\text { Dispositivo mecânico onde se realiza o apoio de um eixo girante, para permitir o } \\
\text { movimento mecânico da carga acoplada no rotor com um mínimo de atrito possível. }\end{array}$ \\
\hline $\begin{array}{l}5 \text { - Caixa de } \\
\text { ligação }\end{array}$ & $\begin{array}{l}\text { Responsável por abrigar os bornes de conexão entre os condutores terminais do motor } \\
\text { elétrico e condutores do circuito que o alimenta. }\end{array}$ \\
\hline Rotor & Componente girante do motor elétrico, composta pelas partes: \\
\hline $6-$ Eixo & $\begin{array}{l}\text { Normalmente construído de aço, possuindo alta resistência mecânica assim como a } \\
\text { carcaça do motor elétrico. Tem a função de estabelecer a conexão entre o motor } \\
\text { elétrico e carga mecânica através de diferenciados tipos de acoplamentos. }\end{array}$ \\
\hline $\begin{array}{l}7-\text { Aletas de } \\
\text { ventilação }\end{array}$ & $\begin{array}{l}\text { Construídas para ventilar os enrolamentos e rolamentos (mancais) aliviando as } \\
\text { manifestações térmicas, causadas pela circulação de corrente elétrica e pelo atrito } \\
\text { entre partes fixas e partes girantes. É importante observar que na maioria dos casos as } \\
\text { aletas giram na velocidade determinada pelo número de polos e pelo escorregamento. }\end{array}$ \\
\hline
\end{tabular}

(Continua...) 


\begin{tabular}{l|l}
\hline Parte construtiva & Características \\
\hline Rotor & Componente girante do motor elétrico, composta pelas partes: \\
\hline $\begin{array}{l}\text { 8- Anéis de curto- } \\
\text { circuito }\end{array}$ & $\begin{array}{l}\text { Geralmente construídas utilizando alumínio, os enrolamentos do rotor são curto- } \\
\text { circuitados em ambos os lados por anéis. Sem a utilização do preenchimento do } \\
\text { núcleo com material ferromagético, o rotor de assemelha a uma "gaiola de esquilo". }\end{array}$ \\
& $\begin{array}{l}\text { Por este motivo o motor também recebe este nome informal. Nos enrolamentos do } \\
\text { rotor circulam as correntes induzidas a partir do enrolamento trifásico localizado no } \\
\text { estator. A interação do campo produzido pelas duas correntes elétricas (enrolamento } \\
\text { do rotor e do estator, provoca o torque). }\end{array}$ \\
\hline 9- Núcleo do rotor & $\begin{array}{l}\text { Semelhantes ao estator, geralmente composta pelos elementos }\left(F e_{26}-S i_{14}\right), \text { também } \\
\text { possuem ranhuras para abrigar os condutores elétricos rígidos em formato de barras, } \\
\text { construídos de alumínio na maior parte dos casos. }\end{array}$ \\
\hline
\end{tabular}

Fonte: Do autor.

\subsection{PRINCÍPIO DE FUNCIONAMENTO}

Até o atual momento histórico, todos os motores elétricos conhecidos operam por meio de interações entre forças magnéticas oriundas de correntes elétricas ou de materiais com manifestação de elevado magnetismo remanente. Este trabalho se limita a discutir os motores elétricos de indução que operam com corrente alternada.

A velocidade de giro do motor elétrico depende dos critérios de projeto admitidos pelo projetista, bem como varia ligeiramente com a carga mecânica no eixo. Classicamente, os motores elétricos de indução podem ser encontrados em quatro velocidades que dependem do número de polos com que os enrolamentos localizados no estator foram dispostos. A velocidade síncrona (velocidade do campo magnético girante) dos motores elétricos de corrente alternada é determinada pela Equação (1):

$$
N_{s}=\frac{120 * f}{P}
$$

\footnotetext{
$N_{s}=$ Velocidade síncrona $(R P M)$ (em condições nominais $)$

$f=$ frequência da tensão elétrica de alimentação $(\mathrm{Hz})$

$P=$ Número total de polos por fase
}

O motor de indução também é chamado de assíncrono, pois em sua operação a velocidade de eixo é ligeiramente menor que a velocidade síncrona. Esta pequena diferença se deve ao fato da velocidade do rotor ficar levemente menor que a velocidade do campo 
magnético girante. A mudança de velocidade é provocada e aumenta a cada incremento de carga mecânica no eixo e leva o nome de escorregamento.

O escorregamento pode ser calculado pela Equação (2).

$$
S=\frac{\left(N_{s}-N_{r}\right)}{N_{s}}
$$

$\mathrm{S}=$ Escorregamento. (Também pode ser expresso em percentual se multiplicado por 100)

$N_{s}=$ Velocidade síncrona do campo magnético girante $(R P M)$

$N_{r}=$ Velocidade do rotor $(R P M)$

Observa-se assim, que o número de polos do motor elétrico é determinante para a velocidade de eixo. O número de polos é formado pelo arranjo e distribuição dos condutores elétricos dos enrolamentos alocados nas ranhuras do estator. Atualmente no mercado, quatro velocidades são as mais utilizadas, tanto para a frequência de tensão de $60 \mathrm{~Hz}$ quanto $50 \mathrm{~Hz}$. São elas apresentadas na Tabela 4.

Tabela 4 - Velocidade dos motores de corrente alternada

\begin{tabular}{ccc}
\hline $\mathrm{N}^{\mathrm{o}}$ de polos & $\begin{array}{c}\text { Velocidade Síncrona } \\
\text { em frequência de } 60 \mathrm{~Hz}\end{array}$ & $\begin{array}{c}\text { Velocidade Síncrona } \\
\text { em frequência de 50 Hz }\end{array}$ \\
\hline 2 & $3.600(\mathrm{RPM})$ & $3.000(\mathrm{RPM})$ \\
4 & $1.800(\mathrm{RPM})$ & $1.500(\mathrm{RPM})$ \\
6 & $1.200(\mathrm{RPM})$ & $1.000(\mathrm{RPM})$ \\
8 & $900(\mathrm{RPM})$ & $750(\mathrm{RPM})$ \\
\hline
\end{tabular}

Fonte: Do autor.

A Figura 13 ilustra de forma didática a distribuição dos polos no estator do motor para os números de polos clássicos disponíveis no mercado, em uma representação monofásica. 
Figura 13 - Distribuição de polos no estator dos motores de indução

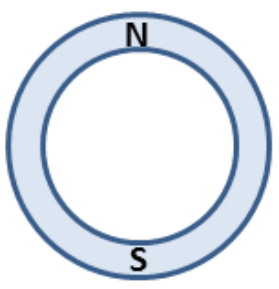

2 POLOS

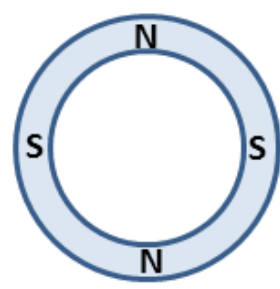

4 POLOS

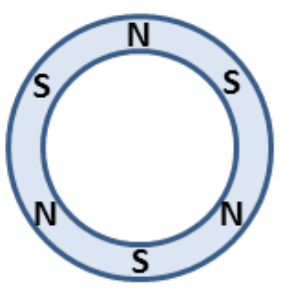

6 POLOS

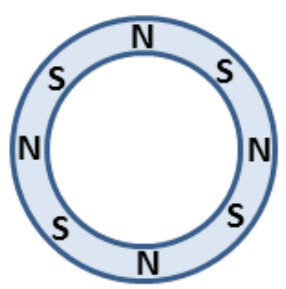

8 POLOS

Fonte: Do autor.

A utilização dos MITRGE pode ser a mais diversa possível, conforme apresentado na Figura 9. Entretanto, cada velocidade tem uma aplicação típica, por exemplo:

a) 2 polos: são comumente utilizados em motobombas e compressores a pistão de até 5 $\mathrm{CV}$, ferramentas como policortes, picadores agrícolas, e compressores radiais;

b) 4 polos: são comumente utilizados em compressores a pistão maiores que $20 \mathrm{PCM}^{7}$, ventiladores, esteiras transportadoras, tornos, fresas e furadeiras de bancada em coluna, bombas centrífugas, bombas de deslocamento positivo, bombas a pistão, bombas dosadoras, compressores tipo parafuso, elevadores automotivos dentro outros;

c) 6 polos: são encontrados em esteiras transportadoras, misturadores e homogeneizadores para tratamento de água e efluentes, ventiladores;

d) 8 polos: podem ser encontrados em misturadores e homogeneizadores para tratamento de água e efluentes, rolos de apoio para posicionadores de grande porte, comportas, elevadores tipo monta cargas;

e) 10 polos: elevadores;

f) 12 polos: içamento de ponte rolante. 


\subsection{GRANDEZAS DOS MOTORES ELÉTRICOS DE INDUÇÃO}

Os motores elétricos devem possuir uma placa informativa acoplada ao seu estator, com as informações nominais básicas para a partida e operação do equipamento. Nos MITRGE as grandezas devem ser informadas conforme solicita a (NBR17094-1, 2013) e serem avaliadas por um laboratório nacionalmente acreditado. É apresentado no APÊNDICE uma placa de identificação de um MITRGE de 100 CV e 4 polos, onde são apresentadas cada grandeza envolvida na referida placa.

\subsection{PERDAS NOS MOTORES ELÉTRICOS DE INDUÇÃO}

Como em todos os processos da natureza, a conversão eletromecânica de energia por meio de motores elétricos também produz perdas intrínsecas e de diferentes origens. Para determinação das perdas são realizados ensaios com o motor em carga variável e com o motor em vazio. Assim, as perdas nos motores elétricos são classicamente subdivididas em três grupos:

\section{PERDAS NO ENSAIO EM CARGA:}

a) Perdas Joule (aquecimento direto) nos enrolamentos do estator (Pje);

b) Perdas Joule (aquecimento direto) no circuito do rotor (Pjr).

PERDAS NO ENSAIO EM VAZIO:

a) Atrito nos mancais e ventilação dos enrolamentos (Pav);

b) Perdas no núcleo (perdas no ferro) (Pf).

Outro grupo de perdas sempre citado na literatura convencional, porém pouco definidas, são as perdas ditas suplementares. As causas das perdas suplementares foram apresentadas por Salotti (1998) como oriundas dos seguintes fatores: 
PERDAS SUPLEMENTARES:
a) Geometria das ranhuras do estator e rotor;
b) Número de ranhuras;
c) Comprimento do entreferro;
d) Isolamento da ranhura do rotor;
e) Processo de fabricação;
f) Harmônicos de corrente;
g) Frequência.

Para mensurar as perdas nos motores de indução, é apresentado na Figura 14 o resultado do ensaio de um MITRGE operando em condições nominais, realizado no Laboratório de Máquinas Elétricas do Instituto de Energia e Ambiente da Universidade de São Paulo. O referido motor possui $100 \mathrm{CV}$ de potência mecânica de eixo e rendimento medido a plena carga em $94,7 \%$. O fator de potência em plena carga foi de $85,1 \%$, sendo o ensaio realizado com tensão e frequência nominal.

Figura 14 - Perdas em MITRGE de 100 CV e 4 polos operando em carga nominal

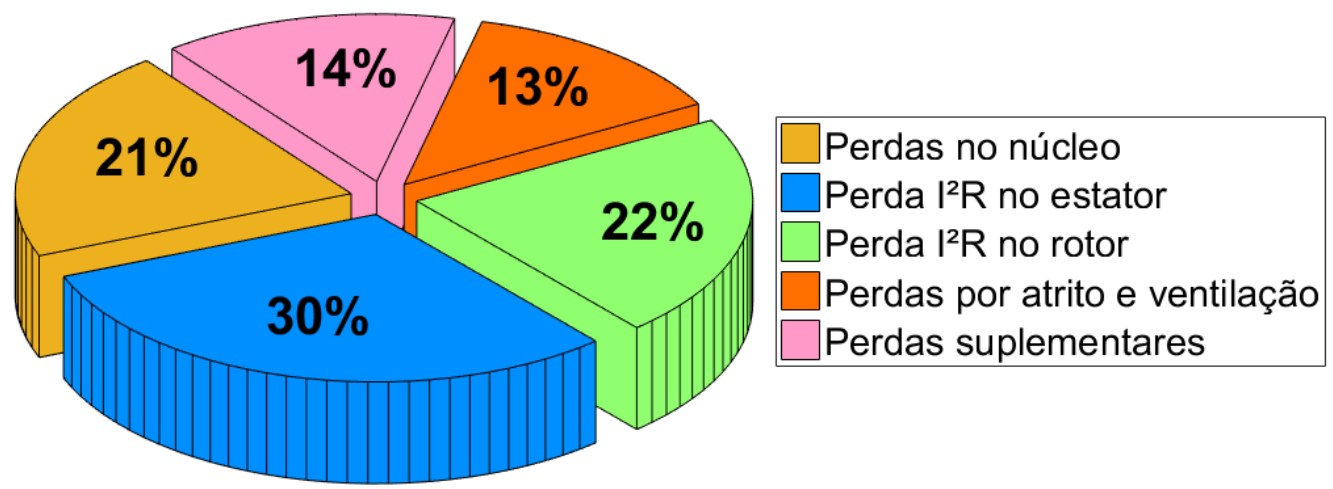

Fonte: Do autor.

As perdas apresentadas na Figura 14 evidenciam que os maiores percentuais de perdas nos MITRGE são por efeito joule, seja nos enrolamentos do estator ou no rotor. As perdas 
joules somadas representaram 52\% para o referido motor, contabilizadas pelo ensaio em carga. Já as perdas em vazio, responsáveis pela magnetização do núcleo do motor elétrico, pelo atrito entre o eixo e os rolamentos nos mancais e a ventilação dos enrolamentos do estator, são responsáveis por $34 \%$ das perdas totais neste referido caso. As perdas suplementares representam percentual pequeno em relação às perdas totais e são de difícil controle por parte dos projetistas por terem a influência de muitos fatores.

Outra forma de expressar as perdas envolvidas nos MITRGE é quanto à sua natureza. As perdas podem ser constantes ou variáveis, relativas à condição de carga mecânica no eixo. As perdas variáveis são as perdas oriundas da circulação de corrente de carga, sejam por efeito Joule nos enrolamentos do rotor ou do estator. As perdas suplementares também aumentam a cada incremento de corrente elétrica que circula nos enrolamentos localizados nas ranhuras do estator, resultado de um incremento de carga mecânica no eixo, ou seja, com a magnitude da carga mecânica acoplada ao eixo conforme apresentado na Figura 15.

Figura 15 - Comportamento das perdas em MITRGE de $100 \mathrm{CV}$ e 4 polos operando em carga variável

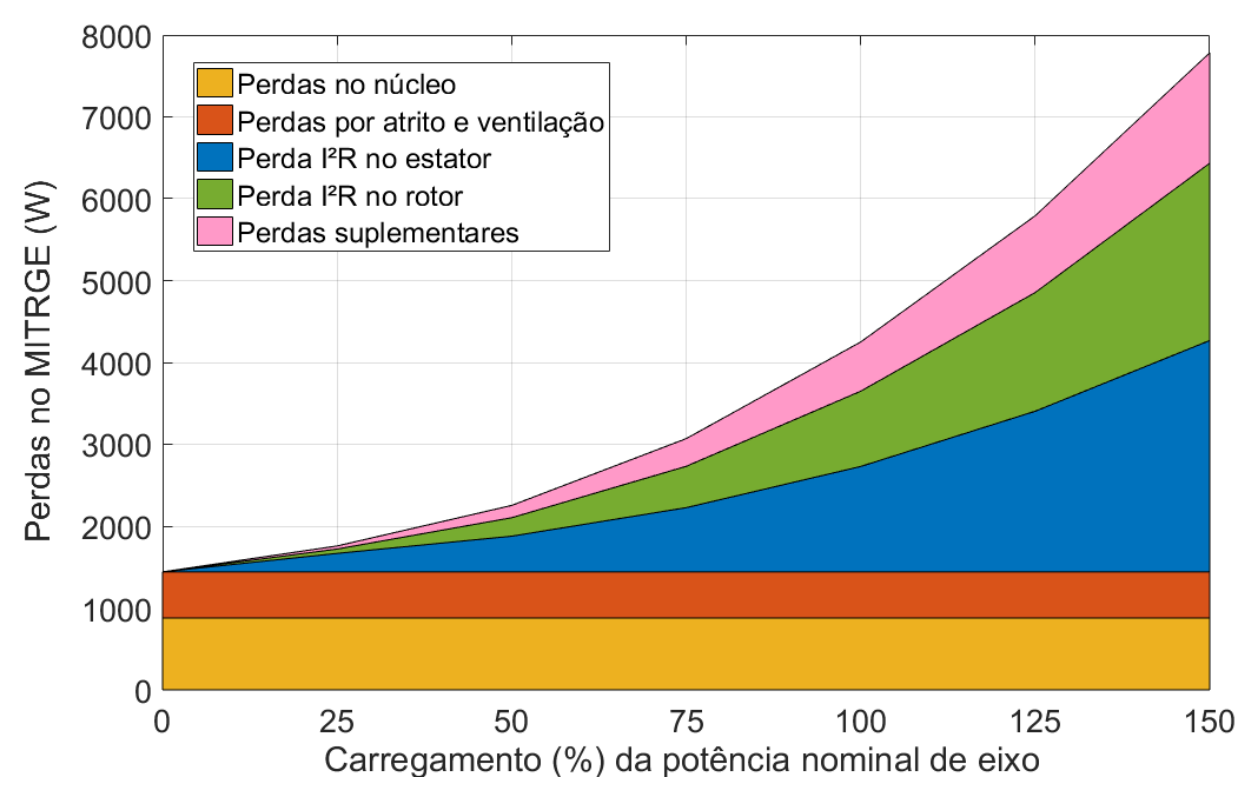

Fonte: Do autor.

Ao analisar o balanço energético do MITRGE, desde a energia disponibilizada nos terminais do motor até o conjugado presente no eixo, passando pela transferência de potência entre estator e o rotor, as perdas acumuladas no processo são representadas na Figura 16. 
Figura 16 - Balanço energético do MITRGE

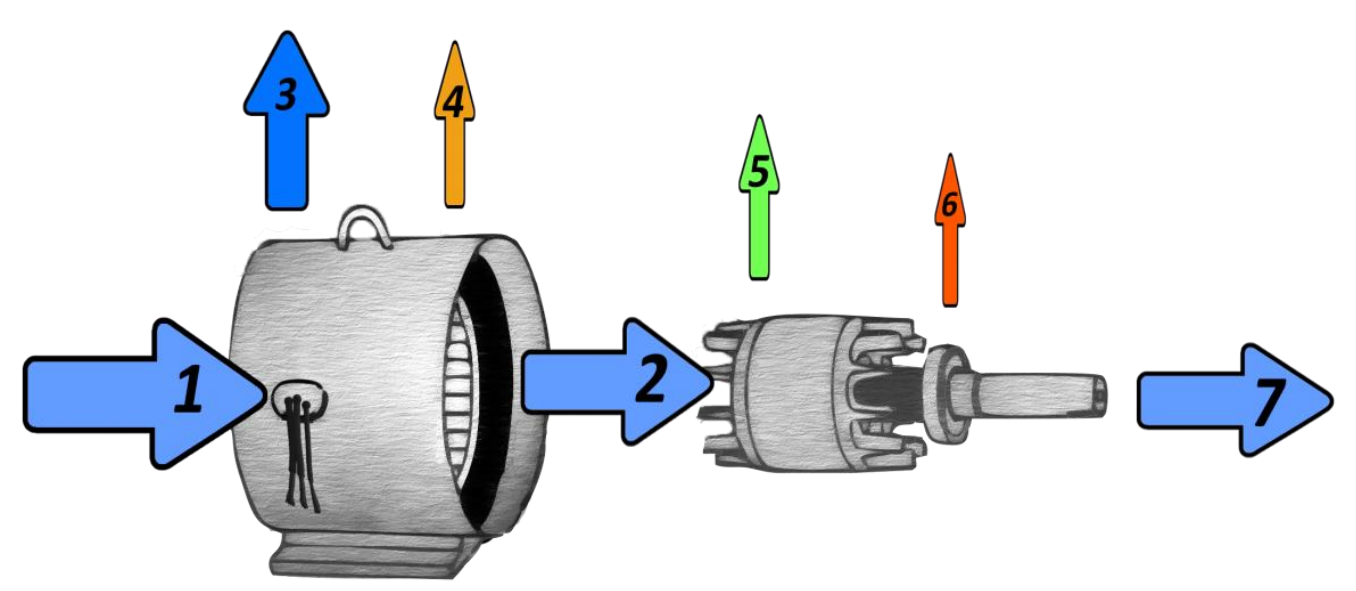

Fonte: Do autor.

1. Potência ativa de entrada nos terminais dos enrolamentos do estator dos MITRGE;

2. Potência elétrica total transferida para o rotor pelo entreferro;

3. Perdas Joule (aquecimento direto) nos enrolamentos do estator (Pje);

4. Perdas no núcleo do estator $(\mathrm{Pf})$;

5. Perdas Joule (aquecimento direto) no circuito do rotor (Pjr);

6. Atrito nos mancais e ventilação dos enrolamentos (Pav);

7. Potência mecânica disponibilizada no eixo.

Para a determinação das perdas nos MITRGE é necessária a execução de ensaio de tipo $^{8}$. No próximo item serão abordados os ensaios em motores elétricos.

\subsection{ENSAIOS NOS MOTORES ELÉTRICOS DE INDUÇÃO}

Existe uma extensa quantidade de ensaios padronizados que os laboratórios podem realizar nos motores elétricos, como também uma ampla gama de ensaios que os clientes podem exigir do seu fornecedor. Neste trabalho, o foco se dá no rendimento dos motores elétricos de indução e, por este motivo, o principal ensaio estudado é a determinação de rendimento e fator de potência do motor elétrico.

\footnotetext{
${ }^{8}$ É realizado geralmente em modelos que serão certificados. Este ensaio determina as condições de operações do motor elétrico em teste sob condições ideais e controladas.
} 
Para a determinação das características de rendimento dos motores elétricos de indução trifásicos, é preciso que os ensaios de desempenho sejam realizados de acordo com a normativa estabelecida nacionalmente. No Brasil, o órgão responsável pela normativa vigente é a Associação Brasileira de Normas Técnica - ABNT, onde as normas são desenvolvidas na maioria das vezes tendo orientação baseada nas experiências consolidadas na Europa por meio da International Electrotechnical Commission - IEC. O Brasil possui normativa nacional própria, apesar da forte influência da IEC. Os demais casos estão organizados em blocos territoriais onde a normativa é vigente, conforme ilustra a Figura 17.

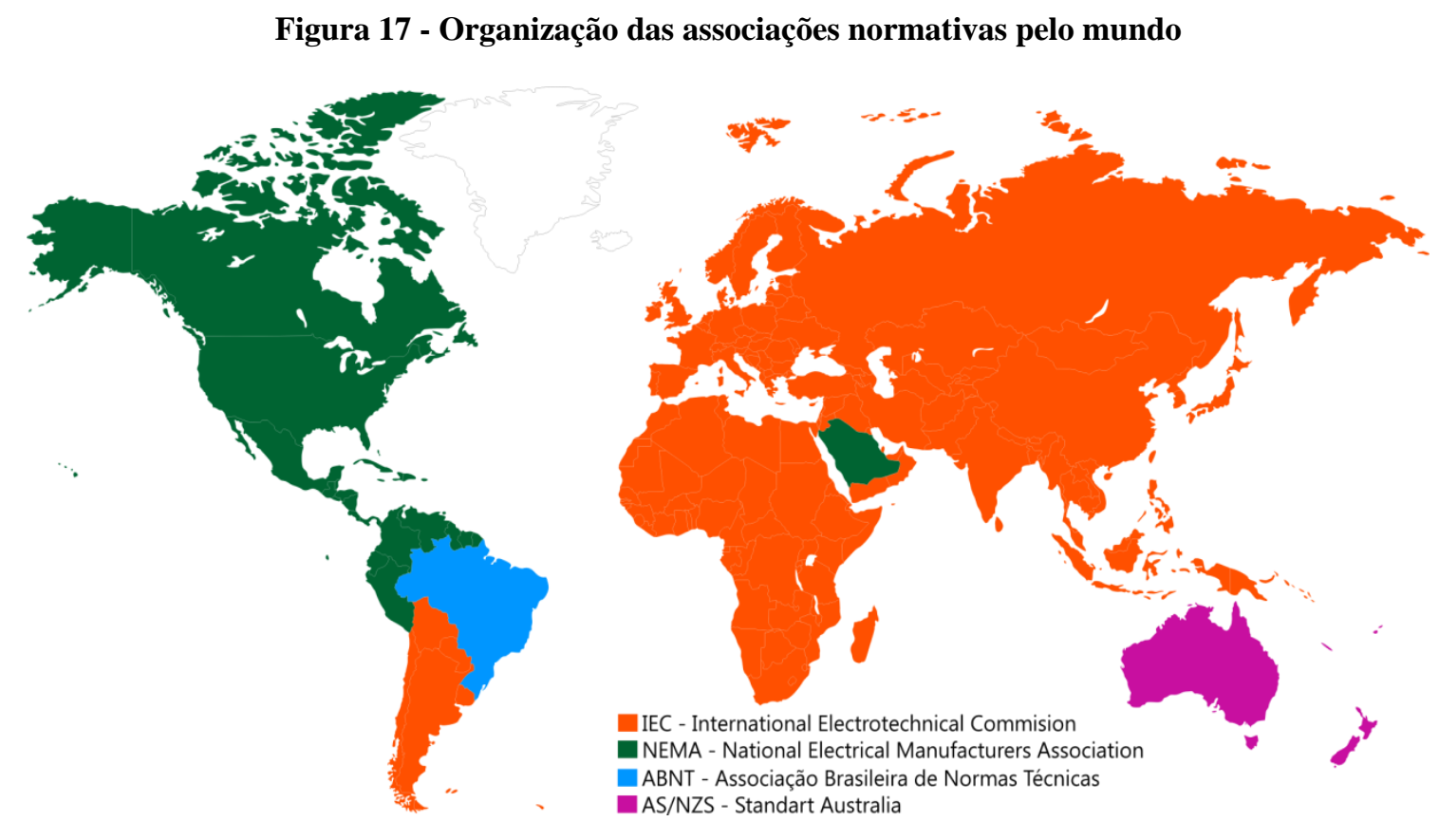

Fonte: Do autor.

De acordo com a ABNT (NBR17094-1, 2013), para motores elétricos de indução trifásicos com rotor em gaiola de esquilo, fabricados visando operação em $60 \mathrm{~Hz}$ e alimentados em baixa tensão, as perdas elétricas, magnéticas e mecânicas devem ser determinadas de acordo com a metodologia de ensaio da ABNT NBR 5383-1:2002.

As perdas denominadas Joules ou R.I ${ }^{2}$ nos enrolamentos do estator e nas barras do rotor são corrigidas para uma temperatura igual à temperatura ambiente padronizada em $\left(25^{\circ} \mathrm{C}\right)$, somadas a elevação da temperatura, determinada por meio do método de variação da 
resistência, onde a elevação de temperatura dos enrolamentos é determinada a partir do aumento da sua resistência.

De acordo com a ABNT NBR 5383-1:2002, o rendimento é determinado pela adição de todas as parcelas de perdas, para cada solicitação de carga ou carregamento. Para determinar os valores de rendimento para diversos carregamentos, as parcelas que correspondem a cada perda são obtidas e separadas pelos seguintes ensaios:

1. Ensaio a vazio: é realizado com o motor desacoplado da carga, aplicando tensão e frequência nominal. Por meio de analisador de energia, são medidos os valores das potências absorvidas (ativa, reativa e aparente). A potência absorvida é composta pelas parcelas perdas no ferro e perdas mecânicas (atrito e ventilação). Para este ensaio, consideram-se as perdas no enrolamento do rotor muito próximo de zero. Neste caso, o conjugado do motor é necessário apenas para vencer os atritos nos mancais e viscosidade do ar no processo de ventilação. Este ensaio é realizado utilizando-se fonte de tensão trifásica controlada em frequência nominal (NBR 5383-1, 2002).

2. Ensaio em plena carga: é aplicada tensão em valor nominal e plena carga no eixo do motor e após atingir sua estabilidade térmica, obtém-se a potência absorvida que é o resultado da soma das parcelas das perdas em vazio e nos enrolamentos do estator, perdas no rotor, perdas suplementares em carga e a potência mecânica entregue a carga (NBR 5383-1, 2002).

Segundo a NBR 5383-1 (2002), o rendimento de um motor elétrico trifásico é a razão entre a potência de saída e a potência ativa de entrada, expressa em percentagem ou fração decimal, podendo ser representado conforme Equação (3).

$$
\text { Rendimento }(\%)=\frac{\text { Potência Mecânica de Saída }(k W)}{\text { Potência Elétrica de Entrada }(k W)}
$$


A NBR 5383-1 (2002) regulamenta dez (10) diferentes formas de se determinar o rendimento dos motores elétricos trifásicos de indução com rotor em gaiola de esquilo. São as seguintes:

1. Método 1 - Medição direta da potência de entrada e de saída;

2. Método 2 - Ensaio dinamométrico com medição indireta das perdas suplementares e medição direta das perdas no estator $\left(I^{2} R\right)$, no rotor $\left(I^{2} R\right)$, no núcleo e por atrito e ventilação;

3. Método 3 - Motores duplicados com segregação de perdas e medição indireta das perdas suplementares;

4. Método 4 - Medição da potência elétrica em carga com segregação de perdas e medição direta das perdas suplementares;

5. Método 5 - Medição da potência elétrica sob carga com segregação de perdas e valor presumido das perdas suplementares;

6. Método 6 - Circuito equivalente com a medição direta das perdas suplementares;

7. Método 7 - Circuito equivalente com valor assumido das perdas suplementares;

8. Método 8 - Circuito equivalente calibrado por um ponto de carga do método 3;

9. Método 9 - Circuito equivalente calibrado por um ponto de carga do método 4;

10. Método 10 - Circuito equivalente calibrado por um ponto de carga do método 5.

O Laboratório de Máquinas Elétricas do IEE utiliza a segunda metodologia de ensaio, pois os equipamentos eletromecânicos adquiridos foram concebidos com esta perspectiva. Escolher a melhor metodologia de determinação do rendimento de um motor não é algo trivial e o que se deseja de forma geral é que a comparação do rendimento entre diferentes motores sejam realizados pelo mesmo método de ensaio, com o conhecimento dos erros e das incertezas inerentes às medições (SALOTTI, F. A. M., 1998).

O ensaio é realizado usando um dinamômetro, com medição indireta das perdas suplementares e medição direta para as perdas no estator ( $\left.\mathrm{I}^{2} \mathrm{R}\right)$, rotor ( $\left.\mathrm{I}^{2} \mathrm{R}\right)$, e o núcleo de ferro, bem como as perdas por atrito e ventilação. Neste método, a potência de entrada e saída são medidas por meio de um analisador de energia, e as perdas aparentes são calculadas subtraindo uma à outra. As perdas suplementares são calculadas subtraindo das perdas 
aparentes os componentes de perda remanescente, que por sua vez são obtidos por medição direta das perdas de $\mathrm{I}^{2} \mathrm{R}$ no estator e no rotor, nas perdas de núcleo de ferro e nas perdas por atrito e ventilação.

\subsection{A EVOLUÇÃO DOS MOTORES ELÉTRICOS DE INDUÇÃO}

\subsubsection{Mudança de massas e inovações tecnológicas}

No final do Séc. XIX já se encontravam desenvolvidas todas as bases físicas e teóricas para o desenvolvimento dos motores elétricos. Os motores de corrente contínua estavam no mercado e os motores de corrente alternada estavam em pleno desenvolvimento, com pesquisas sendo realizadas na Europa e nos Estados Unidos. A primeira patente do motor elétrico com tecnologia assíncrona foi depositada 1888 e aceita em $1889^{9}$ em New York pelo engenheiro Nikola Tesla (DUNSHEATH, P., 1969). O motor assíncrono, dado seu princípio de funcionamento, ficou conhecido como motor de indução. Entretanto, a proposta de Tesla se assemelha mais com os atuais motores monofásicos de enrolamento auxiliar, operando com o rotor bobinado. O texto que explicou o princípio de funcionamento do novo motor elétrico de indução foi publicado por Tesla com o título: A new system of alternate current motors and transformers (TESLA, N., 1888).

O motor trifásico de indução com rotor em gaiola de esquilo, mais próximo do que temos hoje, foi desenvolvido por uma equipe da companhia alemã AEG - Allgemeine Elektricitäts-Gesellschaft, chefiada pelo engenheiro russo Mikhail Dolivo-Dobrovolsky entre 1888 e 1890 (IVANOV-SMOLENSKI, A. V., 1988). O motor desenvolvido pela equipe de Dobrovolsky apresentava características muito positivas, como o elevado torque de partida, característica construtiva mais simples que as outras soluções, robustez na construção e baixa necessidade de manutenção. Até então os sistemas disponíveis eram monofásicos e bifásicos. Os sistemas trifásicos foram implementados com o objetivo de alimentar os motores trifásicos de indução (LAMME, B. G. , 1921).

Dobrovolsky e a companhia $A E G$ ganharam notoriedade pelo grande invento. A artista alemã Irene Ahrens, elaborou a ilustração representada na Figura 18 exposta em Berlin, onde

\footnotetext{
${ }^{9}$ Patente no US382279A.
} 
o engenheiro surge no céu, entrando no Hall da Fama com seu motor elétrico trifásico aberto próximo aos pés.

Figura 18 - Michail von Dolivo-Dobrovolsky entrando no Hall da Fama com seu motor elétrico trifásico

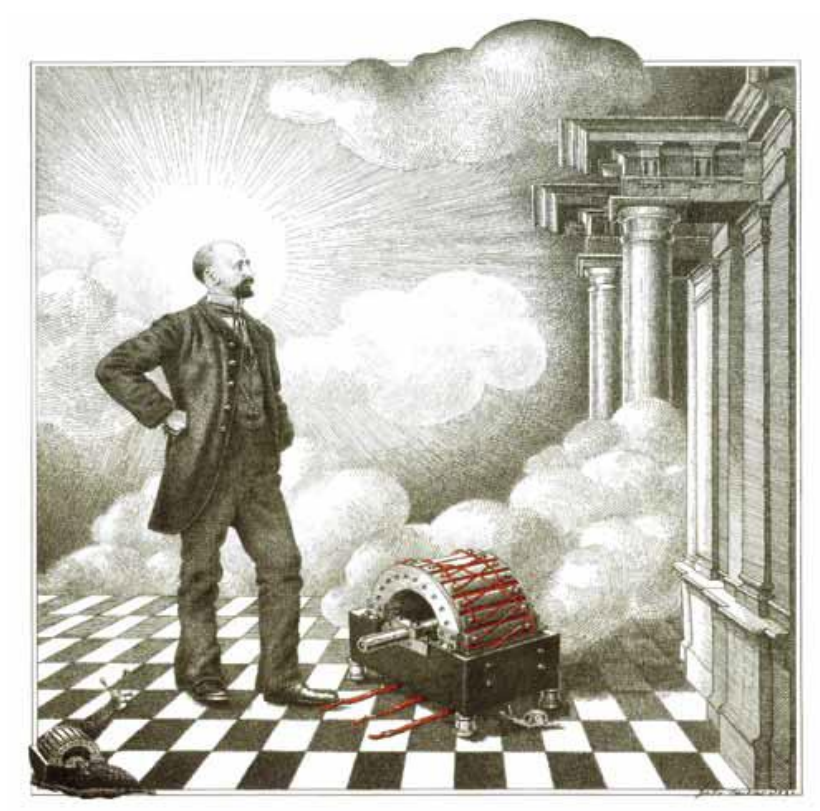

Fonte: (LITTLE chronology, 2003).

Dobrovolsky coordenou em 1891 na $A E G$, a primeira fabricação em série de motores elétricos de indução com potência de eixo entre 0,4 a 7,5 kW. Os primeiros motores elétricos prototipados possuíam rendimento de aproximadamente $80 \%$ para a faixa de potência produzida e massa extremamente elevada para os padrões atuais. Os primeiros motores comerciais de 2 polos e potência de eixo de 5,5 CV foram comercializados em 1891. Estes motores possuíam relação peso/potência de 86 kg/kW, conforme Figura 19. 
Figura 19 - Evolução do motor trifásico na relação Peso/Potência entre 1981-1984

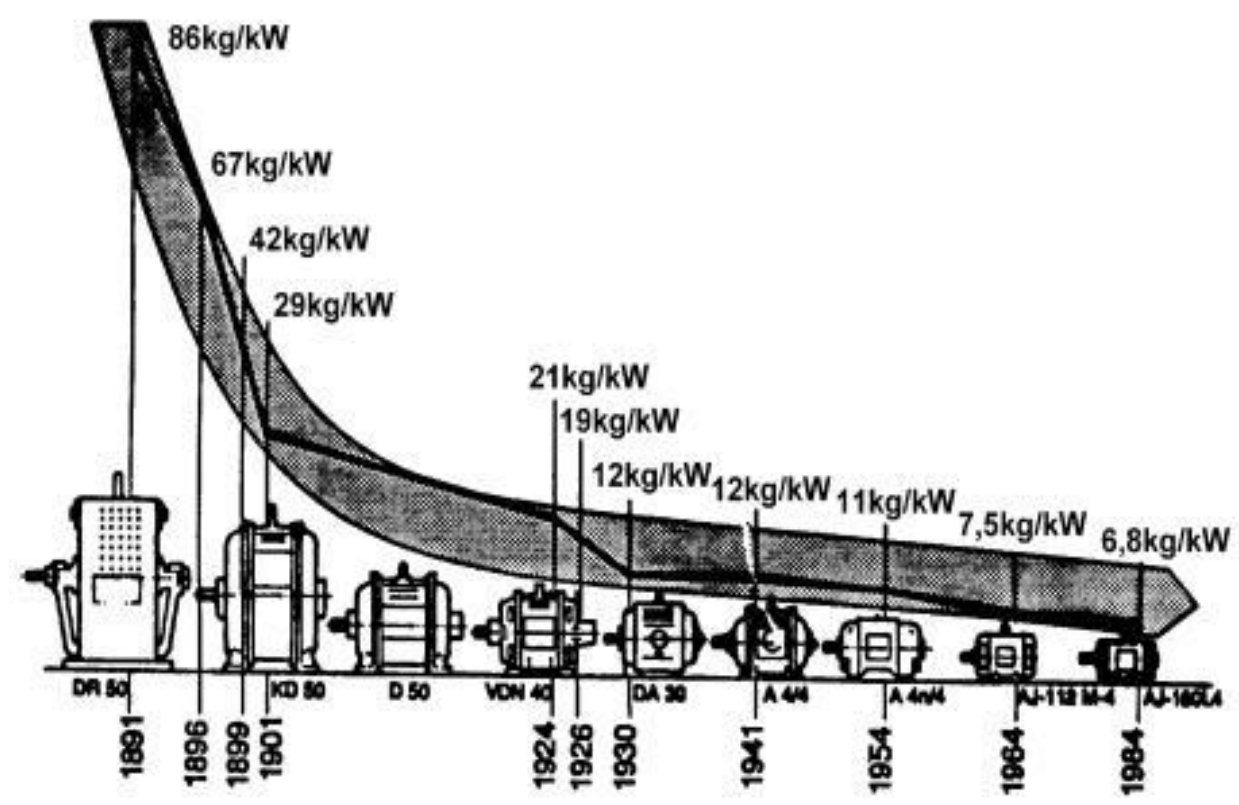

Fonte: (LITTLE chronology, 2003).

A companhia $A E G$ publicou a famosa imagem representada na Figura 19, onde é apresentada a relação Peso/Potência desde os primeiros motores elétricos trifásicos fabricados pela companhia em 1891 até os motores elétricos fabricados em 1984. A otimização da utilização de materiais com objetivos elétricos, magnéticos e mecânicos, combinada com fortes inovações tecnológicas, possibilitaram chegar a uma relação de 6,8 kg/kW em 1984.

Para Ramos (2009), parte da redução de massa dos motores elétricos, ocorreu à custa de redução no rendimento, de maneira que os novos motores que visam a eficiência energética possuem maior relação massa/potência que nos anos anteriores.

É possível observar na Figura 20 as grandes inovações tecnológicas que foram decisivas para a redução de massa e volume dos motores elétricos trifásicos de indução. 
Figura 20 - Evolução da massa de MITRGE de 1 CV entre 1900 e 1990

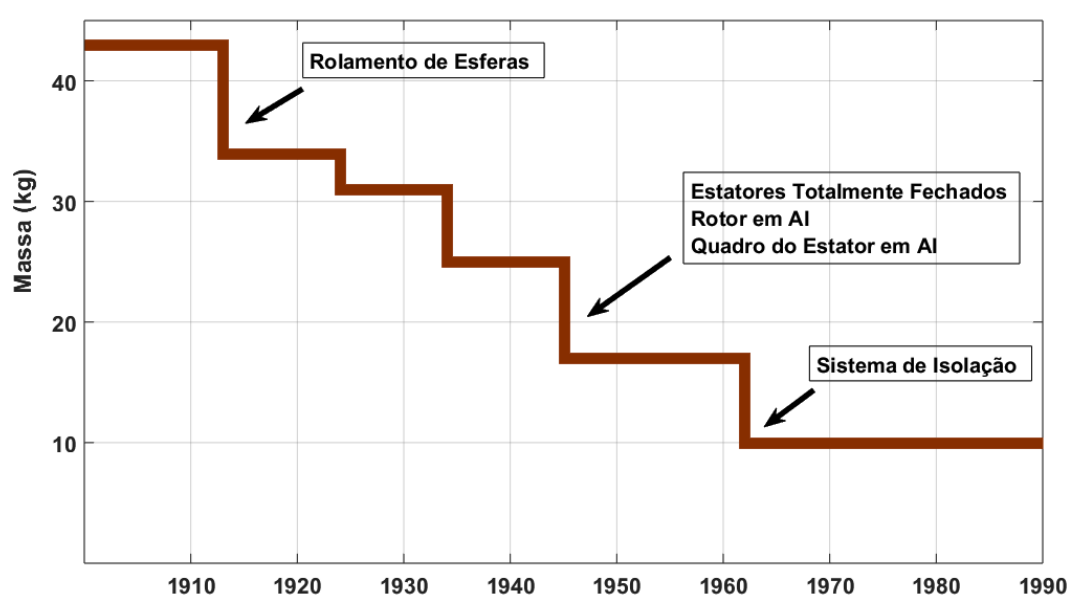

Fonte: (ALMEIDA, A. T.; BERTOLDI, P.; LEONHARD, W., 1997; adaptação do autor).

A primeira grande inovação tecnológica ocorrida no início do Séc. $\mathrm{XX}$ foi o desenvolvimento dos rolamentos de esfera, substituindo os tradicionais mancais de deslizamento que eram volumosos, pesados e lubrificados a óleo. Com os novos mancais, além de redução de perdas por atrito nos mancais, a massa e o volume diminuíram consideravelmente.

Entre 1913 e 1940 os ganhos foram na qualidade dos materiais, melhorando a compactação, possibilitando a redução do volume de cobre e ferro utilizado nos motores elétricos. Nos anos 40, os rotores construídos apenas com chapas de ferro, passaram a ser desenvolvidos em alumínio fundido, somando mais redução de massa, como evidencia a Figura 20. Também nos anos 40, com sucessivos avanços na metalurgia, as carcaças dos motores elétricos puderam ser construídas de forma mais fechada mantendo a ventilação refrigerando os enrolamentos localizados no estator.

No início dos anos 60, uma série de avanços nos sistemas de isolação foi fundamental para a redução de massa e volume dos motores elétricos. Entre 1960 e 1970 os motores elétricos de passaram por 5 gerações de materiais utilizados na construção da isolação dos condutores elétricos. Nos primeiros motores elétricos a isolação basicamente era composta de papel, posteriormente algodão, e a isolação com esmalte predominam até os dias atuais. A Figura 21 apresenta em branco a redução de área necessária para alocação de condutores elétricos de mesma área metálica dentro da ranhura do conjunto de chapas ferro/silício localizadas no estator dos motores elétricos de indução. 
Figura 21 - Espaço ocupado por condutores elétricos nas ranhuras isolados com diferentes materiais

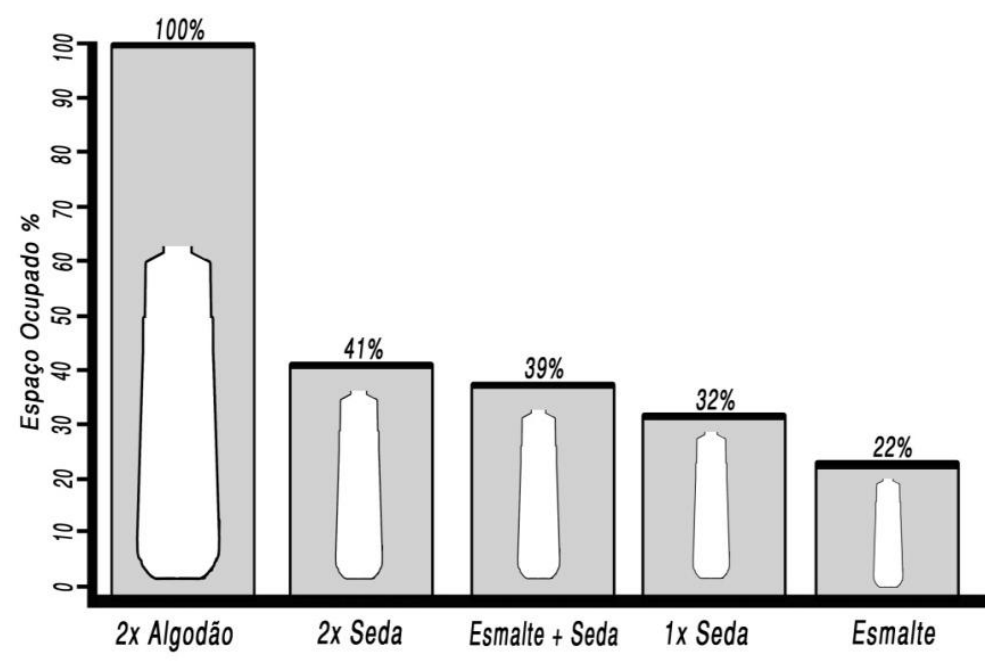

Fonte: (WEG, 2015).

A primeira grande inovação nos sistemas de isolação dos motores foi substituição das duplas camadas de algodão entre os condutores e as chapas, por duas camadas de seda, possibilitando redução de aproximadamente $59 \%$ de área de chapa metálica para construção do estator. A segunda grande inovação foi a introdução do esmalte utilizado em conjunto com seda se conseguiu uma redução de área de mais 2\%, conforme Figura 21. Posteriormente, melhorias na qualidade da seda e do esmalte, possibilitam chegar a uma área equivalente à apenas $22 \%$ da área necessária para um mesmo condutor elétrico utilizando o algodão como isolante.

As sucessivas inovações tecnológicas e as melhorias nos materiais elétricos, magnéticos e mecânicos, conseguiram significativa compactação do volume dos motores elétricos de indução entre 1900 e 1970 como ilustra a Figura 22. 
Figura 22 - Evolução das dimensões dos MITRGE de 15 CV e 4 polos entre 1897 e 1974

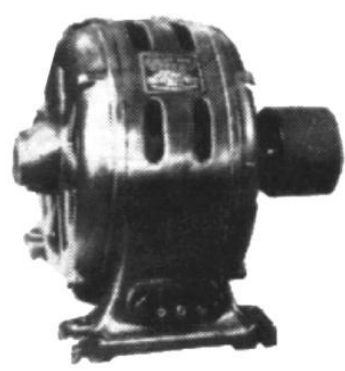

1903

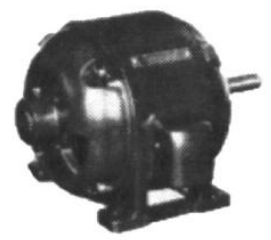

1940

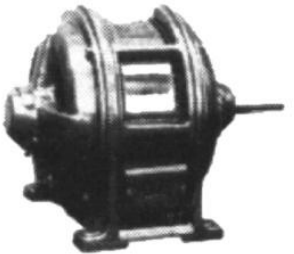

1910

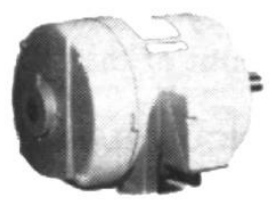

1954

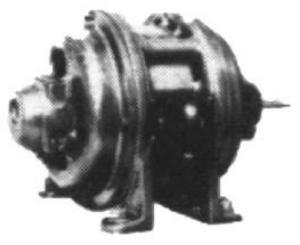

1920

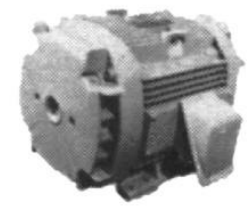

1974

Fonte: (ALGER, P. L.; ARNOLD, R. E., 1976).

A Figura 22 apresenta motores elétricos de indução trifásicos com rotor em gaiola de esquilo, projetados para operação em 220 Volts, 60 HP construídos pela General Electric GE. Na Figura 22 é possível observar a evolução da carcaça NEMA 404 ao longo dos anos, onde duas grandes inovações são evidentes nas imagens dos motores elétricos entre os anos de 1940 e 1954. A substituição dos eixos de deslizamento evidenciado pelo prolongamento axial do rotor na parte traseira, bem como a melhoria na usinagem da carcaça, possibilitando a construção de carcaças fechadas.

Como resultado das melhorias nas habilidades de isolamento, aço e design, os designers conseguiram colocar muito mais cobre em uma mesma ranhura, e a diferença de temperatura entre o cobre e as paredes da ranhura foi bastante reduzida. Por este motivo, foi possível aumentar consideravelmente a potência para uma mesma carcaça. As ranhuras foram feitas mais estreitas e os dentes mais largos, permitindo um aumento no fluxo magnético e uma diminuição no número de voltas por bobina para uma mesma tensão elétrica.

Segundo Alger e Arnold (1979), para evitar pontos quentes nos centros de núcleos longos, foram introduzidos dutos radiais e hélices operando como ventiladores, que atraem o ar através de orifícios nas extremidades do estator. Desta forma, a classificação atribuída à carcaça NEMA 404, com uma altura de eixo de 25,4 cm e comprimento de $31,1 \mathrm{~cm}$ foi 
aumentada em potência mecânica de 7,5 CV em 1897 para 100 CV em 1974, como mostra a Tabela 5. Nos anos apresentados, os fabricantes de motores elétricos conseguiram aperfeiçoar os projetos utilizando menos materiais por unidade potência.

Tabela 5 - Incrementos de potência mecânica em mesma carcaça de 1898 à 1974

\begin{tabular}{ccc}
\hline Tempo & Potência de Eixo (CV) & Temperatura de Operação \\
\hline $1898-1903$ & 7,5 & $40^{\circ}$ Termômetro \\
$1903-1905$ & 10 & $40^{\circ}$ Termômetro \\
$1905-1914$ & 15 & $40^{\circ}$ Termômetro \\
$1914-1924$ & 20 & $40^{\circ}$ Termômetro \\
$1924-1929$ & 25 & $40^{\circ}$ Termômetro \\
$1929-1940$ & 30 & $40^{\circ}$ Termômetro \\
$1940-1956$ & 40 & $50^{\circ}$ Resistência \\
$1956-1961$ & 50 & $50^{\circ}$ Resistência \\
$1961-1966$ & 60 & $50^{\circ}$ Resistência \\
$1966-1974$ & 100 & $80^{\circ}$ Resistência \\
\hline
\end{tabular}

Fonte: (ALGER, P. L.; ARNOLD, R. E, 1976).

\subsubsection{Mudanças de rendimento}

Não foram apenas as massas e o volume que se transformaram. Sucessivas mudanças no rendimento dos motores elétricos de indução com rotor em gaiola ocorrem desde as primeiras versões disponíveis comercialmente, até a fabricação em massa nos dias atuais.

Uma série de elementos tecnológicos explicaram as mudanças no rendimento dos motores elétricos, desde as inovações tecnológicas já citadas, assim como melhoria nos processos produtivos e na purificação dos materiais ativos ${ }^{10}$. Sven SjOberg da ABB Motors (ALMEIDA, A. T.; BERTOLDI, P.; LEONHARD, W., 1997) apresenta 7 elementos de ganho de rendimento dos motores elétricos fabricados pela companhia após o grande ciclo de inovações que se fecha nos anos 70:

a) Ferramental de corte: melhorando a precisão mecânica e possibilitando a eliminação de rebarbas.

b) Pacote laminado: mistura de laminação, controle de laminação antes de prensagem, soldagem ou grampeamento (estator). Controle de amostragem antes da fundição (rotor).

\footnotetext{
${ }^{10}$ Aqueles em que existe circulação de corrente elétrica ou magnética.
} 
c) Usinagem da superfície externa do núcleo do estator (geralmente não necessário): reduzir a rugosidade da superfície e melhorar as tolerâncias.

d) Enrolamento do estator: comprimento das bobinas, tipo de enrolamento, fator de enchimento, sistema de isolamento, laços e conexões.

e) Impregnação: bons resultados de preenchimento e melhorias nas trocas térmicas.

f) Fundição da gaiola do rotor: enchimento das ranhuras e anéis de extremidade, pureza do material de fundição e balanceamento do rotor.

g) Alinhamento do eixo do rotor e usinagem da superfície externa do rotor

Sven SjOberg da $A B B$ Motors apresenta na Figura 23 a evolução de rendimento dos motores elétricos fabricados pela empresa entre 1935 e 1996. Segundo Sven SjOberg, as mudanças de rendimento não são resultados de alguma normativa de rendimento. As mudanças ocorrem devido às melhorias de materiais, inovações tecnológicas e melhorias nos processos produtivos.

Figura 23 - Evolução de rendimento de motores elétricos de 4 polos entre 1935 e 1996

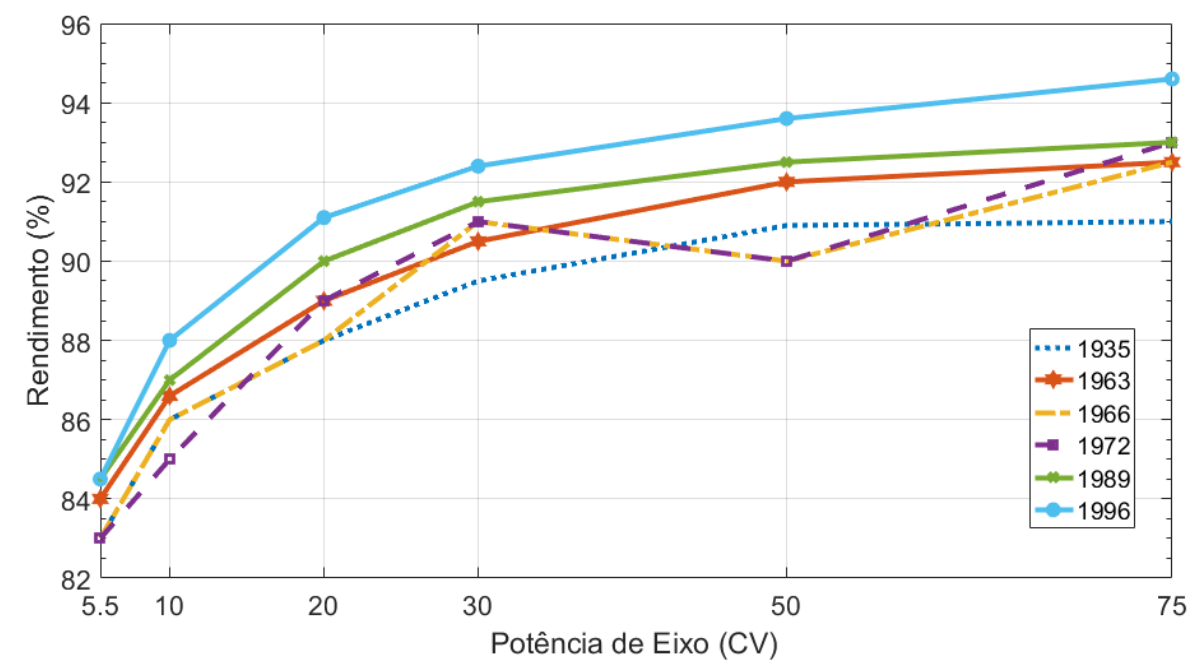

Fonte: (ALMEIDA, A. T.; BERTOLDI, P.; LEONHARD, W., 1997; adaptação do autor).

Também é possível observar na Figura 23, que nos anos 60 e 70, houve redução no rendimento médio dos motores elétricos em uma ampla faixa de potência, chegando a alguns momentos em rendimentos inferiores aos praticados pela indústria nos anos 35 . O 
engenheiro/pesquisador Sven SjOberg não identifica em seu texto os elementos que levaram a esta queda temporária de rendimento entre os anos 70 e 80.

Para o Departamento de Energia dos Estados Unidos, as décadas de 1960 e 1970 foram períodos de crise econômica mundial, onde os fabricantes de motores elétricos construíram equipamentos de menor custo em comparação com os anos anteriores. Estes motores eram menos eficientes, conforme mostra a Figura 24, pois minimizavam a utilização de materiais como cobre, alumínio e aço. Segundo o Departamento, estes motores possuíam custos iniciais mais baixos do que projetos anteriores. Entretanto, eles consumiam mais energia elétrica devido à sua ineficiência, de maneira que a sua utilização em todo o ciclo de vida desde o berço até o tumulo, seria monetariamente mais cara (U.S. DEPARTMENT OF ENERGY, 2014).

Figura 24 - Evolução de rendimento de motores elétricos de 4 polos entre 1944 e 2012

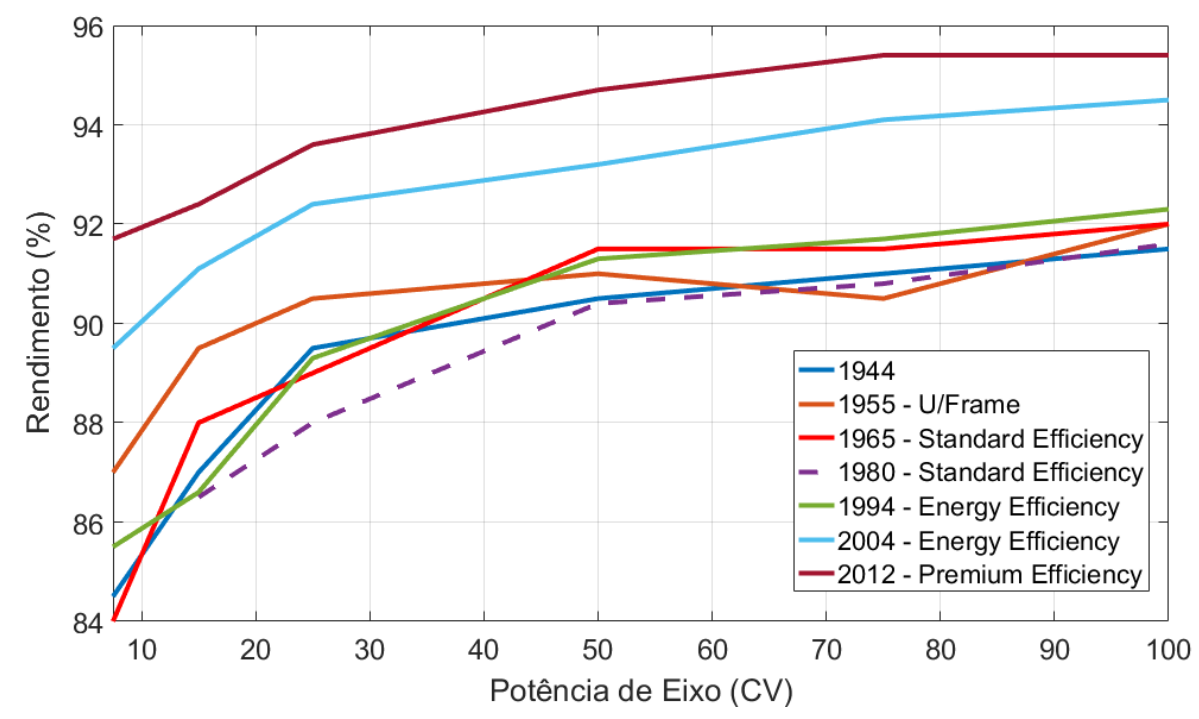

Fonte: Construído a partir dos dados do U.S. Department of Energy (2014).

$\mathrm{Na}$ Figura 24 é possível observar que o rendimento dos motores elétricos de 4 polos fabricados e comercializados no território norte-americano na década de 1980, teve rendimento inferior até mesmo dos motores elétricos fabricados em 1944, sendo esses os primeiros registrados pelo órgão hoje denominado Departamento de Energia dos Estados Unidos.

Segundo o Departamento de Energia, a produção de motores menos eficientes e mais compactos, tornou-se possível com o desenvolvimento de materiais isolantes que podem 
suportar altas temperaturas. Estes motores foram projetados admitindo maiores perdas devido ao aumento da temperatura nas bobinas localizadas no estator, possibilitando acomodar os enrolamentos em carcaças menores sem danificar a isolação (U.S. DEPARTMENT OF ENERGY, 2014).

A Figura 25 apresentada a evolução de rendimento de motores elétricos de indução com rotor em gaiola de esquilo, possuindo enrolamentos de 4 polos, com potências de 50 e 60 CV, com operação em 50 ou $60 \mathrm{~Hz}$, alimentados em baixa tensão.

Figura 25 - Evolução de rendimento de motores elétricos de 4 polos entre 1935 e 2012

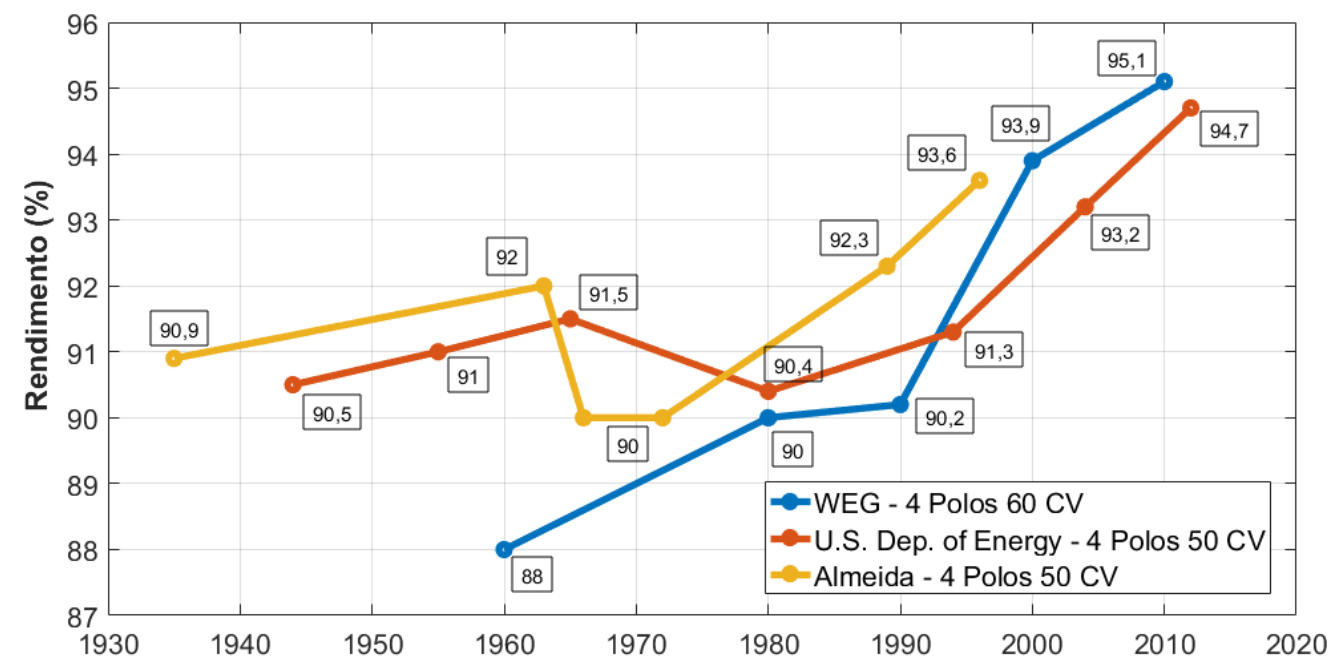

Fonte: Construído por meio de diversas fontes (WEG, 2015), (ALMEIDA, A. T.; BERTOLDI, P.; LEONHARD, W., 1997) e (U.S. DEPARTMENT OF ENERGY, 2014).

É possível observar na Figura 25, na linha média de rendimento apresentados por (ALMEIDA, A. T.; BERTOLDI, P.; LEONHARD, W., 1997) e pelo (U.S. DEPARTMENT OF ENERGY, 2014), que os referidos motores elétricos tiveram redução de rendimento entre os anos 60 e 80 e apenas os dados fornecidos pela (WEG, 2015) apresentam contínuo incremento de rendimento. Isto ocorre, pois como ilustra a Figura 25, pois os dados de rendimento disponibilizado nas publicações da empresa iniciam em 1960, com rendimentos abaixo dos praticados no mercado internacional, terminando em 2016 com rendimentos elevados. 


\subsection{A NORMATIVA INTERNACIONAL PARA O RENDIMENTO DOS MITRGE}

Desde os anos 90, alguns países começaram a implementar selos e determinar o rendimento mínimo permitido para o rendimento dos motores elétricos no seu mercado nacional ou em bloco econômico. A ideia de aplicar selos em motores elétricos tem o objetivo de identificar visualmente, para os compradores, os motores que possuem rendimento superior. Os selos devem fornecer informações necessárias de forma transparente e possibilitar facilmente comparações dos rendimentos de motores elétricos, contribuindo assim, teoricamente, com o desenvolvimento do mercado de motores de alto rendimento e com a conservação da energia elétrica.

Antes da atribuição dos selos, os motores foram separados em classes diferentes de acordo com o rendimento. Isso foi construído de diferentes formas e em vários países, resultando em vários padrões nacionais diferentes. Entretanto, por efeito de barreiras comerciais, dadas pelas diferentes classes de rendimentos, surgiu a necessidade de equivalência internacional de rendimento. Neste contexto, surge a proposta da International Electrotechnical Commission - IEC, que desenvolveu uma classificação internacional de rendimento, padrões de teste e etiquetas para motores elétricos (ALMEIDA, A. T. de et al., 2009). A classificação IEC distingue quatro níveis de eficiência com a nomenclatura "IE1" para os motores menos eficientes até o "IE4" para os motores de maior eficiência. Essas classes são cada vez mais utilizadas nos diversos países que manifestam preocupações com o rendimento dos equipamentos de uso final de energia.

A regulamentação da IEC abrange os motores de indução trifásica, entre 120 Watts e $1000 \mathrm{~kW}$. Os motores menores geralmente acoplados em outros equipamentos, como ventiladores ou bombas de circulação, comumente chamados de "fracionários", estão excluídos da referida regulamentação. As classes de eficiência são mostradas na Figura 26 para motores construídos visando operação em $50 \mathrm{~Hz}$. A classe IE4 foi introduzida na referida norma em 2014, sendo ainda neste momento difícil encontrar motores que atendam o índice. A Figura 26 ilustra com as diferenças de rendimento entre as categorias IE1, IE2, IE3 e IE4, para MITRGE com 4 polos. 
Figura 26 - Valores mínimos de eficiência de 50 Hz definidos na IEC 60034-30-1

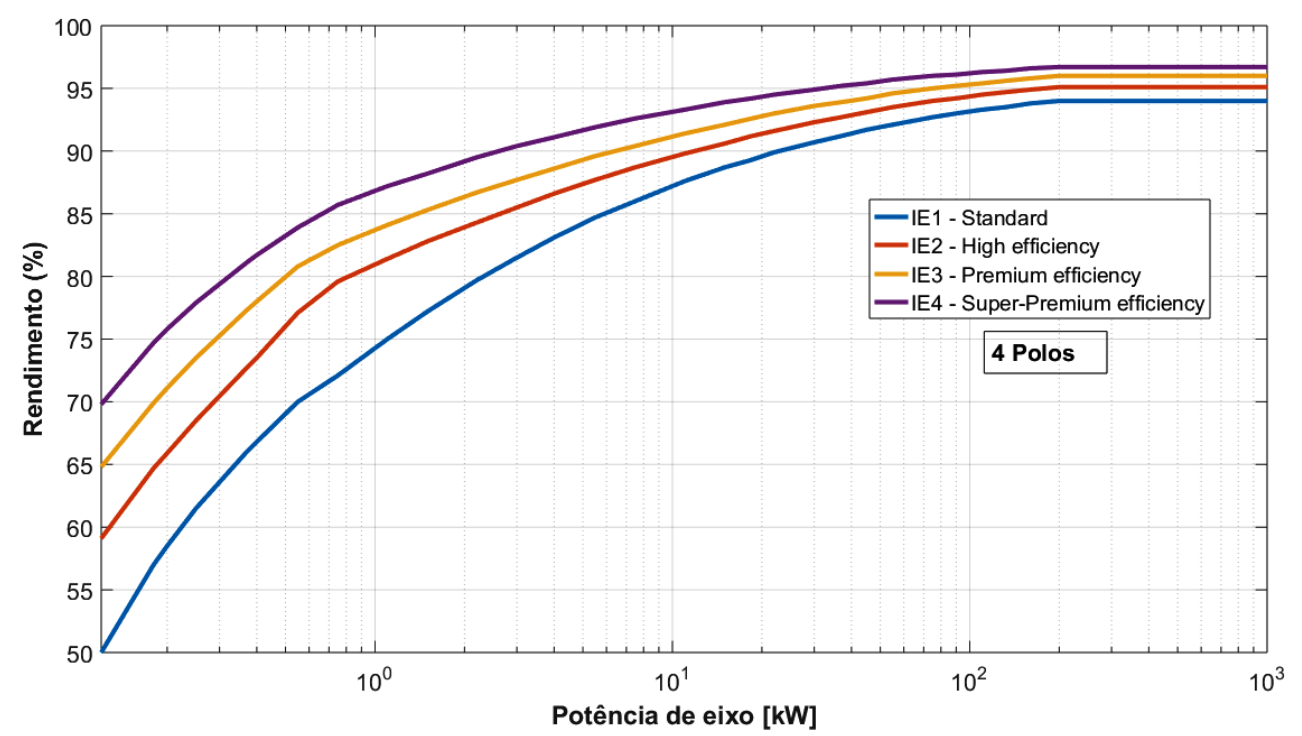

Fonte: Construído a partir dos dados da IEC/EN 60034-30-1 (INTERNATIONAL ELECTROTECHNICAL COMMISSION, 2014).

Muitos países já possuem regulamentação em vigor para o rendimento de motores elétricos ou mesmo datas para entrada em vigor. O primeiro país a introduzir regulamentação para motores elétricos foram os EUA. A regulamentação foi aprovada em lei no ano de 1992, como voluntária. Em 1997 a legislação se tornou obrigatória para os MITRGE comercializados nos EUA. Isso deu aos fabricantes de motores um período de cinco anos para se adaptarem aos novos padrões, otimizando os projetos dos seus equipamentos.

A primeira legislação para o rendimento de MITRGE ficou conhecida como EPAct-92 e é comparável à definição internacional IE2 da IEC. Em 2007 foi publicada a legislação equivalente ao IE3 para os EUA e o Canadá, passando a entrar em vigor em 2010. A Figura 27 apresenta o panorama geral das datas de aplicação da legislação de rendimento mínimos de MITRGE por países. 
Figura 27 - Implementação de legislação de rendimento mínimo para motores elétricos

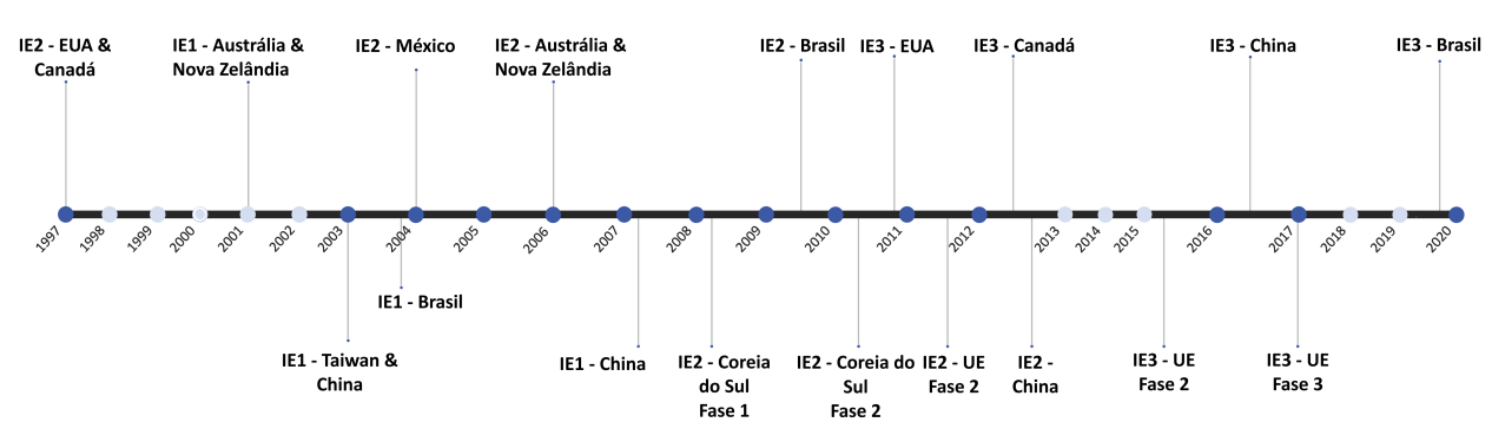

Fonte: Do autor.

É importante destacar que a legislação implementada no Brasil, não corresponde rigorosamente aos padrões de teste e classificação da $I E C$, pois são índices aproximados, mas que permitem a comparação.

\subsection{A NORMATIVA BRASILEIRA PARA O RENDIMENTO DOS MITRGE}

No início dos anos 80, ainda sobre as consequências da crise mundial do petróleo, o governo brasileiro inicia as primeiras preocupações com a utilização final de energia elétrica, estabelecendo em 1985 o Programa Nacional de Conservação de Energia Elétrica - PROCEL que, em sua primeira versão, se preocupa basicamente com a instrução doméstica para utilização racional da energia elétrica, evitando desperdícios (PROCEL, 2009).

Em 1992 são iniciadas as discussões de etiquetagem de equipamentos elétricos. Em 1993 é criado o Selo PROCEL, onde os fabricantes de motores elétricos voluntariamente se cadastraram na Secretaria do Programa, que está vinculada diretamente à ELETROBRAS Centrais Elétricas Brasileiras. O cadastro para MITRGE é iniciado em 1997.

Em 2001 o Brasil sofre com o racionamento da energia elétrica e, paralelamente, as discussões mundiais sobre a importância do setor de energia para a redução dos gases de efeito estufa avançam. Neste cenário, é criada a Lei n ${ }^{\circ} 10.295$ de Outubro de 2001, que recebe o nome de Lei da Eficiência Energética. A referida lei estabelece que devem ser criadas regulamentações específicas de rendimento mínimo para equipamentos de uso final de energia 
elétrica, visando redução de consumo energético e preservação do meio ambiente (BRASIL, 2001).

Em 11 de dezembro de 2002, foi publicado o Decreto $n^{\circ} 4.508$, que estabelece níveis de rendimento mínimos para que os motores elétricos de indução trifásicos - MIT possam ser comercializados no território brasileiro (BRASIL, 2002). O decreto foi elaborado com atenção para os motores elétricos mais comercializados no mercado. São eles: motores elétricos de indução trifásicos - MIT, frequência industrial de $60 \mathrm{~Hz}$ ou $50 \mathrm{~Hz}$ para operação em $60 \mathrm{~Hz}$, rotor tipo gaiola de esquilo, alimentados em tensão de até 600 volts, possuindo velocidades correspondentes à 2, 4, 6 e 8 polos, possuindo potência de eixo entre 1 e $250 \mathrm{CV}$, produzidos para operação contínua.

O Decreto $n^{\circ} 4.508 / 2002$ criou duas categorias de motores separadas pelo rendimento. Os motores standard e os motores de alto rendimento com rendimento superior. Os motores standard equivalem à categoria IE1 e os motores de alto rendimento equivalem internacionalmente à categoria IE2. A Tabela 2 apresenta os níveis de rendimento mínimo para que o motor possa ser comercializado e apresenta também o nível mínimo de rendimento para que possa ser caracterizado como de alto rendimento.

Segundo (SAUER, I. L. et al., 2015), o Decreto 4.508/2002 cobria mais de $80 \%$ do mercado brasileiro de motores elétricos.

O Decreto $\mathrm{n}^{\mathrm{o}}$ 4.508/2002 estabeleceu a data de 30 de Dezembro de 2003, como data limite para a comercialização de motores elétricos fora dos níveis mínimos de rendimento.

Em 8 de Dezembro de 2005, o governo federal do Brasil, publica a Portaria $n^{\text {o }} 553$ estabelecendo como nível mínimo de rendimento, os valores indicados na coluna "alto rendimento" na Tabela 2. Os motores elétricos que não atenderem o nível mínimo conhecido no Decreto $\mathrm{n}^{\mathrm{o}} 4.058 / 2002$ como motor de alto rendimento, não poderão mais ser comercializados no território brasileiro a partir de 2009 (BRASIL, 2005).

Em 4 de setembro de 2009, o Instituto Nacional de Metrologia, Normalização e Qualidade Industrial - INMETRO, publica a Portaria $n^{\circ} 243$, onde são apresentados os requisitos obrigatórios para a avaliação de conformidade dos motores elétricos de indução trifásicos, padronizando assim a metodologia nacional de avaliação de rendimento (INSTITUTO NACIONAL DE METROLOGIA, 2009). No dia 08 de dezembro de 2010, o INMETRO publicou a Portaria nº 488, em substituição a 243. A partir da Portaria nº 488/2009 a etiquetagem dos referidos motores passa a ser obrigatória (Idem, 2010). 
O último documento publicado para o rendimento de MITRGE foi a Portaria Interministerial $\mathrm{n}^{\mathrm{o}} 1$, de 29 de Junho de 2017 publicada em 08 de agosto de 2017 (Idem, 2017). As datas em que serão proibidas a importação e comercialização de MITRGE com rendimentos inferiores (IE3) aos determinados na referida portaria são:

a) 30 de agosto de 2019: fabricação ou importação;

b) 2 de março de 2020: comercialização;

c) 30 de agosto de 2020: fabricação ou importação de equipamentos que contenham MITRGE;

d) $1^{\circ}$ de março de 2021: comercialização de equipamentos que contenham MITRGE.

A referida portaria estabelece o nível de rendimento mínimo para MITRGE comercializados para IE3, e é apresentada na Tabela 6.

Tabela 6 - Portaria ${ }^{0}$ 1/2017 e os rendimentos percentuais mínimos para os MITRGE categoria IE3

\begin{tabular}{c|cccc}
\hline \multirow{2}{*}{ CV } & 2 Polos & 4 Polos & 6 Polos & 8 Polos \\
\cline { 2 - 5 } & \multicolumn{4}{|c}{ Rendimento nominal } \\
\hline 0,16 & 62 & 66 & 64 & 59,5 \\
0,25 & 65,6 & 69,5 & 67,5 & 64 \\
0,33 & 69,5 & 73,4 & 69 & 68 \\
0,5 & 73,4 & 78,2 & 75,3 & 72 \\
0,75 & 76,8 & 79 & 79,5 & 74 \\
1 & 80,5 & 83,5 & 82,5 & 75,5 \\
1,5 & 84 & 86,5 & 87,5 & 78,5 \\
2 & 85,5 & 86,5 & 88,5 & 84 \\
3 & 86,5 & 89,5 & 89,5 & 85,5 \\
4 & 88,5 & 89,5 & 89,5 & 86,5 \\
\hline
\end{tabular}

(Continua...) 


\begin{tabular}{c|cccc}
\hline \multirow{2}{*}{ CV } & 2 Polos & 4 Polos & 6 Polos & 8 Polos \\
\cline { 2 - 5 } & \multicolumn{4}{|c}{ Rendimento nominal } \\
\hline 15 & 91 & 92,4 & 91,7 & 89,5 \\
25 & 91 & 93 & 91,7 & 90,2 \\
30 & 91,7 & 93,6 & 93 & 90,2 \\
40 & 91,7 & 93,6 & 93 & 91,7 \\
50 & 92,4 & 94,1 & 94,1 & 91,7 \\
60 & 93 & 94,5 & 94,1 & 92,4 \\
75 & 93,6 & 95 & 94,5 & 92,4 \\
100 & 93,6 & 95,4 & 94,5 & 93,6 \\
125 & 94,1 & 95,4 & 95 & 93,6 \\
150 & 95 & 95,4 & 95 & 94,1 \\
175 & 95 & 95,8 & 95,8 & 94,1 \\
200 & 95,4 & 96,2 & 95,8 & 94,5 \\
250 & 95,4 & 96,2 & 95,8 & 94,5 \\
300 & 95,8 & 96,2 & 95,8 & 95 \\
350 & 95,8 & 96,2 & 95,8 & 95 \\
400 & 95,8 & 96,2 & 95,8 & 95 \\
450 & 95,8 & 96,2 & 95,8 & 95 \\
500 & 95,8 & 96,2 & 95,8 & 95 \\
\hline
\end{tabular}

Fonte: (BRASIL, 2017).

A Portaria $n^{\circ}$ 1/2017 ampliou a faixa de potência dos motores regulamentados, expandindo para os motores fracionários desde $0,16 \mathrm{CV}$ até $500 \mathrm{CV}$. A portaria continuou a regulamentar apenas os motores trifásicos com rotor em gaiola de esquilo, alimentados em baixa tensão, para operação em $60 \mathrm{~Hz}$.

É apresentada na Figura 28, a linha histórica com todos os documentos que contribuíram para os incrementos de rendimento dos motores elétricos desde 1985 até 2017.

Figura 28 - Legislação de rendimento de MITRGE no Brasil

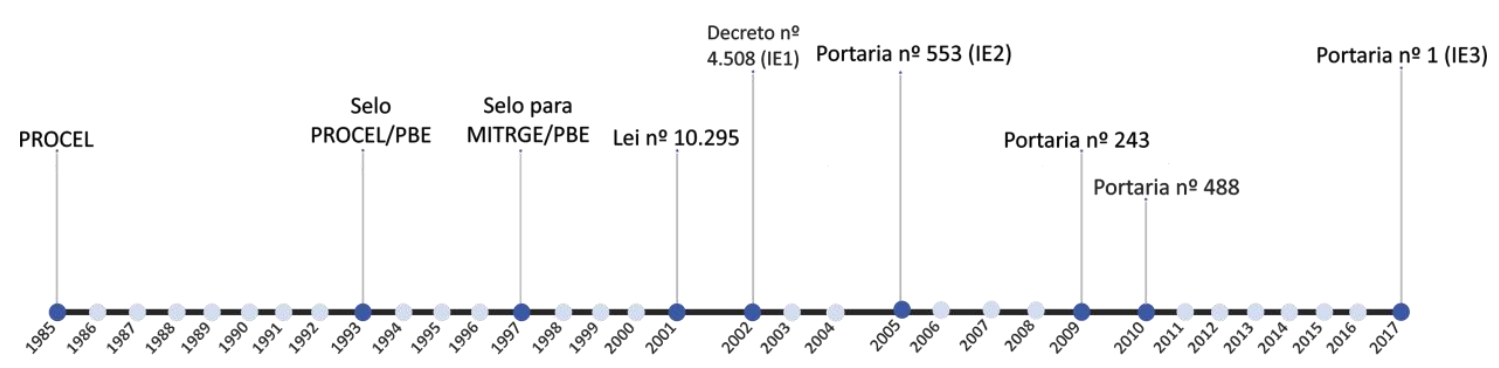

Fonte: Do autor. 
Está apresentado da Figura 29 até a Figura 32 as diferenças de rendimento entre o Decreto $n^{\circ} 4.508 / 2002$, a Portaria $n^{\circ} 553 / 2005$ e a Portaria $n^{\circ} 1 / 2017$ para as 4 diferentes velocidades regulamentadas.

Figura 29 - Evolução da normativa nacional para MITRGE de 2 polos

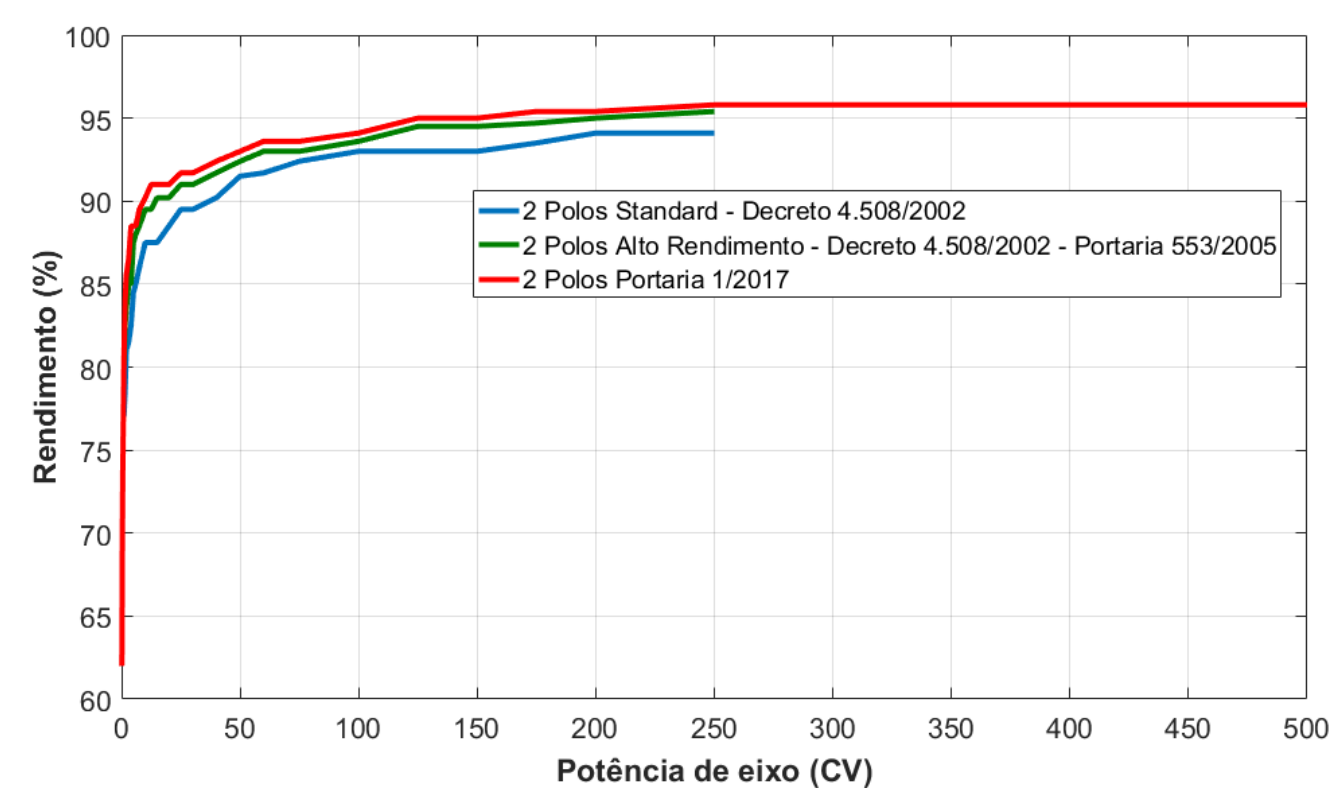

Fonte: Construída a partir dos dados de Brasil (2002; 2005; 2017).

Figura 30 - Evolução da normativa nacional para MITRGE de 4 polos

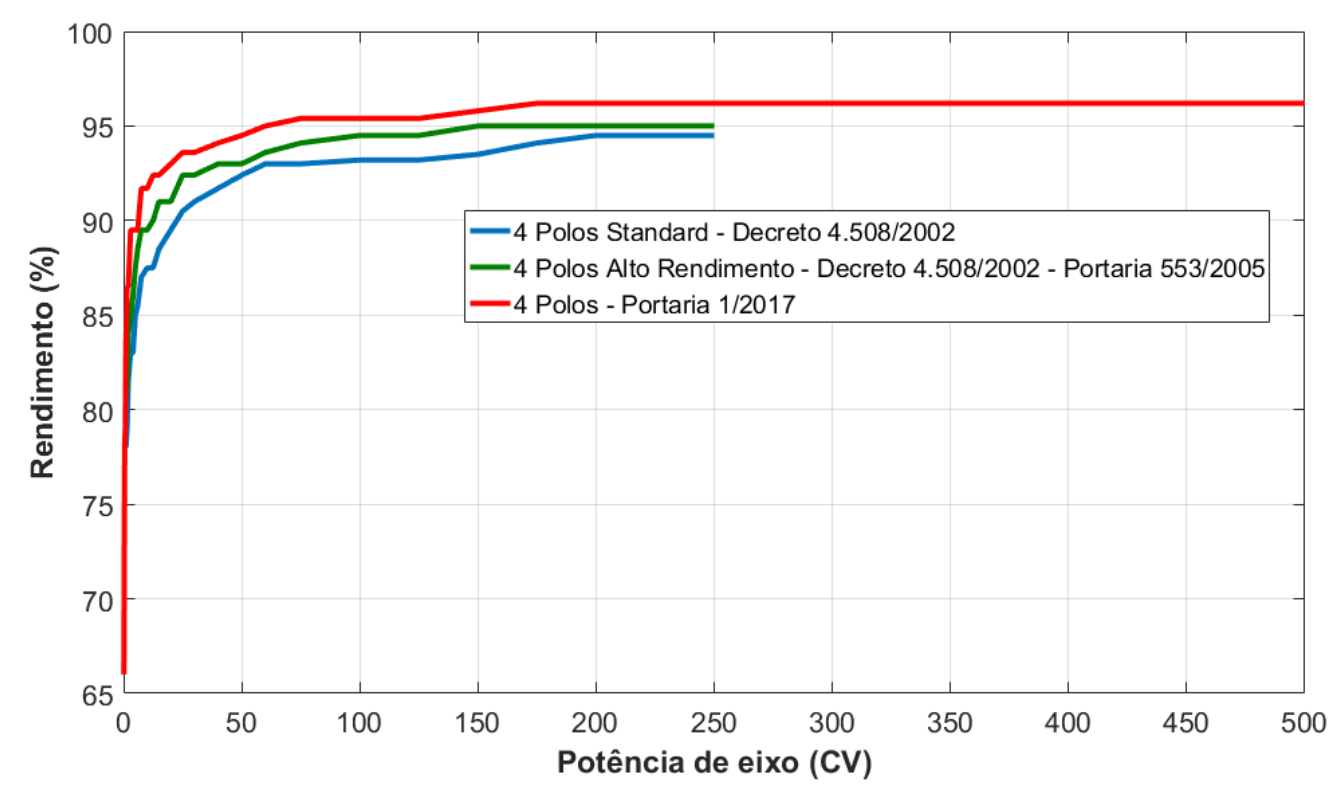

Fonte: Construída a partir dos dados de Brasil (2002; 2005; 2017). 
Figura 31 - Evolução da normativa nacional para MITRGE de 6 polos

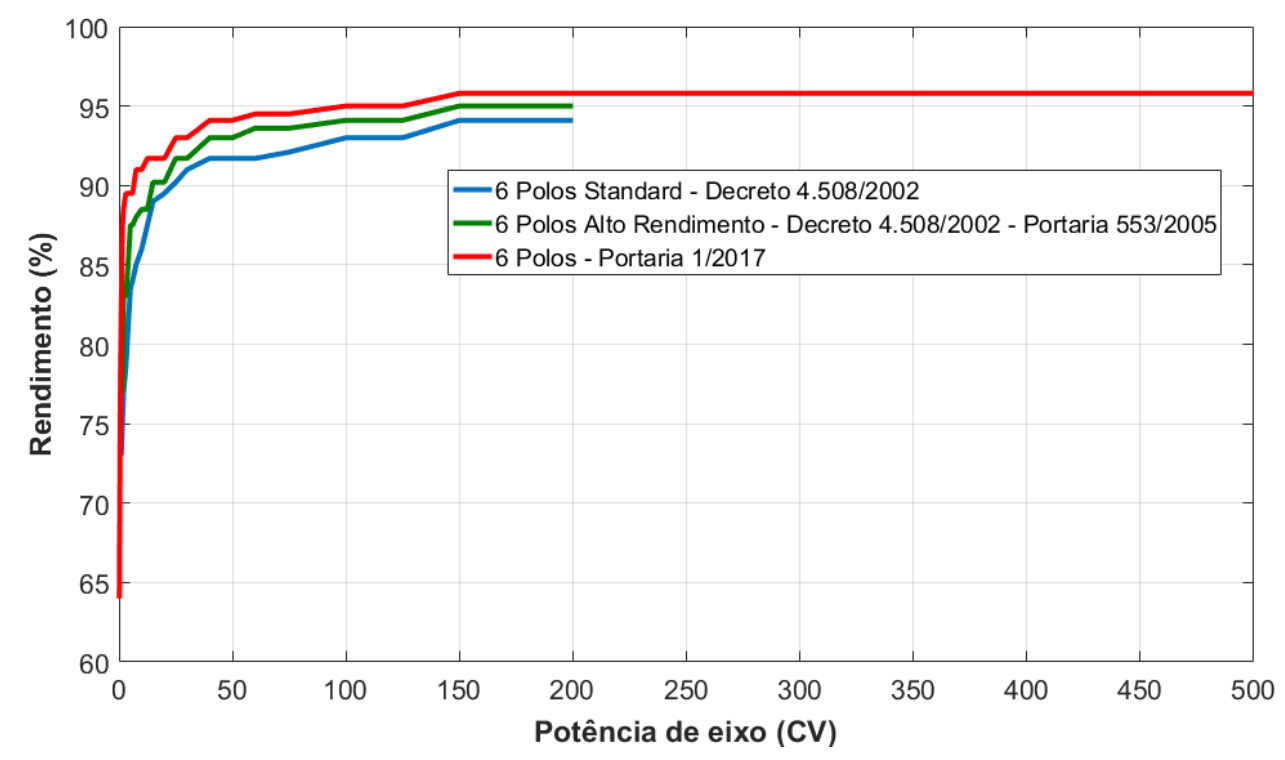

Fonte: Construída a partir dos dados de Brasil (2002; 2005; 2017).

Figura 32 - Evolução da normativa nacional para MITRGE de 8 polos

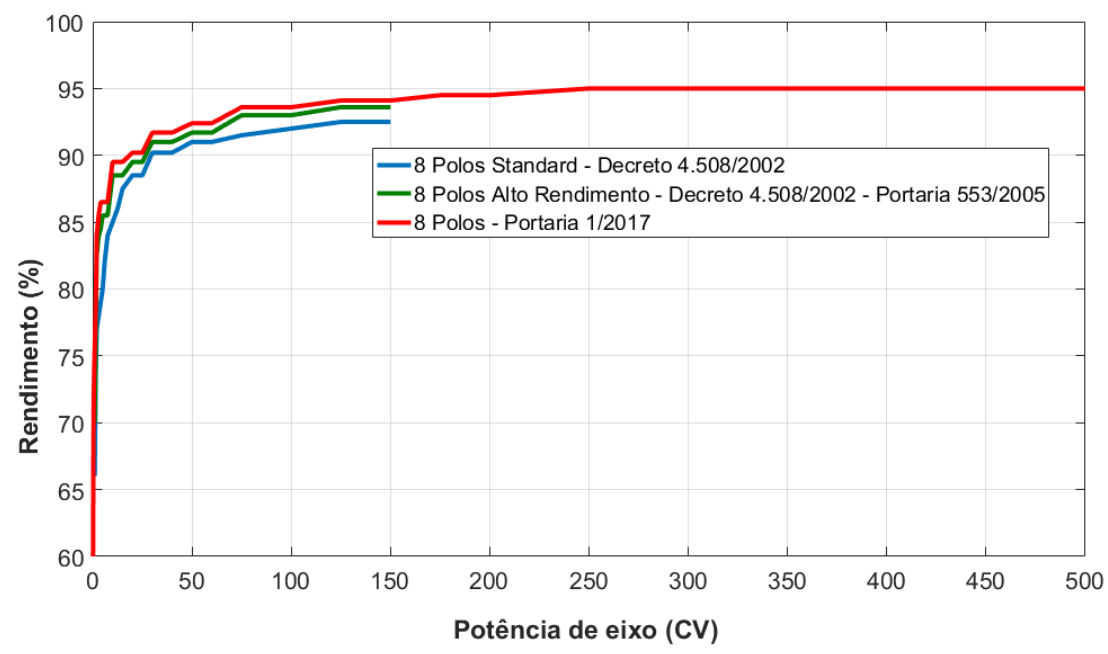

Fonte: Construída a partir dos dados de Brasil (2002; 2005; 2017).

Analisando a Figura 29 até a Figura 32 é possível observar a diferença crescente dos níveis de rendimento entre as legislações aplicadas, bem como a ampla faixa de potência de eixo que abrange a Portaria 1/2017, possuindo em sua regulamentação, desde motores ditos fracionários, menores que $1 \mathrm{CV}$, até grandes motores com potências de $500 \mathrm{CV}$, não comumente encontrados nas plantas industriais. Portanto, é a normativa mais abrangente implantada no território nacional até o momento. 


\subsubsection{O impacto da legislação sobre os MITRGE comercializados no Brasil}

Em A comparative assessment of Brazilian electric motors performance with minimum efficiency standards (SAUER, I. L. et al., 2015), foi analisado o rendimento de 276 MITRGE ensaiados no Instituto de Energia e Ambiente da USP entre 2000 e 2012, com potências de eixo entre $1 \mathrm{CV}$ e $350 \mathrm{CV}$, pertencendo a 29 fabricantes.

No trabalho, foram apresentados resultados de ensaios de rendimento para MITRGE de 2, 4, 6 e 8 polos. Tendo em vista que os MITRGE de 4 polos correspondem à maior parte do mercado mundial, apresentamos na Figura 33, os resultados dos ensaios comparados com os níveis de eficiência IE2 e IE3 da regulação EC640 da União Europeia (EC Nº 640, 2009), o nível de eficiência Premium do padrão NEMA MG1 (NATIONAL ELECTRICAL MANUFACTURERS ASSOCIATION, 2011) e os valores mínimos de acordo com o Decreto $n^{\circ} 4.508 / 2002$.

Figura 33 - Redimentos medidos de MITRGE de 4 polos comparado com a lesgislação nacional e internacional

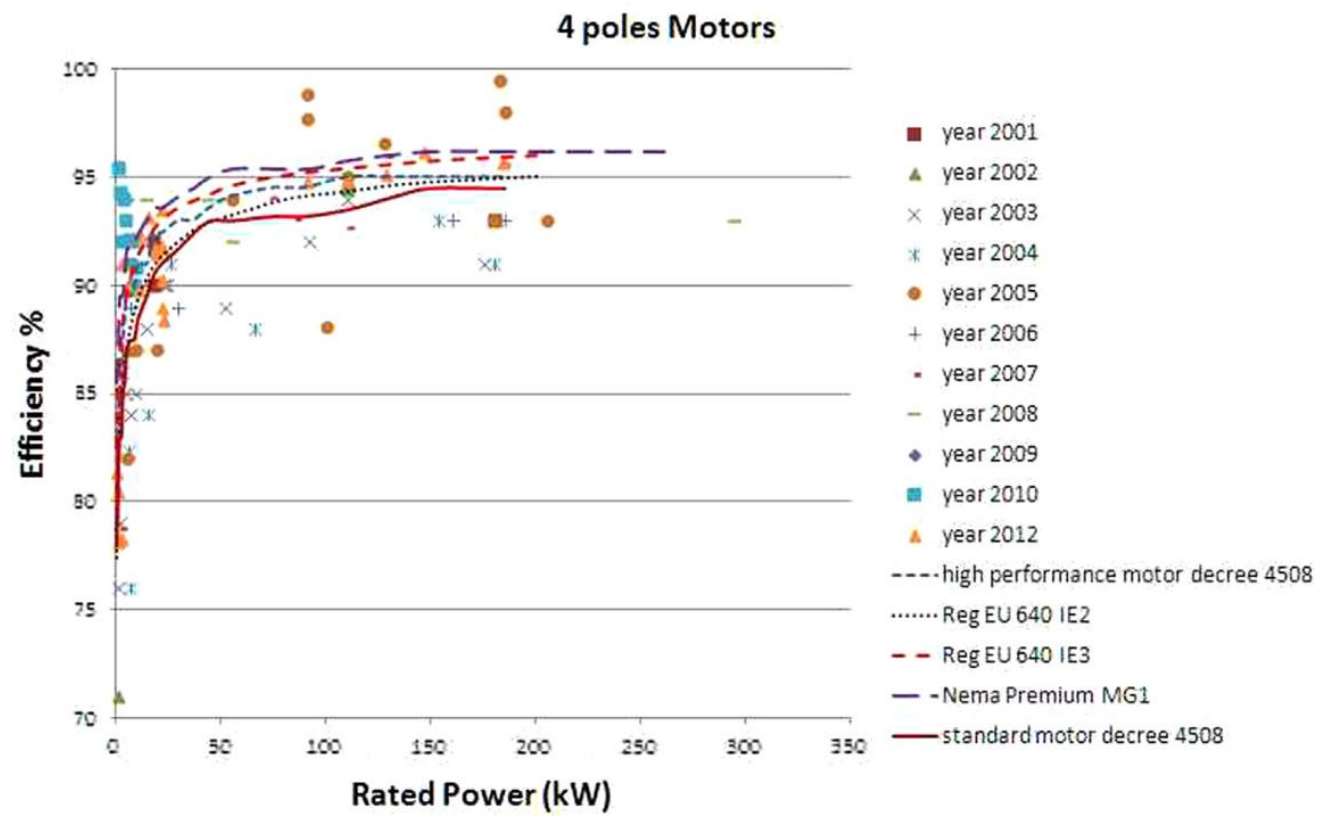

Fonte: (SAUER, I. L. et al., 2015).

Como pode ser observado na Figura 33, a grande maioria dos motores ensaiados exibe níveis de rendimento inferiores aos do Decreto 4.508/2002, como também, não cumprem os 
índices da NEMA MG1 Premium ou os níveis de eficiência da União Européia da regulamentação EU 640. A Figura 34 apresenta os desvios absolutos entre os valores medidos e os valores de rendimento mínimo dos MITRGE apresentados no Decreto 4.508/2002 para motores de 4 polos, categoria chamada pela legislação de Standard. Os valores negativos indicam que a eficiência deste motor está abaixo do nível de eficiência previsto por este regulamento.

Figura 34 - Desvio de rendimento dos MITRGE ensaiados comparados ao Decreto 4.508/2002

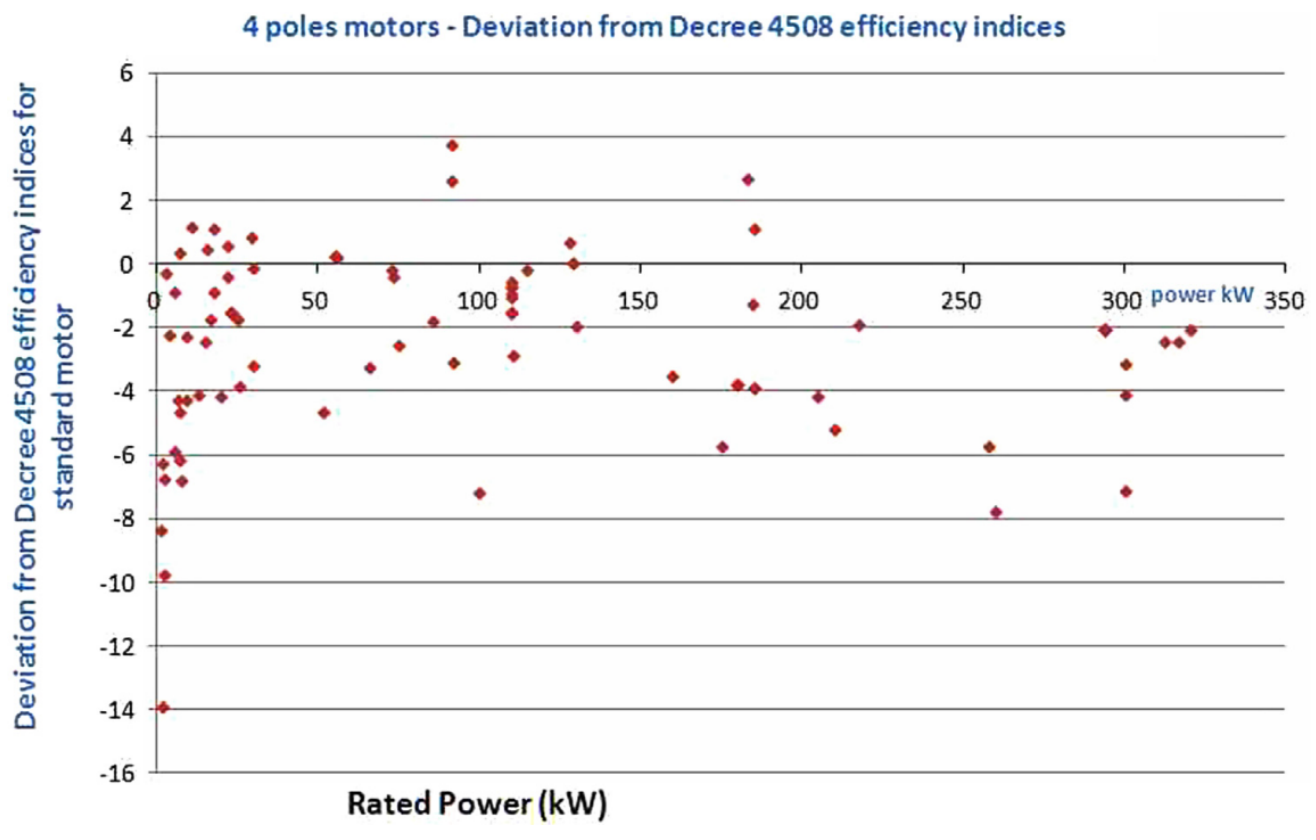

Fonte: (SAUER, I. L. et al., 2015).

No gráfico é possível observar a dispersão dos resultados obtidos nos ensaios em relação à regulamentação mínima apresentada no Decreto 4.508/2002. A Tabela 7 mostra a comparação dos níveis de rendimento (2000-2012) em relação ao mesmo decreto.

Tabela 7 - Comparação dos níveis de rendimento dos MITRGE (2000-2012) em relação ao Decreto no 4.508/2002

\begin{tabular}{cccccc}
\hline Decreto 4.508/2002 & 2 Polos & 4 Polos & 6 Polos & 8 Polos & Total \\
\hline Rendimento abaixo do mínimo & $98 \%$ & $84 \%$ & $94 \%$ & $80 \%$ & $89 \%$ \\
Rendimento acima do mínimo & $2 \%$ & $16 \%$ & $6 \%$ & 20 & $11 \%$ \\
\hline
\end{tabular}

Fonte: (SAUER, I. L. et al., 2015). 
Segundo a Tabela 7, para o conjunto de 276 MITRGE enviados pelos fabricantes e compradores para ensaios, foi obtido um nível de rendimento abaixo do mínimo permitido para comercialização nacional em $89 \%$ dos casos.

A Tabela 8 mostra o resumo da análise estatística elaborada por (SAUER, I. L. et al., 2015), onde é possível observar que para as 4 velocidades analisadas, o desvio médio está abaixo do mínimo permitido pela legislação de rendimento. A Tabela 8 também mostra que os desvios máximos negativos para cada grupo de velocidade foram significativamente abaixo da legislação, alcançando desvios negativos maiores que $10 \%$.

Tabela 8 - Avaliação estatística de rendimento dos MITRGE (2000-2012) em relação ao Decreto ${ }^{0}$ 4.508/2002

\begin{tabular}{cccccc}
\hline $\mathrm{N}^{\mathrm{o}}$ de polos & Desvio médio & Desvio padrão & Mediana & $\begin{array}{c}\text { Desvio máximo } \\
\text { negativo }\end{array}$ & $\begin{array}{c}\text { Desvio máximo } \\
\text { positivo }\end{array}$ \\
\hline 2 & $-3,54$ & 2,83 & $-3,20$ & $-13,43$ & 4,95 \\
4 & $-2,47$ & 2,78 & $-2,07$ & $-13,88$ & 3,73 \\
6 & $-3,98$ & 3,61 & $-3,42$ & $-12,81$ & 2,06 \\
8 & $-2,30$ & 2,70 & $-2,40$ & $-6,71$ & 3,44 \\
\hline
\end{tabular}

Fonte: (SAUER, I. L. et al., 2015).

Desta forma, Sauer et al. (2015) concluem que, mesmo muitos anos após a implantação do Decreto 4.508/2002 e da Portaria 553/2005, os MITRGE comercializados no Brasil ainda estavam com rendimento significativamente abaixo do mínimo permitido. Assim, uma das contribuições deste trabalho é a avaliação dos resultados dos motores ensaiados nos últimos anos, tomando-se por base a legislação atual, analisando-se as mudanças de rendimento e o impacto da legislação. 


\section{METODOLOGIA}

É apresentado na Figura 35 o fluxograma metodológico estabelecido para o desenvolvimento da pesquisa, considerando desde a coleta e processamento dos dados, até a discussão dos resultados.

Figura 35 - Fluxograma metodológico

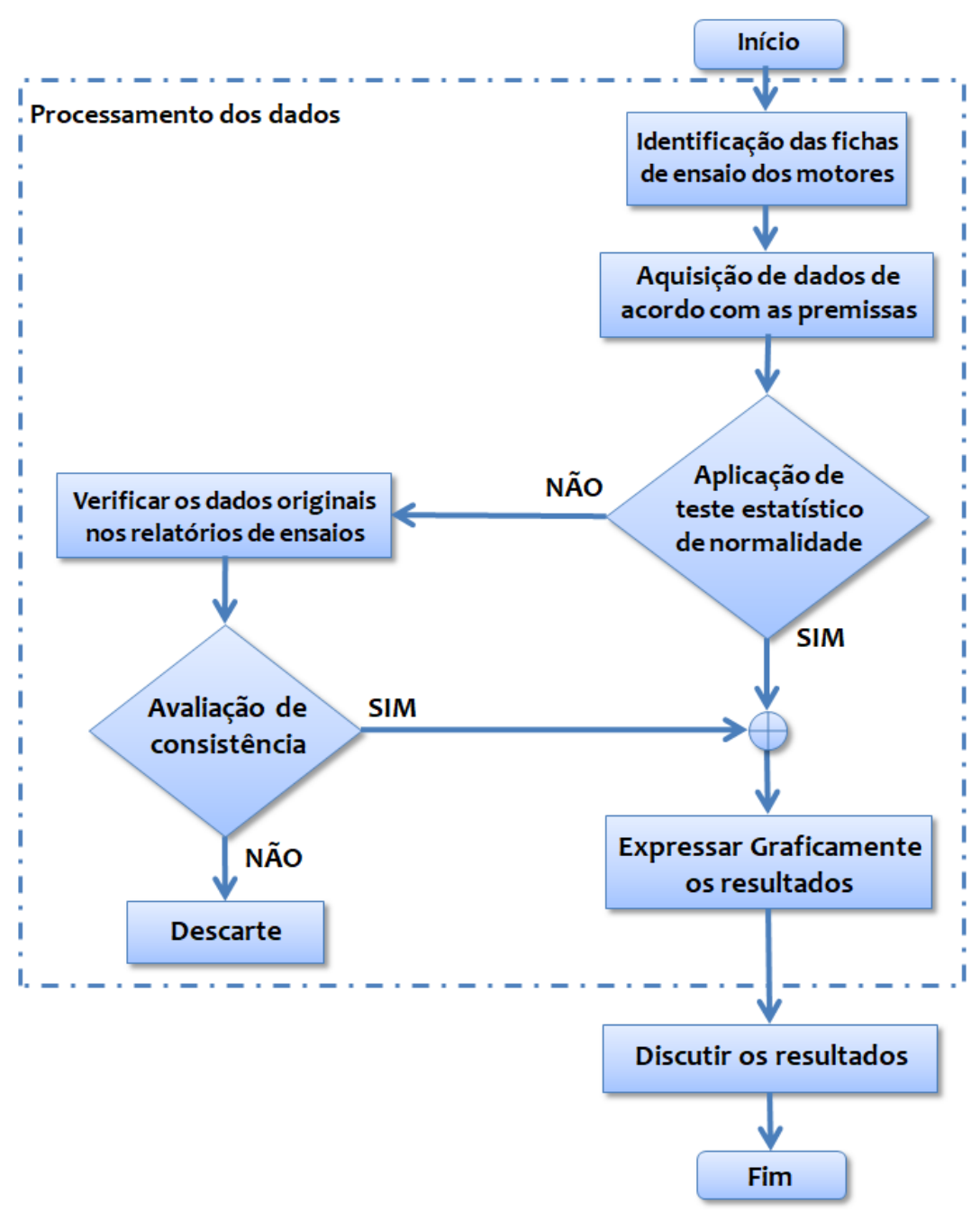

Fonte: Do autor. 


\subsection{IDENTIFICAÇÃO DAS FICHAS DE ENSAIO DOS MOTORES ELÉTRICOS}

O Laboratório de Máquinas Elétricas do IEE possui um grande acervo de resultados de ensaios de equipamentos eletromecânicos. É possível estimar em mais de 21 mil relatórios técnicos, possuindo documentos desde a fundação do instituto em 1902, sendo, portanto anterior à Universidade de São Paulo, denominado naquele momento Gabinete de Física Industrial. Neste sentido, se fez necessário identificar manualmente os relatórios de ensaios que foram objetos desta pesquisa, pois grande parte dos relatórios se encontra impresso. Apenas os mais atuais foram disponibilizados em formato digital.

\subsection{AQUISIÇÃO DE DADOS DE ACORDO COM AS PREMISSAS}

Para a realização da aquisição de dados, premissas foram estabelecidas, dada a ampliada gama de relatórios de ensaios presentes nos arquivos do laboratório. O objetivo das premissas é o estabelecimento de fidedignidade à extração dos dados, procurando-se obter uma generalização dos mesmos para o cenário nacional. As premissas estabelecidas foram:

a) Motores Novos:

- Serão considerados somente motores novos, pois muitos motores elétricos oriundos de empresas de manutenção foram ensaiados para verificação de conformidade e possuem características diferentes das nominais.

b) Dados com experimentos realizados a plena carga:

- O ensaio de rendimento dos motores elétricos é realizado em uma ampla faixa de carga, entretanto, para o trabalho, serão considerados a determinação do fator de potência e rendimento do motor elétrico com operação a plena carga, tensão nominal, frequência de tensão nominal e forma de onda de tensão senoidal.

c) Valores medidos e de placa:

- É necessário realizar a aquisição dos dados considerando-se os valores medidos e também os valores informados pelo fabricante nas placas, objetivando, a realizar de análise comparativa. 
d) Motores trifásicos de indução com rotor em gaiola de esquilo:

- O Laboratório realiza o ensaio em motores especiais, motores de corrente contínua de vários arranjos, como também de motores síncronos de vários arranjos. Porém, este trabalho se resumirá ao rendimento dos motores de indução trifásicos com rotor em gaiola.

e) Motores com os dados de placa disponibilizados:

- Alguns motores foram ensaiados sem a disponibilização dos dados de placa. Os dados destes motores não serão aquisitados para a análise estatística.

f) Alocar a aquisição de dados dos motores por data de fabricação.

g) Não utilizar dados de motores especiais e/ou alimentados por drives.

A aquisição de dados foi agrupada em planilhas eletrônicas sendo preenchida a partir das premissas estabelecidas e mostradas, como por exemplo, na Figura 36. 
Figura 36 - Planilha de aquisição de dados

\begin{tabular}{|c|c|c|c|c|c|c|c|}
\hline Relatório & Fabricante & Fabricação & $\begin{array}{c}\text { Potência } \\
\text { Nominal } \\
(\mathrm{CV})\end{array}$ & $\begin{array}{c}\text { Velocidade } \\
\text { Informada } \\
\text { (RPM) }\end{array}$ & $\begin{array}{c}\text { Número } \\
\text { de Polos }\end{array}$ & $\begin{array}{c}\text { Velocidade } \\
\text { Medida } \\
\text { (RPM) }\end{array}$ & $\begin{array}{c}\text { Classe de } \\
\text { Isolação }\end{array}$ \\
\hline 72968 & A & 2011 & 20 & 1765 & 4 & 1765 & $220 / 380$ \\
\hline 72970 & A & 2011 & 25 & 1770 & 4 & 1766,6 & $220 / 380$ \\
\hline 72972 & A & 2011 & 30 & 1770 & 4 & 1764,9 & $220 / 380$ \\
\hline
\end{tabular}

\begin{tabular}{|c|c|c|c|c|c|c|c|c|c|c|c|}
\hline $\begin{array}{l}\text { Grau de } \\
\text { Proteção }\end{array}$ & $\begin{array}{l}\text { Fator de } \\
\text { Serviço }\end{array}$ & Regime & $\begin{array}{c}\text { Fator de } \\
\text { Potência } \\
\text { Medido (\%) }\end{array}$ & $\begin{array}{c}\text { Fator de } \\
\text { Potência } \\
\text { Informado }(\%)\end{array}$ & $\begin{array}{c}\text { Massa } \\
(\mathrm{kg})\end{array}$ & $\begin{array}{c}\text { Ip/In } \\
\text { Informado }\end{array}$ & $\begin{array}{l}\text { Ip/In } \\
\text { Medido }\end{array}$ & $\begin{array}{c}\mathrm{Cp} / \mathrm{Cn} \\
\text { Medido }\end{array}$ & $\begin{array}{c}\text { Cmáx/Cn } \\
\text { Medido }\end{array}$ & $\begin{array}{l}\text { Rendimento } \\
\text { Informado } \\
(\%)\end{array}$ & $\begin{array}{l}\text { Rendimento } \\
\text { Medido (\%) }\end{array}$ \\
\hline IP 55 & 1,15 & $\mathrm{~S} 1$ & 83,5 & 84,0 & 123 & 6,7 & 6,6 & 2,4 & 3,0 & 91,2 & 91,2 \\
\hline IP 55 & 1,15 & $\mathrm{~S} 1$ & 84,3 & 85,0 & 138 & 7,5 & 7,1 & 2,5 & 3,4 & 92,5 & 91,3 \\
\hline IP 55 & 1,15 & $\mathrm{~S} 1$ & 84,9 & 86,0 & 154 & 7,2 & 7,0 & 2,6 & 3,0 & 92,4 & 91,8 \\
\hline
\end{tabular}

\begin{tabular}{|c|c|}
\hline Conjugado (N.m) & Categoria \\
\hline 80,8 & $\mathrm{H}$ \\
\hline 100,9 & $\mathrm{H}$ \\
\hline 119,9 & $\mathrm{H}$ \\
\hline
\end{tabular}

Fonte: Do autor. 


\subsection{APLICAÇÃO DE TESTE ESTATÍSTICO DE NORMALIDADE}

O teste de normalidade será aplicado para verificar se os dados apresentam distribuição normal. Aqueles que não apresentarem normalidade serão reanalisados a partir dos originais nos relatórios de ensaios. Se a aquisição estiver correta será realizada uma avaliação individual de consistência. Apresentando consistência, a aquisição seguirá para processamento, caso contrário, a amostra será descartada.

\subsection{A ORIGEM DOS DADOS}

Todos os dados de ensaios dos motores de indução trifásicos, utilizados neste trabalho foram coletados no Instituto de Energia e Ambiente da Universidade de São Paulo.

O Instituto de Energia e Ambiente foi fundado em 1901 com o nome de Gabinete de Física Industrial e Eletrotécnica do Estado de São Paulo, instalado dentro da Escola Politécnica no Edifício Paula Souza.

Em 1927, o Instituto emitiu o primeiro laudo técnico oficial. Foi determinado, por meio de ensaio o rendimento de um aquecedor elétrico de água "Electro Thermo Brasileiro", podendo ser considerado um chuveiro elétrico.

Em 1942 foram realizados os primeiros relatórios técnicos de ensaios de motores elétricos, onde foram analisadas grandezas como conjugado, rendimento e fator de potência.

O Laboratório de Máquinas Elétricas ensaiou nos anos 70 e 80, em média, 160 equipamentos elétricos por ano, entre motores e transformadores elétricos. No ano de 2016 foram emitidos 340 relatórios técnicos de ensaios de motores elétricos, transformadores, nobreaks, dentre outros. O referido laboratório faz parte da Rede Brasileira de Laboratórios de Ensaio (RBLE) e está acreditado, conforme as normas da NBR e IEC, para ensaios em transformadores elétricos, motores elétricos de indução e nobreaks. Atualmente, realiza serviços e ensaios em motores elétricos e transformadores de distribuição para o Programa Brasileiro de Etiquetagem (PBE).

A atuação do Laboratório de Máquinas Elétricas inclui análise de rendimento energético, mecânico e elétrico de motores e geradores elétricos, transformadores, 
conversores eletrônicos estáticos, como conversores de frequência para motores, nobreaks e inversores para conexão de fontes alternativas de energia elétrica na rede básica. Realiza também estudos de influência de harmônicos na rede elétrica e em transformadores de distribuição causados por inversores, UPS e cargas não lineares.

A Figura 37 apresenta o panorama do Laboratório de Máquinas do IEE, instalado na Cidade Universitária da USP no Bairro do Butantã.

Figura 37 - Laboratório de Máquinas Elétricas - IEE - 2016

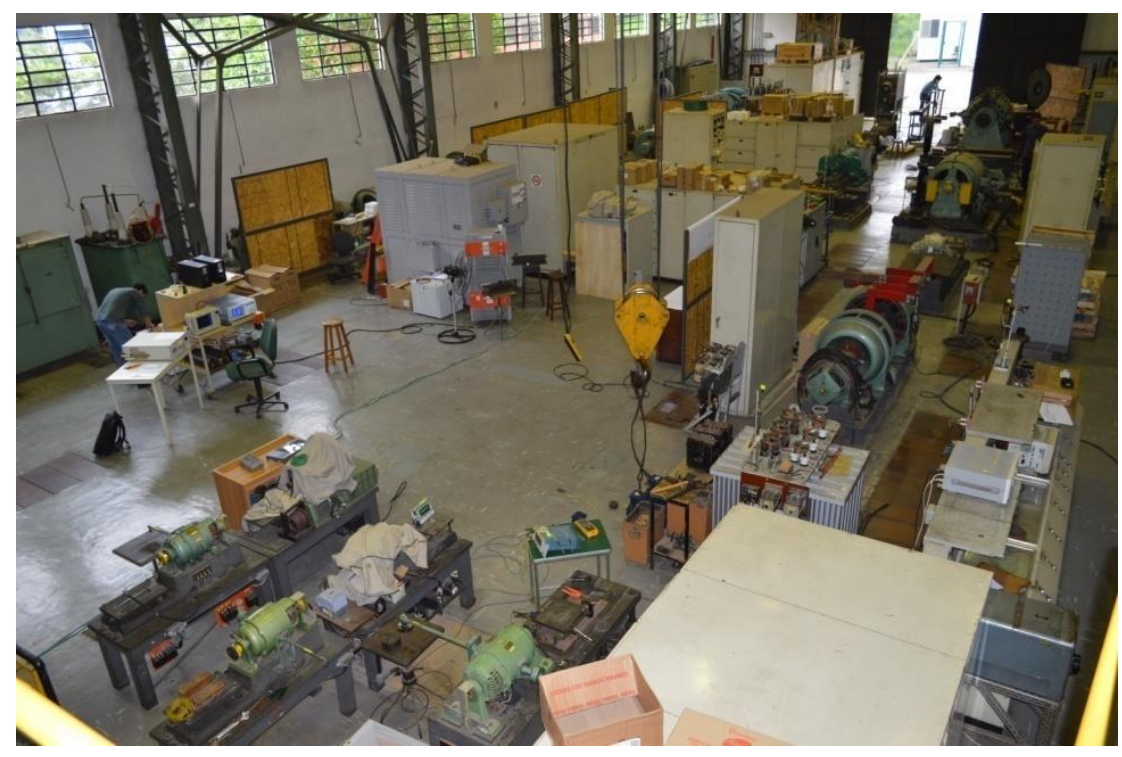

Fonte: Do autor.

Os principais ensaios realizados em motores elétricos de indução trifásicos no Laboratório de Máquinas Elétricas do IEE são:

a) Medição de resistência elétrica dos enrolamentos;

b) Ensaio em vazio;

c) Ensaio com rotor bloqueado;

d) Determinação de características de rendimento;

e) Elevação de temperatura;

f) Medição da resistência do isolamento;

g) Tensão suportável à frequência nominal. 
O Laboratório de Máquinas Elétricas é acreditado pelo CGRE/INMETRO de acordo com a norma ABNT NBR ISO/IEC 17025:2005 sob o N CRL - 0011. O INMETRO realiza periodicamente auditorias nos laboratórios acreditados, visando garantir a qualidade no resultado das medições. O INMETRO é signatário dos acordos de reconhecimento mútuo da International Laboratory Accreditation Cooperation - ILAC e também da Interamerican Accreditation Cooperation - IAAC, seguindo portando padrão mundial de qualidade e confiabilidade, conforme pode ser observado no Certificado de Acreditação disponível no ANEXO - Certificado de Acreditação IEE/USP - no Laboratórios de Ensaio Acreditados (Rede Brasileira de Laboratórios de Ensaio - RBLE), sendo credenciado desde a criação do organismo.

Todos os instrumentos utilizados nas medições no IEE são calibrados e aferidos com rastreabilidade à Rede Brasileira de Calibração - RBC, pertencente ao INMETRO.

Os resultados dos ensaios de rendimento foram obtidos por meio de procedimentos de teste amplamente aceitos pela indústria, baseados na norma brasileira ABNT NBR 53831:2002, método 2, que é semelhante ao padrão (INSTITUTE OF ELECTRICAL AND ELECTRONICS ENGINEERS, 2017), método B. Este método, de acordo com a norma (ASSOCIAÇAO BRASILEIRA DE NORMAS TÉCNICAS, 2014), leva aos resultados de incertezas mais baixos para medições de rendimento.

As incertezas de medição são calculadas nos padrões internacionais estabelecidos nos documentos INTROGUM (2014) e EA-4/02 (EXPRESSION of the uncertainty of measurement in calibration, 1999). Essas normativas são discutidas em comitês mundiais como uma tentativa de uniformizar o cálculo da incerteza de medição em diversas áreas de conhecimento.

Existem apenas três laboratórios acreditados pelo INMETRO, no território brasileiro, para a elaboração da avaliação de rendimento dos motores elétricos. O Centro de Pesquisa de Energia Elétrica - CEPEL/Eletrobrás fundado em 1974, instalado no estado do Rio de Janeiro, o Laboratório de Máquinas Elétricas da Pontifícia Universidade Católica - PUC/RS, operando desde 1950 com capacidade de ensaio de motores elétricos de até $15 \mathrm{CV}$, conhecido como LABELO com atividades iniciadas em 1968. O terceiro citado é o Laboratório de Máquinas Elétricas do Instituto de Energia e Ambiente da Universidade de São Paulo, sendo o primeiro laboratório independente a realizar ensaios de rendimento em motores elétricos no território brasileiro. 
A coleta de dados foi realizada no Laboratório de Máquinas Elétricas, onde os relatórios técnicos de ensaios, entre os anos de 1945 e 1995, foram disponibilizados para a consulta no acervo.

Entre os anos de 1996 e 2016, foram disponibilizados os relatórios de forma digital, facilitando a coleta dos dados necessários para esta pesquisa. 


\section{RESULTADOS}

\subsection{DISTRIBUIÇÃO DOS MOTORES ELÉTRICOS ENSAIADOS}

Os resultados de ensaios que fazem parte do acervo do Laboratório de Máquinas referem-se a motores elétricos enviados por fabricantes, por grandes compradores e por empresas de manutenção. Neste trabalho serão considerados motores novos, ou seja, que não passaram por qualquer intervenção após o processo de manufatura.

Este tópico apresenta o universo da amostragem utilizada para a realização da pesquisa, dados os critérios de aquisição aplicados na metodologia.

A quantidade de motores ensaiados no IEE é bastante extensa e fornece, razoavelmente, um cenário do mercado brasileiro, principalmente por possuir em banco de dados de motores elétricos de uma ampla gama de fabricantes, distribuídos em uma longa escala de tempo.

É conhecido que os motores elétricos de indução são a grande maioria das máquinas elétricas utilizadas para a produção de força. Mas qual é efetivamente o percentual de motores elétricos de indução em relação aos demais? A Figura 38, construída com 2762 motores, ensaiados no laboratório entre 1945 e 2016, apresenta o percentual de cada tecnologia motriz utilizada na indústria.

Figura 38 - Percentual de de motores ensaiados por tecnologia

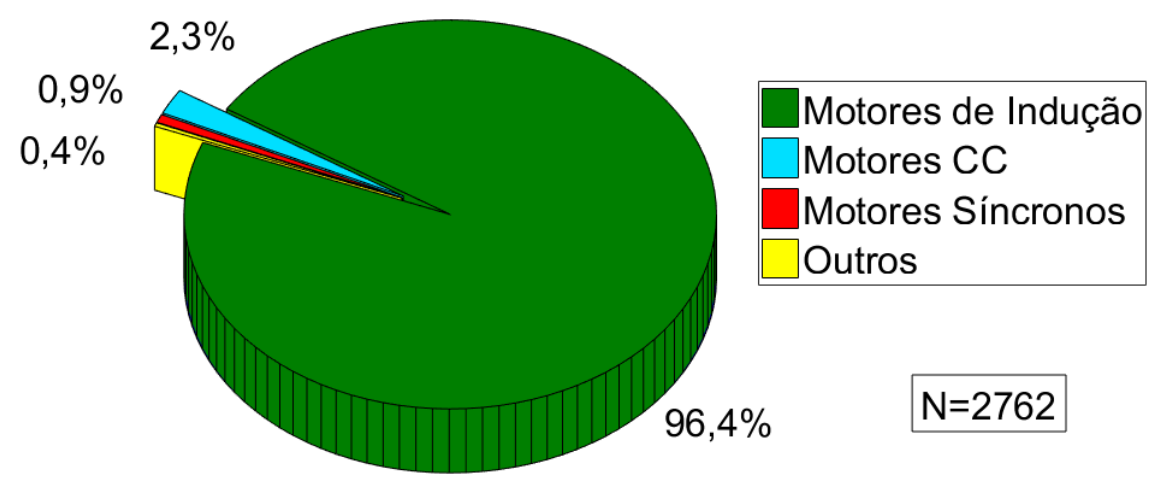

Fonte: Do autor. 
É possível observar na Figura 38, a absoluta predominância da tecnologia de indução para motores elétricos em relação às demais, chegando a mais de $95 \%$ do total, resultado da robustez e custos de aquisição e custos operacionais em todo o ciclo de vida dos motores de indução.

Como apresentado na Figura 10 (página 42), mesmo dentro da tecnologia assíncrona (indução), existe uma ampla gama de formas construtivas. Neste sentido, a Figura 39 apresenta os principais tipos de motores de indução que foram ensaiados no Laboratório de Máquinas no referido período da pesquisa.

Figura 39 - Tipos de motores de indução ensaiados

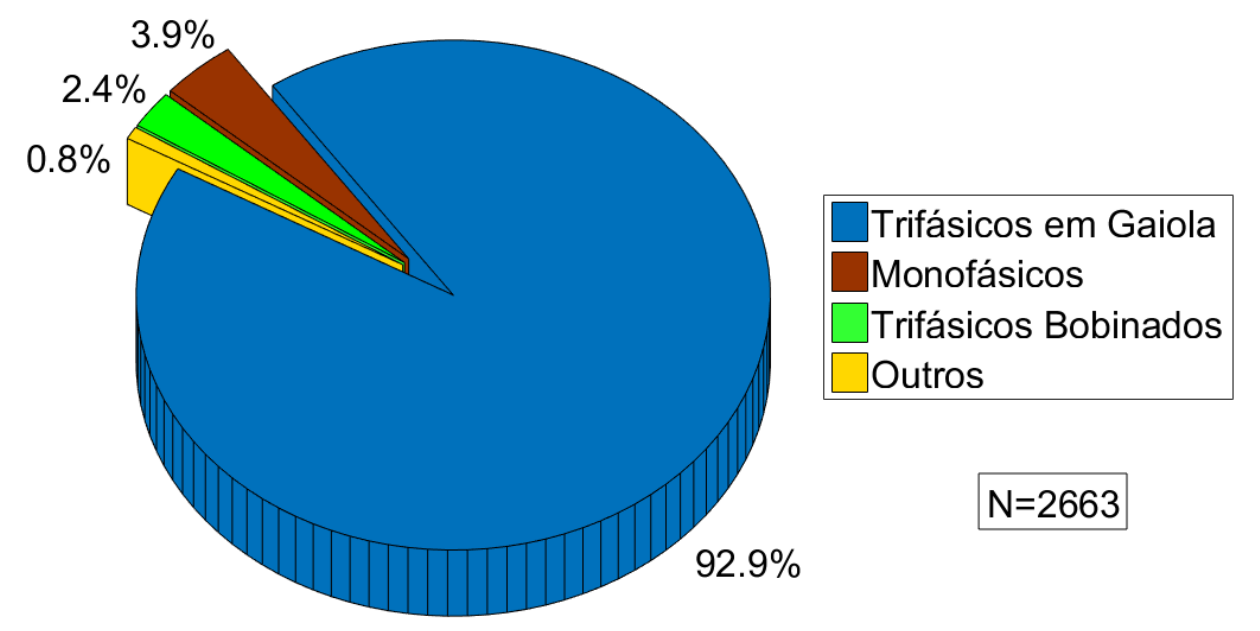

Fonte: Do autor.

A Figura 39 mostra que ampla maioria dos motores de indução para uso industrial é construída para alimentação trifásica e possuem o rotor em gaiola de esquilo. Utilizando uma amostragem de 2.663 motores, mais de $90 \%$ possuem esta particularidade construtiva, sendo, portanto, os motores dominantes no setor industrial.

Dentre os motores trifásicos com o rotor em gaiola de esquilo, uma ampla distribuição de potência mecânica de eixo é verificada. Na Figura 40 os MITRGE ensaiados foram divididos em seis (6) blocos. É possível verificar a predominância em mais de $80 \%$ de motores com potência de eixo menor que $100 \mathrm{CV}$. 
Figura 40 - Distribuição percentual dos motores de indução ensaiados por faixa de potência

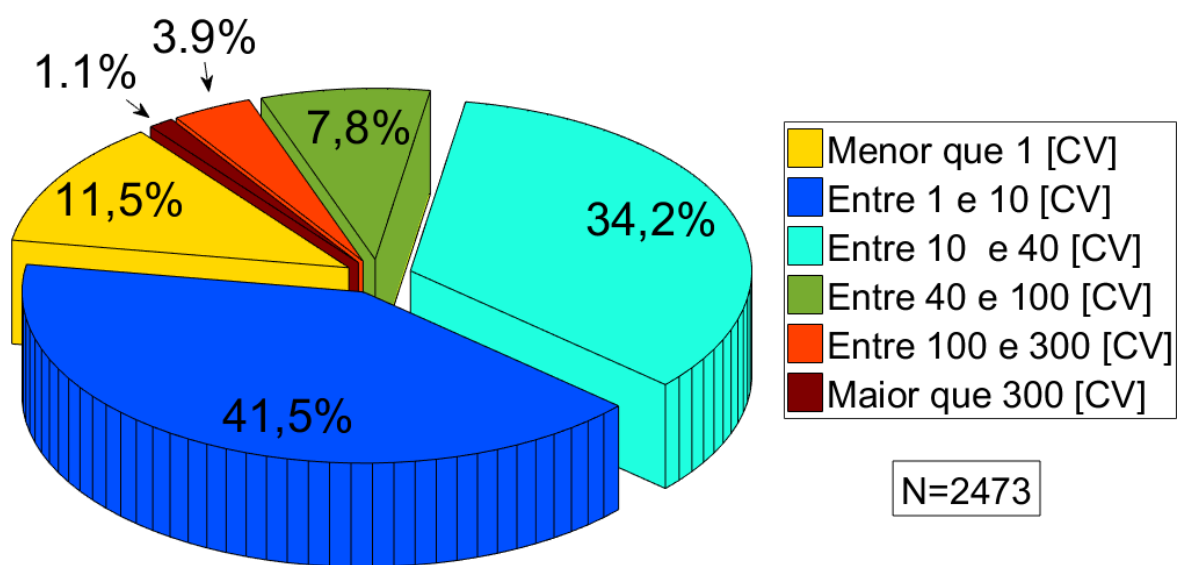

Fonte: Do autor.

Os motores com elevadas potências de eixo (acima de 100CV) apresentaram baixa representatividade nas amostras estudadas, sendo este fato atribuído à normativa vigente no período, como também pela menor necessidade de elevadas potências nas plantas industriais. O Decreto 4.508/2002 e a Portaria 553/2005 regulamentaram os MITRGE até $250 \mathrm{CV}$, o que faz com que os fabricantes de motores de potências maiores não precisem submeter os seus motores para ensaios de tipo, só ocorrendo quando solicitado pelos clientes.

Nas plantas industriais, uma política comum é a divisão dos processos, quando possível, para acionamentos com motores menores, evitando a dependência de um único acionamento.

Os MITRGE oferecem possibilidades de velocidades de acordo com o número de polos em que estator foi construído, sendo então definida a velocidade base de rotação do rotor. Assim muitas possibilidades são disponíveis, sempre em números pares e múltiplos de dois (2). Analisando a amostragem utilizada para o trabalho de pesquisa, a Figura 41 apresenta o percentual de motores ensaiados por número de polos. 
Figura 41 - Distribuição dos motores de indução trifásicos por número de polos
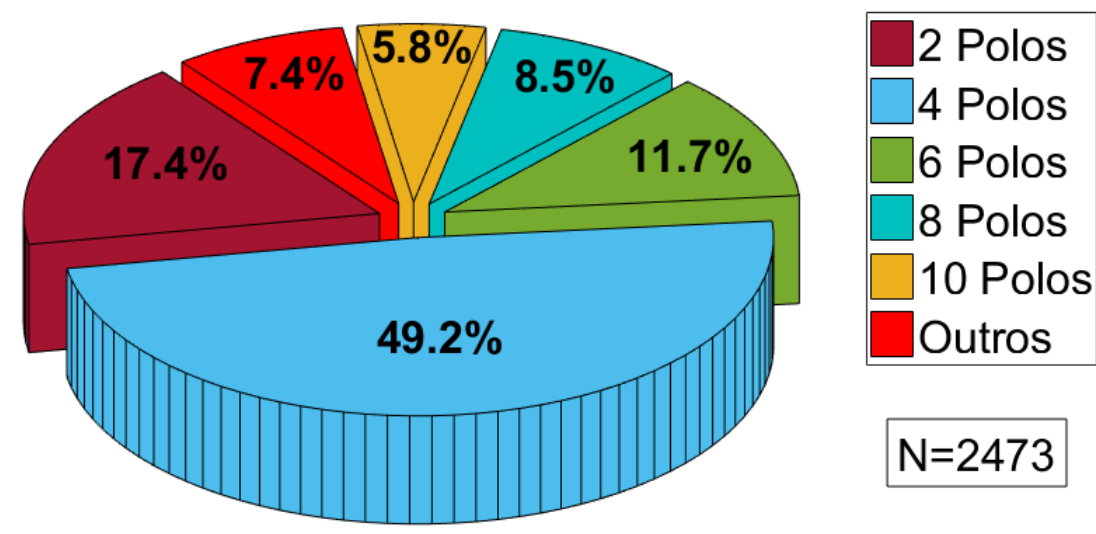

Fonte: Do autor.

A Figura 41 mostra que mais de $85 \%$ dos MITRGE avaliados são de motores de 2 a 8 polos, justificando-se, portanto, o fato do Decreto 4.508/2002 e da Portaria 553/2005 estarem limitados a rotações correspondentes a 2, 4, 6 e 8 polos.

\subsection{MUDANÇA DE RENDIMENTO DOS MITRGE 1945-2016}

Os motores elétricos, assim como a grande maioria dos equipamentos eletromecânicos desenvolvidos no Séc. XIX, sofreram uma série de melhorias e aperfeiçoamento, desde a concepção, passando pelos avanços tecnológicos em processos construtivos e, principalmente, pela melhoria na qualidade dos materiais empregados.

Para analisar as mudanças de rendimento dos motores elétricos ensaiados entre 19452016 foram escolhidas três potências mecânicas de eixo: 5 CV, 50 CV e 200 CV, nas velocidades correspondentes de 2 a 8 polos. As referidas potências podem ser caracterizadas como baixa, média e alta, respectivamente, em função de suas magnitudes consideravelmente diferentes, de maneira que, os processos produtivos empregados na construção dos motores e os padrões de precisão/qualidade de materiais são distintos, mesmo se tratando do mesmo equipamento.

A pesquisa foi realizada com o resultado dos ensaios de desempenho e não com dados do informativo técnico do fabricante, pois como já mencionado, esses dados podem apresentar discrepâncias em relação aos valores reais levantados com o rigor dos testes em laboratórios credenciados. 
A Figura 42 apresenta o comportamento do rendimento dos MITRGE de 2 polos ao longo do tempo, ensaiados desde 1945 até 2016.

Figura 42 - Comportamento do rendimento médio dos motores de 2 polos entre 1945 e 2016

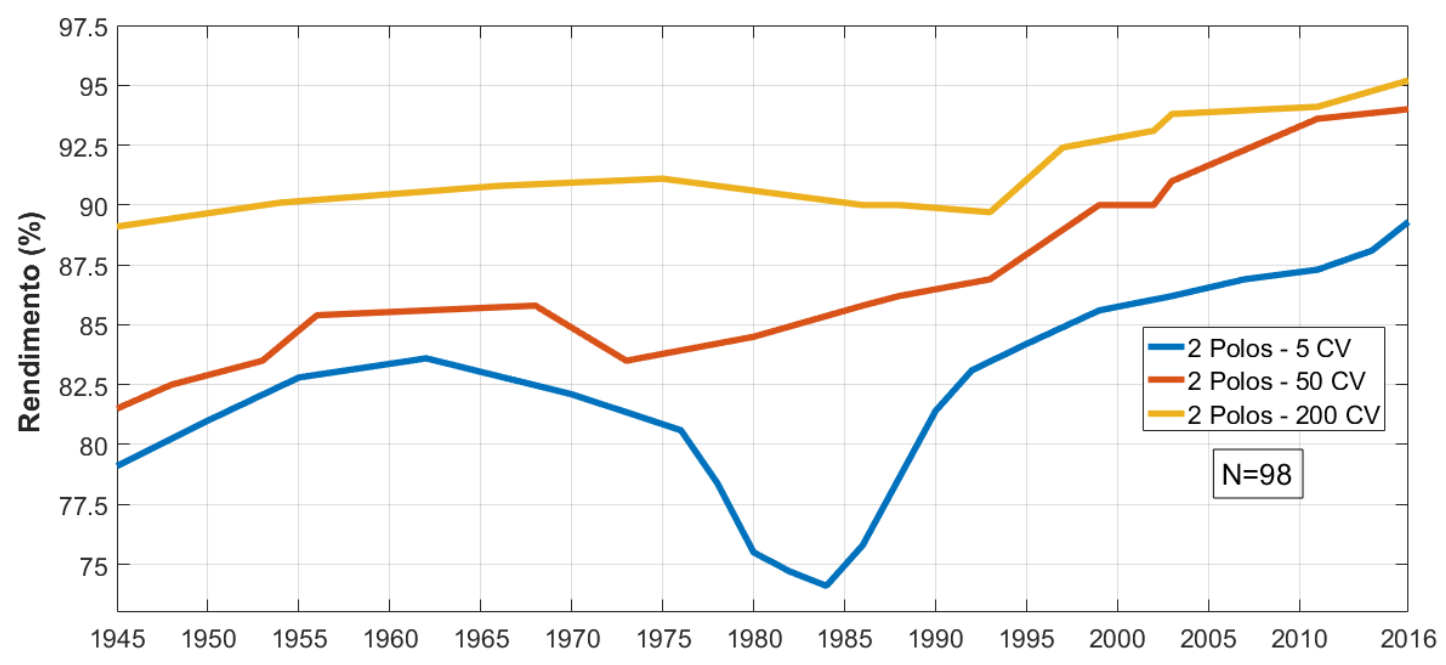

Fonte: Do autor.

O gráfico apresentado na Figura 42 foi construído com resultados de ensaios de 98 MITRGE distribuídos nas três potências de eixo e dispostos ao longo do tempo. Nos anos em que foram obtidos resultados de mais de um motor elétrico de mesma velocidade e mesma potência mecânica, optou-se por calcular o rendimento médio para a construção do gráfico. Bem como, nos anos em que não existiram motores ensaiados nas referidas potências utilizadas para a construção dos gráficos, optou-se por fazer regressão linear utilizando os anos adjacentes em existiam resultados disponíveis. As mesmas considerações foram aplicadas para os gráficos dos motores de 4,6 e 8 polos.

A Tabela 9 apresenta o ganho acumulado de rendimento entre 1945-2016 para as três potências analisadas. 
Tabela 9 - Comportamento do rendimento médio dos motores de 2 polos entre 1945 e 2016

\begin{tabular}{ccccc}
\hline Potência de eixo (CV) & 5 & 50 & 200 \\
\hline Rendimento (\%) 1945 & 79,1 & 81,5 & 89,1 \\
Rendimento (\%) 2016 & 89,3 & 94 & 95,2 \\
Ganho acumulado & 10,2 & 12,5 & 6,1 \\
\hline
\end{tabular}

Fonte: Do autor.

Os motores de maior potência, de modo geral, sempre tiveram rendimentos considerados elevados, por participarem de rotinas de controle de qualidade mais rigorosas tanto por parte dos fabricantes, como por parte dos usuários, preocupados com as perdas dos referidos equipamentos, por se tratarem na maioria dos casos das cargas elétricas predominantes em seguimentos da indústria. Tal fato faz com que os motores de potências mais elevadas, como o caso de $200 \mathrm{CV}$, tenham menores ganhos de rendimento no referido intervalo de tempo. Os motores de potência média $(50 \mathrm{CV})$ e baixa potência $(5 \mathrm{CV})$ tiveram ganhos de rendimento elevados, chegando ao acumulado no período analisado em $12,5 \%$ e $10,2 \%$ respectivamente.

O comportamento apresentado na Figura 42 e Tabela 9 para motores de 2 polos, também se repete de forma semelhante na Figura 43 e Tabela 10 para motores de 4 polos, na Figura 44 e Tabela 9 para motores de 6 polos, bem como, na Figura 45 e Tabela 12 para motores de 8 polos.

Figura 43 - Comportamento do rendimento médio dos motores de 4 polos entre 1945 e 2016

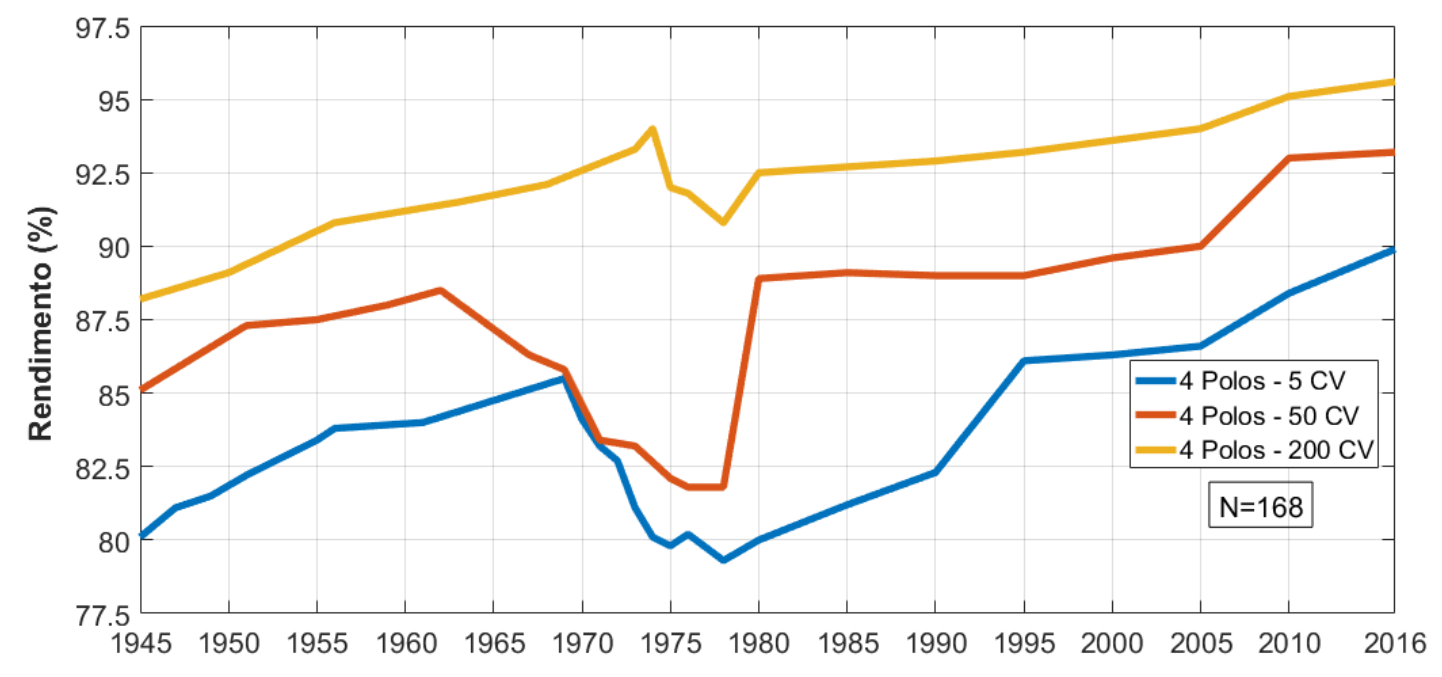

Fonte: Do autor. 
Tabela 10 - Comportamento do rendimento médio dos motores de 4 polos entre 1945 e 2016

\begin{tabular}{ccccc}
\hline Potência de eixo (CV) & 5 & 50 & 200 \\
\hline Rendimento (\%) 1945 & 81,1 & 85,1 & 88,2 \\
Rendimento (\%) 2016 & 89,9 & 93,2 & 95,1 & 7,4 \\
\hline
\end{tabular}

Fonte: Do autor.

Figura 44 - Comportamento do rendimento médio dos motores de 6 polos entre 1945 e 2016

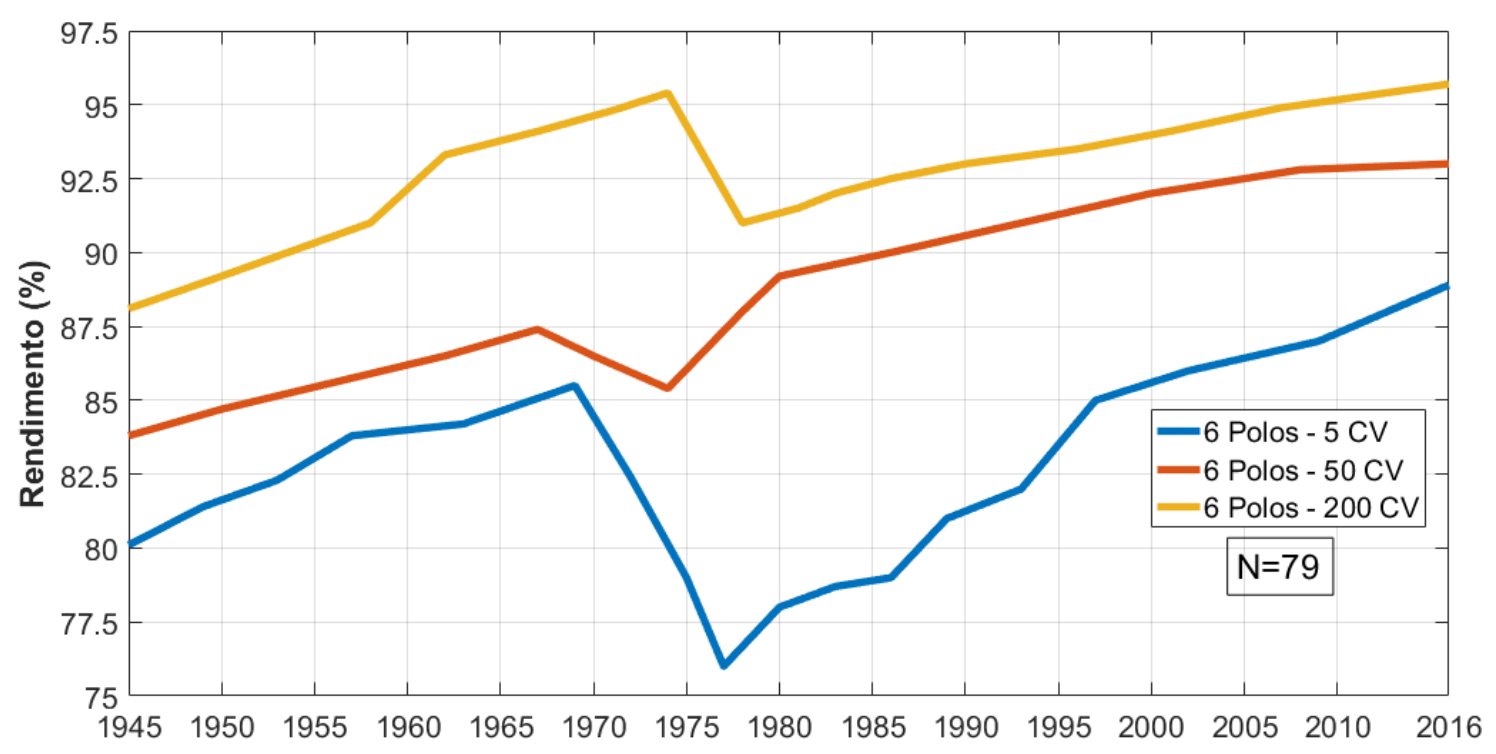

Fonte: Do autor.

Tabela 11 - Comportamento do rendimento médio dos motores de 6 polos entre 1945 e 2016

\begin{tabular}{ccccc}
\hline Potência de eixo (CV) & 5 & 50 & 200 \\
\hline Rendimento (\%) 1945 & 80,1 & 83,8 & 88,1 \\
Rendimento (\%) 2016 & 88,9 & 93 & 95,7 & 7,6 \\
\hline Ganho acumulado & 8,8 & 9,2 & \\
\hline
\end{tabular}

Fonte: Do autor. 
Figura 45 - Comportamento do rendimento médio dos motores de 8 polos entre 1945 e 2016

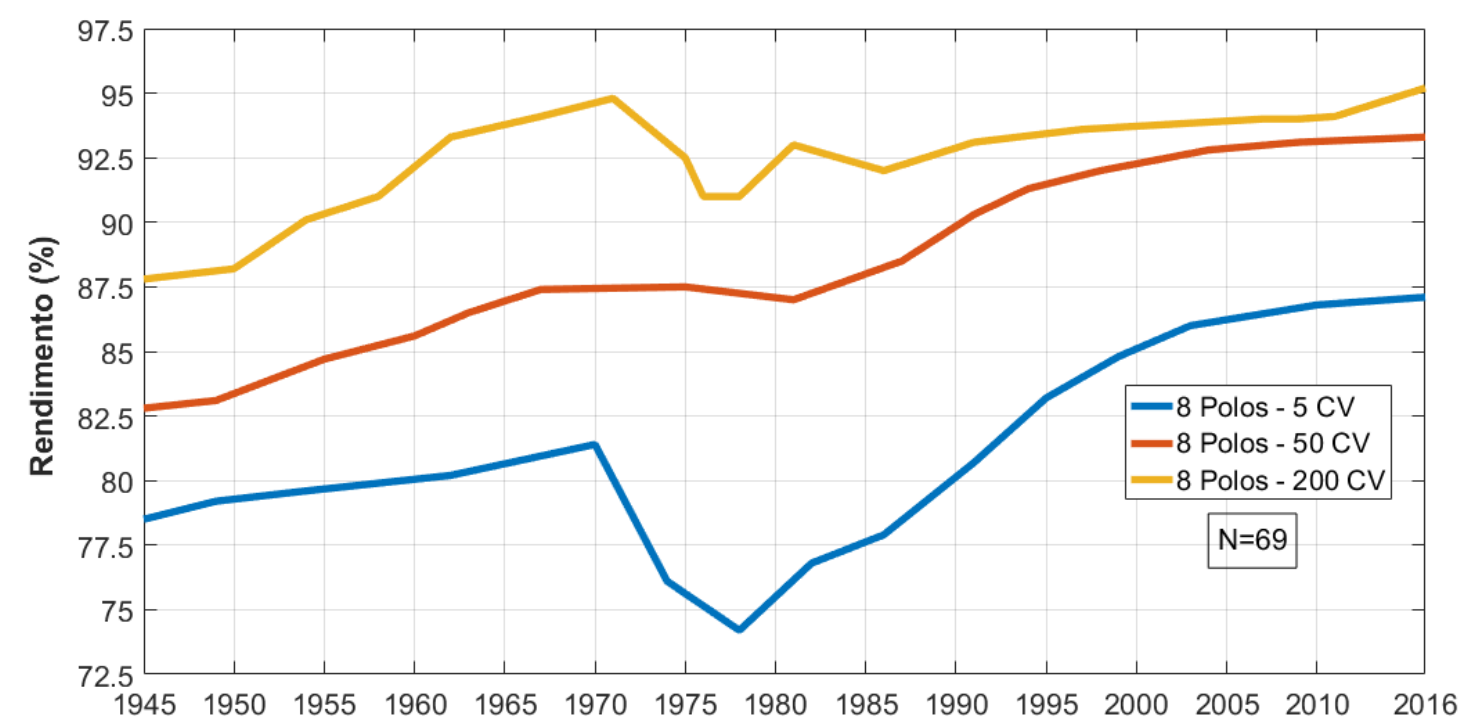

Fonte: Do autor.

Tabela 12 - Comportamento do rendimento médio dos motores de 8 polos entre 1945 e 2016

\begin{tabular}{ccccc}
\hline Potência de eixo (CV) & 5 & 50 & 200 \\
\hline Rendimento (\%) 1945 & 78,5 & 82,8 & 87,8 \\
Rendimento (\%) 2016 & 87,1 & 93,3 & 95,2 \\
Ganho acumulado & 8,6 & 10,5 & 7,4 \\
\hline
\end{tabular}

Fonte: Do autor.

As três curvas ( 5 CV, 50 CV e $200 \mathrm{CV})$ demonstraram comportamento semelhante nos 4 gráficos apresentados, sendo possível separar claramente três momentos na referida linha histórica:

$1^{\circ}$. Entre 1945 e meados dos anos 60 os motores apresentaram curva indicando ganhos crescentes e praticamente constantes de rendimento;

$2^{\circ}$. Entre os anos 60 e 80 os MITRGE apresentaram significativas quedas de rendimento, chegando a alguns casos a patamares inferiores aos motores comercializados em 1945;

$3^{\circ}$. Entre os anos 80 até 2016 o movimento de melhoria no rendimento voltou a dominar o cenário, fazendo com que fossem atingidos patamares elevados nos 
últimos anos da análise, apresentando resultante líquida, no período de 1945 a 2016, com ganhos acima de $10 \%$ no rendimento médio.

Para cada um dos três momentos descritos acima, existe uma série de elementos que influenciaram para que se chegasse a este comportamento.

No primeiro momento, entre 1945 até meados dos anos 60, foi identificado um intensivo processo de inovação tecnológica com destaque para os seguintes elementos que influenciaram diretamente nos ganhos de rendimento dos motores elétricos:

a) Muitos dos motores ensaiados nos anos 40 ainda possuíam rolamentos de deslizamento. Os mancais de deslizamento quando comparado com os mancais de esfera, produzem mais ruídos, são maiores e mais pesados e, geralmente, proporcionam maior atrito, sendo lubrificados a óleo;

b) Nos anos 40 houve uma transição entre rotores construídos com barras de ferro, para rotores com barras em alumínio fundido. $\mathrm{O}$ alumínio apresenta menor resistividade elétrica, menor densidade e, portanto, é mais leve para a mesma potência; c) Os avanços na metalurgia permitiram que as carcaças dos motores elétricos pudessem ser construídas de forma mais compacta, melhorando a segurança dos trabalhadores da operação e manutenção, mantendo a ventilação dos enrolamentos, reduzindo também as massas e o volume;

d) O sistema de isolação no referido período sofreu fortes avanços, passando da utilização do algodão, como isolante, para a seda, onde foi possível uma significativa redução no tamanho das ranhuras, reduzindo o tamanho e volume dos motores elétricos.

e) Devido ao uso da seda, também foi possível inserir mais cobre em uma mesma ranhura, reduzindo as perdas mais significativas nos motores elétricos (Joule nos enrolamentos do estator);

f) As melhorias nos processos de fabricação dos motores foram marcantes no referido período, sejam por avanços nas ferramentas de corte ou por melhor usinagem dos materiais ferromagnéticos ativos dos motores. No segundo momento, entre os anos 60 e 80, os MITRGE apresentaram significativas quedas de rendimento, sendo possível identificar a influência dos seguintes elementos; 
g) Neste período foi desenvolvida a isolação a partir de esmaltes. O esmalte possibilitou suportar temperaturas elevadas sem o rompimento da isolação. Por este motivo, os motores passaram a ser projetados admitindo maiores perdas nos enrolamentos do estator devido ao aumento da temperatura nas bobinas. Foi possível atingir em alguns pontos do MITRGE, temperaturas de até $180{ }^{\circ} \mathrm{C}$, temperatura já padronizada nos anos 70, conforme Tabela 13. O algodão e a seda operavam apenas como isolante elétrico, já o esmalte utilizado, além de isolante elétrico, é condutor térmico, fator que possibilitou acomodar os enrolamentos em carcaças ainda menores sem danificar a isolação e melhorando a refrigeração distribuindo o calor gerado por toda a carcaça. Com o esmalte, a elevação de temperatura oriunda das perdas dos enrolamentos do estator é conduzida até a carcaça, conforme pode ser visualizado na Figura 46, que no referido período recebe o desenho das aletas, aumentando a área de contato com ar, melhorando assim o processo de dissipação de calor e mudando a geometria da carcaça dos motores elétricos.

Tabela 13 - Designação da classe térmica

\begin{tabular}{cc}
\hline Classe térmica $\left({ }^{\circ} \mathbf{C}\right)$ & Letra de Designação \\
\hline 90 & $\mathrm{Y}$ \\
105 & $\mathrm{~A}$ \\
120 & $\mathrm{E}$ \\
130 & $\mathrm{~B}$ \\
155 & $\mathrm{~F}$ \\
180 & $\mathrm{H}$ \\
200 & $\mathrm{~N}$ \\
220 & $\mathrm{R}$ \\
250 & - \\
\hline
\end{tabular}

Fonte: (ASSOCIAÇAO BRASILEIRA DE NORMAS TÉCNICAS, 2017; adaptação do autor). 
Figura 46 - Distribuição de temperatura pelo estator

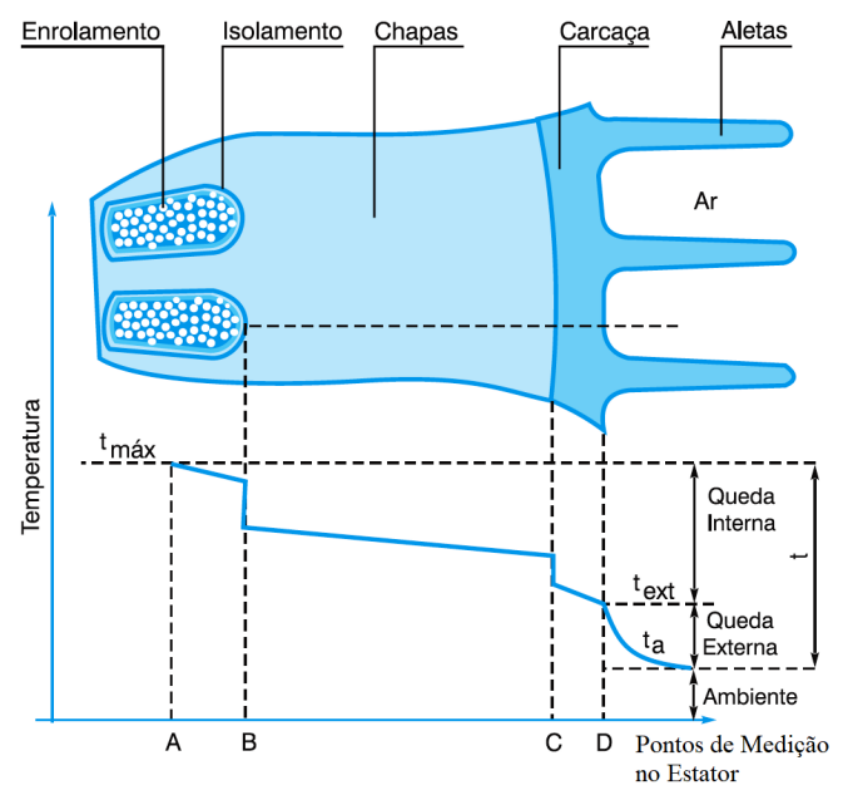

Fonte: (WEG, 2015; adaptação do autor).

h) A redução da massa de cobre fez com que os fabricantes de motores elétricos conseguissem reduzir o custo final do equipamento, pois o cobre é o metal base de maior custo utilizado na construção dos MITGRE. Este comportamento foi verificado nos relatórios de ensaios do referido período, onde se destaca principalmente o aumento das perdas joules ( $\left.\mathrm{I}^{2} \mathrm{R}\right)$ nos enrolamentos do estator, em relação às décadas anteriores. Com a redução da secção dos condutores, houve também a redução da massa total dos motores elétricos. A redução de cobre, além de elevar as perdas joule, também elevou significativamente a temperatura.

No terceiro momento descrito, entre os anos 80 até 2016, as melhorias no rendimento médio dos MITRGE se evidenciam principalmente pelas seguintes observações:

a) Foram aplicadas as políticas de nível mínimo de desempenho nas maiores economias do mundo na década de 90 e nos anos 2000. As legislações foram de modo geral, uma resposta para a pressão pela melhoria na qualidade dos motores, como também uma ação prática no sentido da redução da utilização de energia elétrica, atuando no uso final, pauta muito presente neste momento histórico;

b) Para atender as novas legislações, a principal intervenção verificada nos relatórios de ensaio do referido período foi a redução das perdas joule no estator, que passou a 
ser construído com mais massa de cobre em relação às décadas anteriores. Este movimento também fez com que a massa dos motores, até então somente decrescente com o tempo, passasse a aumentar, retornando aos patamares verificados nos anos 60;

c) Durante este período, foram observados outros elementos secundários que também influenciaram na melhoria do rendimento dos MITRGE:

- Melhorias no projeto dos MITRGE pela utilização de software de modelagem, possibilitando melhorias estruturais de acoplamento, reduzindo as vibrações e ruídos;

- Modelagem computacional em 3D dos campos eletromagnéticos, possibilitando a otimização dos projetos;

- Melhorias nos processos de fundição das chapas de aço-silício.

Os três momentos descritos proporcionaram profundas alterações na relação massa/potência dos MITRGE. Assim, a análise apresentada na Figura 19 (página 58), mostrando a relação massa/potência em queda e apontando para níveis menores nos anos seguintes necessitou ser atualizada, por este motivo foi construída a Figura 47.

Figura 47 - Evolução do motor trifásico na relação Massa/Potência entre 1891-2016

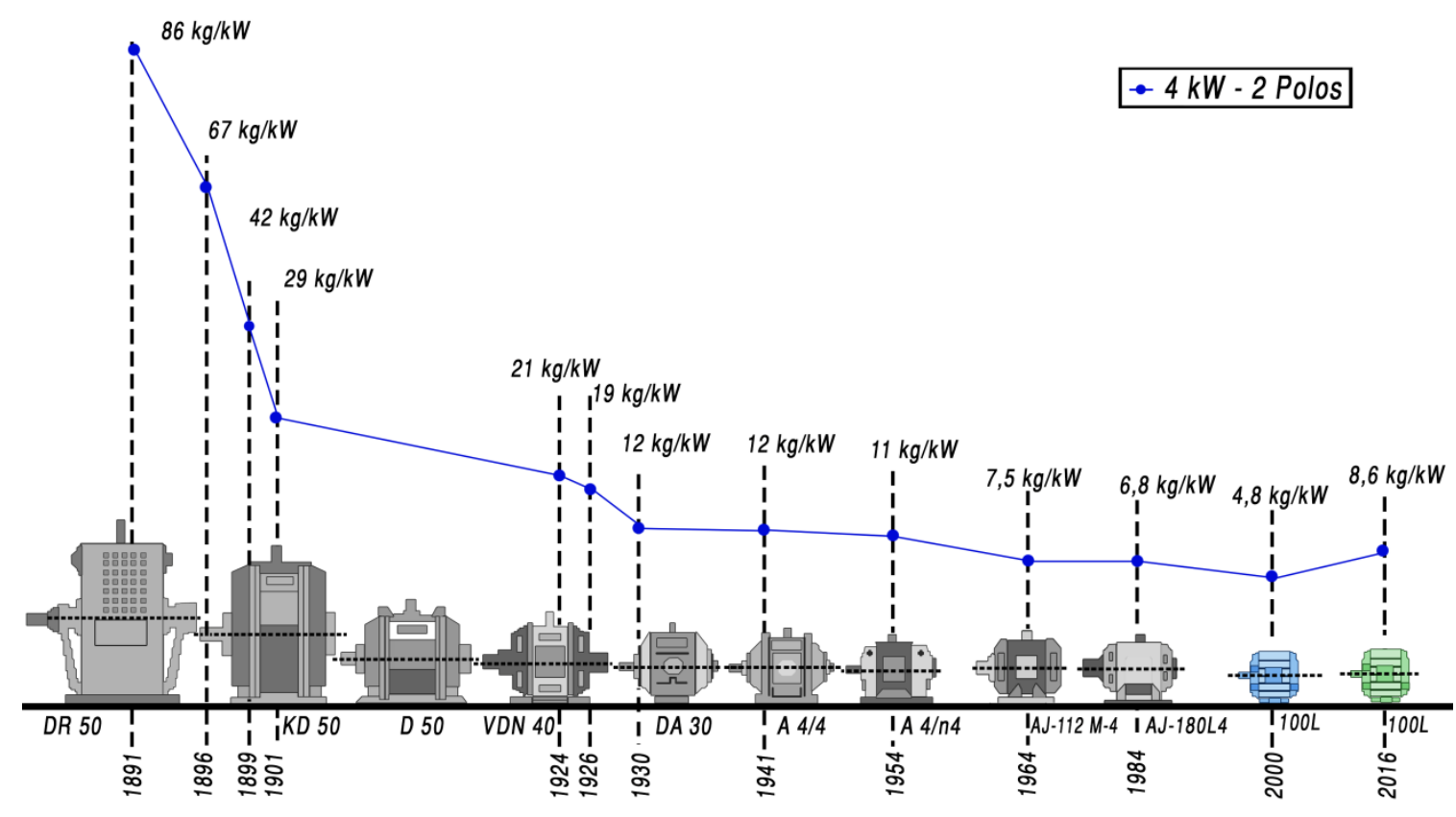

Fonte: Do autor. 
A pesquisa contou com dados de motores elétricos desde 1945 até 2016. Entretanto, dados de massa dos motores só estavam disponíveis nos relatórios técnicos a partir de 1997. Anterior a esta data, poucos relatórios apresentaram registro de massa do motor sob ensaio. Entre 1945 e 2016 foram encontrados registros de 7 motores com potência e velocidades, compatíveis com o Figura 19, possuindo registro de massa. A relação de massa/potência encontrada nesses 7 motores se apresentaram compatíveis com os dados publicados pela $A E G$. Assim, a Figura 19, contendo os resultados entre 1891 e 1984, pode ser atualizada com os dados obtidos nesta dissertação, conforme mostrado na Figura 47.

Para construir a Figura 47, foram utilizados no ano 2000, 9 motores com potências entre 5 e $6 \mathrm{CV}$ (aproximadamente 4kW), 2 polos e, em 2016, foram utilizados 21 motores na mesma faixa de potência e de mesma velocidade. Após calcular a relação massa/potência para cada motor, foi realizada a média aritmética para cada um dos dois anos em análise.

Um resultado importante, verificado na Figura 47, foi o aumento da massa dos motores a partir dos anos 2000, onde se atingiu o patamar de $8,6 \mathrm{~kg} / \mathrm{kW}$ para a referida potência de eixo e velocidade, voltando a patamares verificados entre anos 50 e 60 . O aumento de massa foi verificado principalmente pela utilização de condutores de maior secção, com o objetivo de reduzir as maiores perdas dos MITRGE, ou seja, as perdas por efeito Joule nos enrolamentos do estator.

A relação massa/potência é uma particularidade de cada faixa de potência, de maneira que, para este gráfico os valores não podem ser generalizados para outras potências, mas o formato da curva apresenta comportamento semelhante para outras faixas de potências. Esta discussão foi mais bem explorada no item 3.6.1.

Não existe previsão de tendência de aumento contínuo da relação massa/potência, pois muito foi otimizada nos últimos anos por meio de inovações tecnológicas. Destacando ainda que, para as melhorias de rendimento em acionamentos motrizes, a indústria de motores elétricos vem disponibilizando, com preços decrescentes, os motores síncronos de imã permanente para operação com velocidade variável por meio de conversor de frequência.

Os motores síncronos de imã permanente para a mesma faixa de potência e velocidade como apresentado na Figura 47, apresentam relação massa/potência de aproximadamente 4 $\mathrm{kg} / \mathrm{kW}$ com rendimento acima de $93 \%$ e fator de potência acima de 0,95 , podendo ser vistos como futuros substitutos dos MITRGE em aplicações onde seja vantajoso o controle de velocidade. 


\subsection{RENDIMENTO DOS MOTORES ELÉTRICOS DE INDUÇÃO TRIFÁSICOS}

Nos últimos dois anos (2015-2016) houve um número elevado de ensaios no Laboratório de Máquinas Elétricas, sendo possível considerar para esta etapa da pesquisa 435 motores elétricos, que permitiu uma significativa avaliação do impacto da legislação de desempenho com dados mais recentes disponíveis.

Antes de realizar a avaliação de impacto da legislação de desempenho, é importante analisar as possíveis discrepâncias entre os dados apresentados pelos fabricantes e as medições realizadas no referido laboratório. Para tal análise, foram separadas as duas principais grandezas que expressam o rendimento dos MITRGE: o fator de potência medido a plena carga e o rendimento a plena carga.

\subsubsection{Dados de placa VS valores medidos - uma análise do fator de potência}

O motor elétrico de indução, por ser uma carga com característica indutiva, apresenta fator de potência abaixo do unitário com corrente atrasada em relação à tensão. O quão baixo é o fator de potência do motor elétrico depende, principalmente, de uma série de grandezas:

1. Carga mecânica aplicada ao eixo;

2. Simetria das tensões;

3. Número de polos;

4. Potência mecânica nominal;

5. Qualidade do material ferromagnético.

Os itens 1 e 2 são grandezas controladas no laboratório de ensaio. Os itens 3 e 4 são características construtivas que dependem do projeto e da especificação do cliente. O item 5 depende dos custos finais desejados e do controle de qualidade do fabricante. Desta forma, o fator de potência de um motor elétrico é um elemento importante para o dimensionamento da instalação elétrica que alimenta o referido equipamento, bem como, quanto mais próximo de um (1) for o fator de potência, menor será a energia reativa capacitiva necessária para elevar o 
fator de potência. Consequentemente, os gastos com as instalações serão menores. Por este motivo, é importante saber o valor de fator de potência do MITRGE, devendo ser obrigatoriamente disponibilizado pelo fabricante em seu informativo técnico.

Este item apresenta a comparação entre o fator de potência medido e o informado pelo fabricante para 435 MITRGE, sendo:
a) 129 de 2 polos;
b) 227 de 4 polos;
c) 61 de 6 polos;
d) 18 de 8 polos.

A análise é realizada apenas para motores alimentados em baixa tensão na frequência industrial de $60 \mathrm{~Hz}$. Os motores foram divididos em 4 blocos de acordo com a velocidade determinada pelo número de polos.

A Figura 48 apresenta 129 resultados de ensaios de MITRGE, entre 1 e 200 CV, com 2 polos, testados entre 2015 e 2016. Os círculos em verde referem-se a resultados de medição de fator de potência, igual ou superior ao valor nominal disponibilizado pelo fabricante e representado na figura pela linha em vermelho. Os losangos azuis representam resultados de medições inferiores aos valores informados pelo fabricante. No eixo das ordenadas (y) é apresentada a magnitude do desvio absoluto ${ }^{11}$ entre os valores medidos e informados pelo fabricante e no eixo das abscissas (x) a potência nominal de eixo.

\footnotetext{
${ }^{11}$ Desvio absoluto é a diferença total entre o elemento em questão e um ponto dado, ou uma curva. A unidade deve ser necessariamente a mesma. Neste caso são unidades em bases de cem, ou seja, percentuais (\%).
} 
Figura 48 - Desvio absoluto de fator de potência para motores de 2 Polos

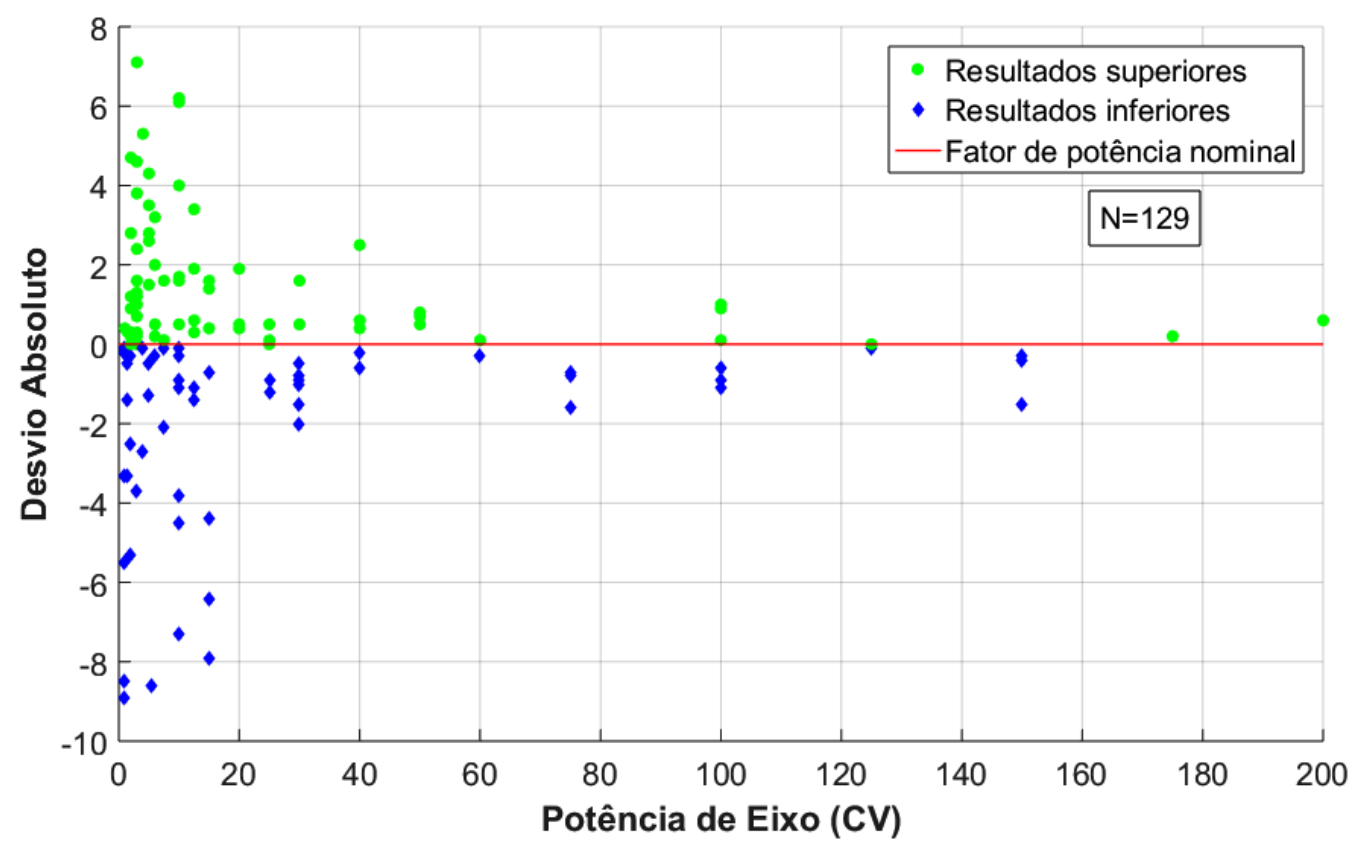

Fonte: Do autor.

A Tabela 14 apresenta a avaliação estatística das medições do fator de potência dos 129 resultados de ensaio em relação ao valor disponibilizado no informativo técnico. O percentual de resultados igual ou acima do registrado no informativo técnico do fabricante foi de $56,59 \%$, deixando desta forma, 43,41\% dos motores elétricos testados, com resultados de medições abaixo do valor apresentado pelo fabricante.

Tabela 14 - Avaliação estatística de fator de potência para motores de 2 Polos

\begin{tabular}{ccccccc}
\hline $\begin{array}{c}\text { Percentual acima } \\
\text { do nominal }\end{array}$ & $\begin{array}{c}\text { Percentual abaixo } \\
\text { do nominal }\end{array}$ & $\begin{array}{c}\text { Desvio } \\
\text { máximo } \\
\text { positivo }\end{array}$ & $\begin{array}{c}\text { Desvio } \\
\text { máximo } \\
\text { negativo }\end{array}$ & $\begin{array}{c}\text { Desvio } \\
\text { médio }\end{array}$ & $\begin{array}{c}\text { Mediana } \\
\text { pesvio } \\
\text { padrão }\end{array}$ \\
\hline $56,59 \%$ & $43,41 \%$ & $7,1 \%$ & $-8,9 \%$ & $-0,073 \%$ & $0,1 \%$ & $2,71 \%$ \\
\hline
\end{tabular}

Fonte: Do autor.

O "Desvio máximo positivo e Desvio máximo negativo" na Tabela 14 apresentam o desvio pontual unitário do resultado de ensaio que mais apresentou discrepância absoluta em relação ao valor nominal disponibilizado pelo fabricante. Neste caso, o Desvio máximo positivo de $7,1 \%$ e negativo de $-8,9 \%$ mostram que existem significativas diferenças entre os valores informados e os resultados das medições. Conforme visualizado na Figura 48, os 
resultados apresentam maior desvio absoluto são os de menor potência de eixo. Este resultado é esperado, pois os motores de menor potência sofrem menores exigências dos processos de qualidades internos às empresas. Também é observado que os motores elétricos de menor potência de eixo possuem maior representação percentual no total de motores ensaiados, assim como é observado numericamente nas plantas industriais.

O Desvio médio, expresso na Tabela 14, trata da distância média entre os resultados dos ensaios e a média aritmética dos dados. Quanto maior for à dispersão dos dados, maior será o desvio médio. E como pode ser observado, - $-0,073 \%$ de desvio médio é um valor baixo, indicando uma distribuição pouco dispersa.

Na Tabela 14, a Mediana é o valor que separa a metade dos motores elétricos que apresentaram no ensaio o rendimento superior ao informado e a metade menor do total das amostras. No caso da Tabela 14 , a mediana positiva de $(0,1 \%)$ mostra que a distribuição dos motores elétricos se encontra equilibrada entre os que possuem resultados de medições superiores aos informados e os que possuem resultados inferiores.

O Desvio padrão expresso na Tabela 14 é uma grandeza de dispersão dos valores de fator de potência medidos em torno dos valores informados pelo fabricante nos informativos técnicos. Quanto menor o desvio padrão, significa que mais próximos os valores medidos estão dos valores informados e, quanto maior, ocorre o contrário.

Estão apresentadas da Figura 49 até a Figura 51 o Desvio Absoluto do fator de potência medido em relação ao informado pelo fabricante, para motores com velocidades de 4, 6 e 8 polos respectivamente. Assim como da Tabela 15 até a Tabela 17 é apresentado a análise estatística para as referidas velocidades.

A Figura 49 apresenta o Desvio Absoluto do fator de potência para 227 motores de 4 polos analisados. A referida análise apresenta maior quantidade de motores elétricos, como também, maior escala de potência de eixo com motores até $250 \mathrm{CV}$. 
Figura 49 - Desvio absoluto de fator de potência para motores de 4 Polos

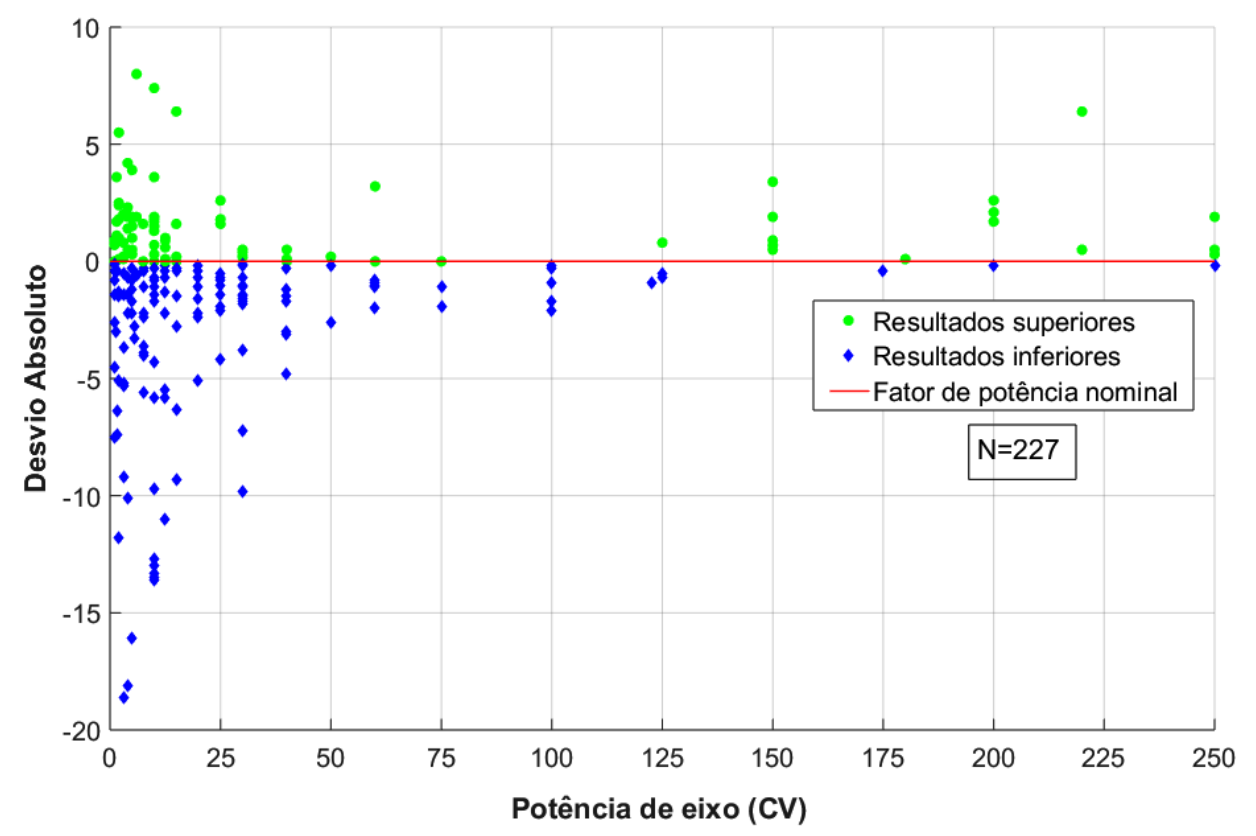

Fonte: Do autor.

A Tabela 15 apresenta percentual de resultados igual ou acima do registrado no informativo técnico do fabricante em 39,21\% do total de motores. Em 60,79\% dos motores ensaiados foram obtidos resultados abaixo do valor apresentado pelo fabricante, demonstrando, portanto, que uma significativa maioria dos resultados encontrados está abaixo dos valores nominais.

Tabela 15 - Avaliação estatística de fator de potência para motores de 4 Polos

\begin{tabular}{ccccccc}
\hline $\begin{array}{c}\text { Percentual acima } \\
\text { do nominal }\end{array}$ & $\begin{array}{c}\text { Percentual abaixo } \\
\text { do nominal }\end{array}$ & $\begin{array}{c}\text { Desvio } \\
\text { máximo } \\
\text { positivo }\end{array}$ & $\begin{array}{c}\text { Desvio máximo } \\
\text { negativo }\end{array}$ & $\begin{array}{c}\text { Desvio } \\
\text { médio }\end{array}$ & Mediana & $\begin{array}{c}\text { Desvio } \\
\text { padrão }\end{array}$ \\
\hline $39,21 \%$ & $60,79 \%$ & $8 \%$ & $-18,6 \%$ & $-1,28 \%$ & $-0,5 \%$ & $3,9 \%$ \\
\hline
\end{tabular}

Fonte: Do autor.

O Desvio máximo negativo visualizado na Tabela 15 foi de um motor elétrico ensaiado, cujo resultado foi 18,6\% abaixo do valor informado pelo fabricante, o que demonstra elevada dispersão entre valores medidos e valores informados.

A Figura 50 apresenta o Desvio absoluto do fator de potência para 61 motores de 6 polos analisados. A referida análise apresenta escala de potência de eixo, com potências de até $180 \mathrm{CV}$. 
Figura 50 - Desvio absoluto de fator de potência para motores de 6 Polos

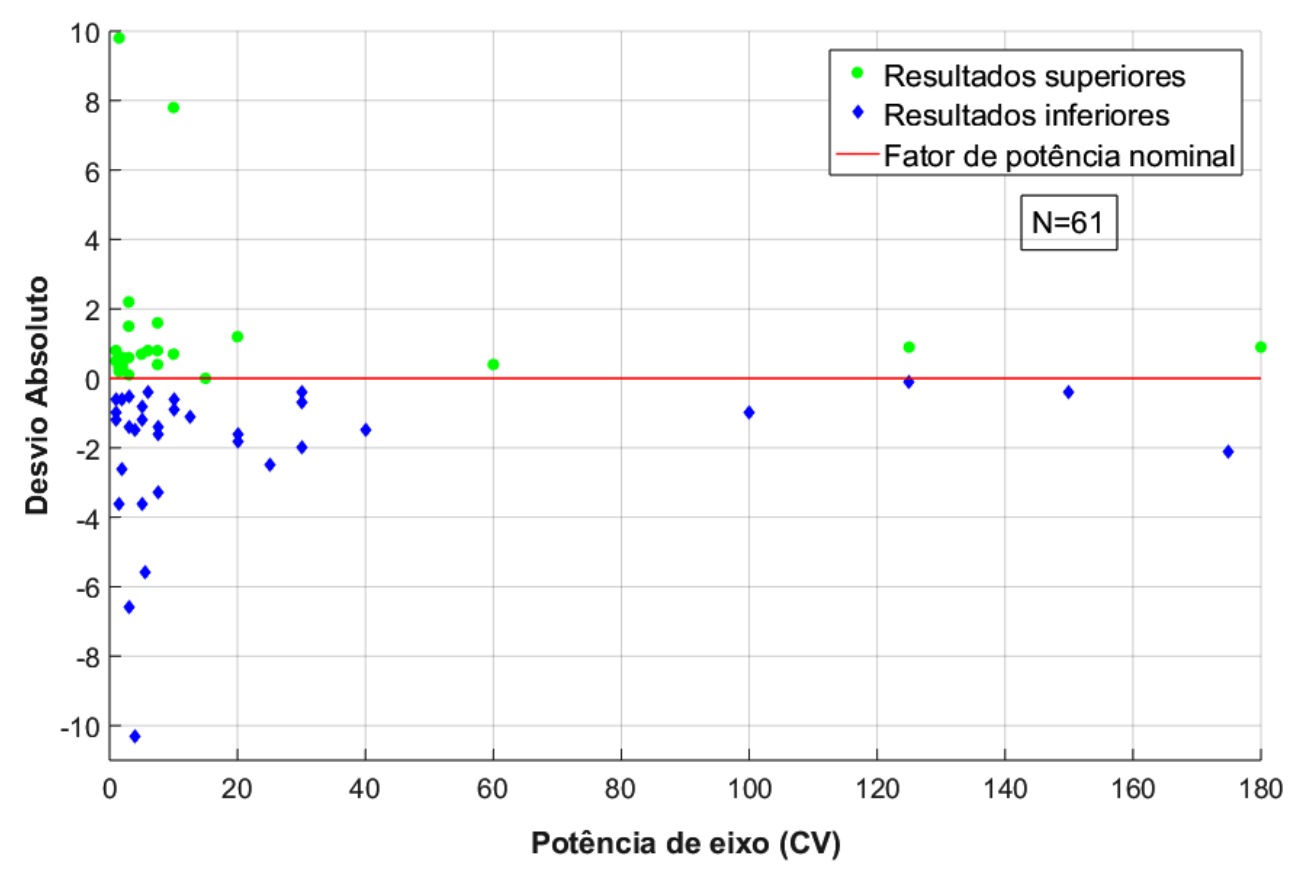

Fonte: Do autor.

A Tabela 16 apresenta o percentual de resultados igual ou acima do registrado no informativo técnico do fabricante, totalizando $40,98 \%$ dos motores com rendimento acima e $59,02 \%$ dos MITRGE com rendimento medido abaixo do valor apresentado pelo fabricante. Os desvios máximos positivos e negativos apresentaram resultados iguais a 9,8\% e -10,3\%, respectivamente.

Tabela 16 - Avaliação estatística de fator de potência para motores de 6 Polos

\begin{tabular}{ccccccc}
\hline $\begin{array}{c}\text { Percentual acima } \\
\text { do nominal }\end{array}$ & $\begin{array}{c}\text { Percentual abaixo } \\
\text { do nominal }\end{array}$ & $\begin{array}{c}\text { Desvio } \\
\text { máximo } \\
\text { positivo }\end{array}$ & $\begin{array}{c}\text { Desvio } \\
\text { máximo } \\
\text { negativo }\end{array}$ & $\begin{array}{c}\text { Desvio } \\
\text { médio }\end{array}$ & Mediana & $\begin{array}{c}\text { Desvio } \\
\text { padrão }\end{array}$ \\
\hline $40,98 \%$ & $59,02 \%$ & $9,8 \%$ & $-10,3 \%$ & $-0,613 \%$ & $-0,6 \%$ & $2,7 \%$ \\
\hline
\end{tabular}

Fonte: Do autor.

A Figura 51 apresenta o Desvio absoluto do fator de potência para 18 motores de 8 polos. A referida análise apresenta escala de potência de eixo com motores até $40 \mathrm{CV}$. 
Figura 51 - Desvio absoluto de fator de potência para motores de 8 Polos

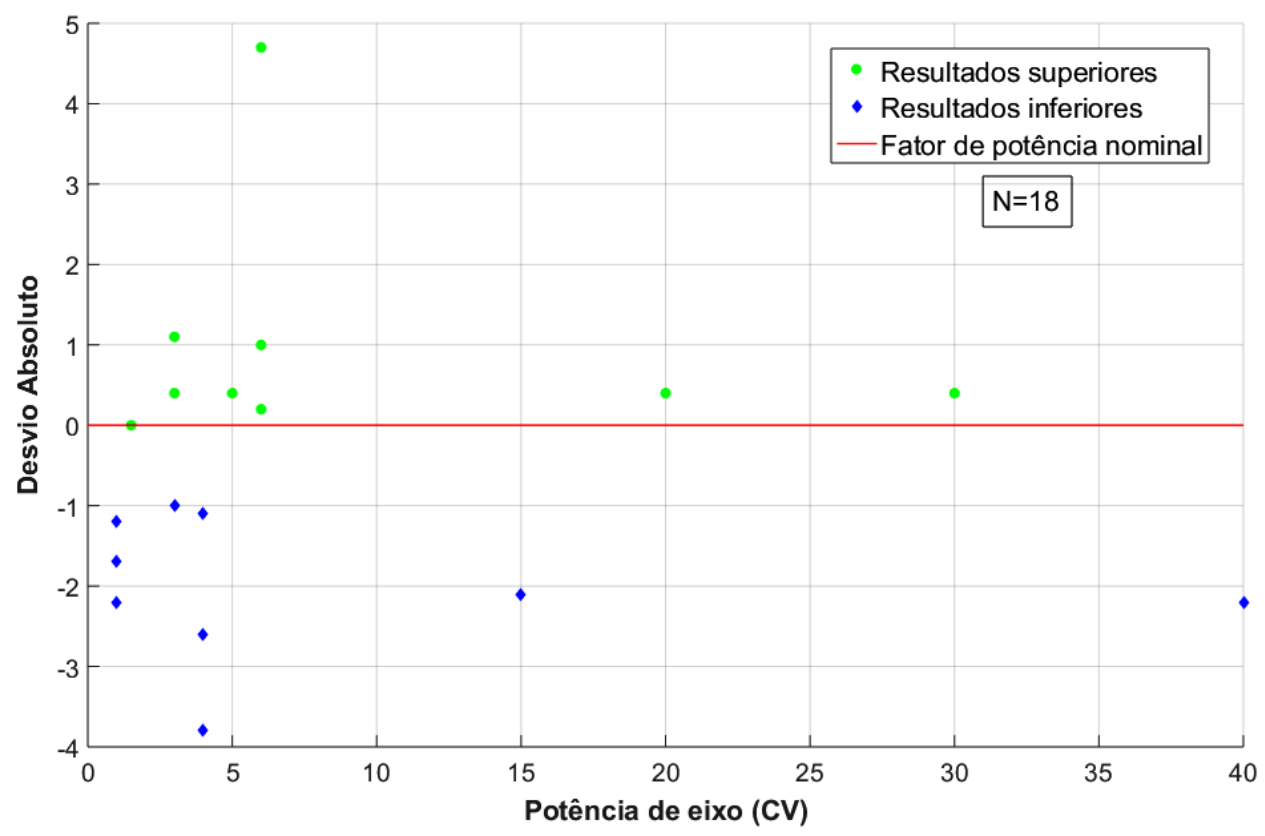

Fonte: Do autor.

Conforme a Tabela 17, os motores elétricos ensaiados apresentaram resultados iguais no que se refere ao Percentual acima do nominal e abaixo.

Tabela 17 - Avaliação estatística de fator de potência para motores de 8 Polos

\begin{tabular}{ccccccc}
\hline $\begin{array}{c}\text { Percentual acima } \\
\text { do nominal }\end{array}$ & $\begin{array}{c}\text { Percentual abaixo } \\
\text { do nominal }\end{array}$ & $\begin{array}{c}\text { Desvio } \\
\text { máximo } \\
\text { positivo }\end{array}$ & $\begin{array}{c}\text { Desvio } \\
\text { máximo } \\
\text { negativo }\end{array}$ & $\begin{array}{c}\text { Desvio } \\
\text { médio }\end{array}$ & Mediana & $\begin{array}{c}\text { Desvio } \\
\text { padrão }\end{array}$ \\
\hline $50 \%$ & $50 \%$ & $4,7 \%$ & $-3,8 \%$ & $-0,5167 \%$ & $-0,5 \%$ & $1,91 \%$ \\
\hline
\end{tabular}

Fonte: Do autor.

Uma análise geral dos resultados da comparação entre valores de fator de potência medidos e os valores informados é apresentada na Tabela 18, onde é possível observar que $55 \%$ dos motores utilizados apresentaram fator de potência medido abaixo do valor informado pelo fabricante. 
Tabela 18 - Comparação geral do fator de potência entre os valores medidos e valores informados

\begin{tabular}{cccccc}
\hline & 2 Polos & 4 Polos & 6 Polos & 8 Polos & Total \\
\hline Medições abaixo do nominal & 56 & 138 & 36 & 9 & $55 \%$ \\
Medições iguais ou acima do nominal & 73 & 89 & 25 & 9 & $45 \%$ \\
\hline
\end{tabular}

Fonte: Do autor.

A determinação da tolerância é estabelecida pela Portaria n ${ }^{\circ} 243$ do INMETRO. Para o fator de potência é calculada conforme Equação (4):

$$
\text { Tolerância }=-(1 / 6) \cdot(1-\cos \emptyset)
$$

Sendo que os valores para a tolerância calculada devem estar compreendidos entre os limites abaixo:

limite inferior $=0,02$

limite superior $=0,07$

Exemplo: sendo 0,92 o fator de potência declarado de um determinado motor:

$-1 / 6 \times(1-0,92)=0,013$. Neste caso, o valor a ser adotado é 0,02 .

Então: $0,92-0,02=0,90$. Então 0,90 é o valor de fator de potência mínimo que o motor pode apresentar como resultado de ensaio.

Neste caso, o limite é apenas inferior, de maneira que, aplicando a referida equação do total de 435 motores elétricos analisados, 58 motores se encontraram fora da tolerância calculada, sendo, portanto, considerados reprovados no referido quesito. Entretanto, a referida legislação apesar de existir não vem sendo aplicada, e mesmo que os motores sejam reprovados, eles podem ser comercializados.

A seguir é apresentada a análise comparativa entre o rendimento medido e o rendimento informado pelo fabricante para os mesmos 435 MITRGE utilizados para a análise anterior. 


\subsubsection{Dados de placa VS valores medidos - uma análise do rendimento}

A Figura 52 apresenta 129 MITRGE entre 1 a 200 CV, 2 polos, ensaiados entre 2015 e 2016. Os círculos em verde referem-se a resultados de medição de rendimento, igual ou superior ao valor de rendimento nominal disponibilizado pelo fabricante e representado na figura pela linha em vermelho. Os losangos azuis representam resultados de medições inferiores aos valores informados pelo fabricante. No eixo das ordenadas (y) é apresentada a magnitude do desvio absoluto entre os valores medidos e informados e no eixo das abscissas (x) a potência nominal de eixo.

Figura 52 - Desvio absoluto de rendimento para motores de 2 Polos

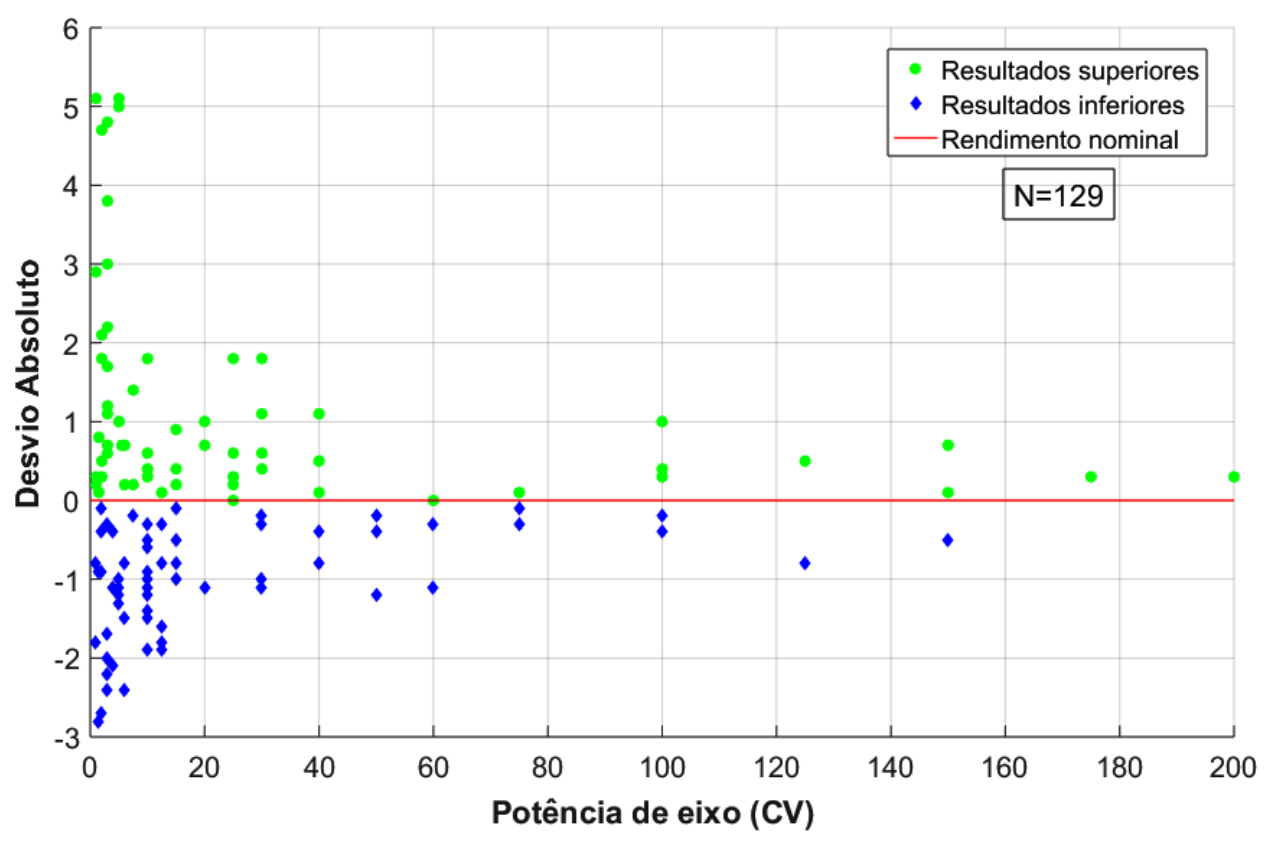

Fonte: Do autor.

Conforme Tabela 19, os motores elétricos ensaiados apresentaram resultados próximos no que se refere ao Percentual acima do nominal e abaixo. Os valores de Desvio máximo positivo e negativo foram iguais a $5,1 \%$ e $-2,8 \%$, respectivamente. O Desvio médio resultou em $0,028 \%$. 
Tabela 19 - Avaliação estatística de rendimento para motores de 2 Polos

\begin{tabular}{ccccccc}
\hline $\begin{array}{c}\text { Percentual acima } \\
\text { do nominal }\end{array}$ & $\begin{array}{c}\text { Percentual abaixo } \\
\text { do nominal }\end{array}$ & $\begin{array}{c}\text { Desvio } \\
\text { máximo } \\
\text { positivo }\end{array}$ & $\begin{array}{c}\text { Desvio } \\
\text { máximo } \\
\text { negativo }\end{array}$ & $\begin{array}{c}\text { Desvio } \\
\text { médio }\end{array}$ & Mediana & $\begin{array}{c}\text { Desvio } \\
\text { padrão }\end{array}$ \\
\hline $48,06 \%$ & $51,94 \%$ & $5,1 \%$ & $-2,8 \%$ & $0,028 \%$ & $-0,1 \%$ & $1,52 \%$ \\
\hline
\end{tabular}

Fonte: Do autor.

A Figura 53 apresenta o Desvio Absoluto do rendimento para 227 motores de 4 polos. A referida análise apresenta maior quantidade de motores elétricos, como também, maior escala de potência de eixo, com potências até $250 \mathrm{CV}$.

Figura 53 - Desvio absoluto de rendimento para motores de 4 Polos

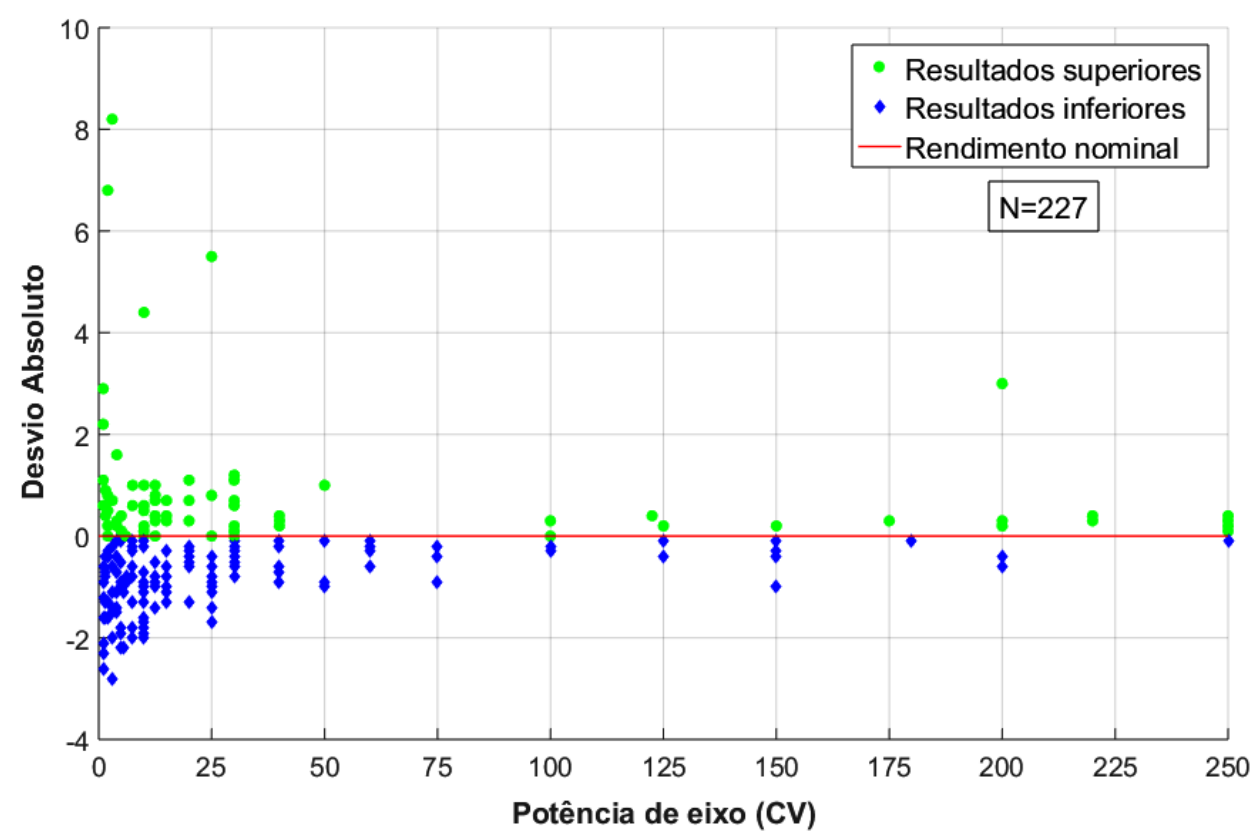

Fonte: Do autor.

A Tabela 20 apresenta percentual de resultados igual ou acima do registrado no informativo técnico do fabricante em 35,24\%, do total de MITRGE. Em 64,76\% dos MITRGE ensaiados com resultados abaixo do valor apresentado pelo fabricante. 
Tabela 20 - Avaliação estatística de rendimento para motores de 4 Polos

\begin{tabular}{ccccccc}
\hline $\begin{array}{c}\text { Percentual acima } \\
\text { do nominal }\end{array}$ & $\begin{array}{c}\text { Percentual abaixo } \\
\text { do nominal }\end{array}$ & $\begin{array}{c}\text { Desvio } \\
\text { máximo } \\
\text { positivo }\end{array}$ & $\begin{array}{c}\text { Desvio máximo } \\
\text { negativo }\end{array}$ & $\begin{array}{c}\text { Desvio } \\
\text { médio }\end{array}$ & Mediana & $\begin{array}{c}\text { Desvio } \\
\text { padrão }\end{array}$ \\
\hline $35,24 \%$ & $64,76 \%$ & $8,2 \%$ & $-2,8 \%$ & $-0,26 \%$ & $-0,3 \%$ & $1,25 \%$ \\
\hline
\end{tabular}

Fonte: Do autor.

A Figura 54 apresenta o Desvio Absoluto do rendimento para 61 motores de 6 polos. A referida análise apresenta potência de eixo até $180 \mathrm{CV}$.

Figura 54 - Desvio absoluto de rendimento para motores de 6 Polos

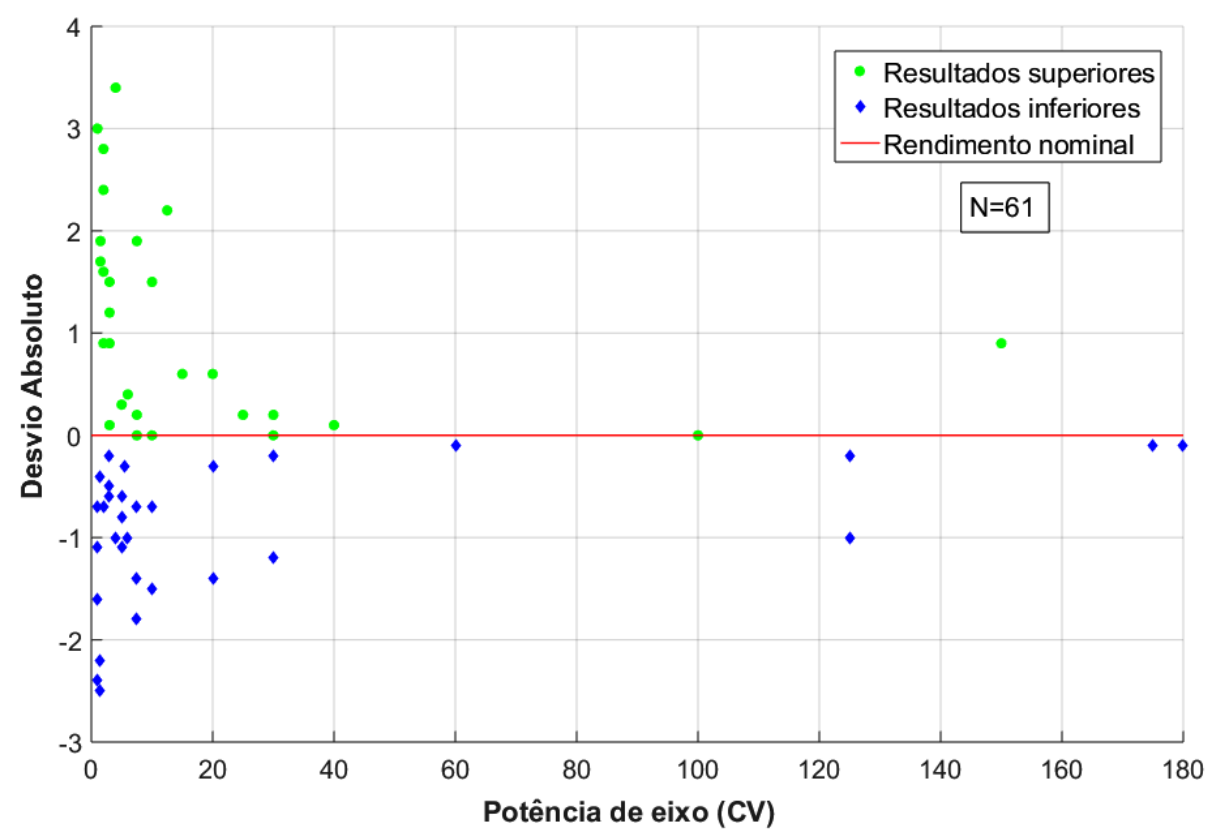

Fonte: Do autor.

Conforme Tabela 21, os motores elétricos ensaiados apresentaram resultados próximos no que se refere ao Percentual acima do nominal e abaixo. Houve baixa discrepância no valor do Desvio máximo positivo em $3,4 \%$ e negativo em $-2,5 \%$. 
Tabela 21 - Avaliação estatística de rendimento para motores de 6 Polos

\begin{tabular}{ccccccc}
\hline $\begin{array}{c}\text { Percentual acima } \\
\text { do nominal }\end{array}$ & $\begin{array}{c}\text { Percentual abaixo } \\
\text { do nominal }\end{array}$ & $\begin{array}{c}\text { Desvio } \\
\text { máximo } \\
\text { positivo }\end{array}$ & $\begin{array}{c}\text { Desvio } \\
\text { máximo } \\
\text { negativo }\end{array}$ & $\begin{array}{c}\text { Desvio } \\
\text { médio }\end{array}$ & Mediana & $\begin{array}{c}\text { Desvio } \\
\text { padrão }\end{array}$ \\
\hline $49,18 \%$ & $50,52 \%$ & $3,4 \%$ & $-2,5 \%$ & $0,044 \%$ & $-0,1 \%$ & $1,3 \%$ \\
\hline
\end{tabular}

Fonte: Do autor.

A Figura 55 apresenta o Desvio absoluto do rendimento para 18 motores de 8 polos. A referida análise apresenta escala de potência de eixo com potências até $40 \mathrm{CV}$.

Figura 55 - Desvio absoluto de rendimento para motores de 8 Polos

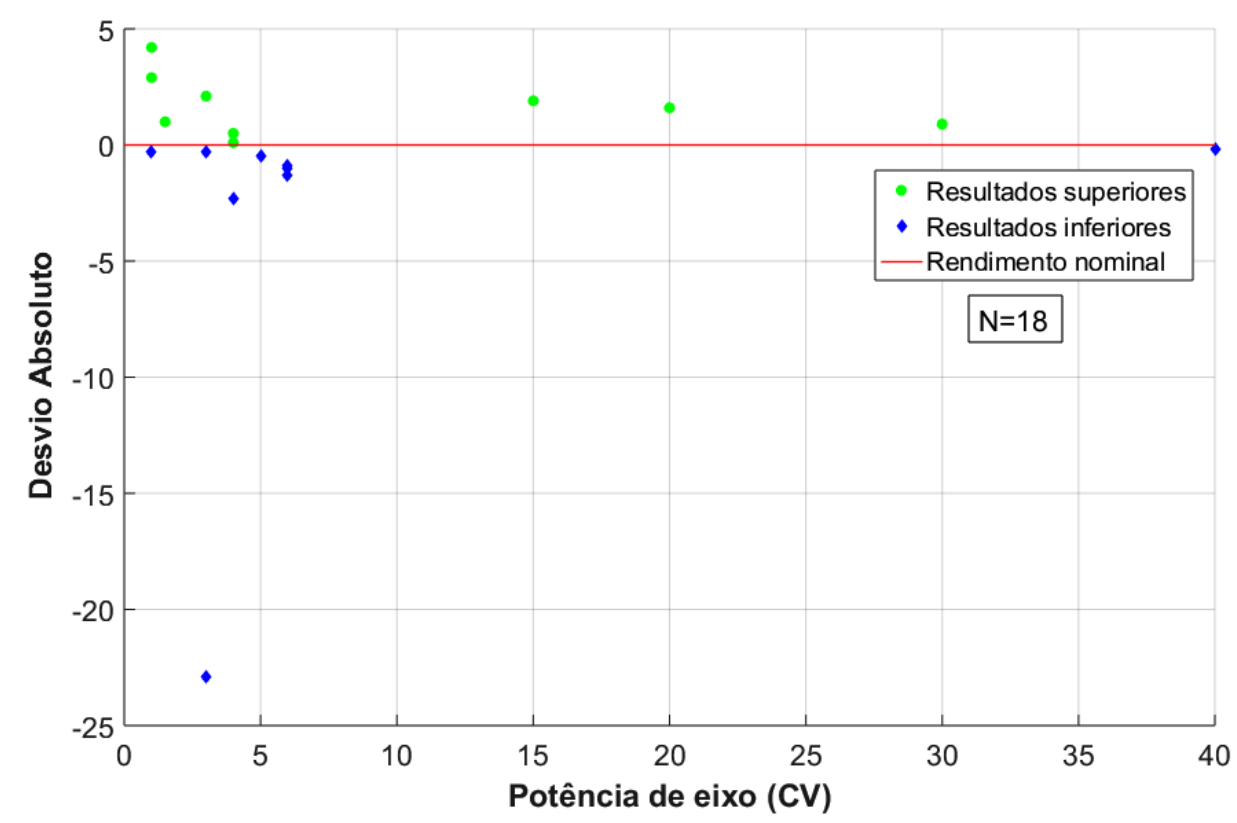

Fonte: Do autor.

Conforme Tabela 22, os motores elétricos ensaiados apresentaram resultados iguais no que se refere ao Percentual acima do nominal e abaixo. Houve grande discrepância no valor do Desvio máximo negativo, obtendo-se o valor $22,9 \%$ abaixo do valor informado pelo fabricante no informativo técnico. 
Tabela 22 - Avaliação estatística de rendimento para motores de 8 Polos

\begin{tabular}{ccccccc}
\hline $\begin{array}{c}\text { Percentual acima } \\
\text { do nominal }\end{array}$ & $\begin{array}{c}\text { Percentual abaixo } \\
\text { do nominal }\end{array}$ & $\begin{array}{c}\text { Desvio } \\
\text { máximo } \\
\text { positivo }\end{array}$ & $\begin{array}{c}\text { Desvio máximo } \\
\text { negativo }\end{array}$ & $\begin{array}{c}\text { Desvio } \\
\text { médio }\end{array}$ & Mediana & $\begin{array}{c}\text { Desvio } \\
\text { padrão }\end{array}$ \\
\hline $50 \%$ & $50 \%$ & $4,2 \%$ & $-22,9 \%$ & $-0,81 \%$ & $-0,05 \%$ & $5,74 \%$ \\
\hline
\end{tabular}

Fonte: Do autor.

Uma análise geral dos resultados da comparação entre valores de rendimento medidos e informados é apresentado na Tabela 23, onde é possível observar que 58\% dos motores utilizados apresentam rendimento medido abaixo do valor informado pelo fabricante.

Tabela 23 - Comparação geral do rendimento entre os valores medidos e valores informados

\begin{tabular}{cccccc}
\hline & 2 Polos & 4 Polos & 6 Polos & 8 Polos & Total \\
\hline Medições abaixo do nominal & 67 & 147 & 31 & 9 & $58 \%$ \\
Medições iguais ou acima do nominal & 62 & 80 & 30 & 9 & $42 \%$ \\
\hline
\end{tabular}

Fonte: Do autor.

Diferentemente do que ocorre com o fator de potência, o rendimento tem um valor mínimo determinado em legislação e o informativo técnico do fabricante deve apresentar um valor igual ou superior ao da legislação mínima de desempenho de MITRGE de acordo com a Portaria n ${ }^{\circ} 488$ do INMETRO.

Para a determinação do rendimento do MITRGE no ensaio de desempenho, é estabelecida uma margem de tolerância para a aprovação ou não do referido motor elétrico sob teste. A determinação da tolerância também é estabelecida pela Portaria $\mathrm{n}^{\circ} 488$ do INMETRO.

Para o rendimento $(\eta)$, a tolerância é definida pelo Índice de Afastamento de Resultado - IAR. Este índice é calculado por duas diferentes equações que dependem do rendimento declarado pelo fabricante. O IAR é calculado conforme as Equações (5) e (6): 


$$
\begin{array}{ll}
\text { Se }(\eta) \geq 0,851 & \text { IAR }=\left(\frac{(\text { valor declarado }- \text { valor obtido })}{0,20 \cdot(1-\text { valor declarado })}\right) \cdot 100 \\
\text { Se }(\eta)<0,851 & \text { IAR }=\left(\frac{(\text { valor declarado }- \text { valor obtido })}{0,15 .(1-\text { valor declarado })}\right) \cdot 100
\end{array}
$$

O valor obtido $(\mathrm{pu})$ é o encontrado durante a realização do ensaio de desempenho e o valor declarado (pu) é o informado pelo fabricante/importador do motor.

O motor é considerado aprovado no ensaio de desempenho quando o IAR não ultrapassar $+100 \%$ ou $-100 \%$ (cem por cento), para cada MITRGE.

Desta forma, do total de 435 motores elétricos analisados, 22 se encontraram fora do espectro de tolerância, sendo, 21 com rendimentos abaixo do permitido e 1 com rendimento acima do permitido, portanto reprovados no quesito rendimento.

\subsubsection{O rendimento e normativa nacional}

Um dos objetivos centrais deste trabalho é analisar o impacto da legislação brasileira de desempenho dos MITRGE disponíveis no mercado brasileiro. Neste sentido, este item apresenta o rendimento de 435 motores elétricos (os mesmos trabalhados no item - "Dados de placa VS valores medidos") ensaiados em 2015 e 2016, comparados à primeira legislação de desempenho (Decreto $n^{\circ} 4.508 / 2002$ ), à legislação atual (Portaria $n^{\circ} 553 / 2005$ ) e à legislação que entrará em vigor nos próximos anos (Portaria nº 1/2017).

Estão apresentadas, desde a Figura 56 até a Figura 60, as três legislações de desempenho para as quatro diferentes velocidades regulamentadas. A curva em vermelho, marcando a cota de rendimento mais elevado, se refere à Portaria $n^{\circ}$ 1/2017. A linha intermediária em verde se refere à Portaria $n^{\circ} 553 / 2005$, como também a cota de alto rendimento do Decreto $\mathrm{n}^{\circ} 4.508 / 2002$. A curva em azul se refere à linha standard do Decreto $\mathrm{n}^{\mathrm{o}} 4.508 / 2002$.

A Figura 56 apresenta 129 MITRGE entre 1 a $200 \mathrm{CV}$ de 2 polos. Os resultados dos motores elétricos são representados pelos círculos amarelos. No eixo das ordenadas (y) é 
apresentado o rendimento ou a eficiência e no eixo das abscissas (x) a potência nominal de eixo.

Figura 56 - Comparação da normativa brasileira com resultados dos ensaios - 2 polos

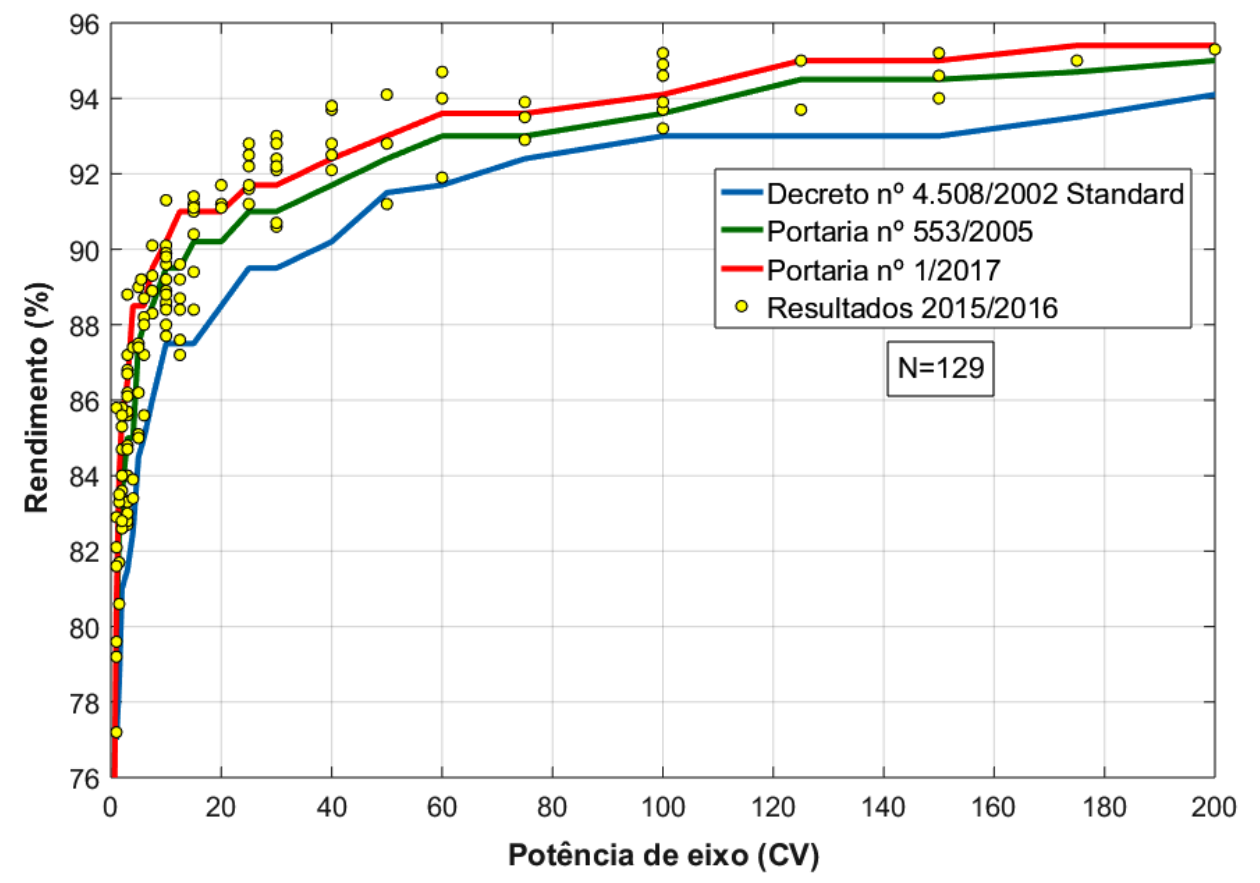

Fonte: Do autor.

A Figura 57 apresenta os resultados do ensaio em 227 motores de 4 polos posicionados em relação a legislação brasileira de desempenho. A referida análise apresenta maior quantidade de motores elétricos, como também, maior escala de potência de eixo, com potências até $250 \mathrm{CV}$. 
Figura 57 - Comparação da normativa brasileira com resultados dos ensaios - 4 polos

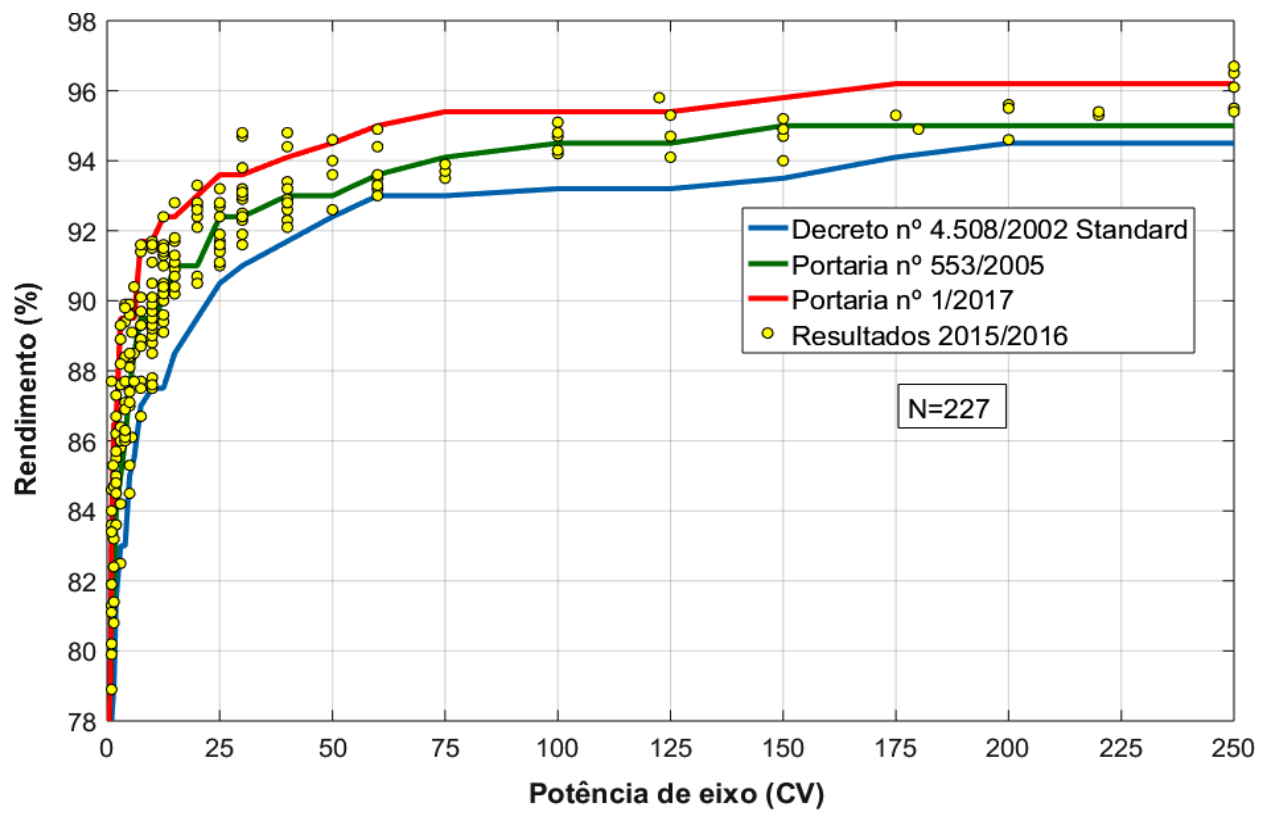

Fonte: Do autor.

A Figura 58 apresenta um detalhamento da Figura 57, porém com 183 resultados de ensaio de motores elétricos de 4 polos em escala com potência até $40 \mathrm{CV}$.

Figura 58 - Comparação da normativa brasileira com resultados dos ensaios - 4 polos (até 40 CV)

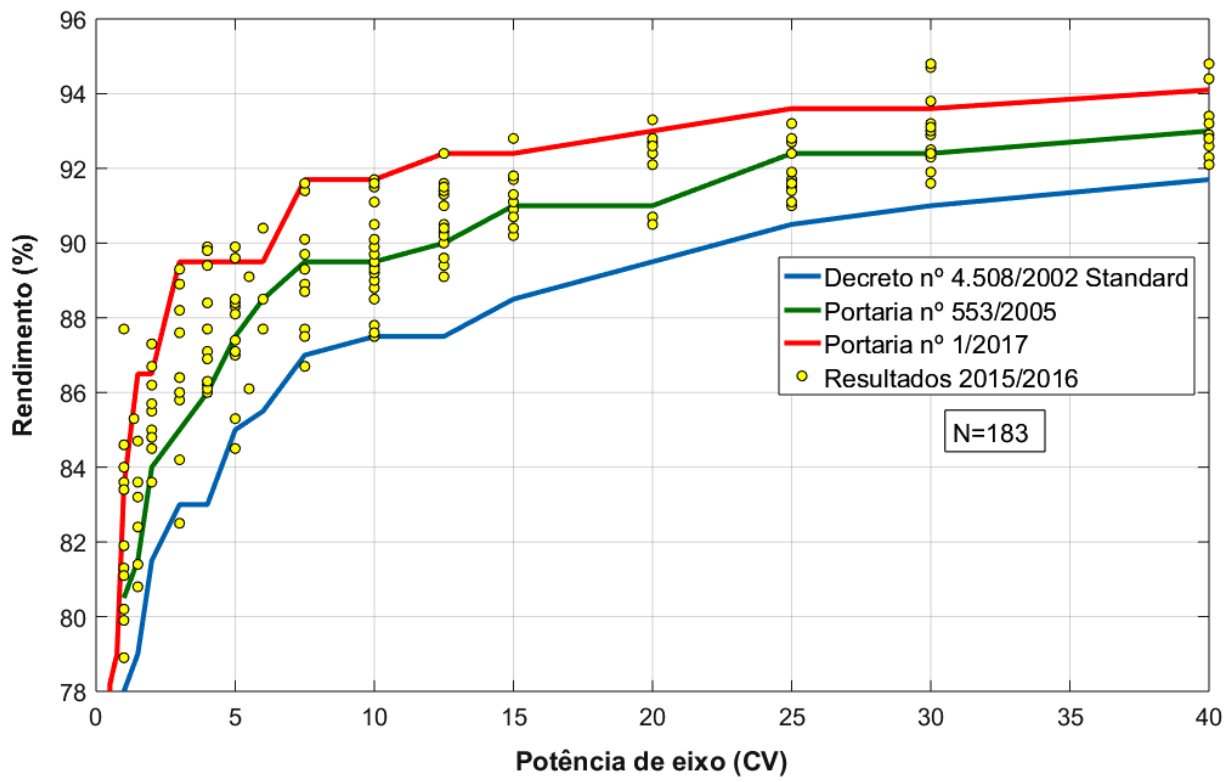

Fonte: Do autor. 
A Figura 59 apresenta o resultado do ensaio em 61 motores de 6 polos. A referida análise apresenta escala de potência de eixo com potências até $180 \mathrm{CV}$.

Figura 59 - Comparação da normativa brasileira com resultados dos ensaios - 6 polos

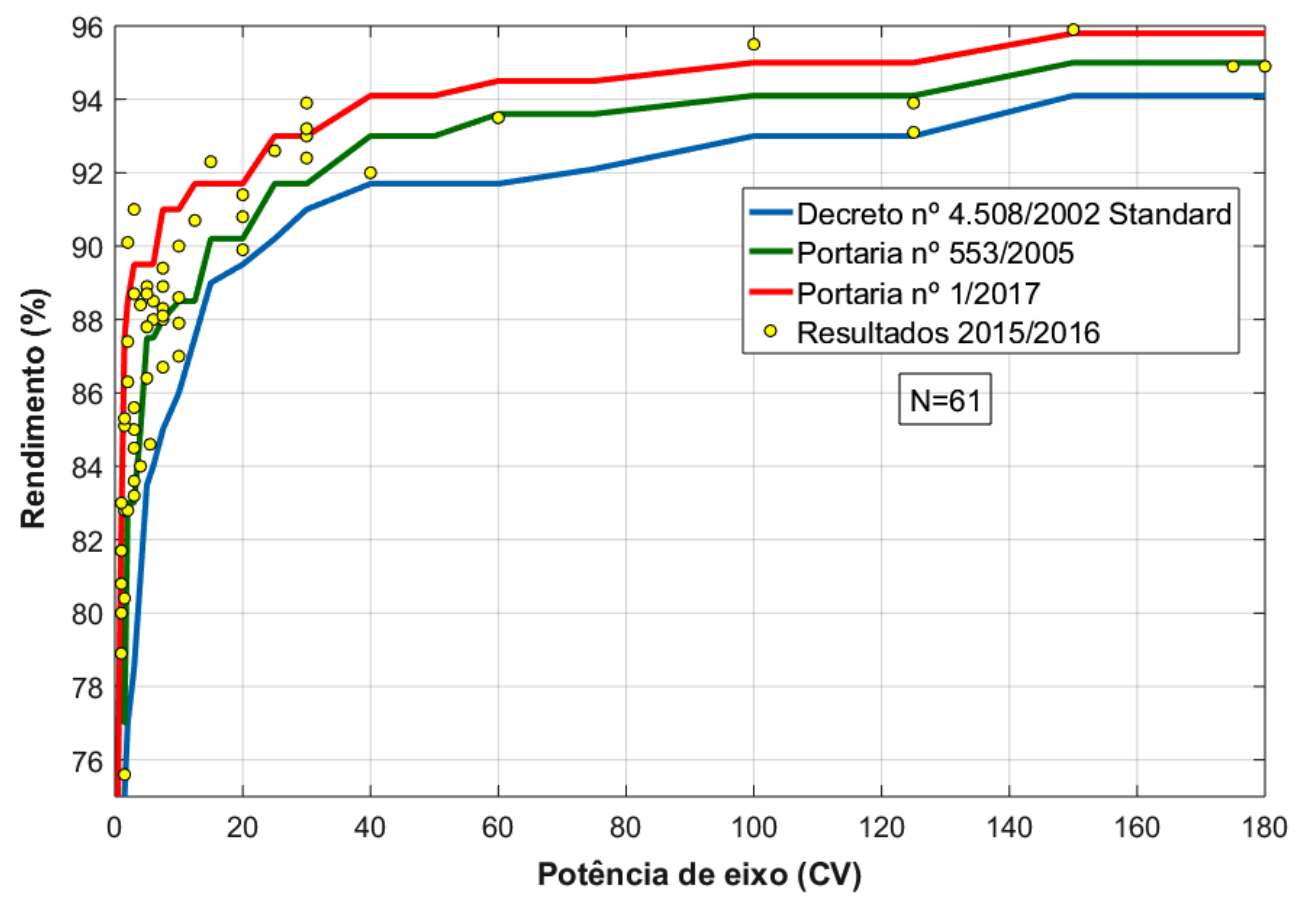

Fonte: Do autor.

A Figura 60 apresenta o resultado do ensaio em 18 motores de 8 polos. A referida análise apresenta escala de potência de eixo com potências até $40 \mathrm{CV}$. 
Figura 60 - Comparação da normativa brasileira com resultados dos ensaios - 8 polos

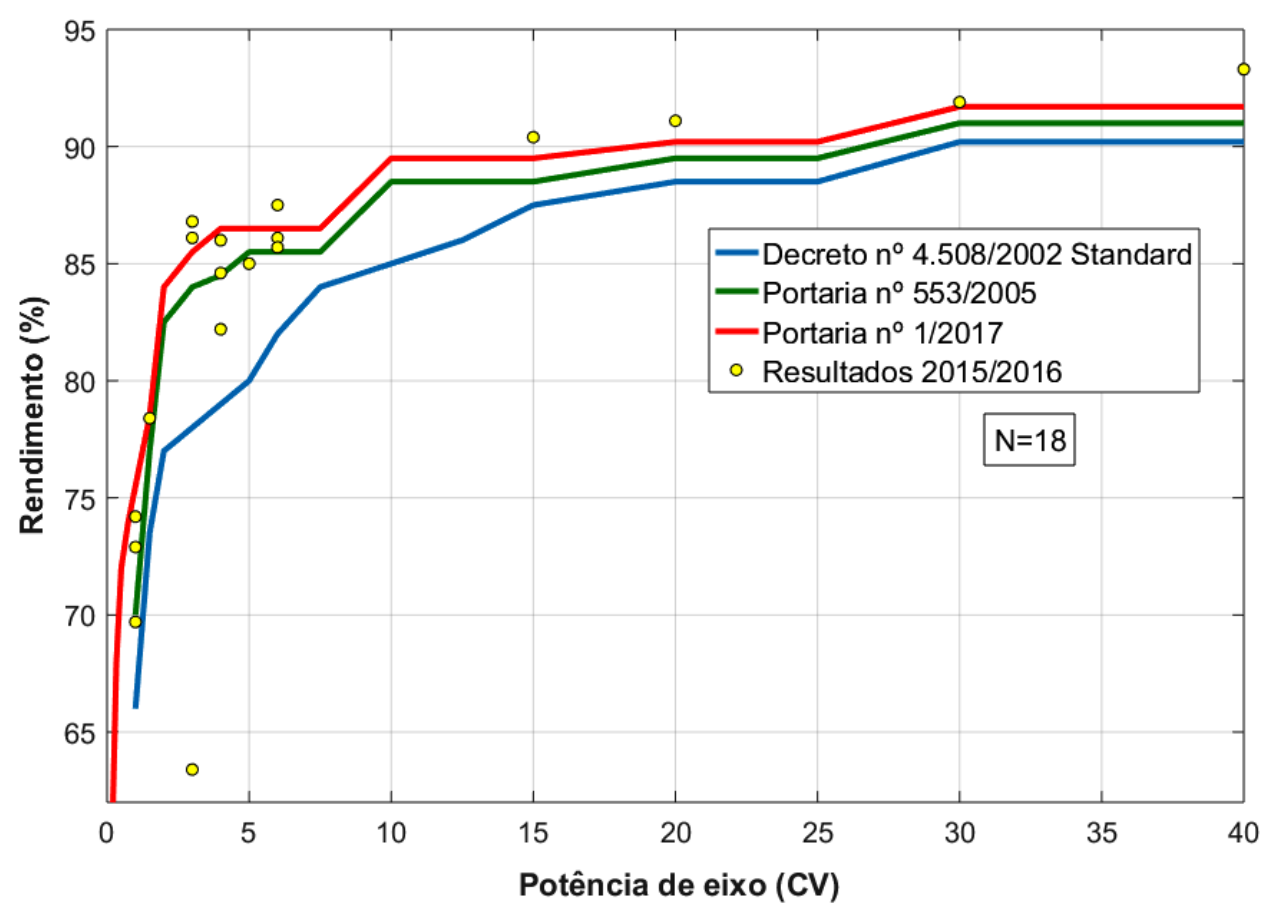

Fonte: Do autor.

\subsubsection{Avaliação do impacto do Decreto n ${ }^{\circ} 4.508 / 2002$}

Conforme discutido no item 5.3, nos últimos dois anos de ensaios analisados (20152016) houve um número elevado de ensaios no Laboratório de Máquinas Elétricas, sendo possível considerar para esta etapa da pesquisa, 435 motores elétricos apresentando a mesma distribuição de velocidade utilizada no referido item.

Está apresentada desde a Figura 61 até a Figura 72 a análise dos MITREG ensaiados no referido período e as três legislações de desempenho já discutidas. No primeiro bloco de análise é discutido o comportamento dos 435 motores nas suas 4 diferentes velocidades em relação à primeira legislação brasileira de desempenho (Decreto ${ }^{\circ}$ 4.508/2002).

A Figura 61 apresenta 129 ensaios de MITRGE, entre 1 e $200 \mathrm{CV}$ de 2 polos. Os motores elétricos, cujos resultados estão representados pelo círculo em verde, apresentaram rendimento igual ou superior ao valor determinado no Decreto $n^{\circ} 4.508 / 2002$. A linha tracejada em vermelho representa o rendimento mínimo de acordo com o Decreto $\mathrm{n}^{\mathrm{o}}$ 4.508/2002, para a velocidade referente a 2 polos. Os losangos azuis representam resultados de medições inferiores ao valor determinado no Decreto. No eixo das ordenadas (y) é 
apresentada a magnitude do desvio absoluto entre os valores medidos e o Decreto. No eixo das abscissas (x) a potência nominal de eixo.

Figura 61 - Desvio absoluto do rendimento de MITRGE de 2 Polos em relação ao Decreto $\mathrm{n}^{\circ}$ 4.508/2002

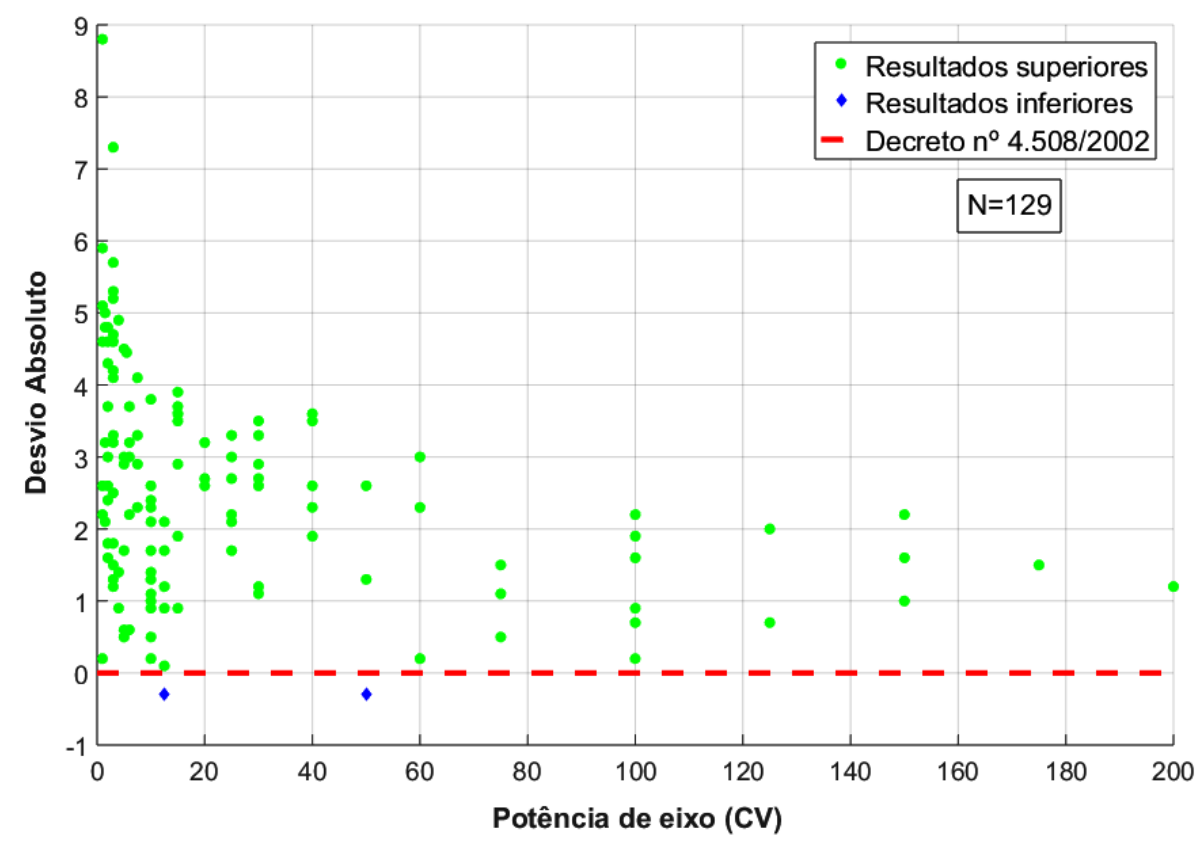

Fonte: Do autor.

A Tabela 24 apresenta avaliação estatística do comportamento das medições do ensaio de rendimento dos 129 resultados de ensaio em relação ao Decreto $n^{\circ} 4.508 / 2002$. O percentual de resultados igual ou acima do Decreto foi de $98,45 \%$, mostrando que a grande maioria dos motores apresentou ganhos de rendimento nos anos seguintes à publicação do documento.

Tabela 24 - Avaliação estatística do rendimento de MITRGE de 2 Polos em relação ao Decreto ${ }^{\circ}$ $4.508 / 2002$

\begin{tabular}{ccccccc}
\hline $\begin{array}{c}\text { Percentual acima } \\
\text { do nominal }\end{array}$ & $\begin{array}{c}\text { Percentual abaixo } \\
\text { do nominal }\end{array}$ & $\begin{array}{c}\text { Desvio } \\
\text { máximo } \\
\text { positivo }\end{array}$ & $\begin{array}{c}\text { Desvio máximo } \\
\text { negativo }\end{array}$ & $\begin{array}{c}\text { Desvio } \\
\text { médio }\end{array}$ & Mediana & $\begin{array}{c}\text { Desvio } \\
\text { padrão }\end{array}$ \\
\hline $98,45 \%$ & $1,55 \%$ & $8,8 \%$ & $-0,3 \%$ & $2,53 \%$ & $2,3 \%$ & $1,55 \%$ \\
\hline
\end{tabular}

Fonte: Do autor. 
A Figura 62 apresenta o Desvio Absoluto do rendimento para 227 motores de 4 polos. A referida análise apresenta maior quantidade de motores elétricos, como também, maior escala de potência de eixo, com motores até $250 \mathrm{CV}$.

Figura 62 - Desvio absoluto do rendimento de MITRGE de 4 Polos em relação ao Decreto ${ }^{0}$ 4.508/2002

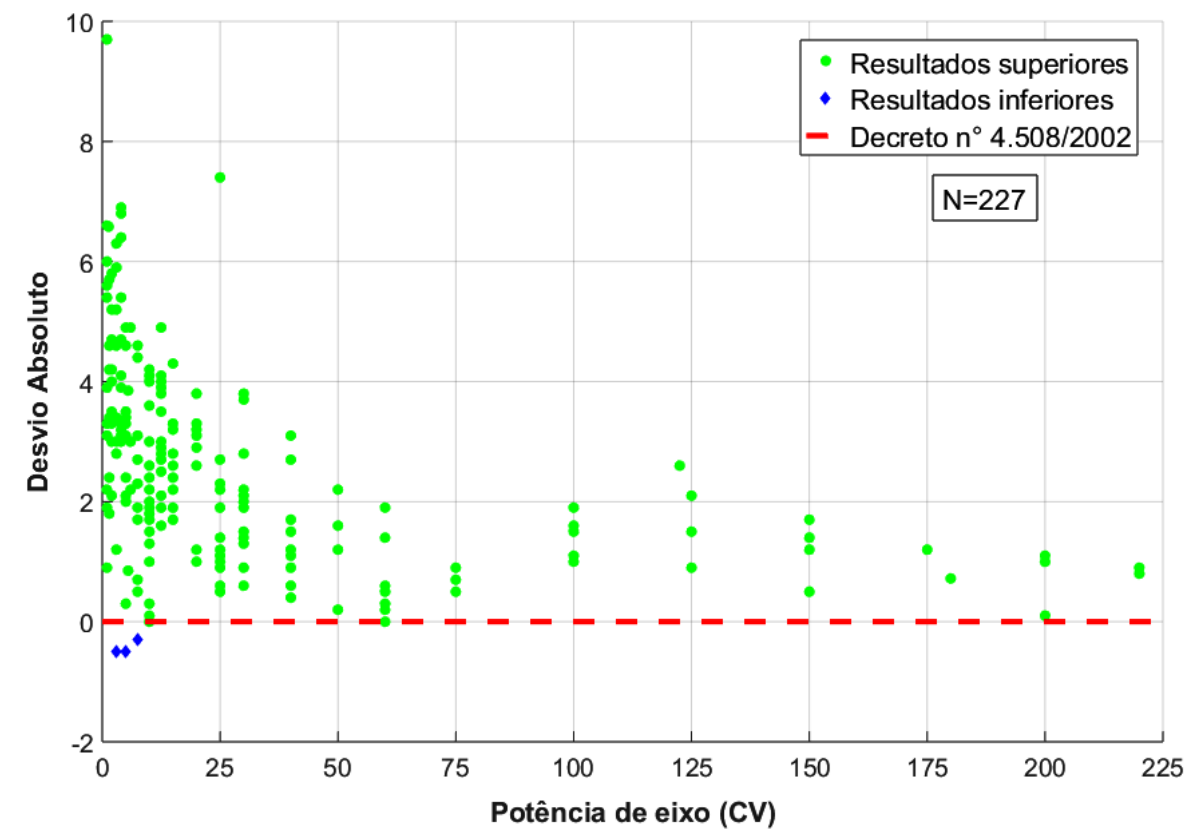

Fonte: Do autor.

Os motores de 2 polos e de 4 polos apresentaram resultados semelhantes. A Tabela 25 apresenta avaliação estatística do comportamento dos 227 motores elétricos em relação ao Decreto $\mathrm{n}^{\circ}$ 4.508/2002. O Percentual de MITRGE com rendimento medido acima do mínimo estabelecido no decreto foi de 96,48\%, evidenciando os avanços no mercado de motores após a publicação do documento.

Tabela 25 - Avaliação estatística do rendimento de MITRGE de 4 Polos em relação ao Decreto $\mathbf{n}^{\circ}$ 4.508/2002

\begin{tabular}{ccccccc}
\hline $\begin{array}{c}\text { Percentual acima } \\
\text { do nominal }\end{array}$ & $\begin{array}{c}\text { Percentual abaixo } \\
\text { do nominal }\end{array}$ & $\begin{array}{c}\text { Desvio } \\
\text { máximo } \\
\text { positivo }\end{array}$ & $\begin{array}{c}\text { Desvio máximo } \\
\text { negativo }\end{array}$ & $\begin{array}{c}\text { Desvio } \\
\text { médio }\end{array}$ & Mediana & $\begin{array}{c}\text { Desvio } \\
\text { padrão }\end{array}$ \\
\hline $96,48 \%$ & $1,32 \%$ & $9,7 \%$ & $-0,5 \%$ & $2,49 \%$ & $2,2 \%$ & $1,69 \%$ \\
\hline
\end{tabular}

Fonte: Do autor. 
A Figura 63 e a Figura 64, bem como a Tabela 26 e Tabela 27 evidenciam os mesmos resultados anteriores, mostram que o Decreto 4.508/2002 já se encontra em pleno atendimento pelos fabricantes nacionais e internacionais de motores elétricos.

Figura 63 - Desvio absoluto do rendimento de MITRGE de 6 Polos em relação ao Decreto no $4.508 / 2002$

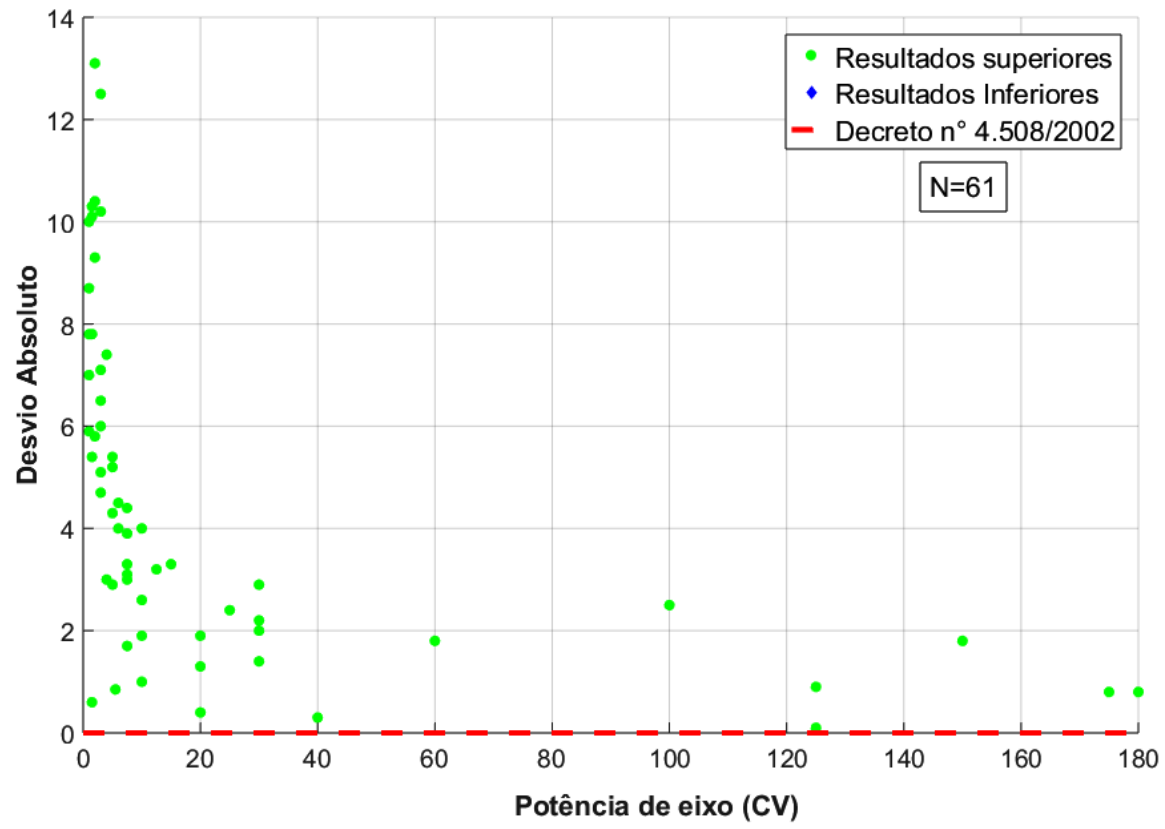

Fonte: Do autor.

Tabela 26 - Avaliação estatística do rendimento de MITRGE de 6 Polos em relação ao Decreto $\mathrm{n}^{0}$ 4.508/2002

\begin{tabular}{ccccccc}
\hline $\begin{array}{c}\text { Percentual acima } \\
\text { do nominal }\end{array}$ & $\begin{array}{c}\text { Percentual abaixo } \\
\text { do nominal }\end{array}$ & $\begin{array}{c}\text { Desvio } \\
\text { máximo } \\
\text { positivo }\end{array}$ & $\begin{array}{c}\text { Desvio máximo } \\
\text { negativo }\end{array}$ & $\begin{array}{c}\text { Desvio } \\
\text { médio }\end{array}$ & Mediana & $\begin{array}{c}\text { Desvio } \\
\text { padrão }\end{array}$ \\
\hline $100 \%$ & $0,0 \%$ & $13,1 \%$ & $0,0 \%$ & $4,5 \%$ & $3,3 \%$ & $3,36 \%$ \\
\hline
\end{tabular}

Fonte: Do autor. 
Figura 64 - Desvio absoluto do rendimento de MITRGE de 8 Polos em relação ao Decreto n 4.508/2002

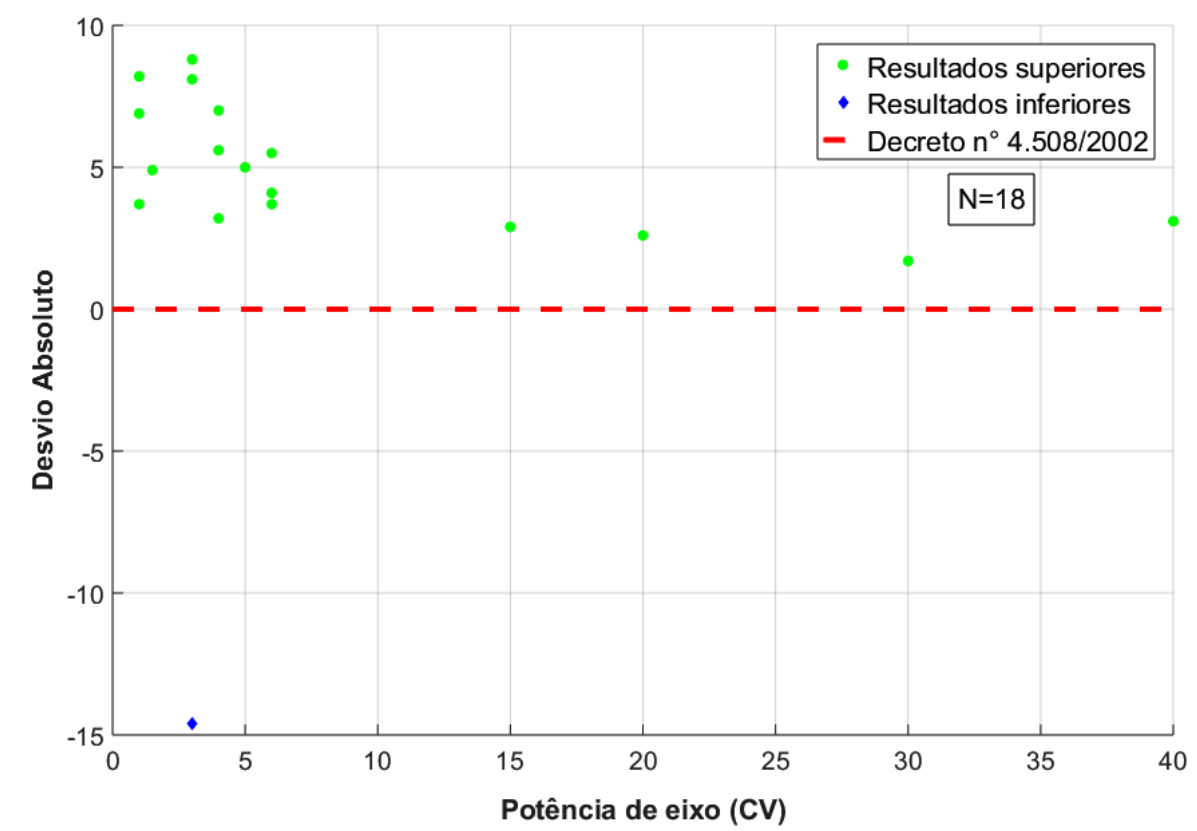

Fonte: Do autor.

Tabela 27 - Avaliação estatística do rendimento de MITRGE de 8 Polos em relação ao Decreto $\mathbf{n}^{\circ}$ 4.508/2002

\begin{tabular}{ccccccc}
\hline $\begin{array}{c}\text { Percentual acima } \\
\text { do nominal }\end{array}$ & $\begin{array}{c}\text { Percentual abaixo } \\
\text { do nominal }\end{array}$ & $\begin{array}{c}\text { Desvio } \\
\text { máximo } \\
\text { positivo }\end{array}$ & $\begin{array}{c}\text { Desvio máximo } \\
\text { negativo }\end{array}$ & $\begin{array}{c}\text { Desvio } \\
\text { médio }\end{array}$ & Mediana & $\begin{array}{c}\text { Desvio } \\
\text { padrão }\end{array}$ \\
\hline $94,44 \%$ & $5,56 \%$ & $8,8 \%$ & $-14,6 \%$ & $3,91 \%$ & $4,5 \%$ & $5,07 \%$ \\
\hline
\end{tabular}

Fonte: Do autor.

$\mathrm{Na}$ análise do resultado de ensaio de rendimento de 276 MITRGE entre 2000-2012, comparada ao nível de rendimento nível standard do Decreto no 4.508/2002, apresentada por Sauer et al. (2015) na Tabela 8, é possível observar que $89 \%$ dos motores avaliados apresentaram rendimento inferior ao nível standard. Na análise atual com 435 motores ensaiados entre 2015-2016, apresentada na Tabela 28, o resultado se comportou de forma oposta, com 97\% dos motores apresentando rendimento superior ao nível standard do Decreto $n^{\circ} 4.508 / 2002$. 
Tabela 28 - Comparação dos níveis de rendimento dos MITRGE (2015-2016) em relação ao Decreto 4.508/2002

\begin{tabular}{cccccc}
\hline & 2 Polos & 4 Polos & 6 Polos & 8 Polos & Total \\
\hline Medições abaixo do nominal & 2 & 8 & 0 & 1 & $3 \%$ \\
Medições iguais ou acima do nominal & 127 & 219 & 61 & 17 & $97 \%$ \\
\hline
\end{tabular}

Fonte: Do autor.

Este resultado mostra a significativa evolução de rendimento sofrida pelos MITRGE comercializados no Brasil nos últimos anos. Bem como a importância da legislação brasileira de desempenho de motores elétricos.

5.3.3.2 Avaliação do impacto da Portaria no 553/2005

Está apresentado na Figura 65 até a Figura 68 o segundo bloco de análise de impacto da legislação brasileira de desempenho de MITRGE. Os mesmos resultados de ensaios utilizados no bloco anterior são agora aplicados à segunda legislação brasileira de desempenho (Portaria ${ }^{\circ}$ 553/2005), que se encontra vigente neste momento. Da Tabela 29 até a Tabela 32 é apresentada a análise estatística do resultado dos ensaios em relação à Portaria $n^{\circ} 553 / 2005$. 
Figura 65 - Desvio absoluto do rendimento de MITRGE de 2 Polos em relação Portaria nº 553/2005

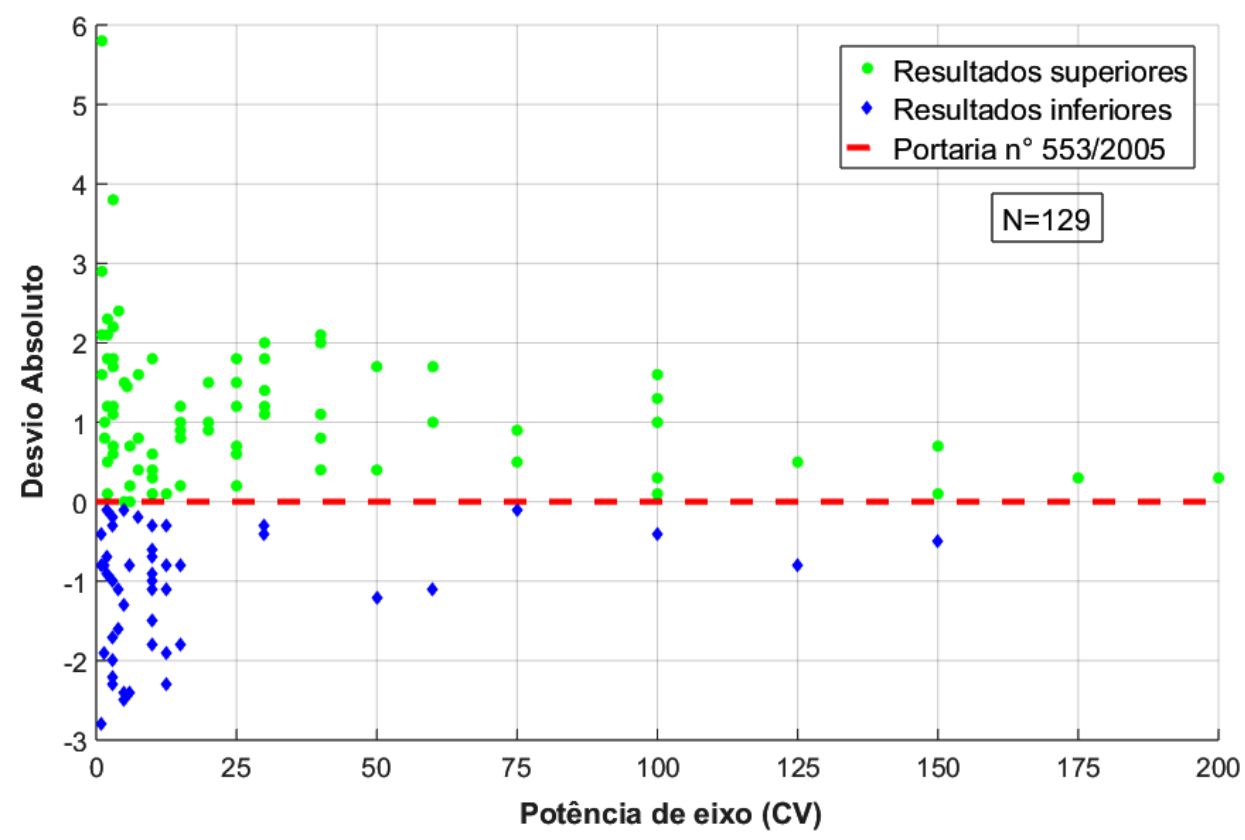

Fonte: Do autor.

Tabela 29 - Avaliação estatística do rendimento de MITRGE de 2 Polos em relação a Portaria n 553/2005

\begin{tabular}{ccccccc}
\hline $\begin{array}{c}\text { Percentual acima } \\
\text { do nominal }\end{array}$ & $\begin{array}{c}\text { Percentual abaixo } \\
\text { do nominal }\end{array}$ & $\begin{array}{c}\text { Desvio } \\
\text { máximo } \\
\text { positivo }\end{array}$ & $\begin{array}{c}\text { Desvio máximo } \\
\text { negativo }\end{array}$ & $\begin{array}{c}\text { Desvio } \\
\text { médio }\end{array}$ & Mediana & $\begin{array}{c}\text { Desvio } \\
\text { padrão }\end{array}$ \\
\hline $62,79 \%$ & $37,21 \%$ & $5,8 \%$ & $-2,8 \%$ & $-0,31 \%$ & $0,4 \%$ & $1,38 \%$ \\
\hline
\end{tabular}

Fonte: Do autor. 
Figura 66 - Desvio absoluto do rendimento de MITRGE de 4 Polos em relação Portaria nº 553/2005

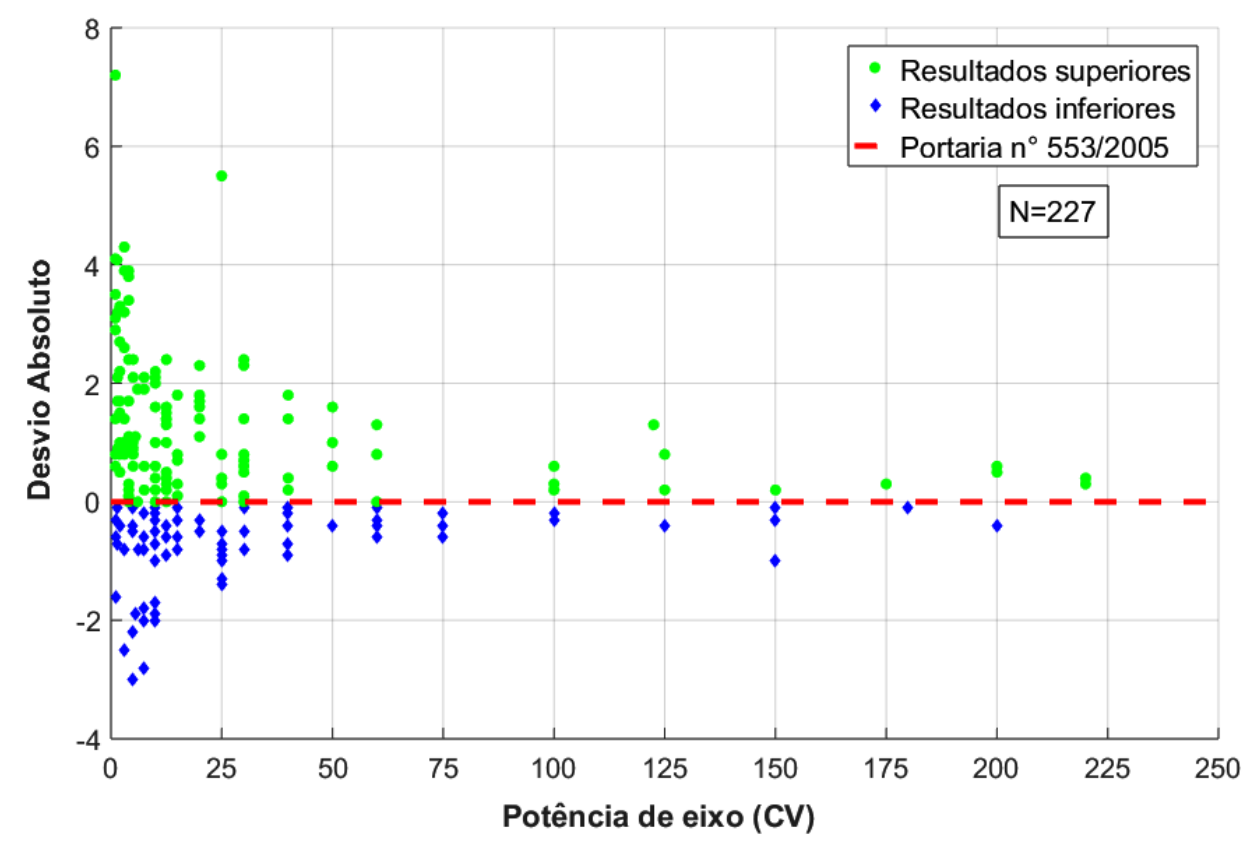

Fonte: Do autor.

Tabela 30 - Avaliação estatística do rendimento de MITRGE de 4 Polos em relação a Portaria n 553/2005

\begin{tabular}{ccccccc}
\hline $\begin{array}{c}\text { Percentual acima } \\
\text { do nominal }\end{array}$ & $\begin{array}{c}\text { Percentual abaixo } \\
\text { do nominal }\end{array}$ & $\begin{array}{c}\text { Desvio } \\
\text { máximo } \\
\text { positivo }\end{array}$ & $\begin{array}{c}\text { Desvio máximo } \\
\text { negativo }\end{array}$ & $\begin{array}{c}\text { Desvio } \\
\text { médio }\end{array}$ & Mediana & $\begin{array}{c}\text { Desvio } \\
\text { padrão }\end{array}$ \\
\hline $61,67 \%$ & $36,12 \%$ & $7,2 \%$ & $-3 \%$ & $0,55 \%$ & $0,3 \%$ & $1,44 \%$ \\
\hline
\end{tabular}

Fonte: Do autor. 
Figura 67 - Desvio absoluto do rendimento de MITRGE de 6 Polos em relação Portaria nº 553/2005

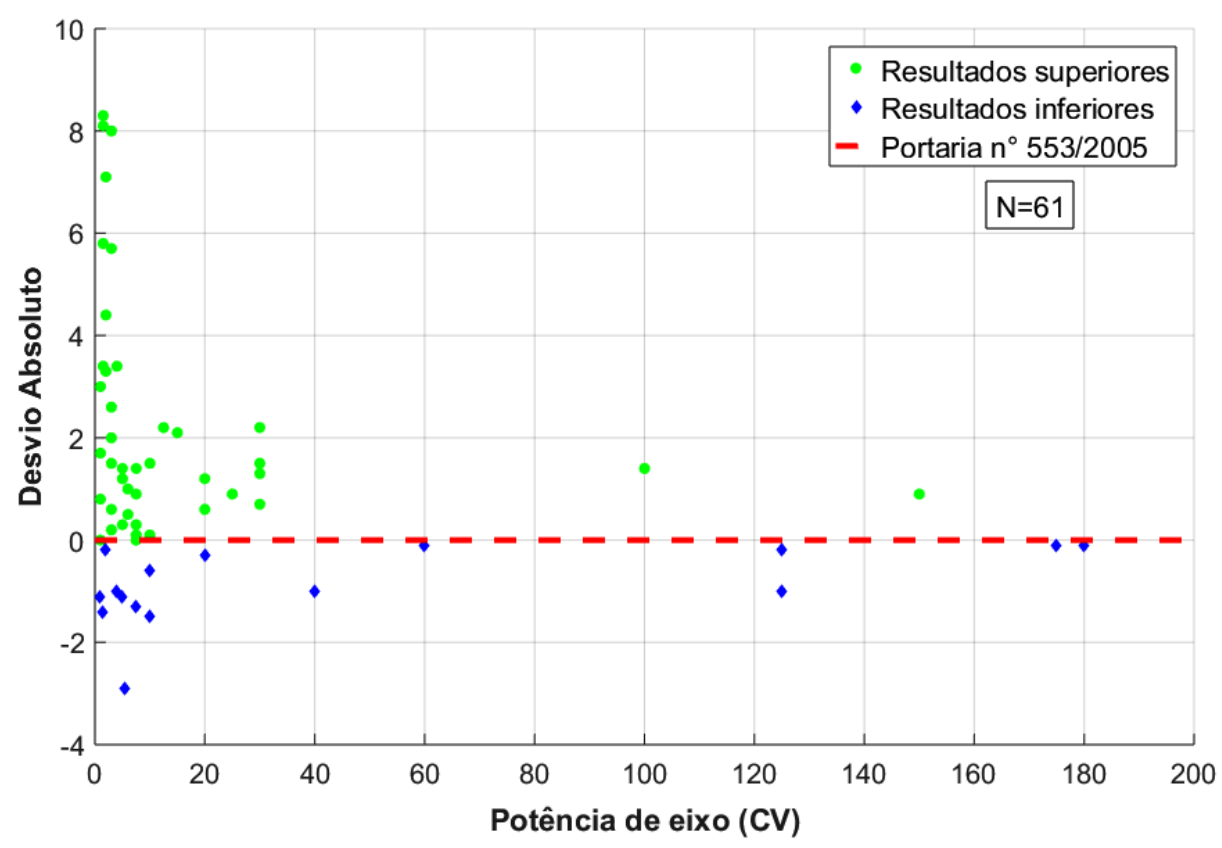

Fonte: Do autor.

Tabela 31 - Avaliação estatística do rendimento de MITRGE de 6 Polos em relação a Portaria n 553/2005

\begin{tabular}{ccccccc}
\hline $\begin{array}{c}\text { Percentual acima } \\
\text { do nominal }\end{array}$ & $\begin{array}{c}\text { Percentual abaixo } \\
\text { do nominal }\end{array}$ & $\begin{array}{c}\text { Desvio } \\
\text { máximo } \\
\text { positivo }\end{array}$ & $\begin{array}{c}\text { Desvio máximo } \\
\text { negativo }\end{array}$ & $\begin{array}{c}\text { Desvio } \\
\text { médio }\end{array}$ & Mediana & $\begin{array}{c}\text { Desvio } \\
\text { padrão }\end{array}$ \\
\hline $73,77 \%$ & $26,23 \%$ & $8,3 \%$ & $-2,9 \%$ & $1,44 \%$ & $0,9 \%$ & $2,41 \%$ \\
\hline
\end{tabular}

Fonte: Do autor. 
Figura 68 - Desvio absoluto do rendimento de MITRGE de 8 Polos em relação Portaria nº 553/2005

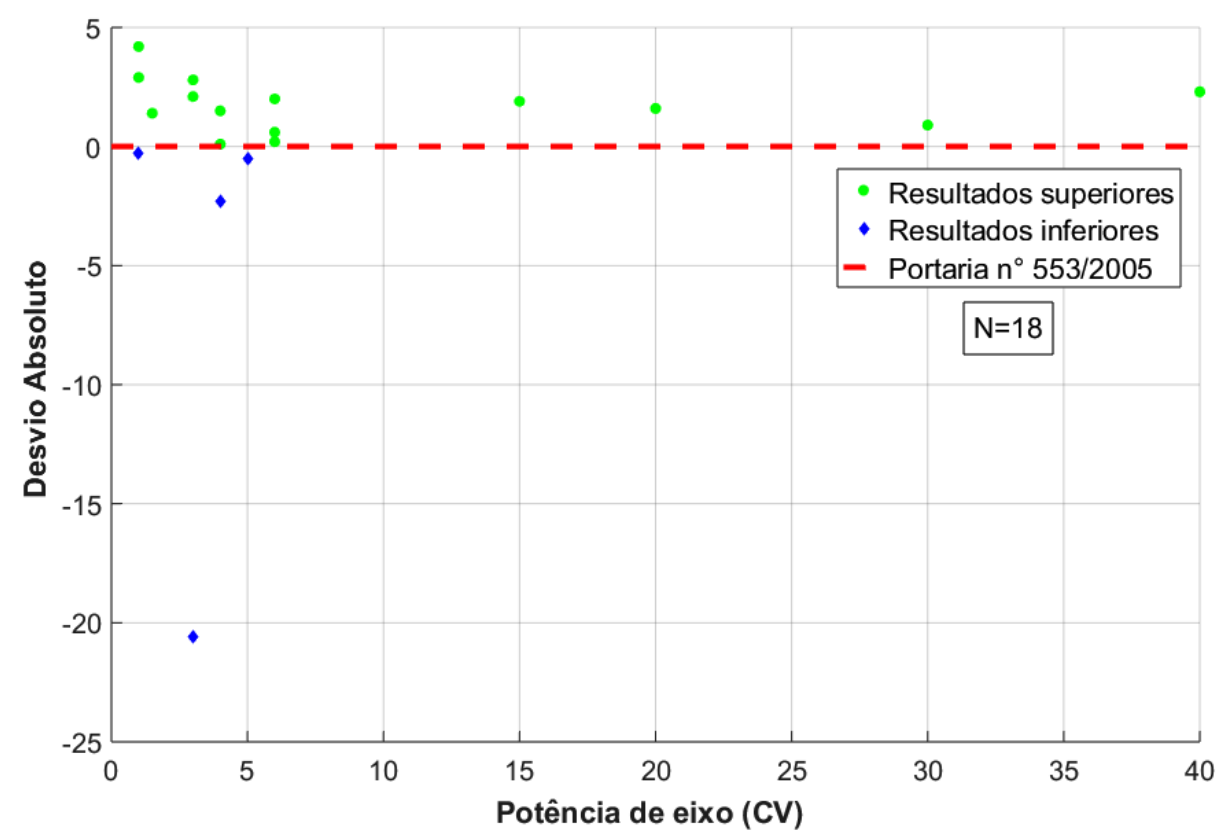

Fonte: Do autor.

Tabela 32 - Avaliação estatística do rendimento de MITRGE de 8 Polos em relação a Portaria n 553/2005

\begin{tabular}{ccccccc}
\hline $\begin{array}{c}\text { Percentual acima } \\
\text { do nominal }\end{array}$ & $\begin{array}{c}\text { Percentual abaixo } \\
\text { do nominal }\end{array}$ & $\begin{array}{c}\text { Desvio } \\
\text { máximo } \\
\text { positivo }\end{array}$ & $\begin{array}{c}\text { Desvio máximo } \\
\text { negativo }\end{array}$ & $\begin{array}{c}\text { Desvio } \\
\text { médio }\end{array}$ & Mediana & $\begin{array}{c}\text { Desvio } \\
\text { padrão }\end{array}$ \\
\hline $77,78 \%$ & $22,22 \%$ & $4,2 \%$ & $-20,6 \%$ & $0,04 \%$ & $1,45 \%$ & $5,36 \%$ \\
\hline
\end{tabular}

Fonte: Do autor.

Uma análise geral dos resultados da comparação entre valores de rendimento medidos e os valores referentes à Portaria $n^{\circ} 553 / 2005$ é apresentada na Tabela 28, onde é possível observar que $64 \%$ dos motores utilizados apresentam rendimento medido superior ao nível da legislação utilizada.

Tabela 33 - Comparação dos níveis de rendimento dos MITRGE (2015-2016) em relação a Portaria no $553 / 2005$

\begin{tabular}{cccccc}
\hline & 2 Polos & 4 Polos & 6 Polos & 8 Polos & Total \\
\hline Medições abaixo do nominal & 48 & 87 & 16 & 4 & $36 \%$ \\
Medições iguais ou acima do nominal & 81 & 140 & 45 & 14 & $64 \%$ \\
\hline
\end{tabular}

Fonte: Do autor. 
5.3.3.3 Avaliação do impacto da Portaria n ${ }^{\circ}$ 1/2017

A Portaria $n^{\circ} 553 / 2005$ é a legislação vigente, assim o valor de $36 \%$ abaixo do mínimo exigido pelo documento pode ser considerado um valor elevado, tendo em vista que o documento foi publicado em 2005 e os MITRGE avaliados foram ensaiados em 2015-2016, ou seja, 10 anos após a publicação do documento.

Estão apresentadas na Figura 69 até a Figura 72 o terceiro bloco de análise de impacto da legislação brasileira de desempenho de MITRGE. Os mesmos resultados de ensaios utilizados nos dois blocos anteriores são agora aplicados a terceira legislação brasileira de desempenho (BRASIL, 2017), que entrará em vigor nos próximos anos.

Está apresentada na Tabela 34 até a Tabela 37 a análise estatística do resultado dos ensaios em relação à Portaria n ${ }^{\circ}$ 1/2017.

Figura 69 - Desvio absoluto do rendimento de MITRGE de 2 Polos em relação Portaria no 1/2017

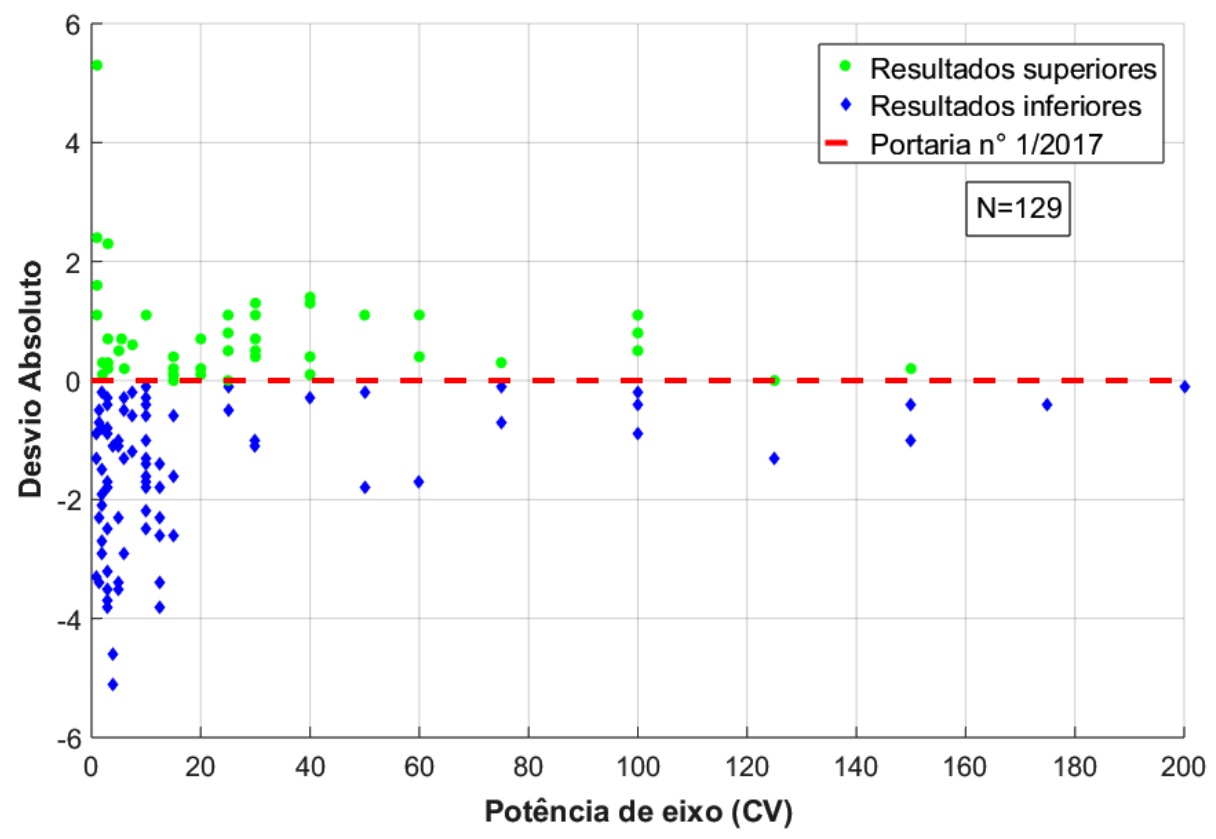

Fonte: Do autor. 
Tabela 34 - Avaliação estatística do rendimento de MITRGE de 2 Polos em relação a Portaria n 1/2017

\begin{tabular}{ccccccc}
\hline $\begin{array}{c}\text { Percentual acima } \\
\text { do nominal }\end{array}$ & $\begin{array}{c}\text { Percentual abaixo } \\
\text { do nominal }\end{array}$ & $\begin{array}{c}\text { Desvio } \\
\text { máximo } \\
\text { positivo }\end{array}$ & $\begin{array}{c}\text { Desvio máximo } \\
\text { negativo }\end{array}$ & $\begin{array}{c}\text { Desvio } \\
\text { médio }\end{array}$ & Mediana & $\begin{array}{c}\text { Desvio } \\
\text { padrão }\end{array}$ \\
\hline $37,21 \%$ & $62,79 \%$ & $5,3 \%$ & $-5,1 \%$ & $-0,69 \%$ & $-0,4 \%$ & $1,57 \%$ \\
\hline
\end{tabular}

Fonte: Do autor.

Figura 70 - Desvio absoluto do rendimento de MITRGE de 4 Polos em relação Portaria n 1/2017

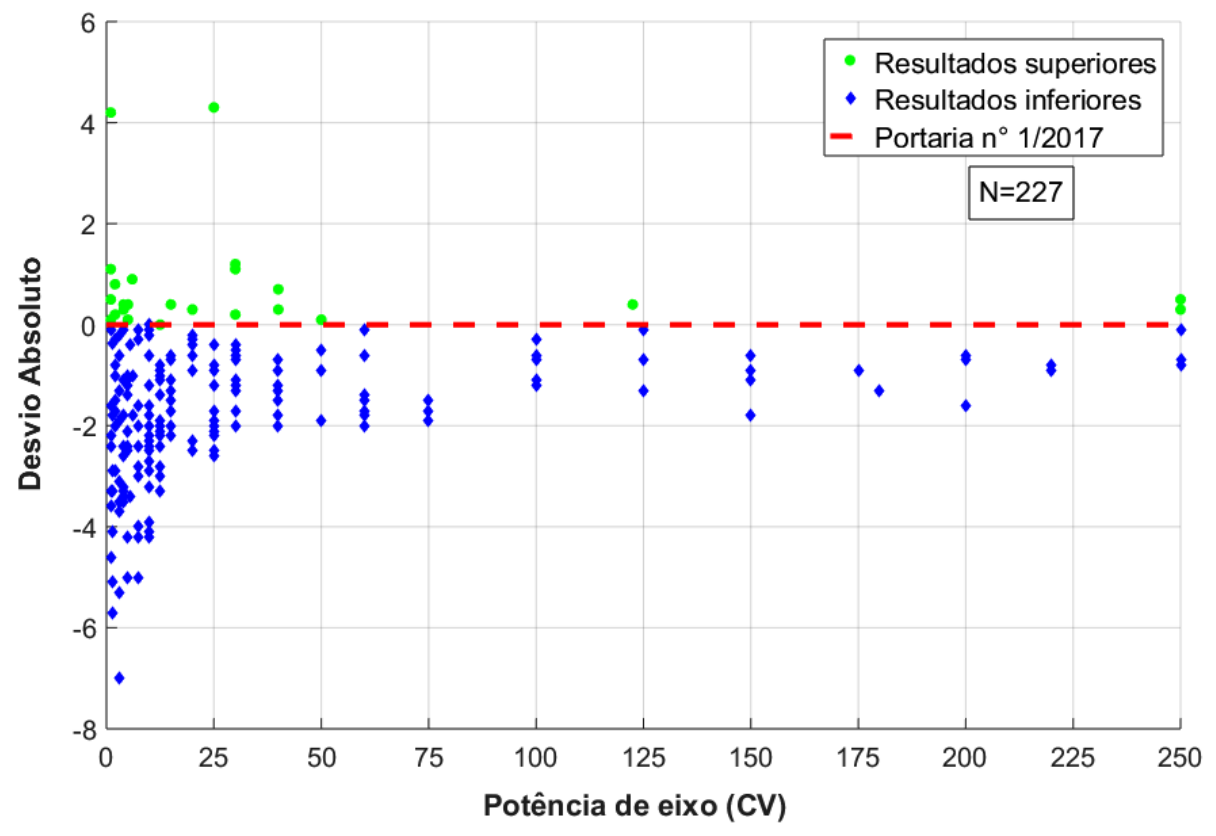

Fonte: Do autor.

Tabela 35 - Avaliação estatística do rendimento de MITRGE de 4 Polos em relação a Portaria n 1/2017

\begin{tabular}{ccccccc}
\hline $\begin{array}{c}\text { Percentual acima } \\
\text { do nominal }\end{array}$ & $\begin{array}{c}\text { Percentual abaixo } \\
\text { do nominal }\end{array}$ & $\begin{array}{c}\text { Desvio } \\
\text { máximo } \\
\text { positivo }\end{array}$ & $\begin{array}{c}\text { Desvio máximo } \\
\text { negativo }\end{array}$ & $\begin{array}{c}\text { Desvio } \\
\text { médio }\end{array}$ & Mediana & $\begin{array}{c}\text { Desvio } \\
\text { padrão }\end{array}$ \\
\hline $11,01 \%$ & $88,99 \%$ & $4,3 \%$ & $-7 \%$ & $-1,48 \%$ & $-1,4 \%$ & $1,43 \%$ \\
\hline
\end{tabular}

Fonte: Do autor. 
Figura 71 - Desvio absoluto do rendimento de MITRGE de 6 Polos em relação Portaria no 1/2017

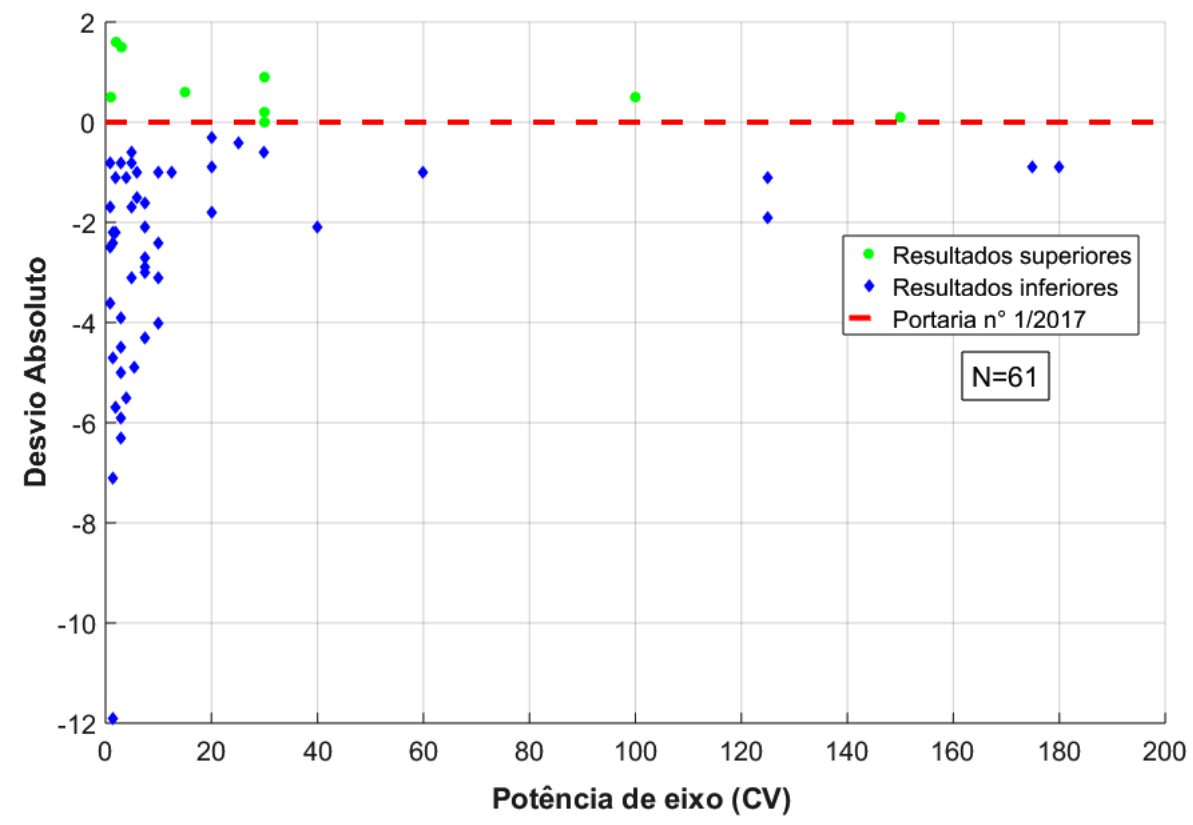

Fonte: Do autor.

Tabela 36 - Avaliação estatística do rendimento de MITRGE de 6 Polos em relação a Portaria n ${ }^{0}$ 1/2017

\begin{tabular}{ccccccc}
\hline $\begin{array}{c}\text { Percentual acima } \\
\text { do nominal }\end{array}$ & $\begin{array}{c}\text { Percentual abaixo } \\
\text { do nominal }\end{array}$ & $\begin{array}{c}\text { Desvio } \\
\text { máximo } \\
\text { positivo }\end{array}$ & $\begin{array}{c}\text { Desvio máximo } \\
\text { negativo }\end{array}$ & $\begin{array}{c}\text { Desvio } \\
\text { médio }\end{array}$ & Mediana & $\begin{array}{c}\text { Desvio } \\
\text { padrão }\end{array}$ \\
\hline $16,39 \%$ & $83,61 \%$ & $1,6 \%$ & $-11,9 \%$ & $-2,11 \%$ & $-1,6 \%$ & $2,35 \%$ \\
\hline
\end{tabular}

Fonte: Do autor. 
Figura 72 - Desvio absoluto do rendimento de MITRGE de 8 Polos em relação Portaria no 1/2017

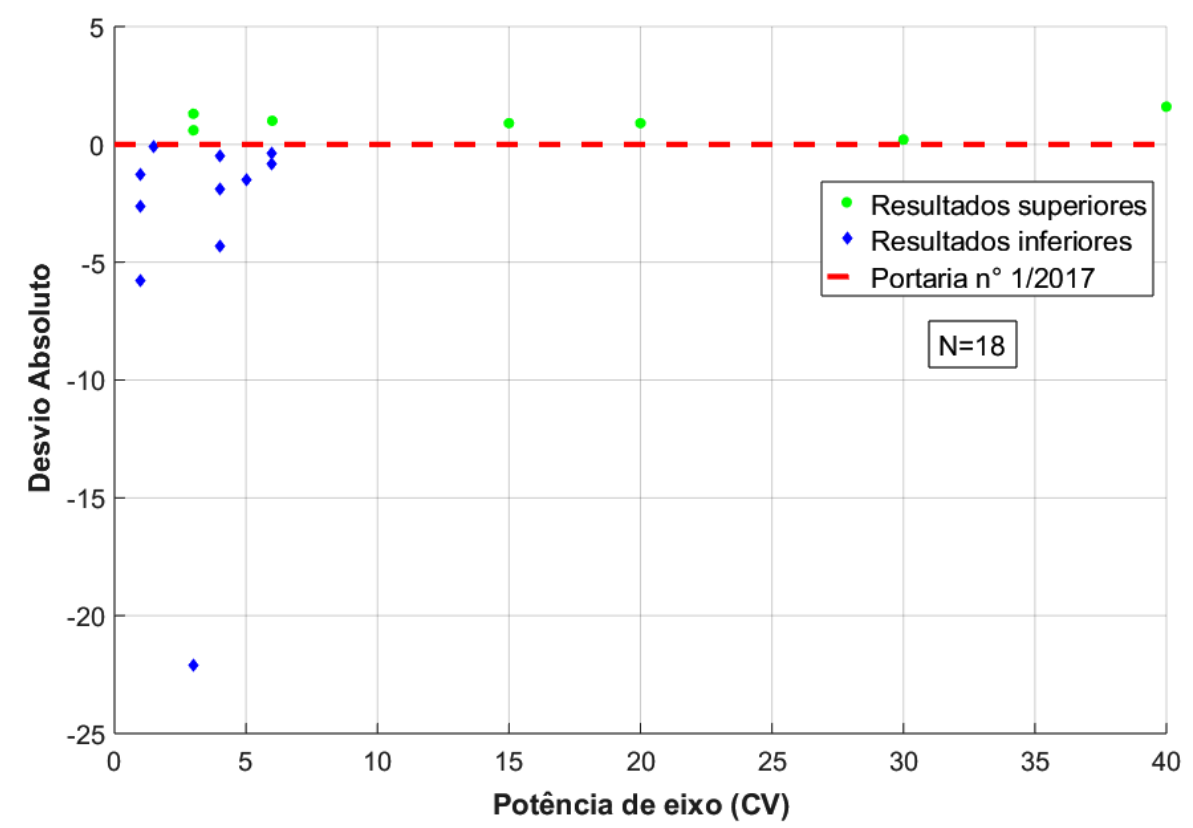

Fonte: Do autor.

Tabela 37 - Avaliação estatística do rendimento de MITRGE de 8 Polos em relação a Portaria no 1/2017

\begin{tabular}{ccccccc}
\hline $\begin{array}{c}\text { Percentual acima } \\
\text { do nominal }\end{array}$ & $\begin{array}{c}\text { Percentual abaixo } \\
\text { do nominal }\end{array}$ & $\begin{array}{c}\text { Desvio } \\
\text { máximo } \\
\text { positivo }\end{array}$ & $\begin{array}{c}\text { Desvio máximo } \\
\text { negativo }\end{array}$ & $\begin{array}{c}\text { Desvio } \\
\text { médio }\end{array}$ & Mediana & $\begin{array}{c}\text { Desvio } \\
\text { padrão }\end{array}$ \\
\hline $38,89 \%$ & $61,11 \%$ & $1,6 \%$ & $-22,1 \%$ & $-1,93 \%$ & $-0,45 \%$ & $5,4 \%$ \\
\hline
\end{tabular}

Fonte: Do autor.

Uma análise geral dos resultados da comparação entre valores de rendimento medidos e os valores referentes à Portaria $n^{\circ}$ 1/2017 é apresentado na Tabela 38 onde é possível observar que $79 \%$ dos motores utilizados apresentam rendimento medido abaixo do mínimo que será permitido pela referida legislação.

Tabela 38 - Comparação dos níveis de rendimento dos MITRGE (2015-2016) em relação a Portaria no $1 / 2017$

\begin{tabular}{cccccc}
\hline & 2 Polos & 4 Polos & 6 Polos & 8 Polos & Total \\
\hline Medições abaixo do nominal & 81 & 202 & 51 & 11 & $79 \%$ \\
Medições iguais ou acima do nominal & 48 & 25 & 10 & 7 & $21 \%$ \\
\hline Fonte:
\end{tabular}


Os resultados apresentados na Tabela 38 indicam que já existem motores elétricos no mercado brasileiro atendendo a Portaria $\mathrm{n}^{\circ}$ 1/2017 que foi publicada recentemente, entretanto, a maioria está abaixo dos padrões mínimos de rendimento.

\subsection{OS MITRGE NOS DIAS ATUAIS}

Dada a importância dos MITRGE, este tópico tem por objetivo discutir o comportamento dos motores elétricos, ensaiados entre 2010 e 2016, de maneira que possa representar os atuais motores disponíveis no mercado.

Os MITRGE apresentam, de modo geral, custos associados de forma proporcional à quantidade de material utilizada para a sua construção, que por sua vez é proporcional à potência disponibilizada no eixo. É apresentada na Figura 73 a relação entre a potência mecânica disponibilizada no eixo e o preço de varejo dos motores elétricos de indução com rotor em gaiola. É importante observar que o referido gráfico foi construído utilizando motores ditos convencionais, com Índice de Proteção - IP55, com alimentação em baixa tensão na frequência industrial de $60 \mathrm{~Hz}$. Os valores encontrados no mercado brasileiro foram dolarizados, pois tem historicamente sofrido influência dos processos inflacionários. 
Figura $73^{12}$ - Relação potência (CV) vs preço (US\$) de motores elétricos de indução

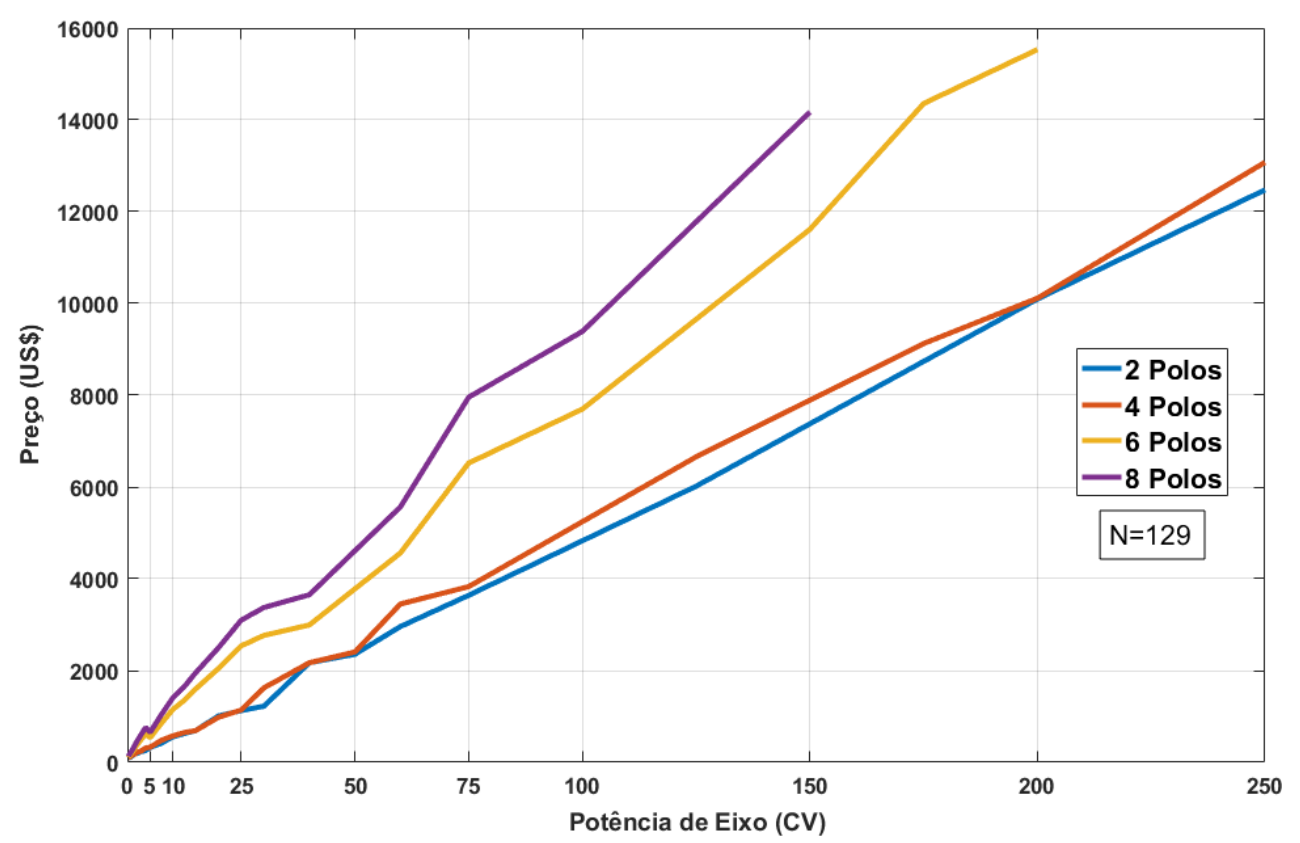

Fonte: Do autor.

A Figura 73 foi construída utilizando valores de notas fiscais dos MITRGE ensaiados entre os anos 2015 a 2016, sendo estes, compatíveis com os praticados no mercado local, nas seguintes amostragens: 32 de 2 polos, 52 de 4 polos, 26 de 6 polos e 19 de 8 polos, totalizando 129 motores.

O gráfico foi construído com valores de potência de eixo até os limites de potência normatizados pela Portaria $\mathrm{N}^{\mathrm{o}} 553$ de 2005, tendo em vista que acima dos respectivos valores, os motores geralmente são fabricados por encomenda, o pode inferir em significativas diferenças de valores.

O preço dos motores elétricos de indução é formado pelo custo de projeto, geralmente amortizados para potências clássicas, como as apresentadas na Portaria $n^{\circ} 553$ de 2005, bem como pela quantidade de trabalho necessária incorporada no motor elétrico em questão, somado os insumos utilizados no processo de fabricação do motor elétrico.

Os insumos utilizados (condutores elétricos, isolantes, materiais magnéticos, materiais de sustentação mecânica e acessórios) quantificados em massa total do motor elétrico,

\footnotetext{
${ }^{12}$ Elaborada com o câmbio do Dólar (US\$) comercial do dia 29/11/2017 em R\$ 3,2401. Entre os pontos em que não se possuía valores, optou-se por fazer regressão linear.
} 
dependem de vários fatores, por exemplo: a potência de eixo, a tensão de alimentação, o índice de proteção e a tecnologia utilizada (rotor em gaiola, rotor bobinado, síncrono, corrente contínua, etc.). Para o caso dos MITRGE o número de polos é fundamental para determinar a massa dos motores elétricos.

A Figura 74 apresenta a relação entre a potência mecânica de eixo e a massa dos MITRGE ditos convencionais, com índice de proteção - IP55, alimentação em baixa tensão na frequência industrial de $60 \mathrm{~Hz}$.

Figura 74 - Relação potência (CV) vs massa (kg) de motores elétricos de indução até $40 C V^{13}$

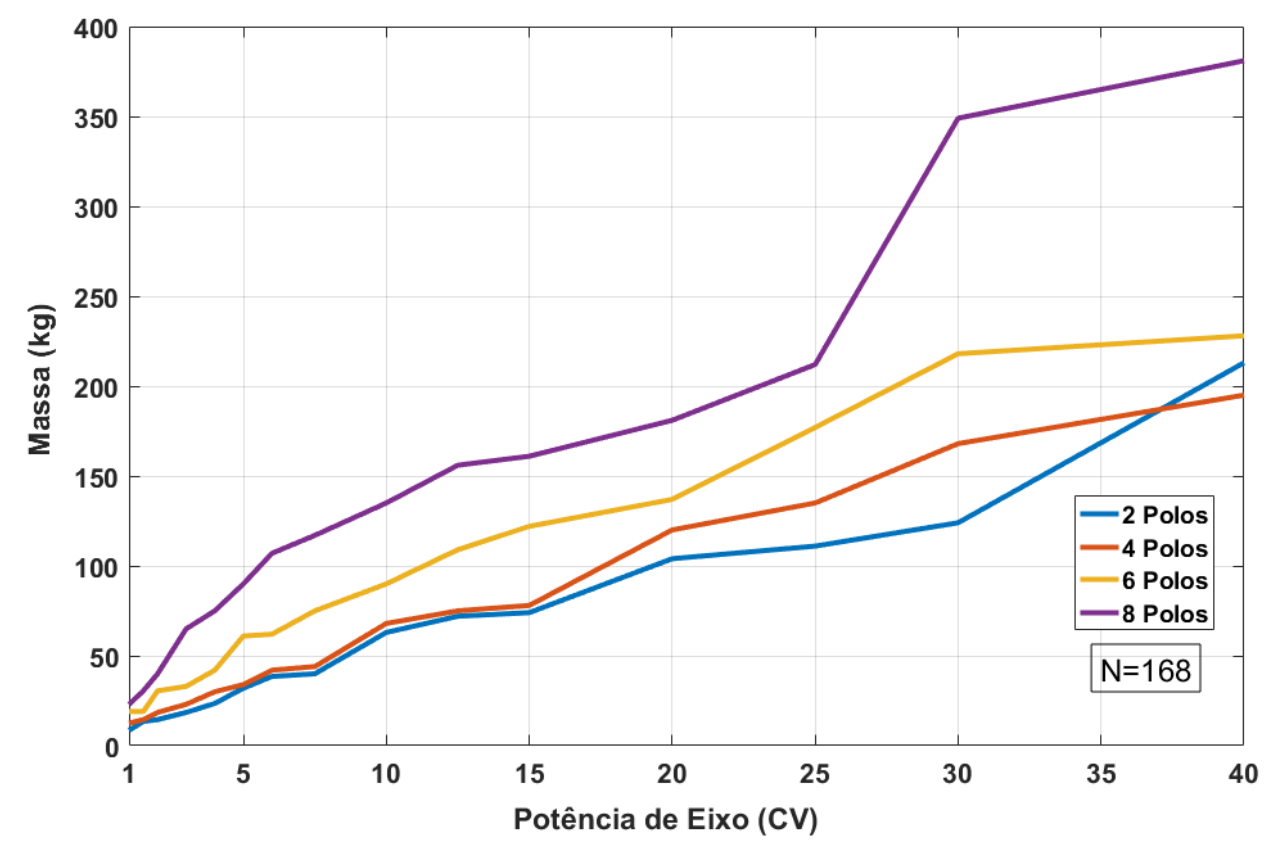

Fonte: Do autor.

A Figura 74 foi elaborada utilizando dados da placa informativa dos MITRGE ensaiados entre os anos de 2002 a 2016, nas seguintes amostragens: 38 de 2 polos, 72 de 4 polos, 32 de 6 polos e 26 de 8 polos. O período de 2002 a 2016 foi escolhido pela disponibilidade dos dados, onde os relatórios de ensaios contam com fotos das placas dos referidos MITRGE.

Observando a Figura 74, é possível concluir que quanto maior o número de polos dos motores elétricos, maior é a sua massa. O que justifica o custo dos motores de 8 polos serem significativamente mais elevados em relação aos motores de dois e quatro polos, conforme

\footnotetext{
${ }^{13}$ Entre os pontos em que não existiram motores ensaiados, optou-se por fazer regressão linear.
} 
ilustra a Figura 73. As curvas resultantes dos motores de dois e quatro polos apresentam comportamento similar no gráfico, o que determina um custo de produção otimizado. Isto se deve ao fato de que os fabricantes utilizam para esta quantidade de polos, carcaça semelhante, reduzindo os custos de produção.

A Figura 75 foi elaborada de modo a visualizar a totalidade de potências dos MITRGE convencionais, aquisitados entre os anos de 2006 e 2016, nas seguintes amostragens: 52 de 2 polos, 124 de 4 polos, 48 de 6 polos e 39 de 8 polos. Os motores possuíam índice de proteção - IP55, alimentação em baixa tensão, frequência de $60 \mathrm{~Hz}$.

Figura 75 - Relação potência (CV) vs massa $(\mathrm{kg})$ de motores elétricos de indução ${ }^{14}$

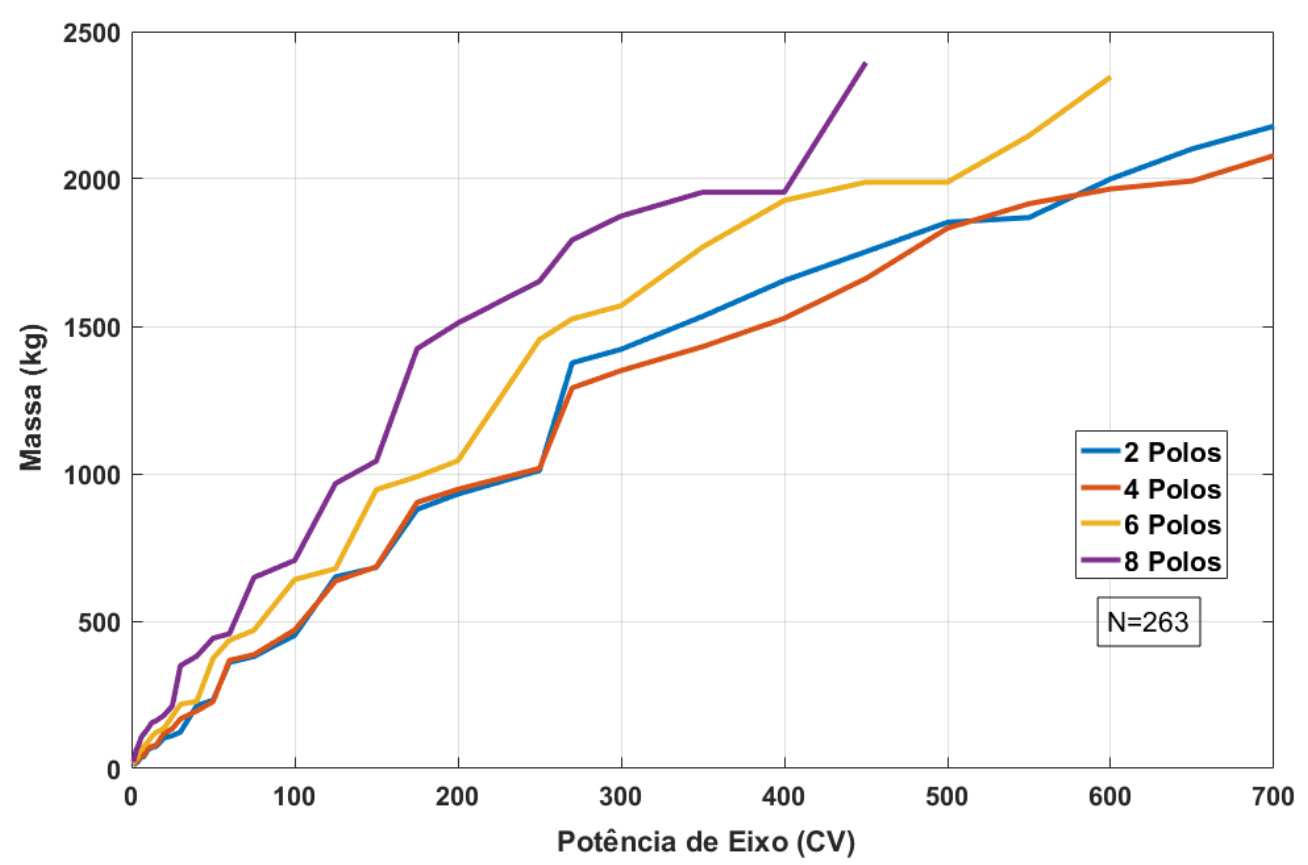

Fonte: Do autor.

$\mathrm{Na}$ Figura 75, fica evidente a estreita relação entre a massa do motor elétrico e o número de polos com que o motor foi construído, em uma dada faixa de potência. Quando observada a Portaria $n^{\circ} 553 / 2005$, pode ser constatado que os níveis de rendimento solicitados para motores de menor número de polos são, de modo geral, mais elevado do que os solicitados para motores construídos com maior número de polos, consequentemente de menor rotação. Este fato se deve a uma série de elementos, dentre eles, as perdas elétricas no

\footnotetext{
${ }^{14}$ O Período de 2002 a 2016 foi escolhido pela disponibilidade dos dados. Onde neste período os relatórios de ensaios contam com fotos das placas dos referidos MITRGE.

Entre os pontos em que não existiram motores elétricos ensaiados, optou-se por fazer regressão linear.
} 
material magnético, que é uma parcela importante e que se manifestam mais fortemente nos motores onde a indutância é maior, devido a maior quantidade de espiras, como ocorre nos motores em que se necessita formar maior quantidade de polos. Para elucidar melhor esta questão, foi construída a Figura 76, relacionando o número de polos dos motores elétricos, com os valores médios medidos de fator de potência.

Figura 76 - Relação potência $(\mathrm{CV})$ vs fator de potência (FP) de motores elétricos de indução até $40 \mathrm{CV}^{15}$

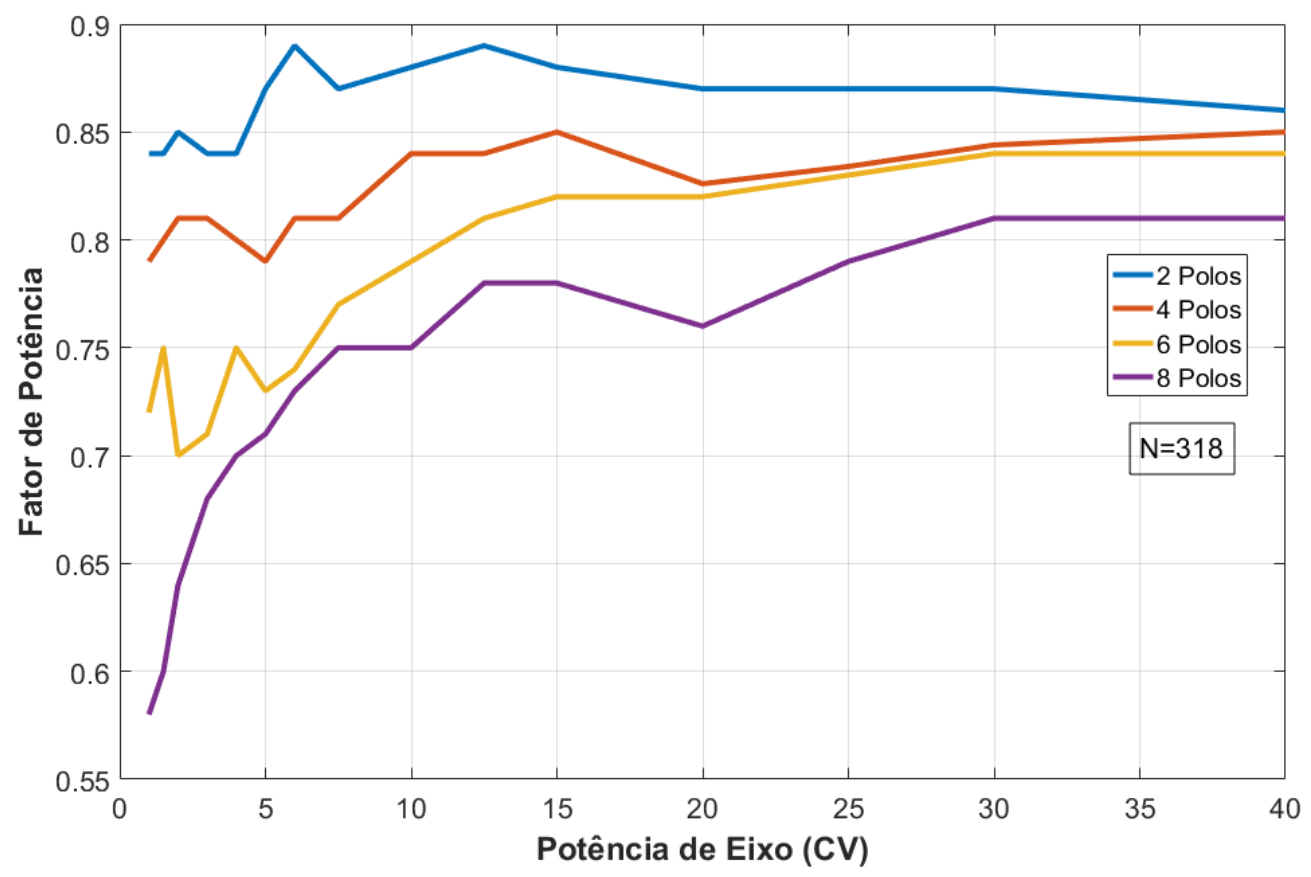

Fonte: Do autor.

A Figura 76 foi elaborada utilizando dados medidos dos MITRGE ensaiados entre 2010 e 2016, nas seguintes amostragens: 69 de 2 polos, 142 de 4 polos, 66 de 6 polos e 41 de 8 polos.

Na Figura 76 fica evidente a estreita relação entre o fator de potência medido e o número de polos com que o motor foi construído, dada a faixa de potência desejada. Como mais de $70 \%$ dos MITRGE analisados estão até a faixa de $40 \mathrm{CV}$, foi construída a Figura 76 limitada à potência de eixo de $40 \mathrm{CV}$. A Figura 77 mostra os valores de fator de potência para toda a faixa de potência.

\footnotetext{
${ }^{15}$ Entre os pontos em que não existiram motores ensaiados, optou-se por fazer regressão linear.
} 
Figura 77 - Relação potência (CV) vs fator de potência (FP) de motores elétricos de indução ${ }^{16}$

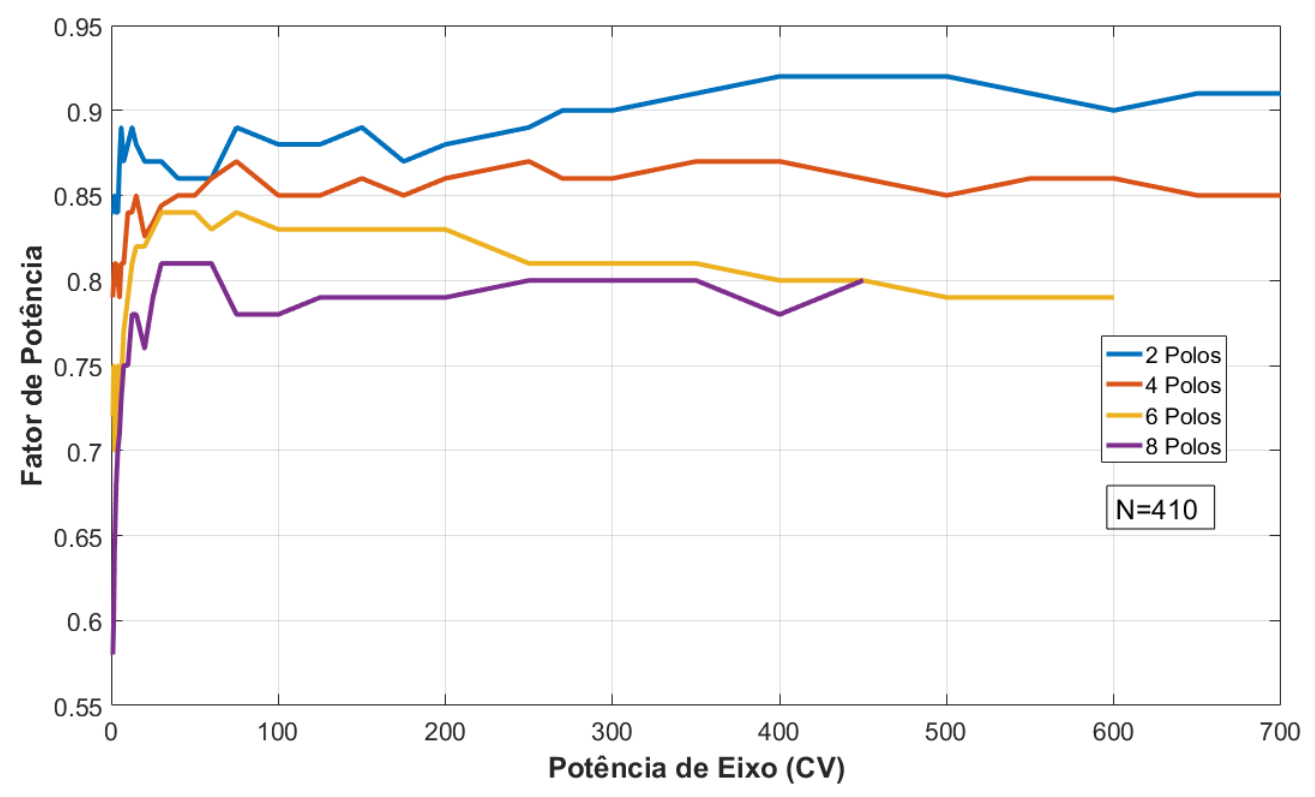

Fonte: Do autor.

Os dados apresentados referem-se a valores medidos dos MITRGE ensaiados entre 2010 e 2016, nas seguintes amostragens: 96 de 2 polos, 189 de 4 polos, 78 de 6 polos e 47 de 8 polos.

\footnotetext{
${ }^{16}$ Entre os pontos em que não existiram motores ensaiados, optou-se por fazer regressão linear.
} 


\section{CONCLUSÕES E TRABALHOS FUTUROS}

A normatização estabelecendo o nível mínimo de rendimento de motores elétricos de indução trifásicos é relativamente recente no Brasil. Quando analisado o rendimento dos motores elétricos antes e depois da entrada em vigor do Decreto $n^{\circ} 4.508 / 2002$ e da Portaria $\mathrm{n}^{\circ} 553 / 2005$, é possível observar que, de modo geral, a indústria de motores elétricos se adaptou às novas imposições para atendimento ao mercado brasileiro. Entretanto, a normativa brasileira é ainda pouco abrangente, pois não apresenta rendimento mínimo para motores monofásicos e para motores fracionários, muito presentes no uso final de energia elétrica nos setores residencial, comercial e serviço público, que hoje, se somadas, representam $57 \%$ do consumo total de energia elétrica no Brasil.

O presente trabalho analisou os níveis de rendimento dos motores elétricos de indução trifásicos, baseando-se em resultados de ensaios realizados no Laboratório de Máquinas Elétricas do IEE/USP, no período entre 1945 a 2016. Inicialmente, para essa análise, foram considerados motores de potências $5 \mathrm{CV}, 50 \mathrm{CV}$ e $200 \mathrm{CV}$, em um total de 414 máquinas. Em relação aos níveis de rendimento, os resultados mostraram que os motores apresentaram comportamentos similares, sendo possível identificar três momentos distintos na referida linha histórica. Entre 1945 e meados dos anos 60 os motores apresentaram ganhos crescentes e praticamente constantes de rendimento. Nos anos 60 a 80 é possível observar significativas quedas de rendimento, resultando, em alguns casos, a patamares inferiores aos motores comercializados em 1945. A partir dos anos 80 até 2016, o movimento de melhoria no rendimento voltou a dominar o cenário. $\mathrm{O}$ aspecto principal dessa variação de rendimento refere-se à tecnologia e materiais utilizados na construção das máquinas. Foi possível observar que, para as potências menores, os ganhos foram significativamente maiores devido à grande margem existente para melhorias nos materiais e projetos, devido ao baixo rigor técnico construtivo.

O Decreto Presidencial no 4.508 de 11 de dezembro de 2002 foi o primeiro documento nacional a estabelecer o rendimento mínimo dos motores elétricos trifásicos de indução com rotor em gaiola de esquilo. Posteriormente, a Portaria no 553/2005 avançou nas exigências para os níveis de rendimento e, recentemente, a Portaria no 1/2017 elevou o patamar mínimo de rendimento. Para a avaliação do impacto dessas três legislações, foram considerados os resultados dos ensaios realizados no período entre 2015 e 2016. Nesse período houve um 
número expressivo de ensaios, sendo 435 motores, com potências entre $1 \mathrm{CV}$ e $250 \mathrm{CV}$, cujos resultados de rendimento forneceram importantes subsídios para o trabalho. Quando os resultados foram analisados em referência ao Decreto $\mathrm{n}^{\circ} 4.508 / 2002$, a quase totalidade atendeu aos requisitos, conforme mostra a Tabela 28. Esse resultado, de certa forma, era esperado uma vez que o nível standard (nível IE1) do Decreto $n^{\circ} 4.508 / 2002$ não se encontra mais em vigor, sendo substituído pela Portaria n 553/2005 (nível IE2). Em relação à referida Portaria, observou-se que uma parcela considerável (36\%) ainda está fora dos níveis mínimos permitidos para a importação e comercialização, conforme mostra a Tabela 33. A recente publicação da Portaria no 1/2017 elevou os níveis mínimos de exigência para o nível IE3. Ao aplicar os resultados dos ensaios para a referida portaria, pode-se observar que $21 \%$ atendem aos novos padrões mínimos de rendimento, entretanto, a maioria dos motores (79\%) está abaixo do novo patamar mínimo, conforme mostra a Tabela 38.

Os resultados apresentados no trabalho, em todos os momentos, se referem a motores ensaiados com $100 \%$ de carga no eixo, ou seja, operando em condições nominais, ponto em que o rendimento é melhor na maioria dos casos. Na prática, em um ambiente industrial, os motores são na maioria dos casos, energizados abaixo do seu carregamento mecânico nominal. Nessa situação, os níveis de rendimento são inferiores aos obtidos durante os testes laboratoriais.

É importante destacar que os motores enviados pelos fabricantes pertencem a um conjunto possivelmente pré-selecionado, onde se acredita que apresentem melhor rendimento do que a média do país, porque eles vieram dos principais fabricantes e usuários, não sendo escolhidos de forma aleatória para a realização do ensaio. Sob essa percepção, há maior preocupação com a qualidade geral dos motores na sua totalidade.

Concluindo, os ganhos contínuos de rendimento ocorreram nos momentos de intensa inovação tecnológica e mostram a importância da existência da legislação de desempenho para os motores. Nos anos 70 e 80, a busca pela manufatura de motores de menor custo, reduziu o rendimento dos equipamentos. Assim, a auto-regulação do mercado de motores elétricos, no que se refere ao rendimento, não se mostrou com resultados positivos. O retorno do movimento de elevação de rendimento foi observado, principalmente, pela imposição da legislação de desempenho.

Existe espaço para avanços na normativa brasileira seguindo os padrões internacionais. Hoje, a normativa vigente equivale internacionalmente ao nível IE2 (Portaria $n^{\circ} 553 / 2005$ ), com data prevista para entrada do nível IE3 (Portaria $n^{\circ} 1 / 2017$ ). Entretanto, 
ainda se pode caminhar no sentido de legislar sobre os motores monofásicos e outros equipamentos em que os motores são a carga predominante.

Como trabalhos futuros, são relacionadas abaixo as seguintes propostas:

a) Análise do rendimento dos motores monofásicos;

b) Avaliação da redução do consumo de energia, considerando-se a substituição do parque de motores monofásicos por motores de indução trifásicos;

c) Análise das três principais metodologias de ensaios de motores de indução trifásicos;

d) Estudo comparativo entre dados de placa fornecidos pelos fabricantes e valores medidos de motores adquiridos aleatoriamente no mercado. 


\section{REFERÊNCIAS}

AGÊNCIA NACIONAL DE ENERGIA ELÉTRICA. Capacidade de geração do Brasil. Brasília: ANEEL, 2016.

ALGER, P. L.; ARNOLD, R. E. The history of induction motors in America. IEEE, v. 64, p. 1380-1383, 1976.

ALMEIDA, A. T. de et al. Electric motor MEPS guide. Zurich: 4E Electric Motor Systems EMSA, 2009. p. 16.

ALMEIDA, A. T. de et al. EUP lot 11 motors. Coimbra: ISR- University of, 2008. p.137.

ALMEIDA, A. T.; BERTOLDI, P.; LEONHARD, W. Energy efficiency improvements in electric motors and drives. 1. ed. Berlin: Springer, 1997.

ARAÚJO, R. P. Setor elétrico brasileiro: uma aventura mercantil. Brasília: Confea, 2009.

ASSOCIAÇAO BRASILEIRA DE NORMAS TÉCNICAS . NBR 5383-1. máquinas elétricas girantes. Rio de Janeiro: ABNT, 2002.

2017.

ABNT NBR IEC 60085: isolação elétrica: avaliação e designação. Rio de Janeiro,

ABNT NBR IEC 60034-5: máquinas elétricas girantes Parte 5: Graus de proteção proporcionados pelo projeto completo de máquinas elétricas girantes (Código IP) Classificação. Rio de janeiro, 2009.

NBR17094-1. máquinas elétricas girantes: motores de indução. Rio de Janeiro: ABNT, 2013.

BRASIL. Decreto $n^{\circ}$ 4.508. de 11 de dezembro de 2002. Dispõe sobre a regulamentação específica que define os níveis mínimos de eficiência energética de motores elétricos trifásicos de indução rotor gaiola de esquilo, de fabricação nacional ou importados, para comercialização ou uso no Brasil, e dá outras providências. Diário Oficial da União, Brasília: 11 dez. 2002. Seção 1.

BRASIL. Lei ${ }^{\circ}$ 10.295, de 17 de Outubro de 2001. Dispõe sobre a Política Nacional de Conservação e Uso Racional de Energia e dá outras providências. Diário Oficial da União, Brasília: 18 out. 2001. Seção 1. 
Lei $n^{\circ} 4.454$, de 6 de novembro de 1964. Dispõe sobre a unificação de frequência da corrente elétrica no País. Diário Oficial da União, Brasília, DF, 10 nov. 1964. Seção 1

BRASIL. Ministério de Minas e Energia . Portaria interministerial $\mathbf{n}^{\mathbf{0}}$ 553, de 8 de dezembro de 2005. Brasília: MME, 2005. p. 3

Ministério de Minas e Energia. Portaria interministerial $\mathbf{n}^{0} \mathbf{1}$, de 29 de junho de 2017. Brasília : MME, 2017.

CARLSON, B. Tesla: inventor of the electrical age. New Jersey: Princeton University Press, 2015.

CASELLA, E. P. Instituto de Eletrotécnica e Energia: ano cinqüenta. São Paulo: Instituto de Eletrtécnica e Energia - USP , 1990.

CHAPMAN, S. Electric machinery fundamentals. 4th. ed. New York: Mc Graw Hill Higher Education, 2005.

COMISSÃO DE INTEGRAÇÃO ENERGÉTICA REGIONAL. Síntese informativa energética dos países da CIER. Montevideo: CIER, 2016.

COSTA DIAS, J. L. P. D.; CARDOSO, J. R. Os 120 anos da Escola Politécnica. Brasil Engenharia, São Paulo, n. 618, p. 136-141, 2014.

Os 120 anos da Escola Politécnica de São Paulo: mil razões para comemorar. São Paulo: Brasil Engenharia, 2014.

CUNHA, L. Padrões brasileiros. O Setor Elétrico, São Paulo, n. 49, Fevereiro 2010.

DUNSHEATH, P. A History of electrical power engineering. London: The MIT Press, 1969.

ELETROBRÁS. A energia elétrica no Brasil: da primeira lâmpada à Eletrobrás. Rio de Janeiro: Biblioteca do Exército, 1977.

EMPRESA DE PESQUISA ENERGÉTICA. BALANÇO ENERGÉTICO NACIONAL. Rio de Janeiro: EPE. 2016. 296 p. 
EXPRESSION of the uncertainty of measurement in calibration. EA-4/02 . 1999.

FONTES, V. O Brasil e o capital imperialismo: teoria e história. 2 ${ }^{\text {a }}$. ed. Rio de Janeiro: UFRJ, 2010.

FURTADO, C. O capitalismo global. [S.1.]: Paz e Terra, 1998.

GARCIA, Agenor Gomes Pinto. Impacto da lei de eficiência energética para motores elétricos no potencial de conservação de energia na indústria. 2003. 139 f. Dissertação ( Mestrado em Planejamento Energético) Universidade Federal do Rio de Janeiro, Rio de Janeiro, 2003.

GONÇALVES JUNIOR, D. Reformas na indústria elétrica brasileira: a disputa pelas 'fontes' e o controle dos excedentes. ?”. Universidade de São Paulo. São Paulo, 2007. 431 p.

GRAMSCI, A. Introdução ao estudo da filosofia e a filosofia de Benedetto Croce.. 3. ed. Rio de Janeiro: Civilização Brasileira, 2004. (Cadernos do cárcere, v.1)

HAMMOND, P. Electromagnetism for egineers: an introductory course. 3. ed. Oxford: Pergamon, 1986. (Applied Electricity and Electronics)

IMPLEMENTING directive 2005/32/EC of the European parliament and of the council with regard to eco-design requirements for electric motors. Commission regulation (EC) $\mathbf{N}^{\mathbf{0}}$ 640/2009 of 22 July 2009. [S.1.] Official Journal of the European Union, 2009.

INSTITUTE OF ELECTRICAL AND ELECTRONICS ENGINEERS. IEEE 112. IEEE Approved Draft Standard Test Procedure for Polyphase Induction Motors and Generators. New York: [s.n.], 2017.

INSTITUTO NACIONAL DE METROLOGIA. Portaria n⿳ 488. Brasília: INMETRO, 2010.

Portaria no 243. Brasília: INMETRO, 2009.

INTERNATIONAL ELECTROTECHNICAL COMMISSION. IEC/EN 60034-30-1: standard on efficiency classes. IEC -. Genebra. 2014.

IEC 60034-2-1: rotating electrical machines - Part 2-1: standard methods for determining losses and efficiency from tests. [S.1.]. 2014. 
INTERNATIONAL ENERGY AGENCY. Key world energy statistics. Paris: IEA , 2016. $78 \mathrm{p}$.

Market report series : energy efficiency 2017. Paris: IEA. 2017. p. 143

INTERNATIONAL Monetary Fund, World Economic Outlook Reports. Washington: FMI, 2015.

INTROGUM. Evaluation of measurement data : an introduction to the "Guide to the expression of uncertainty in measurement" and related documents. Rio de Janeiro: [s.n.], 2014.

IVANOV-SMOLENSKI, A. V. Máquinas eléctricas. Moscou: Editorial Mir, 1988.

JEVONS, W. The coal question : an inquiry concerning the. 2. ed. London: MacMillan and Co, 1866.

JUNG, H.-K. Global movement in developing hegh efficiency motor. Honk Kong. 2015.

LAMME, B. G. The story of the induction motor. IEEE, 1921, p. 203-223.

LITTLE chronology. Berlin: AEG, 2003.

MAGALHÃES, G. Força e luz. 1. ed. [S.1.]: Unesp, 2000.

MARTIN, J.-M. A economia mundial da energia. 1. ed. [S.1.]: [s.n.], 1992.

MAYO, T.; NOHRIA, N. Da crise do petróleo a internet. 1. ed. [S.1.]: Campus, 2008.

MCPHERSON, S. S. War of the currents: Thomas Edison Vs Nikola Tesla (Scientific Rivalries and Scandals). [S.1.]: Twenty-First Century Books, 2012.

MEMORIAL da Eletricidade. Centro da memória da eletricidade no Brasil, 2016.

Disponivel em: <http://www.memoriadaeletricidade.com.br/>. Acesso em: 06 set. 2016.

MOTTELAY. Bibliographical history of electricity and magnetism. [S.1.]: Mottelay Press, 2007.

NAKATA, V. Escola Politécnica da USP 120 Anos - 1983/2013. São Paulo: Riemma, 2013. 
NATIONAL ELECTRICAL MANUFACTURERS ASSOCIATION. NEMA MG1. motors and generators. [S.1.]. 2011.

NATIONAL ENERGY POLICY. Report of the national energy policy development group. Washington : National Energy Policy, 2001.

NOVA MOTORES ELÉTRICOS. Motores Trifásicos Blindados IP56. Joinville/SC, p. 16. 2017.

OPERADOR Nacional do Sistema Elétrico. [S.1.]. 2017.

PROCEL. Pesquisa de posse de equipamentos e hábitos de uso, ano base 2005: classe Residencial Relatório Brasil - Sumário Executivo. ELETROBRAS. Rio de Janeiro, p. 187. 2009.

RAMOS, M. C. D. E. S. Metodologia para avaliação e otimização de motores elétricos de indução trifásicos visando a conservação de energia em aplicações industriais. 2009. Tese (Doutorado) São Paulo: Universidade de São Paulo, 2009.

RATTNER, H. A Crise do Petróleo. Revista Espaço Acadêmico, n. 86, Julho 2008. ISSN 1519-6186.

REINE, P. Industrial motors and drives: global market update. In: ENERGY EFFICIENCY IN MOTOR DRIVEN SYSTEMS, 17., 2017, Rome. Proceedings. EEMOD's-17, Rome, 2017.

ROMÉRO, M. A.; REIS, L. B. Eficiência energética em edifícios. São Paulo: Manole, 2012.

SALOTTI, F. A. M. Estudo comparativo entre os diversos métodos de determinação do rendimento de motores de indução. 1998. Dissertação (Mestrado) Universidade de São Paulo. Escola Politécnica de Engenharia, 1998.

SANTOS, M. T. L. F. A economia perversa: o impacto dos mercados sobre o meio ambiente. Prima Facie - Direito, História e Política, João Pessoa, p. 106-125, dez. 2006.

SAUER, I. L. et al. A comparative assessment of Brazilian electric motors performance with minimum efficiency standards. Renewable and Sustainable Energy Reviews, p. 38-318, 2015. 
SAUER, I. L. Um novo modelo para o setor elétrico brasileiro. $1^{\text {a }}$. ed. São Paulo: [s.n.], 2002.

SLATER, J. ; FRANK, N. Electromagnetism. Cambridge: Dover Publications, 2011.

TESLA, N. A new system of alternate current motors and transformers. New York: AIEE Transitions, v. 5, p. 308-324, 1888.

THORNTON, S.; MARION, J. Dinâmica clássica de partículas e sistemas. 5a . ed. [S.1.]: Cengage, 2010.

TIBÃES, M. C. D. O Artífice John Rose, um inglês em Diamantina. Brasília: Gráfica Cristiane, 2001.

TIEGHI, A. L. Uma vida dedicada ao desenvolvimento da engenharia. Espaço Aberto, São Paulo, v. 13, n. 150, p. 6-8, jun. 2013.

U.S. DEPARTMENT OF COMMERCE. Electric Current Abroad. International Trade Administration. [S.1.]. 2002.

U.S. DEPARTMENT OF ENERGY. Premium efficiency motor selection and application guide: a handbook for industry. Washington, D.C.: [s.n.], 2014.

UNITED NATIONS. World population prospects the 2015 revision. New York: ONU, 2015. p. 60.

WAIDE, P.; BRUNNER, C. Energy-efficiency policy opportunities for electric motordriven systems.. Paris: International Energy Agency, 2011. p. 128.

WEG. Eficiência energética em aplicações de motores elétricos. Jaraguá do Sul: [s.n.], 2015.

WERKHOVEN, Maarten van; WERLE, Rita. 4E EMSA Policy Guidelines for Motor Driven Units. 4E Electric Motor System. Zurique, p. 63, 2016.

WRIGLEY, E. A. Energy and the english industrial revolution. Cambridge: Press, Cambridge University, 2010. 


\section{APÊNDICE}

\section{Análise da placa de informação de um MITRGE de 100 CV - 4 Polos}

Os motores elétricos devem ter suas grandezas, em condições nominais, especificadas em uma placa de identificação, conforme solicita a (NBR17094-1, 2013), e devem ser avaliadas por um laboratório nacionalmente acreditado. É apresentado na Figura 1-A, a placa de identificação de um MITRGE de 100 CV e 4 polos, onde são apresentadas cada grandeza envolvida na referida placa.

Figura 1-A - Placa de um motor elétrico de indução trifásico de 100 CV 4 Polos

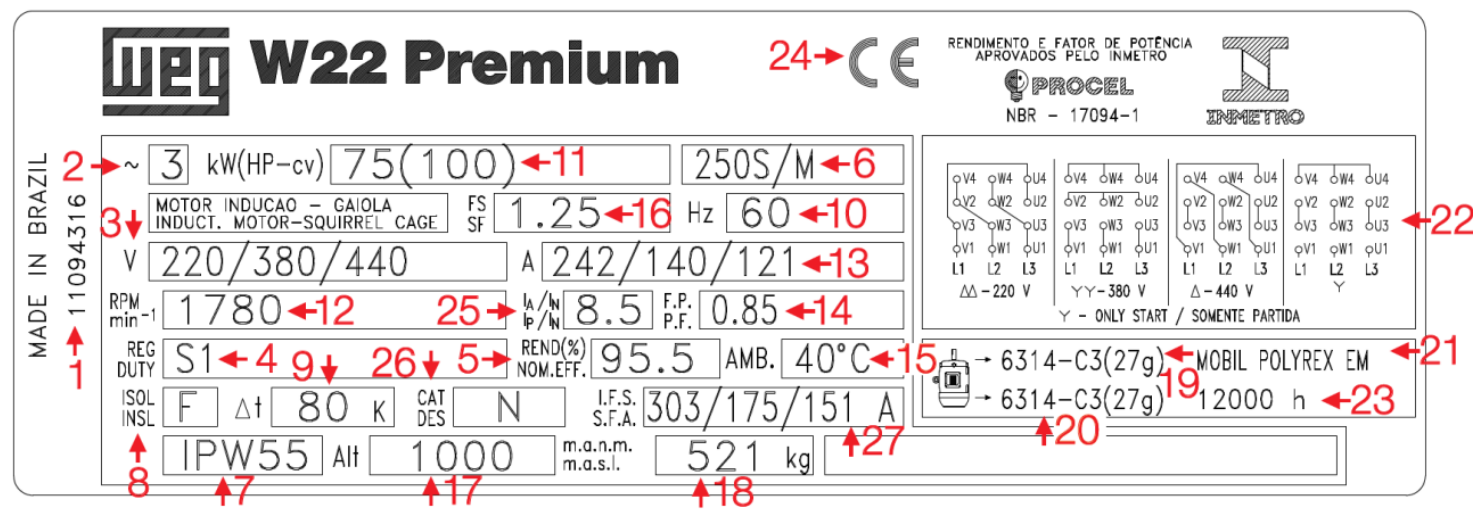

Fonte: (WEG, 2015).

1. Número de série e local de fabricação:

Todo motor elétrico deve apresentar em sua placa de identificação a nacionalidade da manufatura do equipamento, bem como o seu número de série para controle do fabricante.

2. Natureza da alimentação e número de fases:

Deve ser apresentado o tipo de alimentação (contínua ou alternada), bem como, em caso de corrente alternada, a quantidade de fases que deve ser disponibilizadas para a alimentação do referido equipamento. Pela placa de identificação na Figura 1-A, o referido motor deve ser energizado com tensão alternada e trifásica.

3. Tensões de alimentação:

Os MITRGE de modo geral possuem pelo menos duas formas de ligação. Assim, é necessário informar na placa de identificação os níveis de tensão 
nominal possível para cada forma de ligação. Os motores de alta tensão, que de modo geral são utilizados em conjunto com um transformador dedicado, possuem na maioria das vezes apenas uma forma de ligação. Pela placa de identificação na Figura 1-A, o referido motor pode operar em três possibilidades clássicas de tensão 220/380/440 Volts.

4. Regime de operação:

É a indicação das cargas mecânicas às quais o MITRGE é submetido, incluindo os períodos de partida, de frenagem elétrica, de funcionamento em vazio e de repouso, bem como as suas durações. Seguem abaixo as 10 possibilidades de regime admitidas pela (NBR17094-1, 2013).

Regime tipo S1 - Regime contínuo;

Regime tipo S2 - Regime de tempo limitado;

Regime tipo S3 - Regime intermitente periódico;

Regime tipo S4 - Regime intermitente periódico com partidas;

Regime tipo S5 - Regime intermitente periódico com frenagem elétrica;

Regime tipo S6 - Regime de funcionamento contínuo periódico com carga Intermitente;

Regime tipo S7 - Regime de funcionamento contínuo periódico com frenagem elétrica;

Regime tipo S8 - Regime de funcionamento contínuo periódico com mudanças correspondentes de carga e de rotação;

Regime tipo S9 - Regime com variações não periódicas de carga e de rotação; Regime tipo S10 - Regime com cargas e rotações constantes distintas.

Pela placa de identificação na Figura 1-A, o referido motor foi projetado visando operação contínua em regime S1.

5. Rendimento nominal:

O rendimento de um MITRGE é a razão numérica entre a potência mecânica disponibilizada no eixo rotativo e a potência elétrica ativa por ele absorvida da rede. Quanto maior e mais próximo de um (1) for o rendimento de um motor elétrico, mais eficiente é este motor e menores são as suas perdas acumuladas. O referido motor da Figura 1-A, apresenta rendimento de 95,5\%. O que significa que operando em condições nominal, 95,5\% da potência elétrica drenada pela rede é convertida em potência mecânica no eixo, os outros 4,5\% 
são as perdas que ocorrem de diversas formas no processo de conversão eletromecânica.

6. Modelo da carcaça:

Para os motores de indução de aplicação geral, construídos com enrolamentos trifásicos, rotor em gaiola de esquilo, frequência nominal $60 \mathrm{~Hz}$ ou $50 \mathrm{~Hz}$ para operação em $60 \mathrm{~Hz}$, tensão nominal inferior ou igual a $1.000 \mathrm{~V}$ e altura de eixo $63 \mathrm{~mm}$ a $355 \mathrm{~mm}$, devem possuir carcaças padronizadas para cada combinação de potência nominal, conforme consta na Figura 1-A. As carcaças padronizadas favorecem a substituição das máquinas, mantendo o mesmo sistema de fixação, e simplificando o processo de acoplamento com a carga mecânica. Pela placa de identificação na Figura 1-A, o referido motor pode possui carcaça compatível com os modelos 250S e $250 \mathrm{M}$.

Tabela 1-A - Correspondência entre potência nominal, número de polos e carcaça

\begin{tabular}{|c|c|c|c|c|c|}
\hline \multicolumn{2}{|c|}{ Potência nominal } & \multicolumn{4}{|c|}{ Número de polos } \\
\hline \multirow{2}{*}{ CV/HP } & \multirow{2}{*}{$\mathbf{k W}$} & 2 & 4 & 6 & 8 \\
\hline & & \multicolumn{4}{|c|}{ Carcaça } \\
\hline $1 / 4$ & 0,18 & 63 & 63 & 71 & 80 \\
\hline $1 / 3$ & 0,25 & 63 & 63 & 71 & 80 \\
\hline $1 / 2$ & 0,37 & 63 & 71 & 80 & $90 \mathrm{~S}$ \\
\hline $3 / 4$ & 0,55 & 71 & 71 & 80 & $90 \mathrm{~S}$ \\
\hline 1 & 0,75 & 71 & 80 & $90 \mathrm{~S}$ & $90 \mathrm{~L}$ \\
\hline 1,5 & 1,1 & 80 & 80 & $90 \mathrm{~S}$ & $100 \mathrm{~L}$ \\
\hline 2 & 1,5 & 80 & $90 \mathrm{~S}$ & $100 \mathrm{~L}$ & $112 \mathrm{M}$ \\
\hline 3 & 2,2 & $90 \mathrm{~S}$ & $90 \mathrm{~L}$ & $100 \mathrm{~L}$ & $132 \mathrm{~S}$ \\
\hline 4 & 3 & $90 \mathrm{~L}$ & $100 \mathrm{~L}$ & $112 \mathrm{M}$ & $132 \mathrm{M}$ \\
\hline 5 & 3,7 & $100 \mathrm{~L}$ & $100 \mathrm{~L}$ & $132 \mathrm{~S}$ & $132 \mathrm{M}$ \\
\hline 6 & 4,5 & $112 \mathrm{M}$ & $112 \mathrm{M}$ & $132 \mathrm{~S}$ & $160 \mathrm{M}$ \\
\hline 7,5 & 5,5 & $112 \mathrm{M}$ & $112 \mathrm{M}$ & $132 \mathrm{M}$ & $160 \mathrm{M}$ \\
\hline 10 & 7,5 & $132 \mathrm{~S}$ & $132 S$ & $132 \mathrm{M}$ & $160 \mathrm{~L}$ \\
\hline 12,5 & 9,2 & $132 \mathrm{M}$ & $132 \mathrm{M}$ & $160 \mathrm{M}$ & $180 \mathrm{M} / \mathrm{L}$ \\
\hline 15 & 11 & $132 \mathrm{M}$ & $132 \mathrm{M}$ & $160 \mathrm{M}$ & $180 \mathrm{~L}$ \\
\hline 20 & 15 & $160 \mathrm{M}$ & $160 \mathrm{M}$ & $160 \mathrm{~L}$ & $180 \mathrm{~L}$ \\
\hline 25 & 18,5 & $160 \mathrm{M}$ & $160 \mathrm{~L}$ & $180 \mathrm{~L}$ & $200 \mathrm{~L}$ \\
\hline 30 & 22 & $160 \mathrm{~L}$ & $180 \mathrm{M}$ & $200 \mathrm{~L}$ & $225 \mathrm{~S}$ \\
\hline 40 & 30 & $200 \mathrm{M}$ & $200 \mathrm{M}$ & $200 \mathrm{~L}$ & $225 \mathrm{M}$ \\
\hline
\end{tabular}

(Continua...) 


\begin{tabular}{cc|cccc}
\hline \multirow{2}{*}{ Potência nominal } & \multicolumn{4}{|c}{ Número de polos } \\
\hline \multirow{2}{*}{ CV/HP } & \multirow{2}{*}{$\mathbf{k W}$} & $\mathbf{2}$ & $\mathbf{4}$ & $\mathbf{6}$ & $\mathbf{8}$ \\
\cline { 3 - 5 } & 37 & $200 \mathrm{~L}$ & $200 \mathrm{~L}$ & $225 \mathrm{M}$ & $250 \mathrm{~S}$ \\
\hline $\mathbf{5 0}$ & 45 & $225 \mathrm{~S}$ & $225 \mathrm{~S}$ & $250 \mathrm{~S}$ & $250 \mathrm{M}$ \\
$\mathbf{6 0}$ & 55 & $225 \mathrm{M}$ & $225 \mathrm{M}$ & $250 \mathrm{M}$ & $280 \mathrm{~S}$ \\
$\mathbf{7 5}$ & 75 & $250 \mathrm{M}$ & $250 \mathrm{M}$ & $280 \mathrm{~S}$ & $280 \mathrm{M}$ \\
$\mathbf{1 0 0}$ & 90 & $280 \mathrm{~S}$ & $280 \mathrm{~S}$ & $280 \mathrm{M}$ & $315 \mathrm{M}$ \\
$\mathbf{1 2 5}$ & 110 & $280 \mathrm{M}$ & $280 \mathrm{M}$ & $315 \mathrm{M}$ & $315 \mathrm{M}$ \\
$\mathbf{1 5 0}$ & 132 & $315 \mathrm{~S}$ & $315 \mathrm{~S}$ & $315 \mathrm{M}$ & 355 \\
$\mathbf{1 7 5}$ & 150 & $315 \mathrm{~S}$ & $315 \mathrm{~S}$ & $315 \mathrm{M}$ & 355 \\
$\mathbf{2 0 0}$ & 185 & $315 \mathrm{M}$ & $315 \mathrm{M}$ & 355 & 355 \\
$\mathbf{2 5 0}$ & 220 & 355 & 355 & 355 & 355 \\
$\mathbf{3 0 0}$ & 260 & 355 & 355 & 355 & 355 \\
$\mathbf{3 5 0}$ & 300 & - & 355 & 355 & 355 \\
$\mathbf{4 0 0}$ & 330 & - & 355 & & \\
\hline $\mathbf{4 5 0}$ & 370 & - & 355 & & \\
\end{tabular}

Fonte: (ASSOCIAÇAO BRASILEIRA DE NORMAS TÉCNICAS, 2013; adaptação do autor).

7. Grau de Proteção:

São medidas aplicadas ao invólucro de um equipamento elétrico, visando:

a) Proteção de pessoas contra o contato nas partes energizadas sem isolamento; contra o contato as partes móveis no interior do invólucro e proteção contra a entrada de corpos sólidos estranhos;

b) Proteção do equipamento contra o ingresso de água em seu interior. Os invólucros são designados por uma simbologia que é composta de uma sigla "IP", seguido de dois dígitos, que classificam o grau de proteção do equipamento elétrico. Os dígitos possuem significado composto pela Figura 1-

A.

Tabela 2-A - Grau de proteção para equipamentos elétricos (IP)

\begin{tabular}{c|c|c}
\hline Dígito & Primeiro Dígito & Segundo Dígito \\
\hline 0 & Máquina não protegida. & Não protegido. \\
\hline 1 & $\begin{array}{c}\text { Protegido contra objetos sólidos maiores que 50 } \\
\mathrm{mm} .\end{array}$ & $\begin{array}{c}\text { Protegido contra queda vertical de gotas de } \\
\text { água. }\end{array}$ \\
\hline 2 & $\begin{array}{c}\text { Protegido contra objetos sólidos maiores que 12 } \\
\mathrm{mm} .\end{array}$ & $\begin{array}{c}\text { Protegido contra queda de água com } \\
\text { inclinação de } 15^{\circ} \text { com a vertical. }\end{array}$ \\
\hline
\end{tabular}

(Continua...) 


\begin{tabular}{c|c|c}
\hline 3 & $\begin{array}{c}\text { Protegido contra objetos sólidos maiores que 2,5 } \\
\mathrm{mm} .\end{array}$ & Protegido contra água aspergida. \\
\hline 4 & $\begin{array}{c}\text { Protegido contra objetos sólidos maiores que 1,0 } \\
\mathrm{mm} .\end{array}$ & Protegido contra projeções de água. \\
\hline 5 & $\begin{array}{c}\text { Proteção relativa contra poeira e contato a partes } \\
\text { internas ao invólucro. }\end{array}$ & Protegido contra jatos de água. \\
\hline 6 & $\begin{array}{c}\text { Totalmente protegido contra penetração de } \\
\text { poeira e contato a partes internas ao invólucro. }\end{array}$ & Protegido contra ondas do mar. \\
\hline 7 & - & Protegido contra os efeitos de imersão. \\
\hline 8 & - & Protegido contra submersão. \\
\hline
\end{tabular}

Fonte: (ASSOCIAÇAO BRASILEIRA DE NORMAS TÉCNICAS, 2009; adaptação do autor).

Existem ainda simbologias adicionais para identificar proteções específicas aplicadas pelos fabricantes:

- W - Proteção contra intempéries;

- $\mathrm{R}$ - Proteção com refrigeração por tubos;

- $\mathrm{S}$ - Ensaio de proteção contra a entrada de água é realizada com o motor desligado;

- $\quad \mathrm{M}$ - Ensaio de proteção contra a entrada de água é realizada com o motor ligado.

O referido motor da Figura 1-A possui IPW55, significando, portanto a proteção relativa contra poeira e contato a partes internas ao invólucro e contra jatos de água, adicionado à proteção contra intempéries.

8. Classe térmica:

A classificação térmica da isolação deve ser designada pelo valor numérico da máxima temperatura de utilização, em graus Celsius $\left({ }^{\circ} \mathrm{C}\right)$, para a qual o sistema de isolação é adequado. A Figura 1-A apresenta as possibilidades de classe térmica cadastrada na Associação Brasileira de Normas Técnicas (2017). 
Tabela 3-A - Designação da classe térmica

\begin{tabular}{cc}
\hline Classe térmica $\left({ }^{\circ} \mathbf{C}\right)$ & Letra de Designação \\
\hline 90 & $\mathrm{Y}$ \\
105 & $\mathrm{~A}$ \\
120 & $\mathrm{E}$ \\
130 & $\mathrm{~B}$ \\
155 & $\mathrm{~F}$ \\
180 & $\mathrm{H}$ \\
200 & $\mathrm{~N}$ \\
220 & $\mathrm{R}$ \\
250 & - \\
\hline
\end{tabular}

Fonte: (ASSOCIAÇAO BRASILEIRA DE NORMAS TÉCNICAS, 2017; adaptação do autor).

O referido motor da Figura 1-A, possui Classe F, significando, portanto que a temperatura máxima nos enrolamentos, operando de forma contínua sem danificar a isolação, pode chegar até $155^{\circ} \mathrm{C}$.

9. Elevação de Temperatura:

A temperatura na região mais quente do enrolamento deve ser mantida abaixo do limite da classe térmica do material utilizado para a isolação do enrolamento. É medida pela variação de resistências dos enrolamentos do estator a frio e a quente. Para o referido motor da Figura 1-A, a máxima variação de temperatura entre o estado frio e o estado quente deve ser de $80 \mathrm{~K}$.

10. Frequência:

A frequência nominal é expressa em Hertz (Hz). Pela (NBR17094-1, 2013) os MITRGE comercializados no Brasil devem possuir em sua placa de identificação a frequência de $60 \mathrm{~Hz}$, frequência padronizada em todo o território nacional pela (LEI No 4.454, 1964).

11. Potência mecânica:

O MITRGE deve apresentar em sua placa de identificação, a potência mecânica disponibilizada em seu eixo, quando operando em todas as condições nominais. A referida potência é apresentada livre de qualquer tipo de perda, que já deve estar contabilizada no rendimento do equipamento. 
12. Velocidade de eixo:

Os MITRGE na grande maioria dos casos são vendidos em velocidades clássicas, correspondentes aos números de polos com que os enrolamentos do estator foram construídos. Observando a Tabela 4, podemos concluir que a placa de identificação apresentada na Figura 1-A, é referente a um motor elétrico de 4 polos com velocidade síncrona do campo magnético girante em 1.800 rotações por minuto. Aplicando a equação 7, podemos concluir que o referido motor operando em 1780 RPM em condições nominais, teremos um escorregamento de $1,11 \%$ à plena carga.

13. Corrente elétrica em condições nominais:

A placa de identificação dos MITRGE deve evidenciar a corrente elétrica em condições nominais referentes a cada possibilidade de arranjo das bobinas equivalentes a diferentes níveis de tensão de alimentação.

14. Fator de potência:

Fator de potência em um MITRGE, segundo a NBR17094-1 (ASSOCIAÇAO BRASILEIRA DE NORMAS TÉCNICAS, 2013) é a mesma grandeza representada pelo $\cos \Phi$, ou seja, é numericamente igual à relação entre a potência ativa e a potência aparente, medida em condições nominais de alimentação e carga mecânica no eixo.

15. Temperatura Ambiente:

Grande parte dos motores é projetada para temperatura ambiente máxima de 40 ${ }^{\circ} \mathrm{C}$ e, acima deste valor, o usuário deve utilizar um motor para aplicações especiais com reforço nos sistemas de ventilação e possivelmente aplicação de sistema de refrigeração. Ou mesmo, aplicar as metodologias de repotenciação em função da nova condição de temperatura ambiente.

16. Fator de serviço:

É o fator aplicado à potência nominal de eixo, que indica a carga permissível que pode ser aplicada continuamente ao motor. A (NBR17094-1, 2013) regulamenta o fator de serviço para os MITRGE comercializados no território brasileiro por meio dos índices apresentados na Figura 1-A. Pode ser considerada uma reserva de potência que dá ao motor uma capacidade de suportar melhor o funcionamento em condições especiais. Pela placa de identificação na Figura 1-A, o referido motor possui fator de serviço de 1,25. Portanto, com a temperatura sob controle, o referido motor elétrico pode operar 
com até $125 \mathrm{CV}$ em regime contínuo. Operando com o fator de serviço o motor pode operar no máximo com $10 \mathrm{~K}$ acima da elevação especificada.

Tabela 4-A - Fatores de serviço

\begin{tabular}{c|c|c|c|c}
\hline \multirow{2}{*}{ Potência Nominal $(\mathbf{C V})$} & \multicolumn{4}{|c}{ Fator de Serviço } \\
\cline { 2 - 5 } & 2 Polos & 4 Polos & 6 Polos & 8 Polos \\
\hline $1 / 20$ & 1,4 & 1,4 & 1,4 & 1,4 \\
\hline $1 / 12$ & 1,4 & 1,4 & 1,4 & 1,4 \\
\hline $1 / 8$ & 1,4 & 1,4 & 1,4 & 1,4 \\
\hline $1 / 6$ & 1,35 & 1,35 & 1,35 & 1,35 \\
\hline $1 / 4$ & 1,35 & 1,35 & 1,35 & 1,35 \\
\hline $1 / 3$ & 1,35 & 1,35 & 1,35 & 1,35 \\
\hline $1 / 2$ & 1,25 & 1,25 & 1,25 & 1,15 \\
\hline $3 / 4$ & 1,25 & 1,25 & 1,15 & 1,15 \\
\hline 1 & 1,25 & 1,15 & 1,15 & 1,15 \\
\hline 1,5 a 200 & 250 & 1,15 & 1,15 & 1,15 \\
\hline
\end{tabular}

Fonte: (ASSOCIAÇAO BRASILEIRA DE NORMAS TÉCNICAS, 2013; adaptação do autor).

17. Altitude de operação:

Altitude máxima para a qual o motor foi projetado para operar continuamente em condições nominais. Para altitude superior a $1.000 \mathrm{~m}$ acima do nível do mar, a potência nominal do MITRGE deve ser corrigida levando em conta a temperatura ambiente, a nova altitude e a classificação térmica, aplicando a NBR17094-1 (ASSOCIAÇAO BRASILEIRA DE NORMAS TÉCNICAS, 2013).

18. Massa:

Massa total do motor elétrico, obrigatória nas placas de identificação quando superior a $30 \mathrm{~kg}$. A medição é feita com o motor desenergizado, desacoplado, com mancal lubrificado e sem qualquer tipo envelopamento.

19. Rolamento dianteiro:

Os MITRGE devem apresentar em sua placa de identificação, o modelo do rolamento e a quantidade de graxa que deve ser aplicada ao rolamento na manutenção planejada. 
20. Rolamento traseiro:

Assim como no caso do rolamento dianteiro, os MITRGE devem apresentar em sua placa de identificação, o modelo do rolamento e a quantidade de graxa que deve ser aplicada ao rolamento na manutenção planejada.

21. Tipo de graxa:

O fabricante do MITRGE deve identificar o melhor tipo de graxa a ser utilizado na manutenção do equipamento, bem como a seu critério, indicar um fabricante.

22. Esquema de ligação:

Os motores elétricos alimentados em baixa tenção apresentam diversas formas de disposição das bobinas elétricas. Pela placa de identificação na Figura 1-A, o referido motor possui 4 formas de ligação das bobinas, considerando a associação em série ou paralela de cada dupla de bobinas, e, posteriormente, podendo ligar em estrela ou em triângulo, a depender a tensão nominal disponível pela rede de baixa tensão, ou pela metodologia de partida utilizada. Cada forma de ligação apresenta uma corrente nominal de linha para o motor operando em condições nominais.

23. Tempo de relubrificação:

Identifica o tempo em que deve ser aplicada novamente a graxa nas quantidades especificadas nos itens 19 e 20 e qualidade identificada no item 21. Pela placa de identificação na Figura 1-A, o referido motor deve ser relubrificado a cada 12.000 horas de utilização contínua, ou seja, aproximadamente 1 ano e 3 meses, se o referido motor não for desenergizado.

24. Certificações:

Os MITRGE apresentam simbologias referentes às certificações em que foram submetidos:

- CE - Indicativo de que o MITRGE atende à legislação da União Européia em itens como, por exemplo, segurança, higiene e proteção ambiental, sendo assim, credenciado a comercialização no espaço econômico da união europeia;

- Selo PROCEL - Os motores que apresentarem rendimento maior que o valor mínimo exigido pelo Programa Nacional de Conservação de Energia Elétrica - PROCEL, recebem a etiqueta de Conservação de Energia; 
- INMETRO - O Instituto Nacional de Metrologia, Normalização e Qualidade Industrial é o órgão com competência para estabelecer as diretrizes e critérios para a atividade de avaliação da conformidade de equipamentos eletromecânicos comercializados no território nacional;

Norma vigente da Associação Brasileira de Normas Técnicas - ABNT é o foro único nacional de normalização e publica a normativa nacional para avaliação de uma ampla gama de equipamentos, incluindo os MITRGE, onde são classificados pela NBR17094-1 (ASSOCIAÇAO BRASILEIRA DE NORMAS TÉCNICAS, 2013) conforme apresentado na placa de identificação da Figura 1-A.

25. Relação entre a corrente de partida e corrente nominal:

No momento da partida, os MITRGE são vistos pela rede elétrica como equipamentos de baixa impedância, sendo que a impedância aumenta em razão inversa à rotação do motor. Assim, quando energizado com tensão nominal aplicada às suas bobinas, a corrente atinge valores significativamente maiores, que variam conforme as características de projeto dos referidos equipamentos. Como existem diversos arranjos diferentes para as bobinas, os fabricantes fornecem a relação entre o valor eficaz da corrente absorvida pelo motor no momento da partida e o valor eficaz com o motor operando em condições nominais. No caso do MITRGE apresentado na placa de identificação da Figura 1-A, a referida relação (Ip/In) é de 8,5, significando que se o motor for alimentado com 220 Volts na ligação duplo triângulo, em condições nominais de operação, na partida a corrente atingirá 8,5x242 Ampères (corrente nominal $)=2.057[\mathrm{~A}]$.

26. Categoria:

A categoria é definida em função do conjugado que o motor desenvolve no eixo desde a partida até a plena carga. Três categorias de motores são as mais comuns encontradas no mercado, sendo estas padronizadas pela NBR17094-1 (Ibidem, 2013).

- Categoria D - Elevado conjugado de partida, elevado escorregamento, construído com alta resistência no rotor, consequentemente média corrente de partida; 
- Categoria H - Alto conjugado de partida, baixo escorregamento, construído com média resistência no rotor, corrente de partida considerada normal;

- Categoria N - Conjugado de partida normal, corrente de partida normal, baixo escorregamento;

- Relação entre a corrente de partida e corrente nominal:

A NBR17094-1 disponibiliza três relações que possibilitam construir as curvas de conjugado para motores padronizados. São relacionados (Conjugado de Partida/Conjugado nominal), (Conjugado mínimo/Conjugado nominal) e (Conjugado máximo/Conjugado nominal) os itens das relações estão apresentados na Figura 1-A item a). As Categorias D, H e N, são representadas na Figura 1-A, item b) construída com os dados disponibilizados pela norma (ASSOCIAÇAO BRASILEIRA DE NORMAS TÉCNICAS, 2013).

Figura 2-A - a) Curva teórica de conjugado, b) categorias padronizadas de conjugado

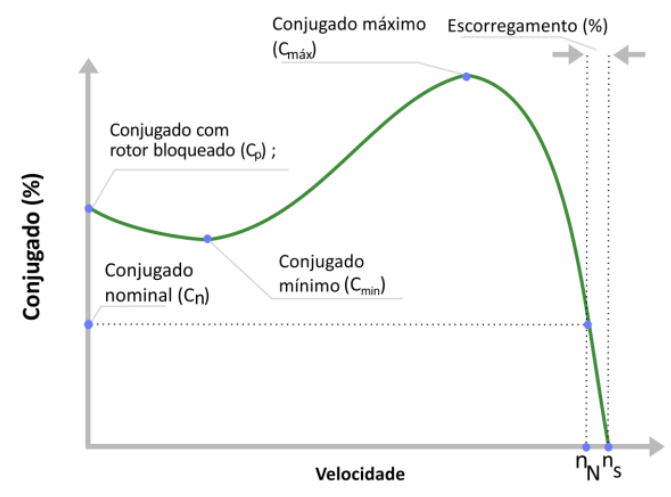

A)

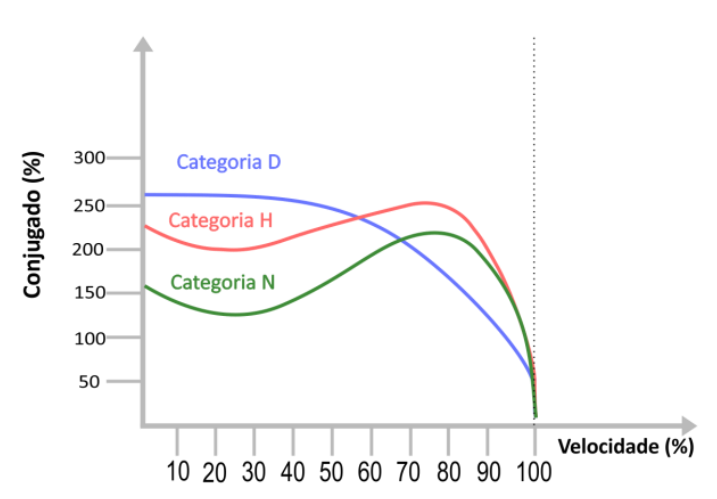

B)

Fonte: (ASSOCIAÇAO BRASILEIRA DE NORMAS TÉCNICAS, 2013; adaptação do autor).

27. Corrente do fator de serviço:

Correte de linha que circula, quando aplicado o fator de serviço. Ou seja, no caso do MITRGE apresentado na placa de identificação Figura 1-A, seria o valor nominal acrescido de $25 \%$ do fator de serviço. 
ANEXO

Certificado de acreditação IEE/USP

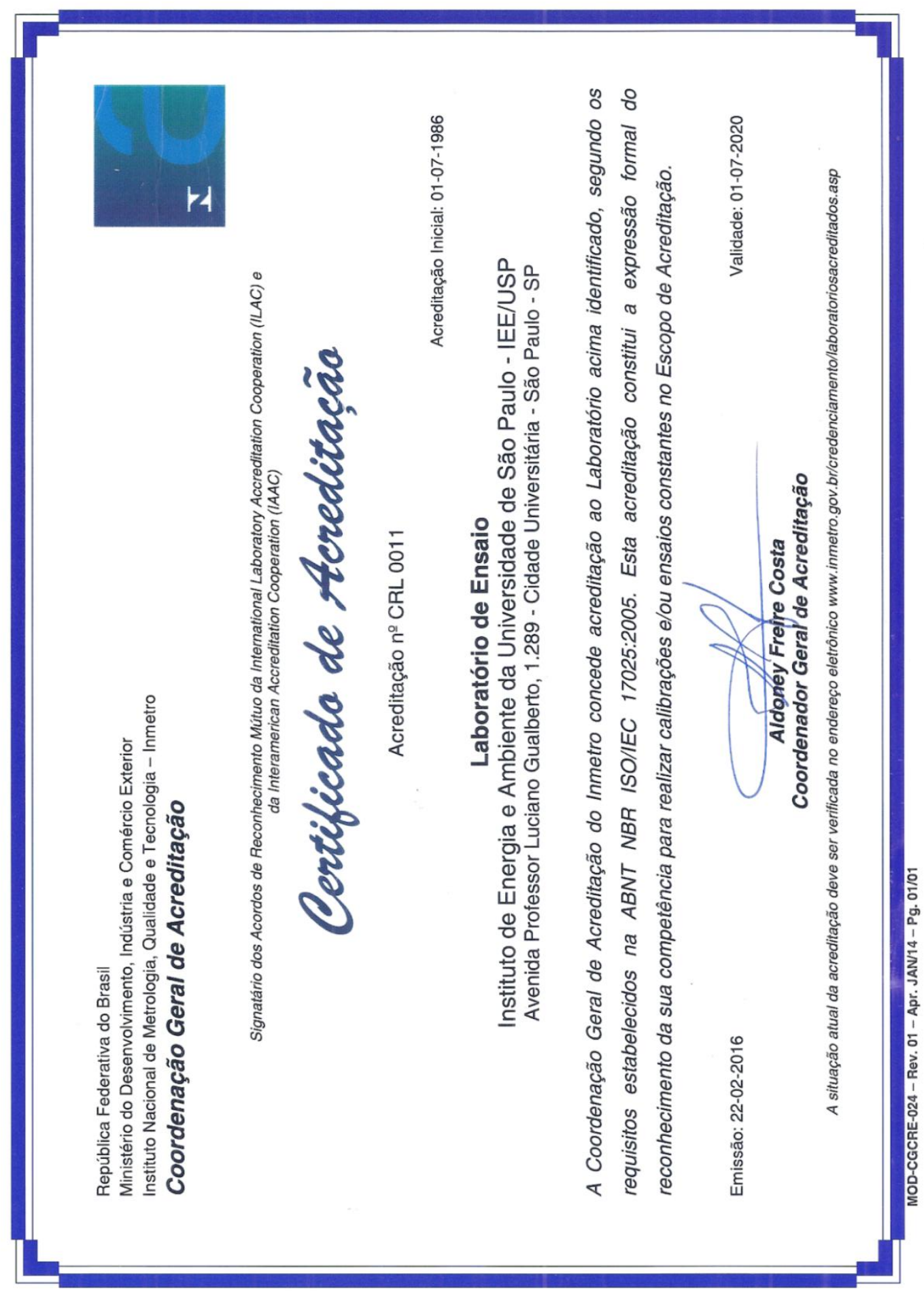

